\title{
Development and Application of the Mollusc Arctica islandica as a Paleoceanographic Tool for the North Atlantic Ocean
}

by

\author{
Christopher R. Weidman
}

B.S., State University of New York College at Oneonta, New York (1988)

Submitted in partial fullfillment of the requirements for the degree of

Doctor of Philosophy

at the

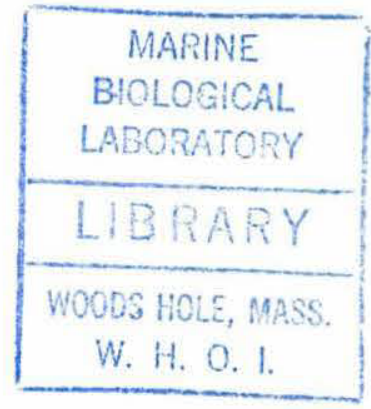

Massachusetts Institute of Technology

and the

Woods Hole Oceanographic Institution

September 1995

(c) Christopher R. Weidman

The author hereby grants to MIT and to WHOI permission to reproduce and to distribute conies of this thesis document in whole or in part.

Signature of Author.

$$
\begin{array}{r}
\text { Joint Program in Marine Geology and Geophysics } \\
\text { Massachusetts Institute of Technology } \\
\text { Woods Hole Oceanographic Institution }
\end{array}
$$

Certified

Glenn A. Jones

Thesis Supervisor

Accepted

by 


\title{
Development and Application of the Mollusc Arctica islandica as a Paleoceanographic Tool for the North Atlantic Ocean
}

by

\author{
Christopher R. Weidman
}

\begin{abstract}
Submitted to the Masachusetts Institute of Technology and the Woods Hole Oceanographic Institution Joint Program in Oceanography/Applied Ocean Science and Engineering on August 10, 1995, in partial fulfillment of the requirements for a degree of Doctor of Philosophy.
\end{abstract}

\begin{abstract}
Until now there has been no tool comparable to corals for reconstructing long term highresolution geochemical time-series for the colder, higher-latitude oceans. In this thesis, the long-lived (+100 years) boreal mollusc (Bivalvia) Arctica islandica is shown to be practical for this purpose in the northern North Atlantic Ocean. The evidence, compiled here, demonstrates that the carbonate shell of this species faithfully records the ambient dissolved inorganic carbon's (DIC) radiocarbon $\left(\Delta^{14} \mathrm{C}\right)$ concentration and accurately reflects the ambient temperature in its stable oxygen isotope $\left(\delta^{18} \mathrm{O}\right)$ composition. However, the stable carbon isotope $\left(\delta^{13} \mathrm{C}\right)$ composition of the A. islandica shell likely is not a good recorder of ambient DIC $\delta^{13} \mathrm{C}$, and likely responds to physiological controls. Four $\Delta^{14} \mathrm{C}$ time histories are reconstructed from the annual bands of $A$. islandica shells for the higher-latitudes of the northern North Atlantic Ocean (from $41^{\circ} \mathrm{N}$ to $70^{\circ} \mathrm{N}$ ). These ocean records show significant spatial and temporal differences in the evolution of the radiocarbon signal between the subpolar and subtropical regions and between eastern and western regions of the northern North Atlantic, which are attributed to regional differences in mixed-layer depth and the presence of deepwater sources. A 109-year interannual record of bottom temperatures for a location near the former Nantucket Lightship position has been reconstructed for the period 1875-1983 from the overlapped stable oxygen isotope composition of four A. islandica shells. This record's annual temperature anomalies (variation from the running ten-year mean) show significant positive correlation with regional bottom, sea surface and air temperature anomalies. However, the shell-derived bottom temperature record describes a century-long cooling $\left(1^{\circ} \mathrm{C}\right)$ in contrast to a century-long warming of regional sea surface temperatures of equal magnitude, indicating a long term divergence between surface and
\end{abstract}


bottom conditions. It is suggested that this contrast may be owed to a reduction in vertical mixing and increased seasonal stratification of shelf waters. This thesis fulfills the prophesy laid out nearly two decades ago by Thompson and Jones [1977] that Arctica islandica could someday be used to reconstruct past ocean history as "the tree of the North Atlantic".

Thesis Supervisor: Dr. Glenn A. Jones Title: Associate Scientist, Woods Hole Oceanographic Institution 


\section{Acknowledgements}

Every thesis owes its inspiration and much of its manifestation to others, animate and inanimate. Thanks are owed to Woods Hole for its incredible community of people whose vision and sharing have created a rich climate for learning and a wonderful place for my kids to grow up. I would also like to thank Nobska, Stony, and Gansett beaches, Eel Pond bridge, Community Hall, the Wall, Coffee at Pie in the Sky, the Martha's Vineyard Ferry, Surf Drive, Shining Sea Bike Path, and the strong westerlies which whistle about the MBL Library and make it hard to leave.

Glenn Jones, my thesis advisor, has provided strong guidance and encouragement throughout this project. I also thank him for his fountain of ideas, sense of the big picture, and his eye for detail. However, I want to thank him most for our late afternoon discussions when we lost track of time (apologies to our families).

I thank the members of my thesis committee for their time and advice: Dan McCorkle, Pat Lohmann, Ed Boyle, Steve Murawski, Dave Chapman, and Glen Gawarkiewicz. A special thanks is owed to K. C. Lohmann for one incredible and largely sleepless week that helped launch a good half of this thesis. I thank, also, some of my most important mentors and counselors, official and unofficial, over the years at WHOI and MIT: Dave Aubrey, John Southard, Ole Madsen, Scott Lehman, Bill Curry, Al Uchupi, and Graham Giese.

I owe more than I know to John, Jake, Abbie, Stella, Kathy, and Marcy, for not making the Education Office a bureaucracy and for covering for my wayward ways.

I thank all my Joint Program friends here at WHOI who have made the heavy loads bearable with much humor and camaraderie, and single out three examples: Gary Jaroslow for his companionship and fellow second incarnation perspective (Gary, schnapps or coffee?), Carl Friedrichs for his excellence and permanent optimism (Carl, how do you do this?), and Javier Escartin for his Catalan sense of the absurd (I can't \#¥*!! believe it). I thank my buddies at NOSAMS: Kathy, Ann, Bob, Susan, Liz, Dan, Karl, John, Greg and especially my officemate $\mathrm{Al} \mathrm{Gagnon}$ for his friendly patience and ability to keep the mass spectrometers running.

I reserve my deepest thanks to my family. This has been a long road guys, and each of you has helped me every step of the way. To my mom and dad for their infectious love of science and chronic curiosity, where all of this began afterall. To Jean and to Bernie (who I miss very much) for their example of never too late and don't be afraid - just go ahead and do it. To my children, Dylan, Lailye and Kaya, of whom I am very proud for becoming independent, honest, and voracious consumers of life, whose lives have much to teach me. And finally, to Melissa Rose, the great love of my life and companion in this ever unfolding adventure, I whisper, "the tomatoes are ripe, babe, what's next ?"

Funding was partly provided by an ORAU Global Climate Change Fellowship. 


\section{CONTENTS}

Abstract 2

Acknowledgements $\quad 4$

Introduction 9

$\begin{array}{ll}\text { References } & 13\end{array}$

\section{PART I. Development}

Chapter 1. A Shell-Derived Time History of Bomb- ${ }^{14} \mathrm{C}$ on Georges Bank and Its Labrador Sea Implications 17

$\begin{array}{ll}\text { Abstract } & 18\end{array}$

$\begin{array}{ll}\text { Introduction } & 18\end{array}$

$\begin{array}{ll}\text { Significance of Bomb- }{ }^{14} \mathrm{C} \text { Studies } & 18\end{array}$

Using Molluscs to Derive Ocean Radiocarbon Records 18

$\begin{array}{ll}\text { Methods } & 19\end{array}$

$\begin{array}{ll}\text { Results } & 19\end{array}$

$\begin{array}{ll}\text { Discussion } & 21\end{array}$

Comparison with North Atlantic Coral-Derived $\Delta^{14} \mathrm{C}$ Records 21

Georges Bank-Labrador Sea $\quad 23$

Georges Bank $\Delta^{14} \mathrm{C}$ Budget $\quad 23$

Estimate of the Bomb- ${ }^{14}$ C Time History for the Labrador Sea 24

Gulf Stream and Antarctic Intermediate Water 25

Ventilation $/{ }^{14} \mathrm{CO}_{2}$ Uptake in the Labrador Sea 26

$\begin{array}{ll}\text { Conclusions } & 27\end{array}$

$\begin{array}{ll}\text { References } & 27\end{array}$

Chapter 2. The Long-Lived Mollusc Arctica islandica: A New Paleoceanographic Tool for the Reconstruction of Bottom Temperatures for the Continental Shelves of the Northern North Atlantic Ocean 30

$\begin{array}{ll}\text { Abstract } & 31\end{array}$

$\begin{array}{ll}\text { Introduction } & 31\end{array}$

$\begin{array}{ll}\text { Methods } & 32\end{array}$ 
Nantucket Shoals Lightship T and S Records $\quad 32$

Predicted Aragonite $\delta^{18} \mathrm{O}$ Record $\quad 34$

Shell Sampling and Analysis $\quad 34$

Results and Discussion 36

Conclusions $\quad 39$

References $\quad 39$

Chapter 3. Stable Oxygen and Carbon Isotope Records from Arctica islandica

Shells in a Monitored Laboratory Growth Experiment 41

Introduction 41

Methods 42

Laboratory Growth Experiment $\quad 42$

Offshore Site Monitoring 43

Sample Preparation and Stable Isotope Analysis $\quad 44$

Results $\quad 45$

Water Column Properties $\quad 45$

Temperature $\quad 45$

Salinity $\quad 46$

$\delta^{18} \mathrm{O}$-water $\quad 46$

DIC $\delta^{13} \mathrm{C}$

Pore Water DIC $\quad 47$

Devil's Bridge Properties (natural cycle) $\quad 48$

Shell Records $\quad 49$

Ring Structure and Shell Growth $\quad 49$

$\delta^{18} \mathrm{O}$-shell Record $\quad 50$

$\delta^{13} \mathrm{C}$-shell Record $\quad 51$

Discussion $\quad 52$

$\delta^{18} \mathrm{O}$-aragonite $\quad 52$

$\delta^{13} \mathrm{C}$-aragonite $\quad 57$

Microhabitat / Pore Water $\delta^{13} \mathrm{C} \quad 59$

Physiological (Vital) Effects $\quad 60$

Summary 63

Acknowledgements 65

References $\quad 66$

$\begin{array}{ll}\text { Tables } & 69\end{array}$

$\begin{array}{ll}\text { Figures } & 73\end{array}$ 


\section{PART II. Application}

Chapter 4. Time History of $\Delta{ }^{14} \mathrm{C}$ in the Surface North Atlantic Ocean $\quad 89$ Introduction $\quad 89$

General Circulation of North Atlantic and the $\Delta^{14} \mathrm{C}$ Signal $\quad 91$

Coastal Environments and the $\Delta^{14} \mathrm{C}$ Signal 93

Methods $\quad 96$

Results 97

Eastern North Atlantic $\Delta^{14} \mathrm{C}$ Time Histories $\quad 97$

North Sea $\quad 97$

Iceland $\quad 98$

Norway $\quad 98$

Western North Atlantic $\Delta^{14} \mathrm{C}$ Time Histories $\quad 99$

Bermuda $\quad 99$

$\begin{array}{lr}\text { Florida } & 99\end{array}$

Georges Bank 100

Discussion 100

North Atlantic Pre-Bomb $\Delta^{14} \mathrm{C} \quad 100$

Time History Comparison 100

Comparison with Other Pre-bomb $\Delta^{14} \mathrm{C}$ Measurements $\quad 101$

Suess Effect 107

1950s Extrema: Norway and North Sea 108

North Atlantic Post-Bomb $\Delta^{14} \mathrm{C} \quad 110$

Time History Comparison 110

Comparison with Other Post-bomb $\Delta{ }^{14} \mathrm{C}$ Measurements $\quad 113$

Determining the Offshore $\Delta^{14} \mathrm{C}$ Signal 113

North Sea 115

Norway 116

The Evolution of the Bomb- ${ }^{14} \mathrm{C}$ Signal in the North Atlantic $\quad 117$

Summary 119

$\begin{array}{ll}\text { Acknowledgements } & 121\end{array}$

References 122

Tables 127

Figures 132 
Chapter 5. A Century-Long Record of Bottom Temperatures Near Nantucket Shoals from Stable Oxygen Isotopic Analysis of Arctica islandica Shells

Introduction 147

Methods 148

Location 148

Sampling and Stable isotope Analysis 149

Chronology 150

Results 150

Data 150

Overlap Comparison and Chronology Check 151

Band Width / Age Corrections 152

$\mathrm{T} / \delta^{18} \mathrm{O}$-aragonite and T / S / $\delta^{18} \mathrm{O}$-water Relationships $\quad 154$

The Combined Shell-Derived Temperature Records 156

BTmean 157

BTmax 158

BTmin 158

Discussion 159

Nantucket Lightship Bottom Temperature Records 159

Nantucket Lightship Sea Surface Temperature Records $\quad 160$

Brenton Reef Lightship and Boothbay Harbor SST Records $\quad 161$

Coastal Northeast U.S. Air Temperature Record 164

Comparison of Detrended Records 164

The Long-Term Trend Problem 165

Conclusions 168

Acknowlegements 171

References 172

Tables 174

$\begin{array}{ll}\text { Figures } & 180\end{array}$

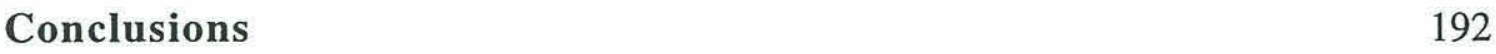

$\begin{array}{ll}\text { Appendix } & 199\end{array}$ 


\section{INTRODUCTION}

The carbon and oxygen isotopic compositions of marine waters and calcareous skeletons of marine organisms have been used to provide important evidence of physical and biological oceanographic processes. The carbon isotopes are important tracers of the global carbon cycle [Broecker, \& Peng, 1982], being used to measure the ocean's uptake of atmospheric carbon dioxide [Suess, 1953][Revelle, \& Suess, 1957][Craig, 1957][Broecker, Peng, Ostlund, \& Stuvier, 1985][Druffel, \& Suess, 1983][Quay, Tilbrook, \& Wong, 1992], as well as the ocean's physical circulation [Broecker, Gerard, Ewing, \& Heezen, 1960][Broecker, et al., 1982][Ostlund, Possnert, \& Swift, 1987][Druffel, 1989][Toggweiler, Dixon, \& Broecker, 1991]. The oxygen isotopes provide a handle on global and regional climate through the hydrological cycle [Shackleton, 1977][Fairbanks, \& Matthews, 1978][Broecker, et al., 1982][Dettman, \& Lohmann, 1993] and the dependence of calcium carbonate's isotopic composition on ambient temperature at the time of calcification [Epstein, Buchsbaum, Lowenstam, \& Urey, 1953][Grossman, \& $K u, 1986]$.

The most direct method of measuring the carbon and oxygen isotopic composition of seawater is to collect and analyze seawater samples. Intensive large ocean studies, such as GEOSECS (1970s), TTO (1980s), and WOCE (1990s), along with more limited seawater sampling efforts, provide an important synoptic perspective on the ocean's geochemical distribution. However, seawater measurements are snapshots of the ocean's isotopic properties and, unless taken in sequence, provide no information on the temporal variability of these properties, and no direct information on past conditions. Also, in the surface ocean where biologic and climatic processes have strong short term impacts on some of these isotopic properties, seawater measurements do not necessarily reflect the long term averages at these sites [Broecker, \& Peng, 1980].

Biogenic marine carbonate records the ambient seawater's carbon and oxygen isotopic composition at the time the carbonate was precipitated, though this relationship is not always simple [Wefer, \& Berger, 1991]. Sclerochronology, the study of sequentiallydeposited calcareous growth structures, and isotopic analysis can be combined to reconstruct seasonal and annual records of past ocean conditions. Many marine organisms possess skeletal growth structures which enable the time of carbonate deposition to be determined quite accurately [Clark, 1974]][Rhoads, \& Lutz, 1980][Jones, 1983]. In the lower latitudes, seasonal and interannual isotope records have been reconstructed by 
sampling and analyzing the annual bands of large stony corals and sclerosponges [Nozaki, Rye, Turekian, \& Dodge, 1978][Druffel, \& Linick, 1978][Druffel, 1981][Druffel, et al., 1983][Patzoid, 1984][Druffel, 1985][Druffel, 1987][Patzoid, Ristedt, \& Wefer, 1987][Druffel, 1989][Chakraborty, Ramesh, \& Krishnaswami, 1994]. In this way, banded-corals have yielded important information on the variability of past ocean conditions, as long term high-resolution monitors of marine geochemistry and temperature for the surface subtropical oceans.

These methods have also been applied to molluscs, which are not latitudinally constrained, and the results have been used: 1) to study aspects of molluscan life history, such as, shell growth as a function of metabolism, ontogeny, and environment [Rhoads, et al., 1980][Erlenkeuser, \& Wefer, 1981][Jones, Williams, \& Romanek, 1986][Krantz, Williams, \& Jones, 1987][Romanek, Jones, Williams, Krantz, \& Radke, 1987][Landman, Druffel, Cochran, Donahue, \& Jull, 1988]; and 2) to reconstruct environmental records of the ocean, such as, modern seasonal and interannual variations in ocean circulation, temperature, salinity, and primary productivity [Killingsley, \& Berger, 1979][Williams, Arthur, Jones, \& Healy-Williams, 1982][Arthur, Williams, \& Jones, 1983][Jones, Williams, \& Arthur, 1983][Jones, Williams, Arthur, \& Krantz, 1984], as well as similar conditions and properties in the ancient oceans [Epstein, et al., 1953][Krantz, 1990].

Despite its widespread application, inherent difficulties arise in reconstructing and interpreting isotopic records obtained from molluscs. Many mollusc species have very limited geographical and ecological ranges, which limit their use as paleoenvironmental recorders. The carbonate mass of most molluscs is small (relative to corals) which limits sampling resolution. Shell growth rates often slow with age, further reducing sampling resolution in the outer (more recent) bands of older specimens. Also, about $80 \%$ of studied marine bivalves are relatively short-lived (less than 20 years) [Heller, 1990] compared to the colonial life-span of stony corals (several hundred years), meaning that most molluscs are inappropriate for reconstructing long term high-resolution isotope records.

Periodicity of the mollusc growth bands must be established for each species because uncorrected sub-annual or episodic banding can create chronological uncertainty [Jones, 1981]. Like most organisms, bivalves respond to a host of external and internal influences, and so their shells are often imperfect integrators of ambient conditions. For example, shell growth often slows or ceases altogether under conditions of extreme cold or warmth, low nutrient or oxygen supply, high levels of sediment suspension or predation, 
or owing to ontogenic or sexual stage [Lutz, \& Rhoads, 1977][Rhoads, et al., 1980][Jones, et al., 1984][Harrington, 1989][Krantz, Jones, \& Williams, 1989]. Finally, many calcareous marine organisms, including molluscs, form carbonate in disequilibrium with the isotopic composition of ambient seawater, and while unusual for the oxygen isotopes this is often the rule for carbon isotopes [Wefer, et al., 1991].

All of these problems constrain the approach to the selection and use of molluscs as tools for reconstructing isotopic time histories in the oceans, and as a consequence, no comparable tool has been developed for the colder, higher latitude oceans that parallels the paleoceanographic role that banded-corals have provided for the warmer subtropical surface oceans. In this thesis, the mollusc Arctica islandica has been selected for this purpose, because of its unique life history and because recent technological advances have created the opportunity to overcome the sampling problems formerly presented by slow growth, long-lived molluscs. Furthermore, A. islandica inhabits the northern North Atlantic Ocean, a region thought to play a critical role in the regulation of global climate as a primary source of deep water for the world's ocean [Warren, 1981][Stocker, \& Broecker, 1992][Broecker, 1991] and as an important sink for atmospheric carbon dioxide [Baes, Bjorkstrom, \& Mulholland, 1985][Sarmiento, \& Sundquist, 1992][Broecker, \& Peng, 1992].

Over the past decades, there has been a growing scientific interest in A. islandica, initially, stemming from this species potential value as a commercial fishery [Nichol, 1951][Loosanoff, 1953][Merrill, \& Ropes, 1969]. Thompson, et al., [Thompson, Jones, $\&$ Dreibelbis, 1980] and Jones [Jones, 1980] were the first to recognize the potential of the bivalve A. islandica as a marine geochemical recorder, calling it the "tree of the north Atlantic shelf" [Thompson, et al., 1977], due to its great longevity, with individual ages commonly in excess of 100 years (with one documented specimen aged at 221 years old [Jones, 1983]). These authors noted that $A$. islandica, commonly known as the ocean quahog, is a large ( 100 $\mathrm{mm}$ in radial length) infaunal species which inhabits the continental shelves and slopes on both sides of the North Atlantic Ocean, spanning a wide depth and latitude range, from $10-200 \mathrm{~m}$, and from Cape Hatteras $\left(\sim 35^{\circ} \mathrm{N}\right)$ to the Barent's Sea $\left(\sim 70^{\circ} \mathrm{N}\right)$. Their studies, along with the subsequent work of others [Murawski, Ropes, \& Serchuk, 1982][Turekian, Cochran, Nozaki, Thompson, \& Jones, 1982][Ropes, Jones, Murawski, Serchuk, \& Jerald, 1984], provided evidence supporting the annual nature of A. islandica's growth bands. 
While several studies have used the shells of $A$. islandica to estimate ocean $\Delta{ }^{14} \mathrm{C}$ [Erlenkeuser, 1976][Turekian, et al., 1982][Tanaka, Monaghan, \& Turekian, 1990], none of these studies was able to take advantage of this species' longevity, because of the large sample mass requirements of conventional beta decay radiocarbon methods. Also, sampling methods used to obtain seasonal and interannual isotopic profiles from corals [Nozaki, et al., 1978][Druffel, 1989] and other faster growing but shorter-lived molluscs, such as Spisula solidissima [Jones, et al., 1983] and Tridacna maxima [Romanek, et al., 1987], have not been applicable to $A$. islandica because of it's slow linear growth rate.

So, although many fundamental aspects of A. islandica's life history have been established over the last three decades, its predicted potential as a paleoceanographic tool has, until now, gone largely unrealized. Two recent technological advances have been central in altering this situation: 1) the introduction of accelerator mass spectrometry (AMS), which has reduced the sample size requirements for radiocarbon analysis by 3 orders of magnitude [Linick, Damon, Donahue, \& Jull, 1989]; and 2) the development of computer - aided microsampling equipment with micron-scale resolution which has provided the means to profile small growth structures in molluscs with precision [Dettman, et al., 1993]. Applying this new technology to A. islandica, the objectives of this thesis are: 1) the development and calibration of A. islandica as a new paleoceanographic tool for reconstructing oxygen and carbon isotope time-series; and 2) the demonstration that long term annual and seasonal time-histories of these isotopes can be reconstructed and used to investigate the temporal and spatial variability of the northern North Atlantic Ocean's temperature, physical circulation, and uptake of atmospheric ${ }^{14} \mathrm{CO}_{2}$. The first objective motivates chapters $1-3$, which discuss the validity and accuracy of this new tool. The second objective motivates chapters 4-5 (and part of chapter 1) which discuss 1) the evolution of the radiocarbon signal in the North Atlantic during the period of anthropogenic influence based on the reconstruction of four high-latitude $\Delta^{14} \mathrm{C}$ time-histories, and 2) a century-long interannual record of bottom temperatures on the northeastern U.S. continental shelf. Regarding the format of the thesis, each chapter has been designed as a separate and distinct paper, though all five chapters are intimately linked to the overall objective of this thesis and provide a context and foundation for each other. 


\section{References}

Arthur, M. A., D. F. Williams and D. S. Jones, Seasonal temperature-salinity changes and thermocline development in the mid-Atlantic Bight as recorded by the isotopic composition of bivalves, Geology, 11, 655-659, 1983.

Baes, C. F. J., A. Bjorkstrom and P. J. Mulholland, Uptake of carbon dioxide by the oceans, in: Atmospheric Carbon Dioxide and the Global Carbon Cycle, edited by J. R. Trabalka, pp. 81-111, U.S. Dept. of Energy, Oak Ridge, TN, 1985.

Broecker, W. S., The great ocean conveyor, Oceanogr., 4, 79-89, 1991.

Broecker, W. S., R. Gerard, M. Ewing and B. C. Heezen, Natural radiocarbon in the Atlantic Ocean, J. Geophys. Res., 65, 2903-2931, 1960.

Broecker, W. S., and T. H. Peng, Seasonal variability in the C14/C12 ratio for surface ocean water, Geophys. Res. Lett., 7, 1020-1022, 1980.

Broecker, W. S., and T. H. Peng, Tracers in the Sea, Lamount-Doherty Geological Observatory Publication, Columbia University, Palisades, N.Y., 1982.

Broecker, W. S., T. H. Peng, G. Ostlund and M. Stuvier, The distribution of bomb radiocarbon in the ocean, J. Geophys. Res., 90, 6953-6970, 1985.

Broecker, W. S., and T. S. Peng, Interhemispheric transport of carbon dioxide by ocean circulation, Nature, 356, 587-589, 1992.

Chakraborty, S., R. Ramesh and S. Krishnaswami, Air-sea exchange of CO2 in the Gulf of Kutch, northern Arabian Sea based on bomb-carbon in corals and tree-rings, Proc. Indian Acad. Sci. (Earth Planet. Sci.), 103, 329-340, 1994.

Clark, G. R., Growth lines in invertebrate skeletons, Ann. Rev. Earth Planet. Sci., 2, 7799, 1974.

Craig, H., The natural distribution of radiocarbon and the exchange time of carbon dioxide between atmosphere and sea, Tellus, 9, 1-17, 1957.

Dettman, D. L., and K. C. Lohmann, Seasonal change in Paleogene surface water d18O: fresh-water bivalves of western North America, in Climate Changes in Continental Isotopic Records, Geophys. Monogr. Ser., vol. 78, edited by P. Swart, K. C. Lohmann, J. McKenzie, and S. Savin, pp. 153-163, AGU, Washington, D. C., 1993.

Druffel, E. M., Radiocarbon in annual coral rings from the eastern tropical Pacific, Geophys. Res. Lett., 8, 59-62, 1981.

Druffel, E. M., Bomb radiocarbon in the Pacific: Annual and seasonal timescale variations, J.Mar.Res., 45, 667-698, 1987.

Druffel, E. M., Decade time scale variability of ventilation in the North Atlantic: Highprecision measurements of bomb radiocarbon in banded corals, J. Geophys. Res., 94, 3271-3285, 1989. 
Druffel, E. M., and T. W. Linick, Radiocarbon in annual coral rings, Geophys. Res. Lett., 5, 913-916, 1978.

Druffel, E. M., and H. E. Suess, On the radiocarbon record in banded corals: exchange parameters and net transport of $14 \mathrm{CO} 2$ between atmosphere and surface ocean, $J$. Geophys. Res., 88, 1271-1280, 1983.

Druffel, E. R. M., Detection of El Nino and decade scale variations of sea surface temperature from banded coral records: Implications for the carbon dioxide cycle, in: The Carbon Cycle and Atmospheric CO2: Natural Variations Archaean to Present, Geophys. Monogr. Ser., vol. 32, edited by E. T. Sundquist and W. S. Broecker, pp.111-122, AGU, Washington, D.C., 1985.

Epstein, S., R. Buchsbaum, H. A. Lowenstam and H. C. Urey, Revised carbonate-water isotopic temperature scale, Bull. Geol. Soc. Am., 64, 1315-1326, 1953.

Erlenkeuser, H., C14 and C13 isotope concentration in modern marine mussels from sedimentary habitats, Naturwis., 63, 338, 1976.

Erlenkeuser, H., and G. Wefer, Seasonal growth of bivalves from Bermuda recorded in their O-18 profiles, Proceedings of 4th International Coral Reef Symposium, vol. 2, 643-648, Manila, 1981.

Fairbanks, R. G., and R. K. Matthews, The marine oxygen isotope record in Pleistocene coral, Barbadoes, West Indies, Quat. Res., 10, 181-196, 1978.

Grossman, E. L., and T. Ku, Oxygen and carbon isotope fractionation in biogenic aragonite: temperature effects, Chem. Geol., 59, 59-74, 1986.

Harrington, R. J., Aspects of growth deceleration in bivalves: Clues to understanding the seasonal O-18 and C-13 record -- A comment on Krantz et al. (1987), Palaeogeogr., Palaeoclimatol., Palaeoecol., 70, 399-403, 1989.

Heller, J., Longevity in molluscs, Malacol., 31, 259-295, 1990.

Jones, D. S., Annual cycle of shell growth and reproduction in the bivalves-Spisula Solidissima-\&-Arctica islandica-, PhD, Princeton University, 1980.

Jones, D. S., Repeating layers in the molluscan shell are not always periodic, $J$. Paleontol., 55, 1076-1082, 1981.

Jones, D. S., Sclerochronology: reading the record of the molluscan shell, Am. Scientist, 71, 384-391, 1983.

Jones, D. S., D. F. Williams and M. A. Arthur, Growth history and ecology of the Atlantic Surf Clam, Spisula Solidissima (Dillwyn), as revealed by stable isotopes and annual shell increments, J. Mar. Biol. Ecol., 73, 225-242, 1983.

Jones, D. S., D. F. Williams, M. A. Arthur and D. E. Krantz, Interpreting the Palaoenvironmental, paleoclimatic and life history records in mollusc shells, Geobios. Mem., 8, 333-339, 1984.

Jones, D. S., D. F. Williams and C. S. Romanek, Life history of symbiont-bearing giant clams from stable isotope profiles, Science, 231, 46-48, 1986. 
Killingsley, J. S., and W. H. Berger, Stable isotopes in a mollusc shell: detection of upwelling events, Science, 205, 186-188, 1979.

Krantz, D. E., Mollusk-isotope records of Plio-Pleistocene marine paleoclimate, U.S. Middle Atlantic Coastal Plain, Palaios, 5, 317-335, 1990.

Krantz, D. E., D. S. Jones and D. F. Williams, Reply to "Aspects of growth deceleration in bivalves: Clues to understanding the seasonal O-18 and C-13 record", Palaeogeogr., Palaeoclimatol., Palaeoecol., 70, 403-407, 1989.

Krantz, D. E., D. F. Williams and D. S. Jones, Ecological and paleoenvironmental information using stable isotope profiles from living and fossil molluscs, Palaeogeogr., Palaeoclimatol., Palaeoecol., 58, 249-266, 1987.

Landman, N. H., E. R. M. Druffel, J. K. Cochran, D. J. Donahue and A. J. T. Jull, Bomb-produced radiocarbon in the shell of the chambered nautilus: rate of growth and age at maturity, 89, 28-34, 1988.

Linick, T. W., P. E. Damon, D. J. Donahue and A. J. T. Jull, Accelerator mass spectrometry: the new revolution in radiocarbon dating, Quat. Internat., 1, 1-6, 1989.

Loosanoff, V. L., Reproductive cycle in Cyprina islandica, Biol. Bull. (Woods Hole), 104, 146-155, 1953.

Lutz, R. A., and D. C. Rhoads, Anaerobiosis and a theory of growth line formation, Science, 198, 1222-1227, 1977.

Merrill, A. S., and J. W. Ropes, The general distribution of the Surf Clam and Ocean Quahog, Proc. Nat. Shellfish. Ass., 59, 40-45, 1969.

Murawski, S. A., J. W. Ropes and F. M. Serchuk, Growth of the Ocean Quahog, Arctica islandica, in the Middle Atlantic Bight, Fish. Bull., U.S., 80, 21-34, 1982.

Nichol, D., Recent species of the veneroid pelecypod Arctica, J. Wash. Acad. Sci., 41, 102-106, 1951.

Nozaki, Y., D. M. Rye, K. K. Turekian and R. E. Dodge, C-13 and C-14 variations in a Bermuda coral, Geophys. Res. Lett., 5, No.10, 825-828, 1978.

Ostlund, H. G., G. Possnert and J. H. Swift, Ventilation rate of the deep Arctic Ocean from Carbon 14 data, J. Gepophys. Res., 92, 3769-3777, 1987.

Patzoid, J., Growth rhythms recorded in stable isotopes and density bands in the reef coral Porites lobata (Cebu, Phillipines)., Coral Reefs, 3, 78-90, 1984.

Patzoid, J., H. Ristedt and G. Wefer, Rate of growth and longevity of a large colony of Pentapora foliiacca (Bryozoa) recorded in their oxygen isotope profiles, Mar. Biol., 96, 535-538, 1987.

Quay, P. D., B. Tilbrook and C. S. Wong, Oceanic uptake of fossil fuel CO2: carbon-13 evidence, Science, 256, 74-79, 1992. 
Revelle, R., and H. E. Suess, Carbon dioxide exchange between atmosphere and ocean and the question of an increase of atmospheric $\mathrm{CO} 2$ during the past decades, Tellus, 9, 18-27, 1957.

Rhoads, D. C., and R. A. Lutz, Skeletal Growth of Aquatic Organisms, New York and London, Plenum Press, 1980.

Romanek, C. S., D. S. Jones, D. F. Williams, D. E. Krantz and R. Radke, Stable isotopic investigation of physiological and environmental changes recorded in shell carbonate from the giant clam Tridacna maxima, Mar. Biol., 94, 385-393, 1987.

Ropes, J. W., D. S. Jones, S. A. Murawski, F. M. Serchuk and A. Jerald, Documentation of annual growth lines in Ocean Quahogs, Arctica islandica Linne, Fish. Bull., U.S., $82,1-19,1984$.

Sarmiento, J. L., and E. T. Sundquist, Revised budget for the oceanic uptake of anthropogenic carbon dioxide, Nature, 356, 589-593, 1992.

Shackleton, N., The oxygen isotope stratigraphic record of the late Pleistocene, Phil. Trans. R. Soc. Lond., 280, 169-182, 1977.

Stocker, T. F., and W. S. Broecker, NADW formation as a branch of the hydrological cycle, EOS, 73, No. 18, 202-203, 1992.

Suess, H. E., Natural radiocarbon and the rate of exchange of $\mathrm{CO} 2$ between the atmosphere and the sea, University of Chicago Press, Chicago, Ill., 1953.

Tanaka, N., M. C. Monaghan and K. K. Turekian, C14 balance for the Gulf of Maine, Long Island Sound and the northern Middle Atlantic Bight: evidence for the extent of the Antarctic Intermediate Water contribution, J. Mar. Res., 48, 75-87, 1990.

Thompson, I., and D. S. Jones, The ocean quahog, Arctica islandica, 'tree' of the north Atlantic shelf, Geol. Soc. of Am. Abstr. Programs, 9, 1199, 1977.

Thompson, I., D. S. Jones and Dreibelbis, Annual internal growth banding and life history of the Ocean quahog Arctica islandica (Mollusca: Bivalvia), Mar. Bio., 57, 25-34, 1980.

Toggweiler, J. R., K. Dixon and W. S. Broecker, The Peru upwelling and the ventilation of the South Pacific thermocline, J. Geophys. Res., 96, 20,467-20,497, 1991.

Turekian, K. K., D. Cochran, Y. Nozaki, I. Thompson and D. S. Jones, Determination of shell deposition rates of Arctica islandica from the New York Bight using natural 228Ra and 228Th and bomb-produced 14C, Limnol. Oceanogr., 27, 737-741, 1982.

Warren, B. A., Evolution of Physical Oceanography, MIT Press, Cambridge, Mass., 1981.

Wefer, G., and W. H. Berger, Isotope paleontology: growth and composition of extant calcareous species, Mar. Geol., 100, 207-248, 1991.

Williams, D. F., M. A. Arthur, D. S. Jones and N. Healy-Williams, Seasonality and mean annual sea surface temperatures from isotopic and sclerochronological records, Nature, 296, 432-434, 1982. 


\section{Chapter 1}

\section{A Shell-Derived Time History of Bomb-14C on Georges Bank}

and Its Labrador Sea Implications 


\title{
A Shell-Derived Time History of Bomb ${ }^{14} \mathrm{C}$ on Georges Bank and Its Labrador Sea Implications
}

\author{
CHRISTOPHER R. WEIDMAN AND GLENN A. JONES
}

Department of Marine Geology and Geophysics, Woods Hole Oceanographic Institution, Woods Hole, Massachusetts

Bomb-produced radiocarbon has been used in the past as an important tracer of ocean circulation and as a valuable tool for calculating. $\mathrm{CO}_{2}$ air-sea exchange. However, previous studies of the ocean's time-varying bomb ${ }^{14} \mathrm{C}$ record have been confined exclusively to analyzing banded corals, and thus their application has been limited to the lower latitudes. The first time history of bomb ${ }^{14} \mathrm{C}$ from the high-latitude North Atlantic Ocean is obtained from a 54-year-old mollusc specimen, (Bivalvia) Arctica islandica, which was collected live from Georges Bank $\left(41^{\circ} \mathrm{N}\right)$ in 1990 . The annual growth bands of its shell were analyzed for $\Delta^{14} \mathrm{C}$ using accelerator mass spectrometry, producing a $\Delta^{14} \mathrm{C}$ time history from 1939 to 1990 . The depleted condition of the Georges Bank bomb ${ }^{14} \mathrm{C}$ signal relative to two coral-derived North Atlantic $\Delta^{14} \mathrm{C}$ time histories suggests a significant deepwater source for the waters on Georges Bank. Supported by previous work linking the origin of waters on Georges Bank to the Labrador Sea, the $\Delta^{14} \mathrm{C}$ budget on Georges Bank is modeled as Labrador Sea water, which largely becomes confined to the shelf and partially equilibrates with the atmosphere during a 1-year transit time from the Labrador Sea to Georges Bank. This model is also used to estimate a time history of bomb ${ }^{14} \mathrm{C}$ for the Labrador Sea. Prebomb $\Delta^{14} \mathrm{C}$ values calculated for the surface Labrador Sea suggest that a greater inventory of bomb ${ }^{14} \mathrm{C}$ has accumulated here than has previously been reported. However, the estimated prebomb average $\triangle^{14} \mathrm{C}(-70.6 \%)$ for this period is nearly identical to the $-70 \%$ previously calculated for the prebomb source of North Atlantic Deep Water and is in agreement with Transient Tracers in the Ocean subsurface tritium data from the central Labrador Sea. Deduced variations in the ventilation and/or ${ }^{14} \mathrm{CO}_{2}$ uptake rates in the Labrador Sea correspond with observed changes in surface salinity of the Labrador Sea, suggesting a reduction in decpwater formation during the late 1960 s and 1970 s.

\section{INTRODUCTION}

\section{Significance of Bomb ${ }^{14} \mathrm{C}$ Studies}

Between the mid-1950s and the mid-1960s, nuclear weapons testing in the atmosphere nearly doubled the atmosphere's radiocarbon concentration [Nydal and Lovseth, 1983; Levin, et al., 1985]. The gradual transfer of this bomb-produced ${ }^{14} \mathrm{C}$ to the oceans has made it an invaluable tracer of atmosphere-ocean exchange processes and ocean circulation [Broecker et al., 1980, 1985; Druffel and Suess, 1983; Druffel, 1987, 1989; MaierReimer and Bacastow, 1990; Quay et al., 1992; Keir et al., 1992]. Measurements of the $\Delta^{14} \mathrm{C}$ [Stuiver and Polach, 1977] of the dissolved inorganic carbon (DIC) of surface seawaters from the Atlantic Ocean during the Geochemical Ocean Sections Study (GEOSECS) in the early 1970s [Ostlund et al., 1974; Stuiver and Ostlund, 1980], clearly show the bomb "pulse" when compared with prebomb (pre-1958) seawater measurements [Broecker et al., 1960] (Figure 1). The low $\Delta^{14} \mathrm{C}$ values of surface waters at the equator and high latitudes have been used as evidence of a deepwater supply to these regions. Deep waters, which have been isolated from the atmosphere, are depleted in radiocarbon owing to radioactive decay [Broecker and Peng, 1982]. However, variation in the supply of deep water to these regions has been difficult to determine using these types of direct seawater measurements, because only a limited number of them exist (i.e., in the North Atlantic, they are largely restricted to two postbomb basin-wide snapshots (GEOSECS (1972-1973) and Transient Tracer in the Ocean (TTO, 1981-1982) [Ostlund and Grall, 1987] and one prebomb set of measurements (1955-1957) extending only as far

Copyright 1993 by the American Geophysical Union.

Paper number 93JC00785. $0148-0227 / 93 / 93 \mathrm{JC}-00785505.00$ north as $39^{\circ} \mathrm{N}$ [Broecker et al., 1960]). In addition, large local and seasonal variations observed in surface water $\Delta^{14} \mathrm{C}$ values imply that direct, instantaneous, seawater measurements are not necessarily representative of the longer-term average [Broecker and Peng, 1980; Kashgarian, 1992].

Alternately, continuous $\Delta^{14} \mathrm{C}$ records derived from banded corals have proven vital in determining variations in ocean ventilation at particular sites on decadal, annual, and seasonal time scales [Nozaki et al., 1978; Druffel and Linick, 1978; Druffel and Suess, 1983; Druffel, 1987, 1989;.Toggweiler et al., 1991]. In addition, sclerochronological methods provide an integrated $\Delta^{14} \mathrm{C}$ value for each coral sample's period of growth and thus are more representative of the longer-term average than surface seawater measurements. However, the application of these high-resolution records has been limited to the low latitudes, where shallowdwelling corals grow. Until now, the lack of $\Delta^{14} \mathrm{C}$ time histories in the high latitudes of the North Atlantic Ocean has been underscored by the critical role this region is thought to play in the regulation of global climate (1) as a primary source of deep water for the world ocean [Warren, 1981; Broecker, 1991; Stocker and Broecker, 1992] and (2) as a strong sink for atmospheric $\mathrm{CO}_{2}$ [Siegenthaler, 1983; Baes et al., 1985; Sarmiento and Sundquist, 1992; Broecker and Peng, 1992].

\section{Using Molluscs to Derive Ocean Radiocarbon Records}

The principle and practice of using the growth bands of mollusc shells to derive marine isotopic time series is over 4 decades old [Urey et al., 1951; Rhoads and Lutz, 1980; Jones, 1983; Krantz, 1990]. However, obtaining detailed long-term geochemical time series from mollusc shells has been hampered by the need (1) to identify species with growth banding of known periodicity and suitably long life spans in order to obtain time series of meaningful length and (2) to identify "standard" species with wide 


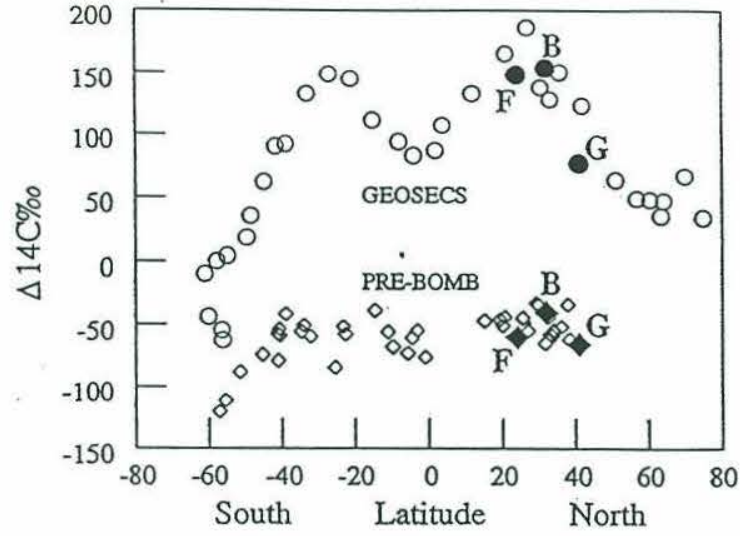

Fig. 1. Latitudinal distributions of $\Delta^{14} \mathrm{C}$ in the Atlantic Ocean surface waters. The bomb "pulse" is clearly shown by the large difference between the prebomb (pre-1958) (open diamonds) [Broecker et al., 1960] and GEOSECS (1972-1973) measurements (open circles). The minina in the equatorial zone and at the high latitiudes are evidence of upwelling of deeper, older, and thus low $\Delta^{14} \mathrm{C}$ valued waters in these regions. The $\Delta^{14} \mathrm{C}$ measurements derived from Florida $(F)$ and Bermuda $(B)$ corals (solid symbols) for 1955 and 1973 [Druffel, 1989] and from a Georges Bank (G) bivalve (also solid symbols) for 1954-1955 and 1973-1975 (this study) are both temporally and latitudinally consistent with the surface ocean waters.

geographical and depth ranges in order to minimize the potential for "vital effect" variability between different species. Finally, a problem inherent to obtaining high-resolution radiocarbon records from molluses has been the absence, until recently, of methods capable of analyzing the small sample sizes typically retrieved from the growth bands of their shells.

Arctica islandica is a large $(\sim 100 \mathrm{~mm})$ and long-lived (commonly +100 years) bivalve inhabiting the continental shelves from 10 to $200 \mathrm{~m}$ depth, on both sides of the North Atlantic Ocean, and spans a wide latitudinal range from Cape Hatteras $\left(\sim 35^{\circ} \mathrm{N}\right)$ to the Barents Sea $\left(\sim 70^{\circ} \mathrm{N}\right)$ [Thompson et al., 1980a]. Jones [1980a, $b$ ] was the first to recognize the great potential of $A$. islandica as a marine geochemical recorder. His studies, along with the subsequent work of others [Thompson $\&$ al., 1980a, $b$; Murawski et al., 1982; Turekian et al., 1982; Ropes et al., 1984], provided evidence supporting the annual nature of $A$. islandica's growth bands. Our recent stable isotope work on the growth bands of $A$. islandica (in preparation) also confirms their annual periodicity and indicates that shell deposition occurs only during the warmer months of the year.

Three earlier studies have used whole shells of $A$. islandica to estimate the average $\Delta^{14} \mathrm{C}$ of DIC in seawater over the life span of the specimen [Erlenkeuser, 1976; Turekian et al., 1982; Tanaka et al., 1990]. Erlenkeuser [1976] showed that the aragonite shell of A. islandica was deposited in isotopic equilibrium with ambient DIC (Baltic Sea) and did not appear to incorporate any appreciable carbon from surrounding $\Delta^{14} \mathrm{C}$-depleted sediments. Turekian et al. [1982] used an inverse method, comparing North Atlantic coralderived bomb ${ }^{14} \mathrm{C}$ records with $\Delta^{14} \mathrm{C}$ values obtained from several $A$. islandica shells of different ages, in order to determine growth band periodicity. Tanaka et al. [1990], used an A. islandica shell collected in 1873 to constrain the preanthropogenic $\Delta^{14} \mathrm{C}$ value of Gulf of Maine seawater. However, the application of these $A$. islandica-derived radiocarbon records is temporally limited owing to conventional beta-decay methods used in obtaining them, which required one or more whole shells for a single $\Delta^{14} \mathrm{C}$ analysis.

This study has taken advantage of the recent introduction of accelerator mass spectrometry (AMS), which has reduced the sample size requirements for radiocarbon analysis by $\sim 3$ orders of magnitude [Linick et al., 1989] and so has enabled us to perform radiocarbon analyses on the tiny $(\sim 1 \mathrm{~mm})$ internal growth bands of A. islandica. The result is a time history of bomb ${ }^{14} \mathrm{C}$ on Georges Bank derived from a single mollusc shell. A comparison of this $\Delta^{14} \mathrm{C}$ time history with two coral-derived time histories from the North Atlantic Ocean provides support for a significant deepwater component in the waters of Georges Bank. This evidence, along with previous work linking the origin of shelf waters on Georges Bank with the Labrador Sea, is used to account for the $\Delta^{14} \mathrm{C}$ budget on Georges Bank and to estimate a time history of bomb ${ }^{14} \mathrm{C}$ for the Labrador Sea.

\section{METHODS}

Live A. islandica were collected from the eastern U.S. continental shelf $\left(35^{\circ}-41^{\circ} \mathrm{N}\right)$ in summer 1990 . Specimen ages were determined by counting the internal growth bands according to methods described by Ropes [1987]. A 54-year-old specimen from the southern flank of Georges Bank $\left(41^{\circ} \mathrm{N}, 67 \mathrm{~W}\right.$, and $76 \mathrm{~m}$ depth) (Figure 2) was selected and prepared by radially sectioning a 2-mm-thick slice from one valve (Figure $3 a$ ). The periostracum (outer organic layer) and the nacre (inner laminated aragonite layer) on the shell slice were ground away in order to isolate the central prismatic layer (banded aragonite), which was then subsectioned into samples containing one to three annual bands (Figure $3 b$ ). The number of annual bands included in a sample was determined by the minimum amount of aragonite $(\sim 10 \mathrm{mg})$ required for one AMS radiocarbon analysis. Less temporal resolution was possible in the more recently deposited bands because of a reduction in the linear growth rate as the specimen aged. Samples obtained in this way ranged in size from 17 to $37 \mathrm{mg}$. Some annual bands were sacrificed because of kerf loss creating gaps in the recovered record. In all, 18 samples were obtained in this way from a single slice of the specimen, of which 13 samples were made into graphite [Gagmon and Jones, 1993] and analyzed at the National Science Foundation Arizona Accelerator Facility for Radioisotope Analysis, at Tuscon, Arizona.

\section{RESULTS}

The results produce a time history of $\Delta^{14} \mathrm{C}$ from 1939 to 1990 for a location on Georges Rank (Table 1 and Figure 4). The prebomb (1939-1952) $\Delta^{14} \mathrm{C}$ data have an average value of $-67.2 \%$ (the 1954-1955 sample is not included in the prebomb data, because tree ring records indicate bomb-related $\Delta^{14} \mathrm{C}$ enrichment of the atmosphere as early as 1955 [Cain and Suess, 1976]). Tanaka et al. [1990] obtained the same prebomb average $\Delta^{14} \mathrm{C}$ of $-67 \%$ (derived from shells) for Long Island Sound for approximately the same period (1935-1954). The five prebomb values also show a negative trend of $\sim 0.88 \% \mathrm{yr}^{-1}\left(1 \sigma \pm 0.62 \% \mathrm{yr}^{-1}\right)$, which, within its error, is consistent with the "Suess effect" [Suess, 1953] (the depletion in $\triangle^{14} \mathrm{C}$ from the late 1800 s to 1955 due, for the most part, to the release of ${ }^{14} \mathrm{C}$-free $\mathrm{CO}_{2}$ from the buming of fossil fuels) noted in other North Atlantic ${ }^{114} \mathrm{C}$ records for the same period [Nozaki et al., 1978; Druffel and Linick, 1978]. The first definite indication of bomb influence in the Georges Bank $\Delta^{14} \mathrm{C}$ 


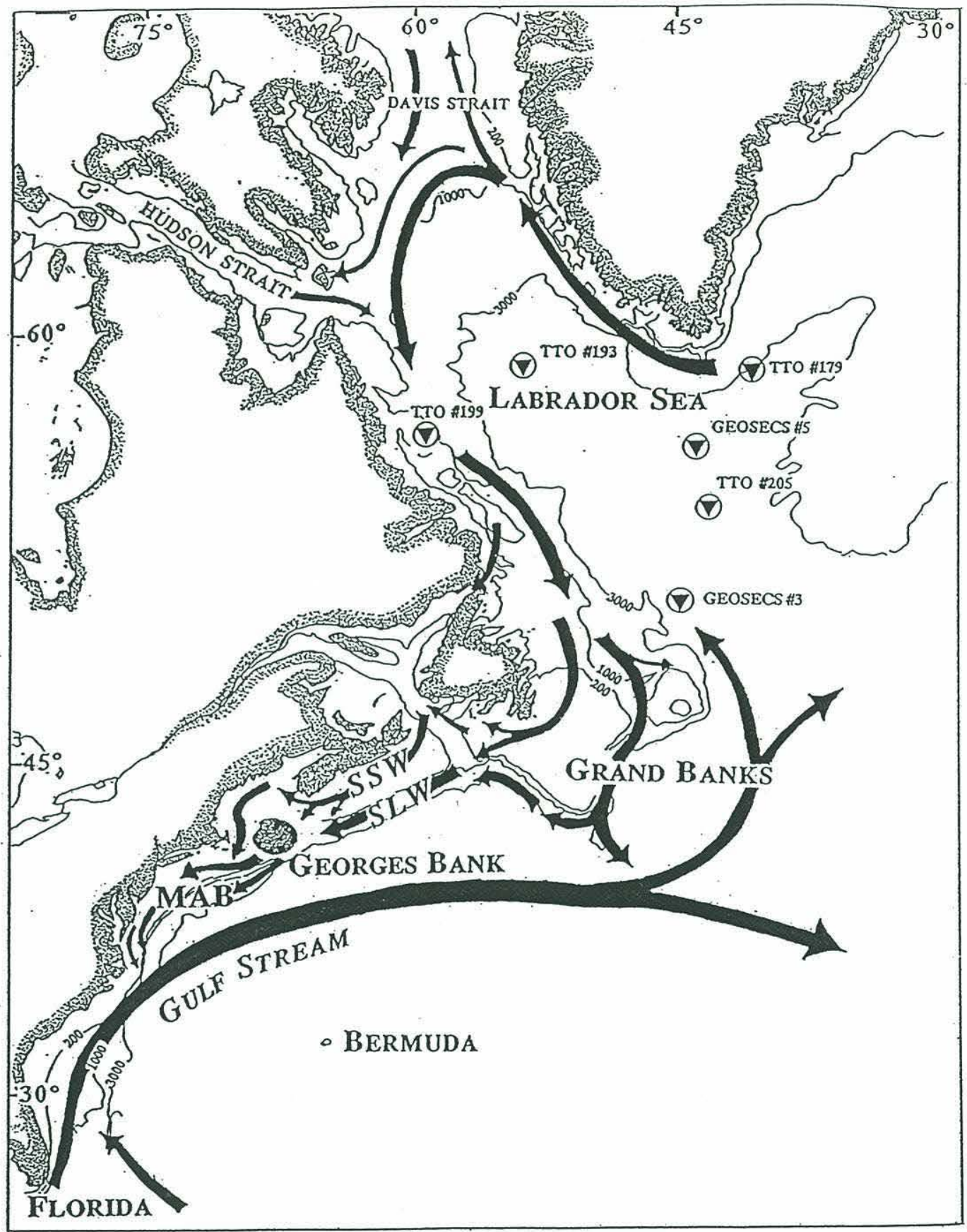

Fig. 2. Schematic of the major surface flow patterns of the northwestern Atlantic Ocean [after Chapman et al, 1986] is shown along with the positions of GEOSECS and TTO stations in and peripheral to the Labrador Sea. The A. islandica collection site on Georges Bank is marked with a clam-shaped symbol. Chapman and Beardsley [1989] have described the shelf waters on the southem flank of Georges Bank as 75\% Scotian Shelf Water (SSW) and 25\% Slope Water (SLW), with both components originating in the Labrador Sea.

data occurs in 1959-1960 and is reflected by a 30\% increase over the earlier 1954-1955 sample. The greatest rate of increase (averaging +11.5\% $\mathrm{yr}^{-1}$ ) occurs between 1959-1960 and 19681970 , which is also the period of maximum atmospheric ${ }^{14} \mathrm{C}$ concentration [Levin et al., 1985]. The Georges Bank $\Delta^{14} \mathrm{C}$ record reaches a peak value of $+77.0 \%$ in $1973-1975$, though the spline fit. suggests that the maximum may have been a bit larger and occurred earlier, about 1972. After this peak, the $\Delta^{14} \mathrm{C}$ signal 

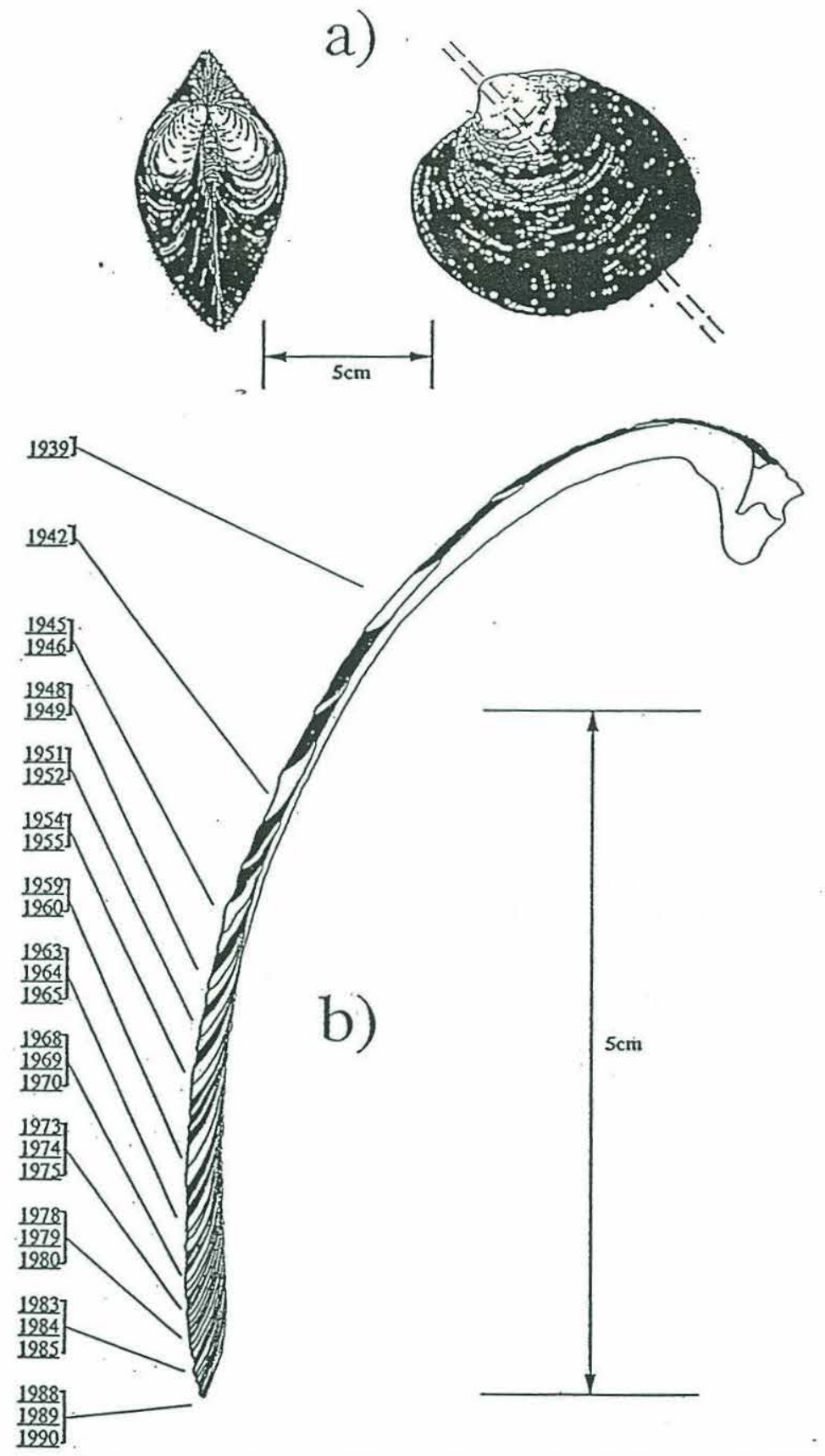

Fig. 3. (a) Two views of a typical 50-year-old A. islandica specimen. One of the valves is radially sliced, along its axis of maximum linear growth. (b) Tracing of a photoenlargement of a thin-section obtained from the same 54-year-old Georges Bank A. islandica specimen used in this stody. The white areas indicated in the outer shell layer correspond to the annual growth bands analyzed for radiocarbon, while the dark areas correspond to the bands that were not analyzed. Less temporal resolution is achieved in the samples comprised of more recently deposited bands due to a reduction in linear growth rate as the specimen aged.

drops almost $30 \%$ by $1978-1980$ but shows no further significant depletion during the 1980 s.

\section{Discussion}

Comparison with North Allantic Coral-Derived $\Delta^{14} C$ Records

The Georges Bank $\Delta^{14} \mathrm{C}$ time history exhibits a strong phase similarity with two other North Atlantic $\Delta^{14} \mathrm{C}$ time histories (1951-
1980) derived by Druffel [1989] from banded corals from Florida : and Bermuda (Figure 5). The timing of the minimum $\Delta^{14} \mathrm{C}$ in the early 1950 s, the first large $\Delta^{14} \mathrm{C}$ increase in the late $1950 \mathrm{~s}$, and the maximum in mid-1970s are features also shared by the coral records. Seven. Georges Bank data points (1951-1980) were correlated with the corresponding means of the Florida and Bermuda annual $\Delta^{14} \mathrm{C}$ records. The computed correlation 
TABLE 1. Georges Bank $\Delta^{14} \mathrm{C}$ Time History

\begin{tabular}{|c|c|c|c|c|}
\hline \multirow[t]{2}{*}{ Year(s) } & \multirow{2}{*}{$\begin{array}{c}\Delta^{14} C^{*} \\
\%_{\infty}\end{array}$} & \multirow{2}{*}{$\begin{array}{c}\text { Precision } \\
\pm \% 0\end{array}$} & \multicolumn{2}{|c|}{ Accession Number } \\
\hline & & & WHG & AA. \\
\hline 1939 & -61.3 & 6.2 & 954 & 6922 \\
\hline 1942 & -64.4 & 6.1 & 955 & 6923 \\
\hline $1945-1946$ & -70.6 & 6.2 & 959 & 6924 \\
\hline $1948-1949$ & -65.3 & 6.3 & 951 & 6925 \\
\hline $1951-1952$ & -74.6 & 6.2 & 952 & 6927 \\
\hline $1954-1955$ & -66.0 & 6.2 & 947 & 6928 \\
\hline $1959-1960$ & -34.4 & 6.4 & 949 & 6929 \\
\hline $1963-1965$ & +32.3 & 6.7 & 956 & 6930 \\
\hline $1968-1970$ & +74.8 & 7.4 & 957 & 6932 \\
\hline $1973-1975$ & +77.0 & 7.6 & 958 & 6933 \\
\hline $1978-1980$ & +47.7 & 7.5 & 960 & 6934 \\
\hline 1983-1985 & +51.1 & 7.7 & 962 & 6935 \\
\hline $1988-1990$ & +42.8 & 7.4 & 961 & 6936 \\
\hline
\end{tabular}

- Sample $\Delta^{14} \mathrm{C}$ is age-corrected to 1950 according to methods outlined by Stuiver and Pollack [1977]. A correction is made for fractionation [Donahue ef al., 1990] using a constant $\delta^{13} \mathrm{C}=+2.3 \%$, which is the mean of 214 analyses performed on a nearby contemporary $A$ islandica shell of similar age. Also, Tanaka et al. [1986] have noted that some estuarine molluscs incorporate upto $50 \%$ metabolic carbon into their shells, and therefore a correction for terrigenous-source carbon (generally more $\Delta^{14} \mathrm{C}$ enriched) may be warranted. We have not made this correction because the Georges Bank site here is over $250 \mathrm{~km}$ offshore and we have assumed that shells from this site are unaffected by terrigenous carbon sources.

coefficients for the period from 1951-1980 are $r=0.993$ and $r=$ 0.966 for Florida and Bermuda, respectively. When the correlations are lagged, the addition of 1 year and 2 years to the Georges Bank chronology optimizes the correlation between the Georges Bank $\Delta^{14} \mathrm{C}$ signal and the Florida and Bermuda, signals respectively. Druffel [1989] reported a phase difference of 0.5-2.0 years between the Florida and Bermuda annual $\Delta^{14} \mathrm{C}$ records for the period 1959-1972 and interpreted this to be the result of deeper convective mixing occuring in the Sargasso Sea and relatively shallow mixing in the Gulf Stream. This interpretation suggests

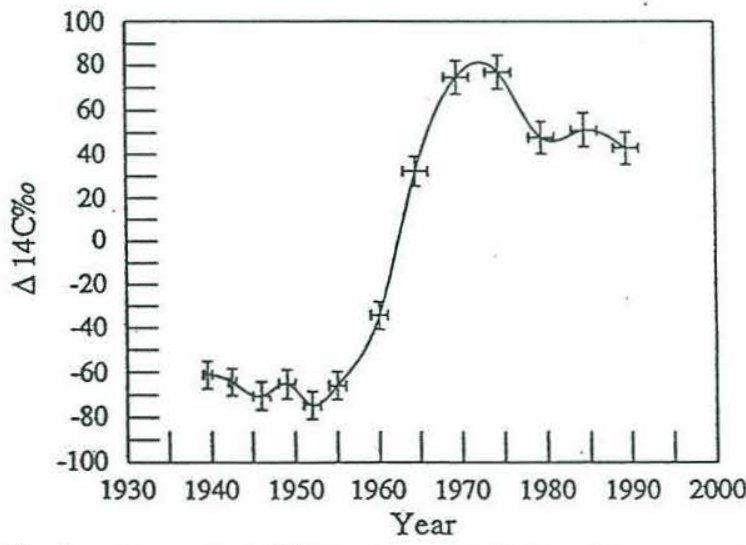

Fig. 4. Georges Bank $\Delta^{14} \mathrm{C}$ time history. The horizontal bars represent the integrated time contained in the sample (number of annual bands), and the vertical bars represent the $\pm 1 \sigma$ precision errors of the $\Delta^{14} \mathrm{C}$ measurements. The line is a spline fit to the data. The prebomb signal shows a slight negative tread which may reflect the "Suess" effect. The steep rise during the 1960 s is caused by the ocean's uptake of bombproduced atmospheric ${ }^{14} \mathrm{CO}_{2}$. The sharp drop in the late 1970 s reflects the decreased air-sea $\Delta^{14} \mathrm{C}$ difference, while the absence of a continued decrease in the signal during the 1980 s is less clear.

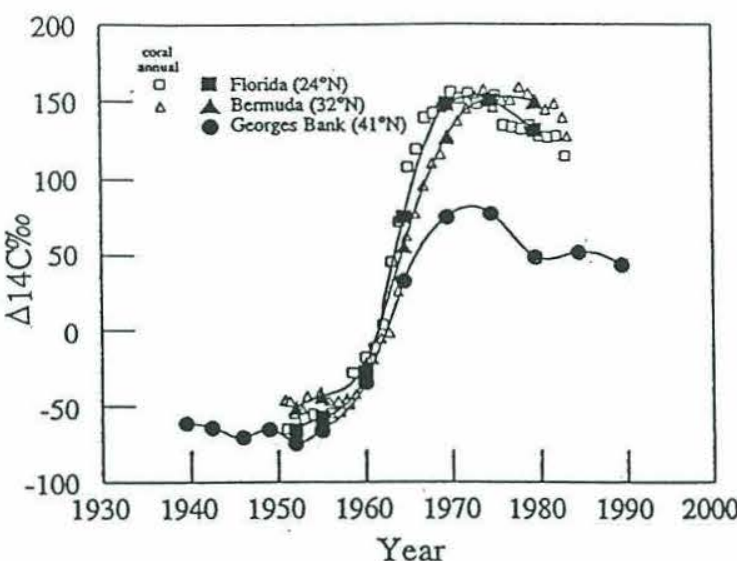

Fig. 5. Three North Atlantic $\Delta^{14} \mathrm{C}$ time histories (1951-1980): Georges Bank, Bermuda, and Florida. To simplify the comparison, Druffel's [1989] annual coral data from Bermuda and Florida have also been averaged for the seven corresponding 2- to 3-year periods represented by the Georges Bank data. The Georges Bank signal is in phase with the two coral-derived $\Delta^{14} \mathrm{C}$ signals from lower latitudes, but its amplitude is smaller and its values are relatively depleted. Standard errors for the coral data are smaller than the symbols.

that the apparent phase difference between the Georges Bank signal and the Florida and Bermuda signals may also be caused by a comparatively shallow reservoir supplying Georges Bank, causing the Georges Bank $\Delta^{14} \mathrm{C}$ signal to display a more rapid response to the atmosphere.

The Georges Bank $\Delta^{14} \mathrm{C}$ signal can be approximated as linear functions of either the Bermuda or the Florida $\Delta^{14} \mathrm{C}$ time histories:

$$
\begin{aligned}
& { }^{14} C_{\text {Georges Bank }}=0.68\left({ }^{14} C_{\text {Bermuda }}\right)-28 \%(r=0.967) \\
& { }^{14} C_{\text {Goorges Bank }}=0.66\left({ }^{14} C_{\text {Florida }}\right)-26 \%(r=0.993)
\end{aligned}
$$

These functions illustrate that the primary differences between the $\Delta{ }^{14} \mathrm{C}$ record at Georges Bank and those at Bermuda and Florida are (1) the smaller amplitude of the Georges Bank signal and (2) the depleted condition of the $\Delta^{14} \mathrm{C}$ values on Georges Bank relative to the other two locations. The smaller amplitude of the Georges Bank's bomb signal inciicates that its source waters have absorbed less bomb-produced radiocarbon per unit volume, which must be caused either by a reduced uptake of atmospheric $\mathrm{CO}_{2}$ or a larger (more deeply mixed) diluting volume (assuming an equal $\mathrm{\Sigma CO}_{2}$ concentration). The former explanation can be rejected, since Georges Bank is biologically more productive, colder, and more wind-stressed than the other two locations, and these factors would tend to increase the gas exchange rate and uptake of atmospheric $\mathrm{CO}_{2}$ rather than reduce it. Deeper mixing would result from the same physical factors, but should be effective in maintaining a lower annual average $\Delta^{14} \mathrm{C}$ concentration in surface waters only over deep regions and not in the vertically confined waters on Georges Bank. So while the relatively rapid response of the Georges Bank bomb ${ }^{14} \mathrm{C}$ signal to the atmospheric bomb ${ }^{14} \mathrm{C}$ signal supports a shallow reservoir, its relatively small amplitude and depleted condition support a deep reservoir resupplied by deep water. One way to resolve this apparent contradiction is for the waters on Georges Bank to originate from a deep (depleted) source seaward of the shelf and then to be confined on the shallow shelf long enough to be enriched significantly by the uptake of atmospheric ${ }^{14} \mathrm{CO}_{2}$. 
The low prebomb and bomb $\Delta^{14} \mathrm{C}$ values on Georges Bank are consistent with its mid-latitude position and the observed depletion of $\Delta^{14} \mathrm{C}$ in the open ocean at latitudes poleward of the subtropics (Figure 1). However, the latitudinal $\Delta^{14} \mathrm{C}$ variation seen in the open ocean's surface water does not necessarily reflect conditions on the continental shelves at the ocean's boundaries. In particular, a satisfactory explanation for the depleted Georges Bank's $\Delta^{14} \mathrm{C}$ values must take into account the influence of the nearby Gulf Stream, which advects $\Delta^{14} C$-enriched surface water from the subtropical North Atlantic gyre poleward along the western boundary. Hence in order for the shelf waters on Georges Bank to maintain a low $\Delta^{14} \mathrm{C}$ value, a significant supply of deep-water to this region must be procured. Two candidates for this deepwater source are (1) the Labrador Sea at the north end of the shelf where deep water isopycnals outcrop at the surface and/or (2) upwelling deep water along the adjacent continental slope.

\section{Georges Bank-Labrador Sea}

The concept of a high-latitude origin for the shelf waters north of the Mid-Atlantic Bight is not new [Bigelow, 1927], but only within the past decade has this continuity been substantiated by comparing oxygen isotope and salinity compositions of waters from the continental shelf and the Labrador Sea [Fairbanks, 1982; Chapman et al., 1986; Chapman and Beardsley, 1989]. Fairbanks [1982] demonstrated that the $\delta^{18} \mathrm{O}$ of meteoric water entering the sea along the east coast of North America possessed a large northsouth gradient, with $\delta^{18} \mathrm{O}$ decreasing northward. Using this evidence, he was able to show that the fresh component of the waters from the Mid-Atlantic Bight (MAB), Gulf of Maine (GOM), Scotian shelf (SS), and slope must have a high-latitude primary source. Chapman et al. [1986] described the shelf waters from these same regions as being a mixture between fresher $(S=$ $32.35 \%)$ and lighter $\left(\delta^{18} \mathrm{O}=-1.09 \%\right)$ Scotian Shelf Water (SSW) and saltier $(S=35.5 \%)$ and heavier $\left(\delta^{18} \mathrm{O}=+0.75 \%\right)$ Slope Water (SLW). Using these parameters, they placed the ratio of SSW:SLW on the southern flank of Georges Bank at $75 \mathrm{~m}$ depth at about $3: 1$, with a sharp property front (increasing SLW seaward) near the shelf break $(\sim 100 \mathrm{~m})$. Chapman and Beardsley [1989] identified the Labrador Sea as the origin of both water mass types (Figure 2), with SLW having a composition $\left(S, \delta^{18} \mathrm{O}\right)$ similar to that of the deep waters of the central Lobrador Sea and SSW having a composition similar to that of the shoreward nearsurface waters. They described the formation of SSW as a dilution process, where glacial and riverine water (with a combined $\delta^{18} \mathrm{O}$ $-20 \%$ ) enter and mix with the Labrador Sea water along the west coast of Greenland, in Davis Strait, and east of the Hudson Strait. They also demonstrated that this fresh input could provide a mechanism for a buoyancy-driven, southward flowing coastal current, which becomes confined over the shelf.

Recently, Kashgarian [1992], using direct seawater measurements of $\Delta^{14} \mathrm{C}$ (1987-1988), has described the nearby onand off-shelf waters of the MAB $\left(\Delta^{14} \mathrm{C}=+85 \%\right)$ as a mixture of $\sim 75 \%$ Labrador Sea water $\left(\Delta^{14} C_{\text {Labrador }}=+50 \%\right)$ and $\sim 25 \%$ Sargasso Sea water $\left(\Delta^{14} C_{\text {Bermuda }}=+160 \%\right)$. Thus the shelf water along the southern flank of Georges Bank can be viewed as a downstream part of an along shelf flow originating in the Labrador Sea.

\section{Georges Bank $\Delta^{14} C$ Budget}

To account for the $\Delta^{14} \mathrm{C}$ composition of shelf water on Georges Bank, we simplify the problem by first assuming that the waters on the southern flank of Georges Bank are a mixture of the two components mentioned previously, SSW and SLW. We also assume that both SSW and SLW begin in the Labrador Sea with the same $\Delta^{14} \mathrm{C}$ value, but that downstream of the Labrador Sea, their relative $\Delta^{14} \mathrm{C}$ compositions diverge.

The more shoreward SSW is confined to the shelf, and we allow only gas exchange with the atmosphere to alter its $\Delta^{14} \mathrm{C}$ properties. Adopting a net velocity along the outer shelf of $\sim 0.1 \mathrm{~m}$ $\mathrm{s}^{-1}$, [Chapman et al., 1986] and a distance of $~ 3000 \mathrm{~km}$ (Labrador Sea to Georges Bank), we derive a transit time of $\sim 1$ year for a parcel of SSW. Based on an average Atlantic Ocean $\mathrm{CO}_{2}$ invasion rate $I$ of $22.3 \mathrm{~mol} \mathrm{C} \mathrm{m}^{-2} \mathrm{yr}^{-1}$ and a $\Sigma \mathrm{CO}_{2}$ of $2.15 \mathrm{~mol} \mathrm{~m}^{-3}$ [Broecker, et al., 1985], the $\Delta^{14} \mathrm{C}$ of a $100 \mathrm{~m}$ deep column of outer shelf water will be increased annually by about $10 \%$ of the atmosphere-ocean $\Delta^{14} \mathrm{C}$ difference $\left(U=I /\left[D \times \Sigma \mathrm{CO}_{2}\right]=0.1\right.$, where $U$ is uptake and $D$ is depth). This model, then also predicts an along shelf $\Delta^{14} \mathrm{C}$ gradient, with the $\Delta^{14} \mathrm{C}$ of SSW increasing downstream as a function of residence time on the shelf and the air-sea $\Delta^{14} \mathrm{C}$ difference:

$$
{ }^{14} \mathrm{C} \text { SSW }={ }^{14} \mathrm{C}_{\text {LabSea }}+(U)\left({ }^{14} \mathrm{C}_{\text {Atm }}-{ }^{14} \mathrm{C}_{\text {Lebsea }}\right)
$$

Tanaka et al. [1990] and Kashgarian [1992] suggest that water mass mixing dominates the radiocarbon budget of the shelf waters in the MAB region and assign a negligible role for atmospheric equilibration because it can only account for about $5 \%$ of the total inorganic carbon flux in the MAB. This argument appears valid when used to determine the relative fraction of two suspected water masses on the shelf, provided that (1) the $\Delta^{14} \mathrm{C}$ difference between the two components is large relative to measurement precision, (2) the mean shelf water residence time is short, and (3) the air-sea surface $\Delta^{14} \mathrm{C}$ difference is small, such as during the prebomb period. However, atmospheric input cannot be ignored in considering the spatial and temporal variations of the bomb ${ }^{14} \mathrm{C}$ signal in these same shelf waters, because the air-sea $\Delta^{14} \mathrm{C}$ difference is large and the potential shelf water residence time is of the order of a year or more, if we assume its source to be the Labrador Sea. Further, the values we have chosen to calculate the uptake rate parameter should produce a conservative estimate of shelf water equilibration with the atmosphere, since a slower mean along shelf flow, shallower depths near the coast, and a greater $\mathrm{CO}_{2}$ gas exchange rate (due to higher than average wind speeds in this region of the Atlantic) will all result in a higher uptake rate. During prebomb times (and at present) the air-sea $\Delta^{14} \mathrm{C}$ difference was only $\sim 50 \%$, so that an annual uptake of $\sim 5 \%$ associated with atmospheric equilibration would be difficult to measure. However, in 1965 the air-sea $\Delta^{14} \mathrm{C}$ difference in this region was $\sim 800 \%$, so that the annual $\Delta^{14} \mathrm{C}$ increase of confined shelf waters associated with atmospheric equilibration alone would have been $\sim 80 \%$.

SLW, the other water mass component on Georges Bank, is not confined to the shelf and remains mostly an along-shelf current over the deeper slope. As evidence of SLW's ability to mix deeply, Kashgarian [1992] cited Csanady and Hamilhon's [1988] winter observation of a thick $(250 \mathrm{~m})$ surface layer of constant density that extended for almost $100 \mathrm{~km}$ offshore of the shelf break in the northern MAB. Deeper mixing will dilute SLW's uptake of atmospheric $\Delta^{14} \mathrm{C}$ during its downstream transit, so that SLW's $\Delta^{14} \mathrm{C}$ signal should remain closer to its original Labrador Sea value and more depleted than SSW. Our simple model suggests, then, that both an along shelf $\Delta^{14} \mathrm{C}$ gradient, as well as a cross shelf $\Delta^{14} \mathrm{C}$ gradient should exist, with the latter steepening downstream as, on the shelf, SSW becomes more enriched during its transit, 
while off the shelf, SLW remains little changed from its original Labrador Sea value. Also, since SSW and SLW have been described in terms of their distinct salinity and $\delta^{18} \mathrm{O}$ differences, with SSW being fresher and isotopically lighter than SLW, our model implies that shelf water $\Delta^{14} \mathrm{C}$ should correlate negatively with these two properties.

Of course, cross and along shelf mixing processes would tend to obscure these $\Delta^{14} \mathrm{C}$ gradients, but some limited evidence for them exists. Fairbanks [1982] calculated a mean residence time of 1.4 years for $\mathrm{MAB}$ waters, and if that is added to our estimated 1year transit time from the Labrador Sea to Georges Bank, the MAB shelf waters should exhibit enriched $\Delta^{14} \mathrm{C}$ levels compared with Georges Bank. Figure 6 shows the results of using equation (3) and letting ${ }^{14} \mathrm{C}_{\mathrm{Gcorges}}$ Bank substitute for ${ }^{14} \mathrm{C}_{\mathrm{Lab}} \mathrm{Sea}_{\mathrm{ea}}$ to estimate the effect of an additional 1-2 years atmospheric equilibration on the $\Delta^{14} \mathrm{C}$ signal. The results are compared to Tanaka et al.'s [1990] seawater $\Delta^{14} \mathrm{C}$ data from Long Island Sound (LIS) showing a mean of $+92 \%$ in 1983, Kashgarian's [1992] seawater data from the MAB shelf (sites with bottom depths less than or equal to 100 m) showing a mean of $+70 \%$ in 1987 , and two other coastal sites reported by Kashgarian in the MAB (where a full seasonal sampling was done) showing a combined mean of $+82 \%$ in 1986. The higher $\Delta^{14} \mathrm{C}$ values in the LIS correspond to an additional $\sim 2$ years of residence time, the other coastal sites to an additional $\sim 1.5$ year, and the offshore shelf waters of the MAB to an additional 1 year. Alternatively, the higher values shoreward and downstream of Georges Bank could be accounted for by a greater ratio of SSW:SLW in nearshore waters, higher uptake rates in shallower coastal depths, and/or a biasing of these mean $\Delta^{14} \mathrm{C}$ values toward the seasonally higher values measured in stratified surface waters during the summer.

\section{Estimate of the Bomb $\Delta^{14} \mathrm{C}$ Time History for the Labrador Sea}

Based on the evidence of continuity between the Labrador Sea and Georges Bank, the bomb $\Delta^{14} \mathrm{C}$ signal on Georges Bank can be used to make an initial estimate of the upstream bomb $\Delta^{14} \mathrm{C}$ signal

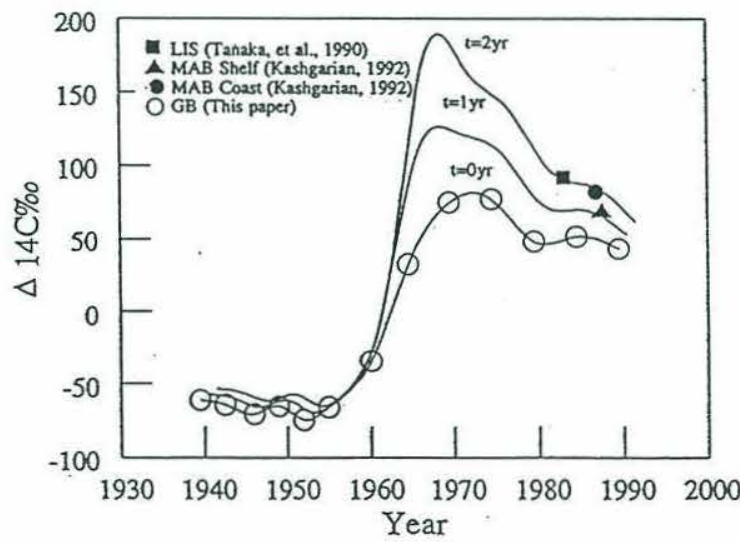

Fig. 6. Modeled effect of additional residence time on the $\Delta^{14} \mathrm{C}$ signal of shelf waters due solely to the uptake of atmospheric ${ }^{14} \mathrm{CO}_{2}$ (using equation (3)). An additional 1-2 years of shelf residence time could account for the apparent $\Delta^{14} \mathrm{C}$ difference between Georges Bank and mean surface shelf water and coastal waters from Mid-Atlantic Bight [Kashgariam, 1992] and Long Island Sound [Tanaka et al, 1990]. However, a higher ratio of SSW:SLW and/or seasonally higher uptake rates in stratified surface and shallow coastal water could also acoount for the difference.
TABLE 2. Estimated Labrador Sea $\Delta^{14} \mathrm{C}$ Time History

\begin{tabular}{ll}
\hline Ycar(s) & $\Delta^{14} \mathrm{C}^{*}$ \\
\hline 1938 & -64.6 \\
1941 & -66.8 \\
$1944-1945$ & -74.7 \\
$1947-1948$ & -68.6 \\
$1950-1951$ & -78.4 \\
$1953-1954$ & -72.6 \\
$1958-1959$ & -55.5 \\
$1962-1964$ & -27.8 \\
$1967-1969$ & +36.0 \\
$1972-1974$ & +50.5 \\
$1977-1979$ & +27.0 \\
$1982-1984$ & +37.5 \\
$1987-1989$ & +33.5 \\
\hline
\end{tabular}

- The Labrador Sea $\Delta^{14} \mathrm{C}$ time history is estimated using equation (6).

in the Labrador Sea. To keep it simple, the $\Delta^{14} \mathrm{C}$ composition of the SLW component of Georges Bank water is left equal to its original value in the Labrador Sea, ignoring for the moment any effects of SLW mixing with Gulf Stream waters:

$$
{ }^{14} \mathrm{C}_{\mathrm{SLW}}={ }^{14} \mathrm{C}_{\mathrm{LabSea}}
$$

We then use Chapman et al.'s [1986] mixing ratio (SSW:SLW = 3:1) for the southem flank of Georges Bank (equation (5)) and combine it with (3) and (4) to back-calculate the Labrador Sea $\Delta^{14} \mathrm{C}$ signal (equation (6)):

$$
{ }^{14} \mathrm{C}_{\text {GeorgesBank }}=(0.75)^{14} \mathrm{C}_{\text {SSW }}+(0.25)^{14} \mathrm{C}_{\mathrm{SLW}}
$$

${ }^{14} \mathrm{C}_{\text {Labsea }}=\left[{ }^{14} \mathrm{C}_{\text {GoorgesBank }}-(0.75)(U)\left({ }^{14} \mathrm{C}_{\mathrm{Atm}}\right) \mathrm{V} /[1-(0.75)(U)]\right.$

The model results (Table 2, Figure 7) provide the first well-

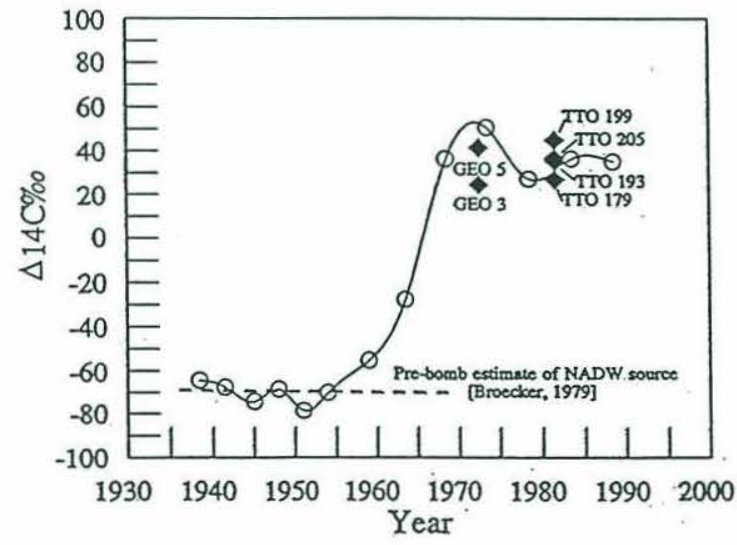

Fig. 7. Estimated Labrador Sea $\Delta^{14} \mathrm{C}$ time history (using equation (6)) compared with mixed layer $\Delta^{14} \mathrm{C}$ measurements from two GEOSECS and four TTO stations in and adjacent to the Labrador Sea (the uippermost two $\Delta^{14} \mathrm{C}$ values from each station were used to calculate a mean for the layer $0-100 \mathrm{~m}$ ). The prebomb mean of $-70.6 \%$ is lower than the $-55 \%$ previously used to estimate the bomb ${ }^{14} \mathrm{C}$ inventory for the Labrador Sea [Broecker et al., 1985], though almost identical to the -70\%o estimated for prebomb NADW source waters [Broecker, 1979]. Seawater $\Delta^{14} \mathrm{C}$ measurements in the Labrador Sea region in the 1970s and 1980s are in general agreement with our estimated $\Delta^{14} \mathrm{C}$ time history. Standard errors for GEOSECS and TTO data are smaller than symbols. 
constrained estimate of the Labrador Sea $\Delta^{14} \mathrm{C}$ time history and are in general agreement with radiocarbon measurements of seawater obtained from two GEOSECS stations (1972) and four TTO stations (1981) in and peripheral to the Labrador Sea (Figure 2). The GEOSECS and TTO values used for comparison are the means of the upper $100 \mathrm{~m}$, which were calculated from a linear fit of the two uppermost (depth) $\Delta^{14} \mathrm{C}$ values at each station. The low amplitude and depleted condition of the estimated Labrador Sea $\Delta^{14} \mathrm{C}$ signal are compatible with the concept of deep mixing and convective overturning that are thought to occur in the Labrador Sea as part of process of deepwater formation [Clarke and Gascard, 1983]. The model's estimated prebomb average $\Delta^{14} \mathrm{C}$ of $-70.6 \%$ is significantly lower than the generalized surface $\Delta^{14} C$ value of $-55 \%$ Broecker et al. [1985] used to calculate the bomb ${ }^{14} \mathrm{C}$ inventory in the high-latitude western North Atlantic including the Labrador Sea. However, the tritium-radiocarbon trend for the subsurface central Labrador Sea (TTO station 193) shows a zerotritium intercept at $\Delta^{14} \mathrm{C}=-69.6 \%$ [Oslund and Grall, 1987], and our estimated prebomb value is also nearly identical to the $-70 \%$ Broecker [1979] estimated for the prebomb source of North Atlantic Deep Water (NADW).

Though the bomb $\Delta^{14} \mathrm{C}$ values are sensitive to our annual uptake parameter $(U)$ because of the large atmosphere-ocean $\Delta^{14} \mathrm{C}$ difference, the prebomb values are not (Figure 8). While an increase in the uptake rate beyond $U=0.1$ seems to improve the fit with the two GEOSECS data, it worsens the fit with the four TTO values and also creates an unrealistic depletion of $\Delta^{14} \mathrm{C}$ in the Labrador Sea during the early 1960 s, when air-sea $\Delta^{14} C$ differences were very large. Oppositely, a reduction of the uptake rate tends to enrich the surface Labrador Sea beyond the constraints provided the GEOSECS and TTO data.

The prebomb $\Delta^{14} \mathrm{C}$ values of ocean waters are critical in determining the total uptake of bomb ${ }^{14} \mathrm{C}$, and our lower estimate of the prebomb $\Delta^{14} \mathrm{C}$ implies that the bomb ${ }^{14} \mathrm{C}$ inventory in the Labrador Sea is greater than has previously been reported. We recalculated the bomb ${ }^{14} \mathrm{C}$ inventory for TTO station 193 in the

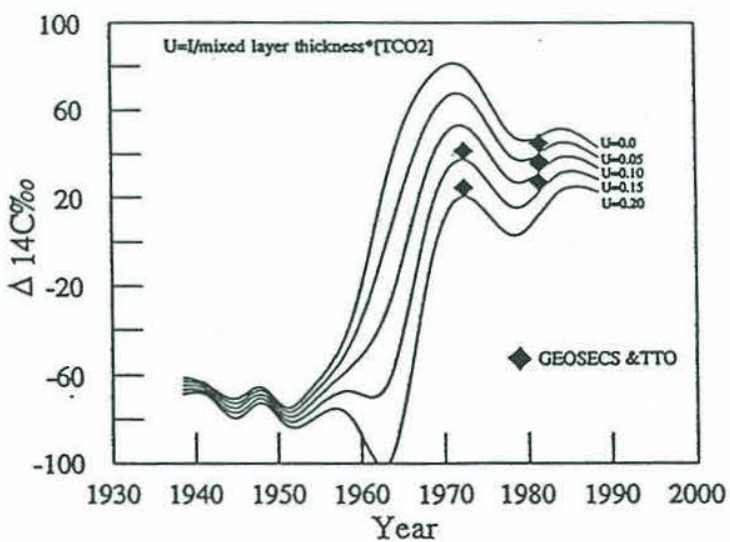

Fig. 8. Sensitivity of the Labrador Sea estimate to uptake rate $U$. The model shows the sensitivity of the estimated $\Delta^{14} \mathrm{C}$ value during the bomb period when the atmosphere-ocean $\Delta^{14} \mathrm{C}$ difference was large. $U$ here is constrained by the GEOSECS and TTO $\triangle^{14} \mathrm{C}$ measurements. Higher uptake rates improve fit with GEOSECS data but worsen fit with TTO data. The prebomb estimate is much less sensistive to $U$ because of the smaller air-sea $\Delta^{14} \mathrm{C}$ difference, but higher rates result in unrealistic $\Delta^{14} \mathrm{C}$ depletions in the Labrador Sea during the peak of the atmospheric bomb signal in the early 1960 s. central Labrador Sea using Broecker et al.'s [1985] methods and our lower estimate of the prebomb $\Delta^{14} \mathrm{C}$ value. The resulting inventory of $33.8 \times 10^{9}$ atoms cm$~^{-2}$ for this station is $~ 30 \%$ greater than their earlier estimate, requiring a higher average $\mathrm{CO}_{2}$ invasion rate and/or increased horizontal convergence and downward vertical advection of $\Delta^{14} \mathrm{C}$ enriched surface waters to account for this excess. The stormy Labrador Sea might well be expected to exhibit a greater than average $\mathrm{CO}_{2}$ invasion rate, because of the demonstrated dependence of gas exchange rates on wind speed [Wanninkhof, 1992]. The $53 \mathrm{mols} \mathrm{m}^{-2} \mathrm{yr}^{-1}$ required to account for the large bomb ${ }^{14} \mathrm{C}$ inventory is much higher than previously reported invasion rates, though it is only somewhat higher than the $\sim 30-45 \mathrm{mols}^{-2} \mathrm{yr}^{-1}$ predicted using various wind speed/gas exchange relationships [Broecker et al., 1985; Jenkins, 1988], and a combined 25-year (1947-1974) mean annual wind speed of $\sim 10.0 \mathrm{~m} \mathrm{~s}^{-1}$ for two stations in the Labrador Sea (OWS Bravo at $57^{\circ} \mathrm{N}, 50^{\circ} \mathrm{W}$, and station 7 at $55^{\circ} \mathrm{N}, 43^{\circ} \mathrm{W}$ ) [Meserve, 1974]. However, Broecker and Peng [1982] demonstrated that there is an upper limit on the gas exchange dependence on wind speed and that long-term regional $\mathrm{CO}_{2}$ gas exchange rates greater than $\sim 30$ $\mathrm{mols}^{-2} \mathrm{yr}^{-1}$ seem unlikely. Alternatively, if the Labrador Sea is a region of deepwater formation, then continuity requires lateral convergence of surface and intermediate waters to balance the downwelling. Our evidence of a larger inventory of bomb ${ }^{14} \mathrm{C}$ here suggests that these processes may be more vigorous than was previously thought, which further supports recent suggestions that the Labrador Sea may be the primary supplier of NADW [Stocker and Broecker, 1992].

Our initial estimate of the Labrador Sea $\Delta^{14} \mathrm{C}$ time history uses two assumptions which require further discussion (1) that the fresh water input to the Labrador Sea to form SSW does not significantly alter its $\Delta^{14} \mathrm{C}$ and (2) that the $\Delta^{14} \mathrm{C}$ of SLW is not affected by mixing with other water masses on its southward journey to Georges Bank. Though we have no direct evidence to support the first assumption, we base it on the low $\mathrm{\Sigma CO}_{2}$ concentration of fresh waters in general and the reported similarity between marine and adjacent riverine $\Delta^{14} \mathrm{C}$ values [Spiker, 1980; Kashgarian, 1992]. The second assumption, which holds SLW $\Delta^{14} \mathrm{C}$ constant between the Labrador Sea and Georges Bank, is unrealistic in view of the proximity of the Gulf Stream and its observed interaction with SLW [Flagg, 1987]. We can investigate the Gulf Stream influence on the composition of SLW by treating SLW as a mixture of Labrador Sea water and Gulf Stream water (GSW). Figure 9 compares the mean $\left(0-100 \mathrm{~m}\right.$ depth) $\Delta^{14} \mathrm{C}$ values from two GEOSECS stations with a series of Labrador Sea $\Delta^{14} \mathrm{C}$ time histories estimated using a range of values for the percentage of GSW in SLW at Georges Bank. The greater the percentage of GSW in SLW, the lower becomes the $\Delta^{14} \mathrm{C}$ estimate of Labrador Sea. The GEOSECS data very roughly constrain the proportion of Gulf Stream water in SLW (at Georges Bank) to $25-75 \%$, with values higher than $50 \%$ again producing an unrealistic depletion of the Labrador Sea $\Delta^{14} \mathrm{C}$ in the early 1960 s. Larger inputs of GSW in SLW also lower even further the prebomb estimate of $\Delta^{14} \mathrm{C}$ value for the Labrador Sea.

\section{Gutf Stream and Antarctic Intermediate Water}

The depleted radiocarbon signal on the southern flank of Georges Bank can also be interpreted as partly the result of local upwelling of deep water along the adjacent slope. Tanaka et al. [1990] developed a $\triangle{ }^{14} \mathrm{C}$ budget for the MAB and GOM, which they derived from a set of coastal and offshore seawater 


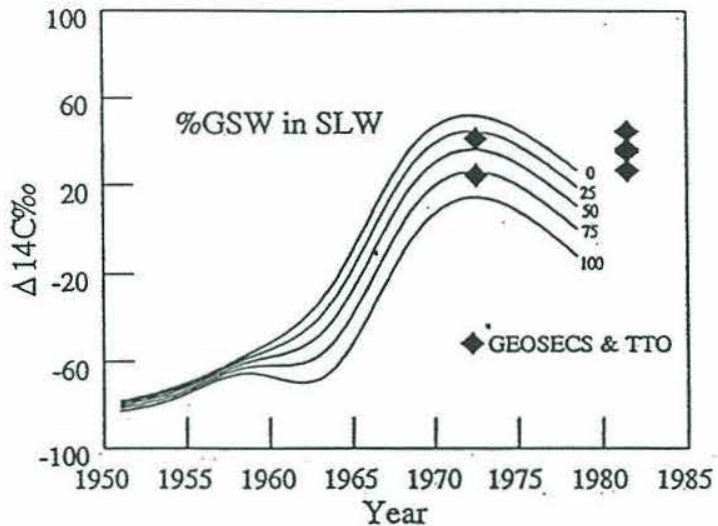

Fig. 9. Dependence of Labrador Sea $\Delta^{14} \mathrm{C}$ time history estimate on the percentage of Gulf Stream Water (GSW) in Slope Water (SLW). The GEOSECS data roughly bracket the amount of GSW in SLW between $25 \%$ and $75 \%$. However, values higher than $50 \%$ result in an unrealistic lowering of the Labrador Sea $\Delta^{14} \mathrm{C}$ value in the earty 1960 s.

measurements and analyses of whole shells. Describing the source waters for the MAB as a mixture of Sargasso Sea Water $\left({ }^{14} \mathrm{C}_{\text {Sargasso }}={ }^{14} \mathrm{C}_{\mathrm{Bermuda}}\right.$; values from Nozaki et al. $[1978 \mathrm{]})$ and Antarctic Intermediate Water $\left({ }^{14} \mathrm{C}_{\mathrm{AATW}}=-90 \%\right)$, they estimated the ratio of Sargasso Sea Water:AAIW for the Gulf of Maine to be about 60:40. Applying their general model and substituting ${ }^{14} \mathrm{C}_{\text {Sargasso }}$ with ${ }^{14} \mathrm{C}_{\mathrm{GSW}}={ }^{14} \mathrm{C}_{\text {Florida }}$ (values from Druffel [1989]) because of the Florida signal's closer correlation with the Georges Bank signal, we obtained a least squares fit $(r=0.997)$ to the Georges Bank $\Delta^{14} \mathrm{C}$ data using a $69: 31$ mixing ratio for GSW:AAIW (Figure 10).

The success of Tanaka et al.'s simple model can be used to support their hypothesis that shelf waters off the northern U.S. east coast are a mixture between these two important water masses. However, it may be, as was suggested by Broecker et al. [1985], that the phase. and shape of the bomb ${ }^{14} \mathrm{C}$ signal is similar

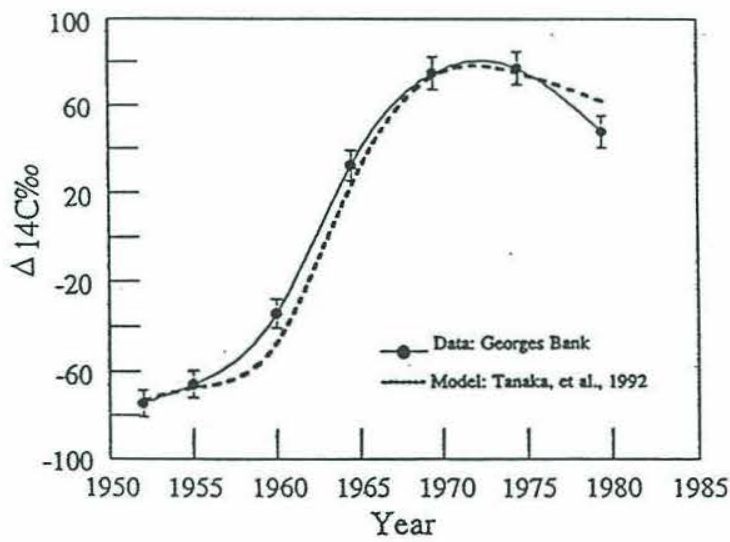

Fig. 10. Comparison of Tanaka et al.'s [1990] two-end-member model (Shelf Water = GSW + AAIW) with the Georges Bank record. Using a mixing ratio for GSW:AAIW of 69:31 their model shows a very close fil to our Georges Bank record ( $r=0.997$ ). Its success is most likely the result of a uniform phase of the bomb ${ }^{14} \mathrm{C}$ signal throughout the North Atlantic and the similarity between Gulf Stream (or Sargasso Sea) water and'surface water which has partially equilibrated with the atmosphere. throughout the North Atlantic, and, as was mentioned by Kashgarian [1992], it is difficult to differentiate between atmosphere equilibrated surface shelf water and Sargasso Sea water. In fact, Kashgarian [1992] concludes that by combining different proportions of constant value deep-water to the Sargasso Sea $\Delta^{14} \mathrm{C}$ signal, almost any $\Delta^{14} \mathrm{C}$ time history anywhere in the surface North Atlantic can be reproduced. This implies that Tanaka et al.'s [1990] model may work regardless of the actual sources, which consequently weakens it as a diagnostic of specific water mass composition.

Tanaka ef al. [1990] do note that much of the shelf water in the MAB region likely originates in the Labrador Sea. However, it is also suggested that, at times, AAIW may be entrained at depth $(1000 \mathrm{~m})$ into the SLW, upwelled, and introduced directly onto the continental shelf. Recently, Kashgarian [1992, p.68] has suggested the possibility "that the combination of prevailing southwestly winds in the summer and the divergent effect of the Gulf Stream" north of Cape Hatteras may provide a mechanism for such upwelling, at least south of $\mathrm{New}$ Jersey. At present, there is a lack of firm evidence for the hypothesis of deep upwelling and direct input of AAIW onto the shelf to the north of Cape Hatteras, and though our Georges Bank $\Delta^{14} \mathrm{C}$ time history does not contradict this possibility, neither does it require it. If local upwelling is a significant and continuous source of deep water on the shelf, then the dependence of the shelf water $\Delta^{14} \mathrm{C}$ budget on the Labrador Sea for its deepwater supply would be diminished.

\section{Ventilation $1{ }^{14} \mathrm{CO}_{2}$ uptake in the Labrador Sea}

Tanaka et al. [1990] use their model results and whole shell data from Long Island Sound to infer that deepwater supply to the shelf has varied in the past, and they use their evidence to support the idea of direct episodic upwelling along the shelf. If, as we contend, ventilation processes in the Labrador Sea largely govern the proportion of deep water introduced onto the shelf, we can use the radiocarbon time history on Georges Bank to reconstruct a ventilation history of the Labrador Sea. The radiocarbon data alone cannot separate the effect of changing uptake rates of atmospheric ${ }^{14} \mathrm{CO}_{2}$ versus water mass renewal rates, since both processes control the $\Delta^{14} \mathrm{C}$ of the surface ocean. However, as was discussed above, the Gulf Stream signal can be used as a proxy for surface water $\Delta^{14} \mathrm{C}$ and AAIW's constant value as a proxy for deepwater $\Delta^{14} \mathrm{C}$. Tanaka et al.'s mixing model can then be inverted to investigate variations in the proportion of deep water to surface water as a proxy for variations in the ventilation and/or ${ }^{14} \mathrm{CO}_{2}$ uptake in the Labrador Sea:

AAIW/LSW $\left.=\left[\left({ }^{14} \mathrm{C}_{\text {LebSea }}\right)\left({ }^{14} \mathrm{C}_{\mathrm{GSW}}\right)\right] /\left({ }^{14} \mathrm{C}_{\mathrm{AATW}}\right)-\left({ }^{14} \mathrm{C}_{\mathrm{GSW}}\right)\right]$

The calculated fraction of AAIW in the Labrador Sea water (LSW) for the period from 1951-1980 is $\sim 0.5$ (Figure 11). The pre-1960 fractions are poorly constrained owing to the small difference between the surface and deep water $\Delta^{14} \mathrm{C}$ values in prebomb times. However, the maximum in the mid-1960s and the minimum in the 1970 s do show a significant difference and may indicate contrasting periods of higher versus lower ventilation, respectively. It is also possible that the lower AAIW/LSW fractions in the 1970 s partly reflect the bomb ${ }^{14} \mathrm{C}$ enrichment of deep waters in the Labrador Sea.

Independent evidence exists for corresponding changes in the ventilation of the Labrador Sea. Lazier [1988], in his long-term study (1962-1986) of temperature and salinity changes in the Labrador Sea, observed that salinities dropped from their highest 


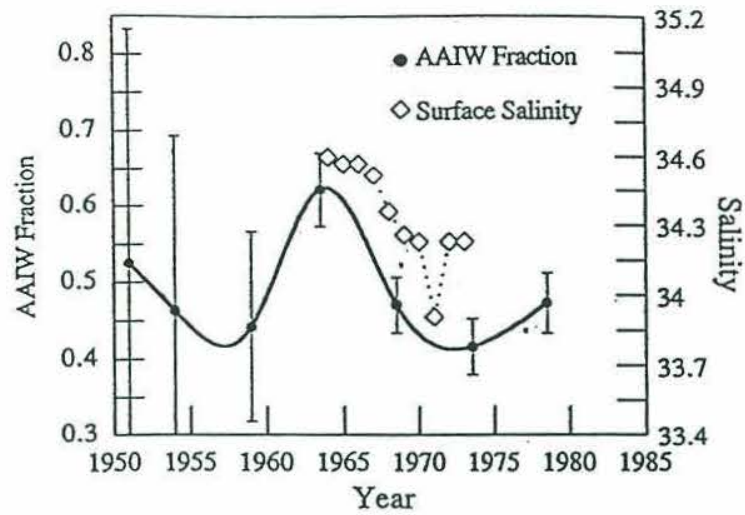

Fig. 11. A modeled history of the fraction of AAIW in Labrador Sea water (using equation (9)) compared with a 10-year history (1964-1973) of the mean annual surface salinity in the Labrador Sea [Lazier, 1988]. The $\pm 1 \sigma$ error bars show that the calculated pre-1960 fractions are not significant owing to the smail $\Delta^{14} \mathrm{C}$ difference between prebomb surface and deep waters. However, the maximum deep water fraction in the mid1960 s and minimum in the 1970 s correspond positvely to surface salinity variations in the Labrador Sea. Ventilation changes in the Labrador Sea may account for this correlation.

point in the mid-1960s to their lowest point in 1971 (Figure 11). Dickson et al. [1988] charted the migration of the "Great Salinity Anomaly" (1968-1982) throughout the northern North Atlantic from 1968-1982 and located this low-salinity event in the Labrador Sea in the late 1960s and the early 1970s. These authors suggested that the salinity variations reflected changes in the density of the waters of the Labrador Sea which may in turn have affected the rate of deepwater formation in this region. More recently, Schlosser et al. [1991] have reported upto an $80 \%$ reduction in the rate of deepwater formation in the East Greenland Sea during the 1980 s. Our estimated Labrador Sea $\Delta^{14} \mathrm{C}$ signal shows a positive trend for this same period despite a falling atmosphere-ocean $\Delta^{14} \mathrm{C}$ difference, implying a similar reduction in the vertical exchange of the waters of this region during the 1980s. Finally, in the adjoining Sargasso Sea, Jenkins [1982] and Druffel [1989] have described similar variations in water mass renewal rates which are coincident with those in Labrador Sea.

\section{CONCLUSIONS}

A time history of $\Delta^{14} \mathrm{C}$ on Georges Bank from 1939 to 1990 has been derived from the growth bands of a single shell of the bivalve $A$. islandica using AMS. This is the first bomb ${ }^{14} \mathrm{C}$ record reconstructed for the higher-latitude North Atlantic, where processes critical to the maintenance of global climate and ocean circulation are concentrated. This shell-derived $\Delta^{14} \mathrm{C}$ signal from Georges Bank is in phase with two low-latitude North Atlantic $\Delta^{14} \mathrm{C}$ time histories derived from banded corals but has a smaller amplitude and is more depleted. The depleted condition of the Georges Bank $\Delta^{14} \mathrm{C}$ signal implies a deepwater source, and supported by previous evidence, we identify the likely origin of this deep water as the Labrador Sea, though some input from local upwelling cannot be ruled out.

Chapman et al.'s [1986] two-end-member model of continental shelf water composition (75\% Scotian Shelf Water and $25 \%$ Slope Water), combined with the uptake of atmospheric $\mathrm{CO}_{2}$ during a 1year transit time from the Labrador Sea is used to account for the
$\Delta^{14} \mathrm{C}$ budget on Georges Bank. This model predicts both an alongshelf, and a cross-shelf $\Delta^{14} \mathrm{C}$ gradient for shelf waters, with $\Delta^{14} \mathrm{C}$ increasing downstream and decreasing seaward toward the shelf break as a function of the air-sea $\Delta^{14} \mathrm{C}$ difference and water mass residence time. Some limited evidence for these gradients is shown to exist.

This model is also used to back calculate a $\Delta^{14} \mathrm{C}$ time history for the Labrador Sea. The results prescribe lower prebomb $\Delta^{14} \mathrm{C}$. values for the Labrador Sea than were previously used to estimate the bomb ${ }^{14} \mathrm{C}$ inventory, suggesting greater penetration of the bomb signal and uptake of bomb-produced ${ }^{14} \mathrm{C}$ in this region than were previously reported. This prebomb evidence strengthens the view that the Labrador Sea acts as a primary region of deepwater formation as well as a strong sink for atmospheric $\mathrm{CO}_{2}$. The predicted bomb signal is consistent with the GEOSECS and TTO radiocarbon data from the Labrador Sea region.

A slight modification of Tanaka et al.'s [1990] two-end-member (Gulf Stream Water and Antarctic Intermediate Water) model of the $\Delta^{14} \mathrm{C}$ budget for the Middle Atlantic Bight and Gulf of Maine produces a remarkably close prediction of the Georges Bank $\Delta^{14} \mathrm{C}$ time history. However, their model's success is most likely owed to the generality of the radiocarbon signal phase in the North Atlantic along with inclusion of a diluting deep water component, and not specifically to the existence of these water masses on Georges Bank. We have shown that a Labrador Sea source for the waters on Georges Bank, adjusted for equilibration with the atmosphere, can account for the $\Delta^{14} \mathrm{C}$ composition of Georges Bank waters and that it is not necessary at this time to invoke deepwater upwelling onto the shelf to account for the $\Delta^{14} \mathrm{C}$ budget on Georges Bank.

Finally, we inverted Tanaka et al.'s [1990] GSW/AAIW model to examine changes in ventilation and/or atmospheric ${ }^{14} \mathrm{CO}_{2}$ uptake in the Labrador Sea, using AAIW as a proxy for deepwater $\Delta^{14} \mathrm{C}$ and Gulf Stream water (Florida) as a proxy for surface water $\triangle^{14} \mathrm{C}$. High and low fractions of our AAIW/LSW parameter in the mid-1960s and 1970s, respectively, correspond with independent observations of salinity changes in the North Atlantic and Labrador Sea, thus offering limited but direct support to the much discussed linkage between deepwater formation and surface salinity in the high-latitude North Atlantic. This also demonstrates that the longlived mollusc Arctica islandica might be a particularly useful marine geochemical tool by providing records of interannual ventilation changes throughout the northern North Atlantic Ocean.

Acknowledgments. Financial support has been provided by NOAA, DOE's Global Climate Change Fellowship Program, and WHOTs Ocean Venture Fund. A large debt is owed the late John Ropes of NMFS at Woods Hole for his work on A. islandica. We wish to thank Lanry Toolin, Doug Donahue, and Tim Jull for performing the radiocarbon analyses at the Arizona Accelerator Facility for Radioisotope Analysis, Tuscon, Arizona, which is supported by NSF. Al Gagnon, at WHOI, performed all sample and tanget preparations. Steve Murawski and others from NMPS at Woods Hole provided invaluble assistance throughout this research. Woods Hole Oceanographic Institution contribution 8152

\section{REFERENCES}

Baes, C. F. J., A. Bjorkstrom, and P. J. Mulholland, Uptake of carbon dioxide by the oceans, in Atmospheric Carbon Dioxide and the Global Carbon Cycle, edited by J. R. Trabalka, pp. 81-111, U.S. Department of Energy, Oak Ridge, Tenn., 1985.

Bigelow, H. B., Physical oceanography of the Gulf of Maine, Bull. Bur. Fish., 40, 511-1027, 1927.

Broecker, W.S., A revised estimate for the radiocarbon age of North Atlantic Deep Water, J. Geophys. Res., 84, 3218-3226, 1979. 
Broecker, W. S., The great ocean conveyor, Oceanography, 4, 79-89, 1991.

Broecker, W. S., and T. H. Peng, Seasonal variability in the C-14/C-12 ratio for surface ocean water, Geophys. Res. Lett., 7, 1020-1022. 1980.

Broecker, W. S., and T. H. Peng, Tracers in the Sea, Lamont-Doherty Earth Observatory, Columbia University, Palisades, N.Y., 1982.

Broecker, W. S., and T. S. Peng, Interhemispheric transport of carbon dioxide by ocean circulation, Nature, 356, 587-589, 1992.

Broecker, W. S., R. Gerard, M. Ewing, and B. C. Heezen, Natural radiocarbon in the Atlantic Ocean, J. Geophys. Res., 65, 2903-2931. 1960.

Broecker, W. S., T. H. Peng, G. Ostlund, and M. Stuvier, The distribution of bomb radiocarbon in the ocean, J. Geophys. Res., 90 , 6953-6970, 1985.

Broecker, W.S., T. H. Peng, and T. Takahashi, A strategy for the use of bomb-produced radiocarbon as a tracer for the transport of fossil fuel $\mathrm{CO}^{2}$ into the deep-sea source regions, Earth Planet. Sci. Lett., 49, 463$468,1980$.

Cain, W. F., and H. E. Suess, Carbon 14 in tree rings, J. Geophys. Res., $81,3688-3694,1976$.

Chapman, D. C., and R. C. Beardsley, On the origin of shelf water in the Middle Atlantic Bight, J. Phys. Oceanogr., 19, 384-391, 1989.

Chapman, D. C., J. A. Barth, R. C. Beardsley, and R. G. Fairbanks, On the continuity of mean flow between the Scotian shelf and the Middle Atlantic Bight, J. Phys. Oceanogr., 16, 758-772, 1986.

Clarke, R. A., and J. C. Gascard, The formation of Labrador Sea Water: Large-scale processes, J. Phys. Oceanogr., 13, 1764-1778, 1983.

Csanady, G.T., and P. Hamilton, Circulation of slope water, Cont. Shelf Res., 8, 565-624, 1988.

Dickson, R. R., J. Meincke, S. Malmberg, and A. J. Lee, The "Great Salinity Anomaly" in the northem North Atlantic 1968-1982, Prog. Oceanogr., 20, 103-151, 1988.

Donahue, D. J., T. W. Linick, and A. J. T. Jull, Isotope-ratio and background corrections for accelerator mass spectrometry radiocarbon measurements, Radiocarbon, 32, 135-142, 1990.

Druffel, E. M., Bomb radiocarbon in the Pacific: Annual and seasonal timescale variations, J. Mar. Res., 45, 667-698, 1987.

Druffel, E. M., Decade time scale variability of ventilation in the North Atlantic: High-precision measurements of bomb radiocarbon in banded corals, J. Geophys. Res., 94, 3271-3285, 1989.

Druffel, E. M., and T. W. Linick, Radiocarbon in annual coral rings, Geophys. Res. Lett., 5, 913-916, 1978.

Druffel, E. M., and H. E. Suess, On the radiocarbon record in banded corals: Exchange parameters and net transport of ${ }^{14} \mathrm{CO}^{2}$ between atmosphere and surface ocean, J. Geophys. Res., 88, 1271-1280, 1983.

Erlenkeuser, H., C-14 and C-13 isotope concentration in modern marine mussels from sedimentary habitats, Naturwissenschften, 63, 338, 1976.

Fairbanks, R. G., The origin of Continental Shelf and Slope Water in the New York Bight and Gulf of Maine: Evidence from $\mathrm{H}_{2}{ }^{18} \mathrm{O} / \mathrm{H}_{2}{ }^{16} \mathrm{O}$ ratio measurements, J. Geophys. Res., 87, 5796-5808, 1982.

Flagg, C. N., Hyrdographic structure and variability, in The Georges Bank Book, edited by R. H. Backus, pp. 108-124, MTT Press, Cambridge, Mass., 1987

Gagnon, A. R., and G. A. Jones, AMS-graphite target production methods at the Woods Hole Oceanographic Institution between 198691, Radiocarbon, 35, 301-310, 1993.

Jenkins, W. J., On the climate of a sub-tropical ocean gyre: Decade timescale variations in the water mass renewal in the Sargasso Sea, J. Mar. Res., 40, 265-290, 1982.

Jenkins, W. J., The nitrate flux into the euphotic zone near Bermuda, Nature, 331, 521-523, 1988.

Jones, D. S., Annual cycle of shell growth and reproduction in the bivalves Spisula Solidissima and Arctica islandica, Ph.D. dissertation, Princeton Univ., Princeton, N. J., $1980 \mathrm{a}$.

Jones, D. S., Annual cycle of shell growth increment formation in two continental shelf bivalves and its paleoecologic significance, Paleobios, $6,331-340,1980 b$.

Jones, D. S., Sclerochronology: Reading the record of the molluscan shell, Am. Sci., 71, 384-391, 1983.

Kashgarian, M., Radiocarbon in the coastal waters off the eastern United States, Ph.D. dissertation, Yale Univ., New Haven, Conn., 1992.
Keir, R. S., R. L. Michel, and R. F. Weiss, Ocean mixing vesus gas exchange in Antarctic Shelf Waters near $150^{\circ}$ E, Deep Sea Res., 39, 97 119, 1992.

Krantz, D. E., Mollusk-isotope records of Plio-Pleistocene marine paleoclimate, U.S. Middle Atlantic coastal plain, Palaios, S, 317-335, 1990.

Lazier, J. R. N., Temperature and salinity changes in the deep Labrador Sea, 1962-1986, Deep Sea Res., 35, 1247-1253, 1988.

Levin, I. B. Kromer, H. Schoch-Fischer, M. Bruns, M. Munnich, D. Berdau, J. C. Vogel, and K. O. Munnich, 25 years of tropospheric ${ }^{14} \mathrm{C}$ observations in Central Europe, Radiocarbon, 27, 1-19, 1985.

Linick, T. W., P. E. Damon, D. J. Donahue, and A. J. T. Jull, Accelerator mass spectrometry: The new revolution in radiocarbon dating. Quat. Int., 1, 1-6, 1989.

Maier-Reimer, E., and R. Bacastow, Modelling of geochemical tracers in the ocean, in Climate-Ocean Interaction, edited by M. E. Schlesinger, pp. 233-267, Kluwer Academic, Hingham, Mass., 1990.

Meserve, J. M., U.S. Navy marine climate atlas of the worid-North Atlantic Ocean, 1, Naval Weather Service Command, Asheville, N.C., 1974.

Murawski, S. A., J. W. Ropes and F. M. Serchuk, Growth of the ocean quahog, Arctica islandica, in the Middle Atlantic Bight, Fish. Bull. U.S., 80, 21-34, 1982.

Nozaki, Y., D. M. Ryc, K. K. Turekian, and R. E. Dodge, C-13 and C14 variations in a Bermuda coral, Geophys. Res. Lett., 5, 825-828, 1978.

Nydal, R., and K. Lovseth, Tracing bomb ${ }^{14} \mathrm{C}$ in the atmosphere 1962 1980, J. Geophys. Res., 88, 3621-3642, 1983.

Ostlund, H. G., and C. Grall, TTO: Data Rep. 16, Tritium Lab., Univ. of Miami, Coral Gables, Fla., 1987.

Ostlund, H. G., H. G. Dorsey, and C. G. Rooth, Geosecs North Atlantic radiocarbon and tritium results, Earth Planet. Sci. Lett., 23, 69-86, 1974.

Quay, P. D., B. Tilbrook, and C. S. Wong, Oceanic uptake of fossil fuel $\mathrm{CO}^{2}$ : Carbon-13 evidence, Science, 256, 74-79, 1992.

Rhoads, D. C., and R. A. Lutz (Eds.), Skeletal Growth of Aquatic Organisms, 750 pp., Plenum, New York, N. Y., 1980.

Ropes, J. W., Procedures for preparing acetate peels and evidence validating the annual periodicity of growth lines formed in the shells of ocean quahogs, Arctica islandica, Mar. Fish. Rev., 46, 27-35, 1987.

Ropes, J. W., D. S. Jones, S. A. Murawski, F. M. Serchuk, and A. Jerald, Documentation of annual growth lines in ocean quahogs, Arctica islandica Linne, Fish. Bull. US., 82, 1-19, 1984.

Sarmiento, J. L., and E. T. Sundquist, Revised budget for the oceanic uptake of anthropogenic carbon dioxide, Nature, 356, 589-593, 1992.

Schlosser, P., G. Bonisch, M. Rhein, and R. Bayer, Reduction of deep water formation in the Greenland Sea during the 1980s: Evidence from tracer data, Science, 251, 1054-1056, 1991.

Siegenthaler, U., Uptake of excess $\mathrm{CO}^{2}$ by an outcrop-diffusion model of the ocean. J. Geophys. Res., 88, 3599-3608, 1983.

Spiker, E. C., The behavior of C-14 and C-13 in estuarine water. Effects of in situ $\mathrm{CO}^{2}$ production and atmospheric exchange, Radiocarbon, 22, $647-654,1980$.

Stocker, T. F., and W. S. Broecker, NADW formation as a branch of the hydrological cycle, Eos Trans. AGU, 73, 202-203, 1992.

Stuiver, M., and H. G. Ostlund, GEOSECS Atlantic radiocarbon, Radiocarbon, 22, 1-24, 1980.

Stuiver, M., and H. A. Polach, Discussion: Reporting of ${ }^{14} \mathrm{C}$ Data, Radiocarbon, 19, 355-363, 1977.

Suess, H. E., Natural radiocarbon and the rate of exchange of $\mathrm{CO}^{2}$ between the atmosphere and the sea, in Proceedings of the Conference on Nuclear Processes in Geological Settings, University of Chicago Press, Chicago, III, 1953.

Tanaka, N., M. C. Monaghan, and D. M. Rye, Contribution of metabolic carbon to mollusc and barnacle shell carbonate, Nature, 320, 520-523, 1986.

Tanaka, N., M. C. Monaghan and K. K. Turekian, ${ }^{14} \mathrm{C}$ balance for the Gulf of Maine, Long Island Sound and the northern Middle Atlantic Bight: Evidence for the extent of the Antarctic Intermediate Water contribution, J. Mar. Res, 48, 75-87, 1990.

Thompson, I., D. S. Jones, and D. Dreibelbis, Annual internal growth banding and life history of the ocean quahog Arctica islandica (Mollusca: Bivalvia), Mar. Biol., 57, 25-34, 1980a.

Thompson, I., D. S. Jones, and J.W. Ropes, Advanced age for sexual 
maturity in the ocean quahog Arctica islandica (Mollusca: Bivalvia), Mar. Biol., 57, 25-34, 1980 b.

Toggweiler, J. R., K. Dixon, and W. S. Broecker, The Peru upwelling and the ventilation of the South Pacific thermocline. J. Geophys. Res., 96, 20,467-20,497, 1991.

Turekian, K. K., D. Cochran, Y. Nozaki, I Thompson, and D. S. Jones, Determination of shell deposition rates of Arctica islandica from the New York Bight using natural ${ }^{228} \mathrm{Ra}$ and $228 \mathrm{Th}$ and bomb-produced ${ }^{14} \mathrm{C}$. Limnol. Oceanogr., 27, 737-741, 1982.

Urey, H. C., H. A. Lowenstam, S. Epstein, and C. R. McKinney, Measurement of paleotemperatures and temperatures of the Upper Cretaceous of England, Denmark, and southeastom United States, Bull.

Geol. Soc. Am., 62, 399-416, 1951.
Wanninkhof, R., Relationship between wind speed and gas exchange over the ocean, J. Geophys. Res., 97, 7373-7382, 1992.

Warren, B. A., Evolution of Physical Oceanography, MTT Press, Cambridge, Mass., 1981.

G. A. Jones and Christopher Weidman, Department of Marine Geology and Geophysics, Woods Hole Oceanographic Institution, Woods Hole. and Geophysi 02543.

\section{Received September 28, 1992. \\ revised March 1, 1993; \\ accepted March 10,1993.)}




\section{Chapter 2}

The Long-Lived Mollusc Arctica islandica:

A New Paleoceanographic Tool for the Reconstruction of Bottom Temperatures for the Continental Shelves of the Northern North Atlantic Ocean 


\title{
The long-lived mollusc Arctica islandica: A new paleoceanographic tool for the reconstruction of bottom temperatures for the continental shelves of the northern North Atlantic Ocean
}

\author{
Christopher R. Weidman and Glenn A. Jones \\ Department of Marine Goology and Goophysics. Woods Iolc Occanographic Institution. Wonds I Iolc. \\ Massachusetts
}

Kyger C. Lohmann

Geological Sciences Department. University of Michigan. Ann Arbor

\begin{abstract}
The carbonate shcll of the bivalve Arctica is/andica has becn recognized. for more than a decade, as a potentially important marine gcochemical biorccorder owing to this specics' great longevity (200+ ycars) and vide geographic distribution throughout the northern North Atlantic Occan, a region vital to global climatc and occan circulation. Howcrer. until now this potential has not been realized owing to the difficulty of preciscly sampling the shcll of this slow growing specics. Using newly availablc automatcd microsampling tochniques combincd with micromass stable isotope mass spectrometry, a stable oxygen isotope record (1956-1957 and 1961-1970) has becn obtained from a live-captured. 38-ycar-old .A. is/andica specimen collected near the former position of the Nantucket Shoals Lightship $\left(+1^{\circ} \mathrm{N}\right.$. 69 $\left.{ }^{\circ} \mathrm{W}\right)$. The shell's $\delta^{18} \mathrm{O}$ signal is compared with an cxpected signal derived from ambicnt bottom temperature and salinity data recorded at the lightship for the same period. The results show that $A$. islandica's $\delta^{18} \mathrm{O}$ record (1) is in phase with its growth banding. confirming the annual periodicity of this species' growth bands. (2) is in oxygen isotopic cquilibrium with the ambient scawater. (3) shows a consistent shell growth shutdown tempcraturc of $\sim 6{ }^{\circ} \mathrm{C}$. which translates into an $\sim 8$ month (May-December) shell growth period at this location. and (4) records the ambient bottom temperature with a precision of $\sim 1.2^{\circ} \mathrm{C}$. These results add important information on the life history of this commercially important shellfish species and demonstratc that $A$. islandica shells can be used to reconstruct inter- and intra-annual records of the contincntal shelf bottom temperature.
\end{abstract}

\section{Introduction}

Since the 1940s it has been known that the stable oxygen isotope composition of carbonate is dependent on the ambient temperature at the time of precipitation and on the isotopic composition of the surrounding water [(irey, 1947; lipstein et al., 1953]. This knowledge has been successfully applied to the calcareous growth structures of many marine organisms to investigate their life historics [11efer and Berger, 1991] as well as their enviromments [Duplessy, 1978: Arrluer et al.e 1983: Krantz et al., 1987]. This research has foctsisd on many timescales using various marine specics. For example, the fossil tests of foraminifera recovered from ocean sediment cores have been used to look at changes in ocean climatc over the past several tens of thousands of years on century to millenial scales, while corals and molluses have boen analyzed to reconstruct shorter-length records on seasonal to decadal scales. Some corals have been particularly useful in reconstructing highresolution climate records of a century or more bocause of their longevity and rapid growth rates $(\sim 1 \mathrm{~cm} / \mathrm{yr})$. However, these stony corals are restricted to the warmer, lower-latitude surface oceans, and no comparable high-resolution tool has been developed for the colder, higher-latitude oceans, despite the vital

Copyright 1994 by the Ankrican (icophỵxical t inicn.

Paper numler 94JC01882.

$0148-0227 / 94 / 94 J C-0188255 .(40$ role these regions are thought to play in the regulation of global climate and occan circulation [c.g., Broecker, 1991].

Although sclerochronology (the marine equivalent of dendrochronology) and stable oxygen isotope methods have boen applied to the shells of bivalved molluses, which inhabit higher latitudes, most marine bivalves are relatively short-lived (less than 20 years) [Heller, 1990] compared to corals, limiting the length of record available. Also, bivalves are small (relative to stony corals) and their shells grow slowly so that sampling resolution is restricted. In addition, growth band periodicity and the matter of isotopic equilibrium between the shell and ambient seawater mist be established for each molluse species in order to create valid and dependable chronologies of the ambient environment [Jones, 1981).

In recognition of some of thesc problems, Thompson et al. $\cdot[1980 \mathrm{a}, \mathrm{b}]$ and Jones $[1980 \mathrm{a}, \mathrm{b}]$ were the first to identify the great potential of the bivalve Arctica islandica as a marine geochemical recorder owing to its longevity, with individual ages commonly in excess of $I(X)$ years and one documented specimen aged at 221 years old [Jones, 1983]. They noted that A. islandica is a large $(-100) \mathrm{mm}$ in radial length) and common infaunal spocies which inhabits the continental shelves and slopes on both sides of the North Atlantic Occan, spanning a wide depth and latitude range, from $10-200 \mathrm{~m}$ and from Cape Hattcras $\left(-35^{\circ} \mathrm{N}\right)$ to the Barents Sea $\left(-70^{\circ} \mathrm{N}\right)$. Their studics, along with the subsequent work of others (Afuraviski et al. 1982; Turekian et al.. 1982: Ropes et al.. 1984; Heidnutu and Jones, 1993| have provided evidence supporting the anutal 
nature of growth bands in $A$. islandica's aragonitic shell.

Many important aspects of $A$. islandica's life history have been established over the last two docades [c.g., Namu, 1982; Lutz et al., 1982; Fritz, p. 1991] through rescarch driven, in part by the importance of a conmercial fishery for this species in the United States and Canada. However, A. islandica's notod potential as the "tree of the North Atlantic shcle" [Thompson and Jones, 1977, p.1199] has, until how, gone unrealized. This has largely been because the conventional sampling methods usod to obtain seasonal and interannual isotopic profiles from corals [Druffel, 1989] and other faster growing but shorter-lived molluscs, such as Spisula solidissima [Jones et al.. 1983] and Tridacna maxima [Romanek et al., 1987], have not ben applicable to $A$. islandica owing to its slow growth rates. The recent development of computcr-aided microsumpling equipment with micron-scale resolution and micromass mass spectrometry has now altered this situation by providing the means to profilc and analyze the small growth increments in long-lived, slow growing molluses such as $A$. islandica. As an example, the recent development of accelerator mass spectrometry (AMS) reduced the mass roquirements for obtaining a ${ }^{14} \mathrm{C}$ analysis by 3 orders of magnitude and enabled Weidman and Jones [1993] to reconstruct time historics of the $\Delta^{14} \mathrm{C}$ of the dissolved inorganic carton for specific oceun sites The research reported here has taken advantage of some of these new technologies to investigate the shell growth history of $A$. islandica as well as to calibrate its stable oxygen isotope record with its ambient environment. The results reveal $A$. islandica to be an important new paleoceanographic tool for the northern North Atlantic Ocean. Stable carbon isotope results were also obtained as part of this research, but these results will be addressed in a separate paper (C.R. Weidman and G.A. Jones, manuscript in preparation, 1994).

\section{Methods}

\section{Nantucket Shoals Lightship TS records}

Sea surface temperatures (SST) werc recorded daily at the Nantucket Shoals Lightship $\left(-40^{\circ} 40 \mathrm{~N}, 69^{\circ} 40^{\prime} \mathrm{W}\right)$ (Figurc 1) for almost a century from 1878 until 1970, though this rocord is not without gaps lasting up to sevcral years [Bumpus, 1957a]. From 1956 to 1971, more detailod water column rocords were kept at this location, including temperature measurements from six different depths $(0,9,15,30,46$, and $60 \mathrm{~m})$ and salinity measurements from the surface $(0 \mathrm{~m})$ and hottom $(60) \mathrm{m})$ waters, although some short gaps also exist (lasting up to several months), and only surface records cxist for 1959) [Bumpus, 1957b; Dav, 1959a, b, 1960, 1963; Chase, 1964, 1965, 1966, 1967, 1969a, b, 1971a, b, c, 1972]. During this period, bottom temperature measurements were perfonned daily, while bottom salinity measurements were performed, on average, about once per week. Figure 2 shows two examples from Chase 11966 , 1969b] of the seasonal evolution of water column temperature at this location. The water colunn is isothernal from approximately November to May, and coldest temperatures reach $\sim 3^{\circ} \mathrm{C}$. During the summer the water coluun becomes stratified and sea surface temperatures can cercoed $18^{\circ} \mathrm{C}$, while bottom water temperatures reach their maximum $\left(10^{\circ}-16^{\circ} \mathrm{C}\right)$ during or after the fall overtum, when the water coltumn becomes isothermic.

Mean monthly bottom temperatures $T_{b}$ and salinities $S_{b}$ werc calculated from the lightship observations for cach year of record

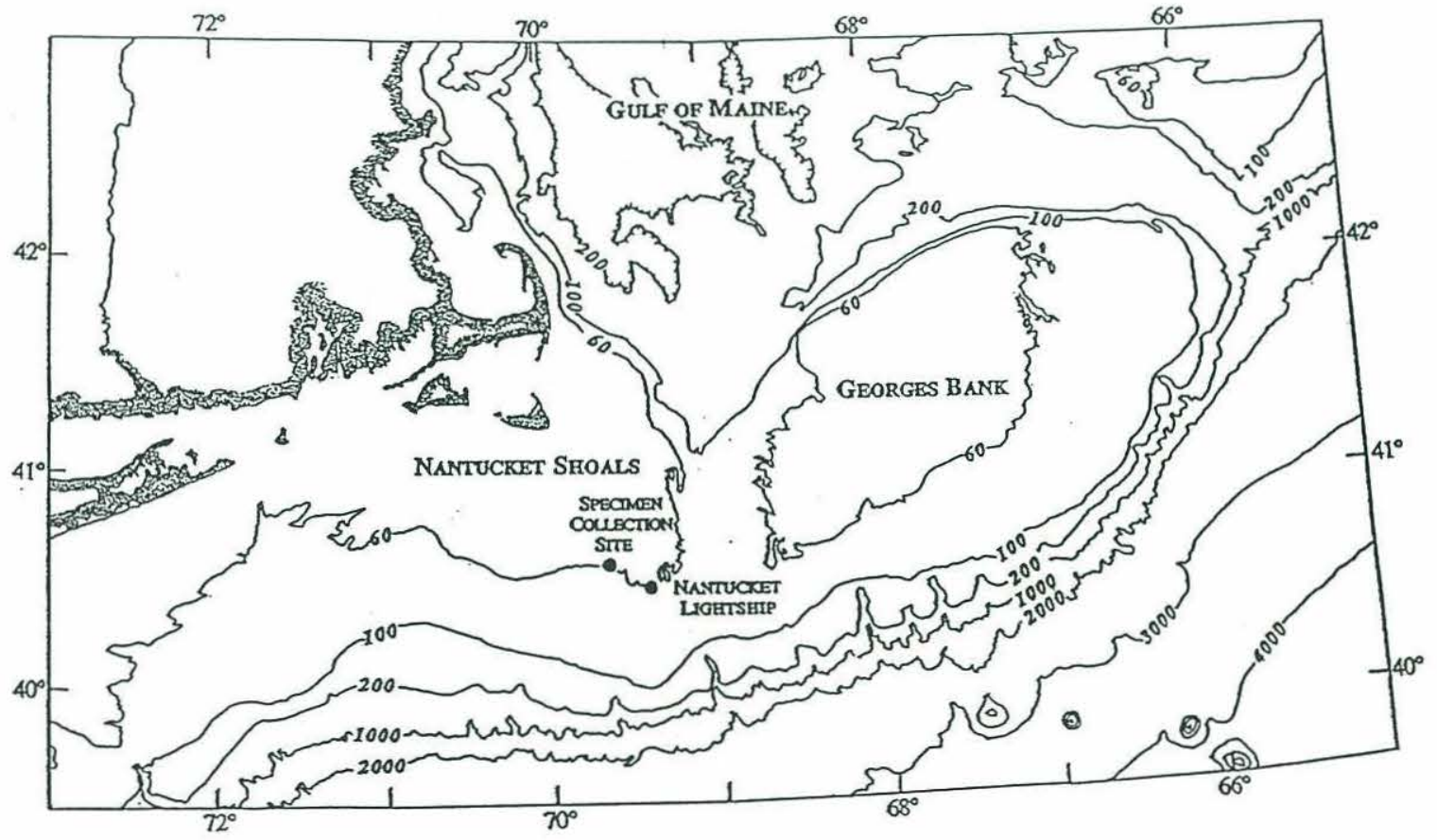

Figure 1. Nantucket Shoals and Georges Bank. The collection site of the A. islandica specimen used in this study is near the former position of the Nantucket Stroals Lightship at about the same $60 \mathrm{~m}$-depth contour. 

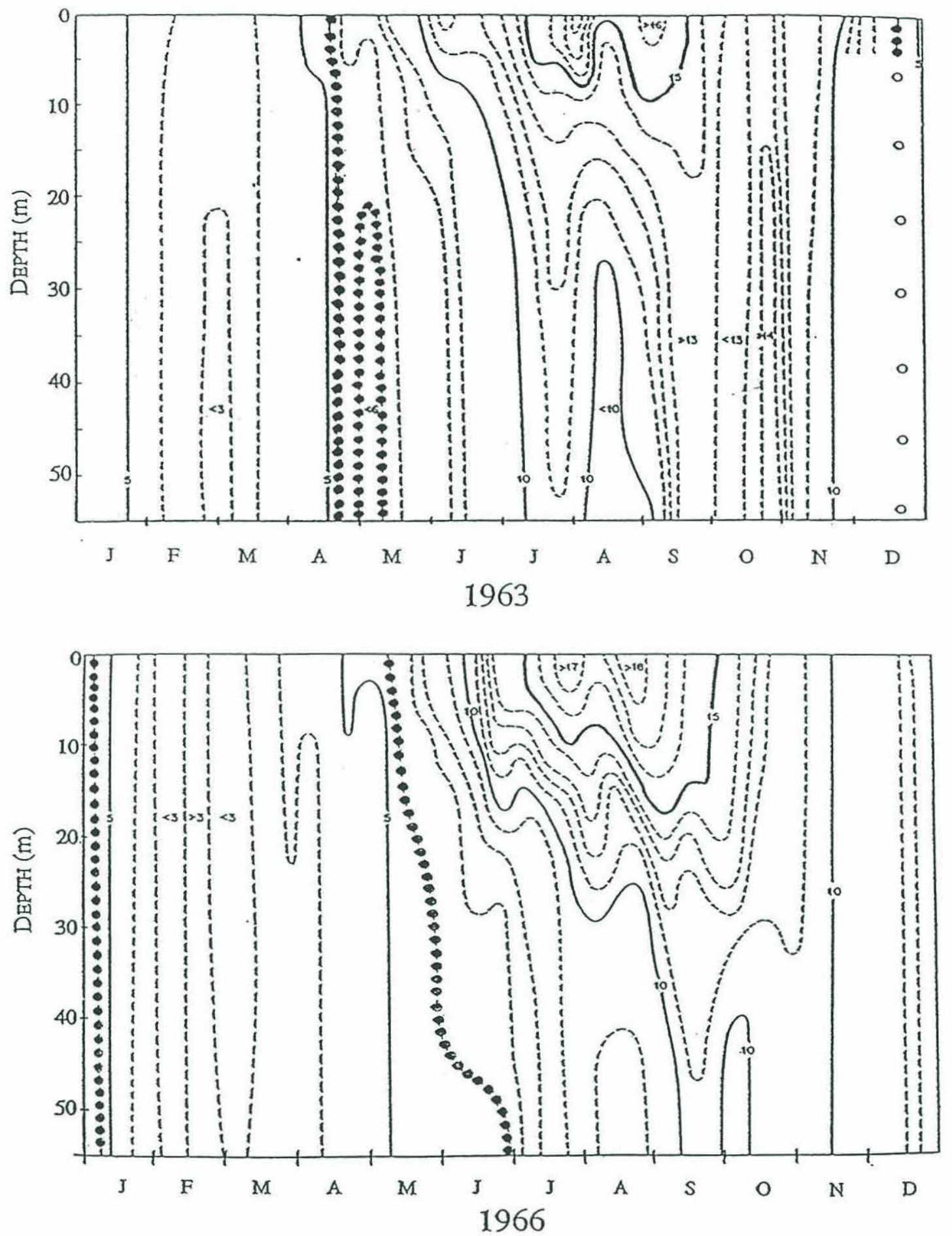

Figure 2. Hydrographs of the seasonal temperature evolution of the water column at the Nantucket Shoals Lightship for the years 1963 and 1966 (adapted from Chase, [1966, 1969b]. The dotted lines are the $6^{\circ} \mathrm{C}$ isotherms. Bottom temperatures are at or ahove $6^{\circ} \mathrm{C}$ from about May to December and below $6^{\circ} \mathrm{C}$ from January to April. Note that both years show a similar evolution and range of surface temperatures, while the bottom experiences a much colder year in 1966 than in 1963, with maximum bottom temperatures $4^{\circ} \mathrm{C}$ lower in 1966. 
(Figures 3a and 3b). No boltom water data werc collected from the lightship during the latter third of 1958 and all of 195\%. Bottom salinities for the period 1956-1970 have a mean of $32.72 \% \pm 0.37 \%(1 \sigma)$ and show no significant linear correlation with bottom temperatures, although some of the most prominent positive salinity anomalies $(1956,1957,1961$, and 1963) coincide with the seasonal bottom temperature maxima.

\section{Predicted Aragonite $\delta^{18} \mathrm{O}$ Record}

Several $\delta^{18} \mathrm{O}_{\text {aragonite-temperature fractionation relationships }}$ have been published [Tarutani et al., 1969: Horibe and Oba, 1972; Sommer and Rue, 1978; Grossman, 1982: Jontes et al., 1983; Grossman and Ku, 1986]. With the exception of Iloribe and Oba [1972] all of these relationships show aragonite to be enriched $(-0.6 \%)$ in $\delta^{18} \Omega$ relative to calcite for a given
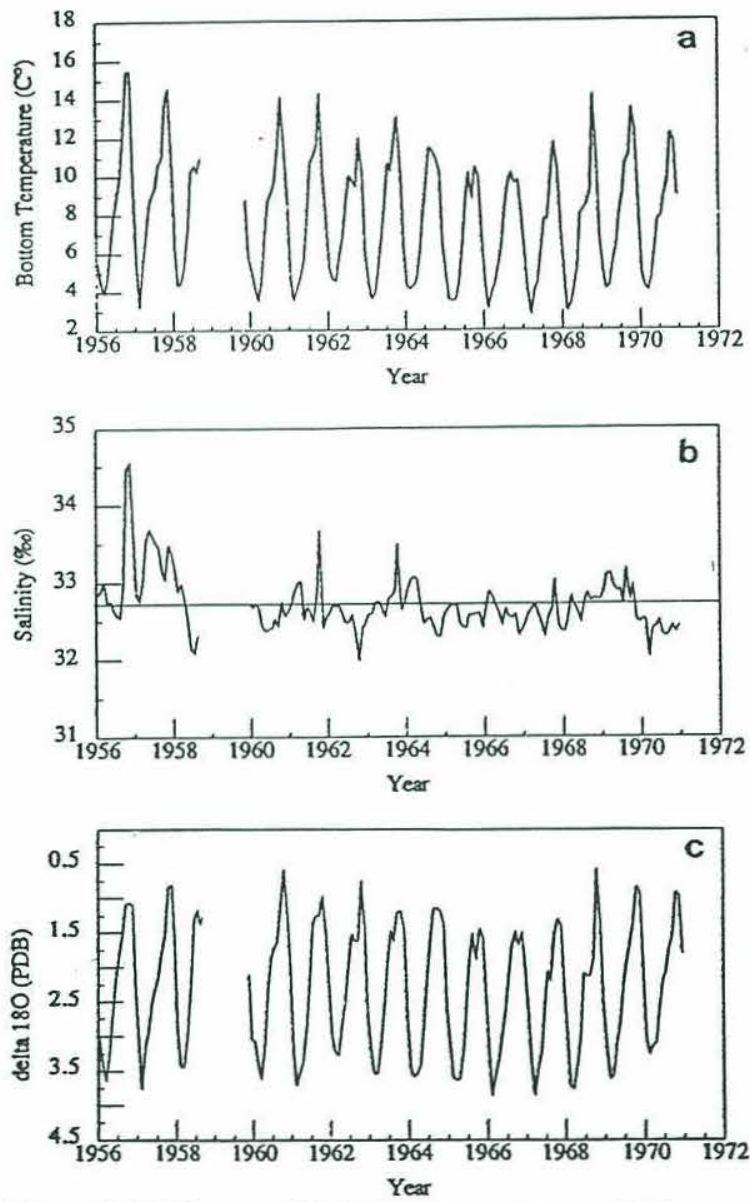

Figure 3. (a) Mean monthly bottom temperatures and (b) mean monthly bottom salinities calculated from observations at the Nantucket Shoals Lightship for the period 1956-1970. No bottom data exist for the latter third of 1958 and all of 1959. (c) The predicted $\delta^{18} \mathrm{O}$ record (1956-1970) for aragonite deposited in equilibrium with the TS data from the Nantucket Shoals Lightship observations, derived from equations (1) and (3). Note the strong similarity between the bottom temperature record and the predicted $\delta^{18} \mathrm{O}$, record indicating that temperature (and not salinity) dominates the signal. temperature, and their slopes are in reasonable agreement with each other. However, it is not clear at this time which of these paleotemperature equations is the more accurate one to usi when applied to biogenic aragonite data from species other than those used for calibration in some of theie same studies. Ideally, each species considered for $\delta^{18} \mathrm{O}$ thermometry should be calibrated under controllod conditions so as to diroctly measure skeletal growth and the $\delta^{12} O$ composition of the ambient water. While this approach has its own difliculties, such as the potentially varying biological response of spocimens grown under laboratory versus natural conditions, we are currently performing this time intensive calibration for the slow growing A. islandica.

For this paper we take advantage of more than a decade of TS measurements ncar the site of a naturally growing $A$. islandica population to predict the $\delta^{18} \mathrm{O}$ composition of aragonitc deposited in equilibrium with these conditions using one of the previously published $\delta^{18} \mathrm{O}_{\text {arapmutc }}$-temperature relationships. Wc have chosen to use one of Grossman and Ku's [1986] aragonite palcotemperature relationships which is derived from mollusc data only. This equation is modified here to include the approximate difference $\left(\Delta-0.2 \%\right.$ ) between $\mathrm{CO}_{2}$ equilibrated with standard mean ocean water (SMOW) and $\mathrm{CO}_{2}$ generated from the hydrolized cartmenate standard Poe Dee helemnite (PDB), and it is also inverted to solve for $\delta^{16} O_{\text {aresentice }}$

$$
\delta^{18} \mathrm{O}_{\text {arepentile }}(\mathrm{PDB})=4.45-\left(1.21 .3\left(T_{h}\right)+\delta^{18}()_{\text {water }}(\mathrm{SMOW})\right.
$$

Here we use the standard notation for oxygen isotopic composition where

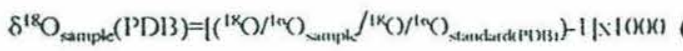

The $\delta^{18} \mathrm{O}_{\text {water }}$ term in (1) is the oxygen isotopic comprosition of the ambient water, which is estimated using liairthanks' |1982| salinity- $\delta^{18} \mathrm{O}$ relationship for the (iulf of Maine

$$
\delta^{18} \mathrm{O}_{\text {water }}(\mathrm{SMOW})=0.421\left(S_{h}\right)-14.66
$$

Cenfidence intervals $(95 \%)$ for $(1)$ and $(3)$ average $\sim(0.2 \%$ (for the temperature region $3^{\circ}-16^{\circ} \mathrm{C}$ ) and $\sim(0.04 \%$ (for the salinity region $32.0 \%(\mathrm{~m}-3.3 .5 \%$ ), respectively. The mean $\delta^{18} \mathrm{O}_{\text {water }}$ for the $1956-1970$ period is determined to be $-(1.88 \%$ by applying the mean salinity of $32.72 \%$ to (3). 1 predicted $\delta^{18} \mathrm{O}_{\text {aragonite }}$ record for this same period (Figure $3 \mathrm{c}$ ) is generated by applying (1) and (3) to the mean monthly bottom temperatures and salinities. That temperature dominates this predicted $\delta^{18} \mathrm{O}_{\text {aragenite }}$ signal is demonstrated by the strong similarity between the holtom temperature and prodictod $\delta^{18} \mathrm{O}_{\text {aragonite }}$ signals. Also, (1) predicts that an annual temperature range from $3{ }^{\circ} \mathrm{C}$ to $16^{\circ} \mathrm{C}$ will contribute an $-2.7 \%$ magnitude signal, whereas only an $-0.3 \%$ magnitude signal is contributed by an average seasonal salinity variation of $0.8 \%$ (kx.

\section{Shell Sampling and Analysis}

As part of the National Marine Fisheries Service's annutal sca scallop survey, the shell of a 38-year-old A. islandica specimen was collected live in August 1991 at $60 \mathrm{~m}$ water depth from near the location of the former Nantucket Shoals Iightship (Figure 1). This shell was chosen for calibration with the prodicted $\delta^{18} O$ record becaitse its carly growth (i.c., period of greatest radial shell growth rate) overlapped the 1956-1970 period of 
observational data. The age of this specimen was deternined by preparing a thin section ( $100 \mu \mathrm{m}$ thick) from a radial slice of the shell and counting the grouth bands in both the hinge and prismatic layer. The thin section was photographed, and the shell's banding structure in the enlargement digitized. This digital information was used to navigate a microsampling systcm (KCL microsampler, Stable Isotope Laboratory, University of Michigan), which consists of a belt-driven dental drill in a fixed position and an automated, throc-axis precision stuge with 10$\mu \mathrm{m}$ resolution. The thin section of the $A$. islandica was mounted on the throc-axis stage and then milled along adjacent paths parallel to the shell's growth bands (or growth surface) in the prismatic layer only. The carbonate powder produced from two or more of these contiguous paths was collected manually and represented cocvally deposited shell material. $\wedge$ more detailod description of these micro sampling methods is given by Dettman and Lolimann [1993]. Two hundred and ninctecn samples were obtaincd in this manner, and average sample weights were $\sim 50 \mu \mathrm{g}$.

Prior to analysis the aragonite samples were roasted in vacuo

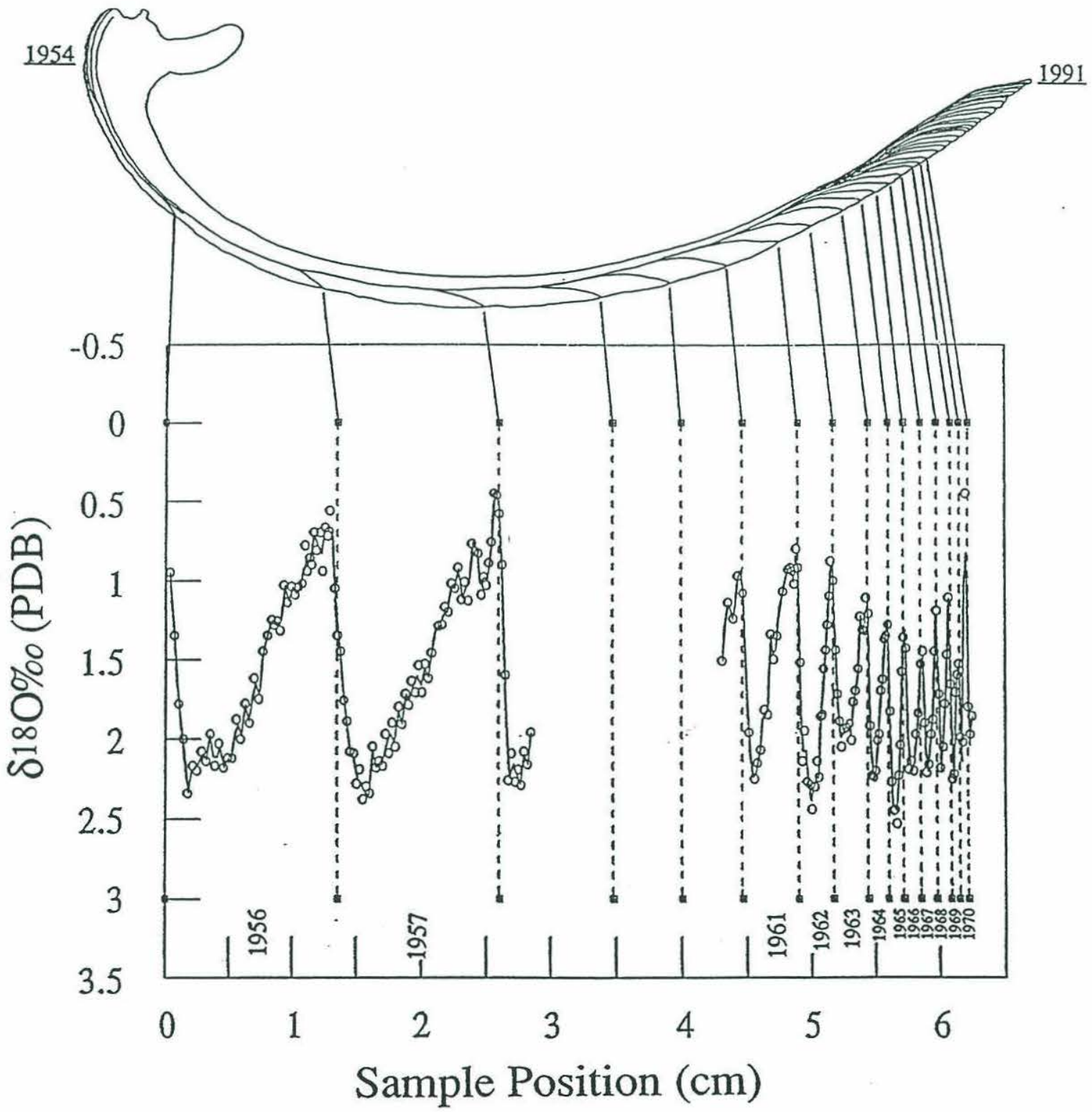

Figurc 4. Shell $\delta^{18} \mathrm{O}$ composition versus cumulative sample position. The seasonal $\delta^{18} \mathrm{O}$ signal is in phase with the banding pattern, and the annual "marks" (represented by vertical dashed lines) are deposited at or just after the seasonal $\delta^{18} \mathrm{O}$ minima (or bottom temperature maxima). As shown in the radial cross section through the shell, annual bandwidths decrease with age, reducing sampling resolution (and temporal resolution) in the outermost bands. 
for 1 hour at $200^{\circ} \mathrm{C}$ to volatilize any organic matter (the 20$)^{\circ} \mathrm{C}$ roasting temperature was chosen to proclude any fractionation resulting from the conversion of aragonitc to calcitc). The University of Michigan Stable Isotope I aboratory's Finnigan MAT 251 mass spectrometer with an on-line Kicl extraction system was used for the analyses. The overall analytical precision reportod for this instrument, based on daily analysis of powdered National Institute of Standards and Fochnology carbonate standards, is $\sim 0.1 \%$ ( $1 \sigma)$.

\section{Results and Discussion}

The 219 oxygen isotope analyses were performed (214 successfully) on sample powders extracled from the hand years 1956-1957 and 1961-1970. The rav 16 $^{16} \mathrm{O}$ results (Figure 4) show the much greater resolution obtainable in the earlier years of this record than in the later years $(50$ values/hand for 1956 versus four values/band for 1970), which reflects the decreasing radial growth rate of the shell with age. The $\delta^{1 x}()$ signal fluctuates between minima which vary from $\sim 0.5$ to $\sim+1.5 \%$ and maxima which have a rather consistent value $\sim+2.3 \%$, resulting in a signal amplitude which ranges from a magnitude of $0.8 \%$ to $1.8 \%$. This oscillation is consistently in phase with the shell's annual growth bands, confirming their seasonal nature and providing the first stable isotopic evidence of annual banding in this species.

The results also show that the annual "marks" or thin dark layers which separate the annual bands are deposited at or inmediately after the seasonal $\delta^{12} \mathrm{O}$ minima. The predicted $\delta^{18} \mathrm{O}_{\text {aragonite }}$ minima (Figure ic) correspond to the annual bottom temperature maxima which occur at this depth and location near the time of the autumn overturn (Figure 2), gencrally in late October or early November. This evidence is in agrecment with Jones' [1980b, p.337] population studics of A. islandica which noted that the annual mark (or growth increment 1) appeured to be deposited during the fall and carly winter, coincident with this species' pcak spawning phase [A famn, 1982].

The predicted $\delta^{18} \mathrm{O}_{\text {aragonite }}$ record displays seasonal minima varying between $\sim+0.5 \%$ and $\sim+1.5 \%$, as does the shell record. However, the predictod $\delta^{18} \mathrm{O}_{\text {sragonite }}$ maxima which average $+2.85 \%$ are not reproduced in the shell record. This indicates that shell deposition occurred only during the warmer months and ceased during the coldest months. An average threshold temperature for shell deposition of $-6.2^{\circ} \mathrm{C}$ can be calculated from the shell's seasonal $\delta^{18} \mathrm{O}$ maxima (which averagc $+2.25 \%$ ) and the mean salinity for 1956-1970 (32.72\%) using (1) and (3). This result is also in agreement with Jones' [1980a] observation that $A$. islandica populations displayed little, if any, measureable shell growth during the coldest months of the year. On the basis of the observed 1956-1970 average monthly bottom temperatures at the lightship, this implics a scasonal shell growth period -8 months long from May through Decerriber (when the bottom temperatures exceod $-6^{\circ} \mathrm{C}$ ) and a cessation of shell growth for $\sim 4$ months from January through April (when bottom temperatures fall below $-6^{\circ} \mathrm{C}$ ) (sec the $6^{\circ} \mathrm{C}$ isotherms in Figure 2). Our $\delta^{18} \mathrm{O}$ evidence and Jones' $[1980$ a] observations of shell growth in $A$. islandica populations in the Mid-Atlantic Bight indicate that the seasonal cessation of shell growth docs not necessarily coincide with the annual mark but may occur sometime later, leaving no obvious physical structure within the annual growth band.

The hypothesis of an 8-month shell growth scason for this $A$. islandica specimen was quantitatively tested using a least squares fit between the shell's scasonal $\delta^{18} \mathrm{O}$ maxima and the predicted annual $\delta^{18} \mathrm{O}$ maxima for a $12-, 11-, 1(1), 9-, 8-, 7-$, and 6-month growth season. The mus diflerence for the 8-month growth season was $0.13 \%$, while rms diflerences for a "-month and a 7-month shell growth season were $0.27 \%$ and $0.29 \%$ m, respectively, and progressively greater for longer and shorter growth seasons. Figure 5 graphically illustrates this fit by comparing a portion of the shell's $\delta^{18} \mathrm{O}$ record with a series of predicted $\delta^{18} \mathrm{O}$ curves which are gencrated by successively removing the coldest months from the record. While, in general, the 8-month growth season curve best matches the shell data, warmer bottom temperatures, such as occurred during the winter of 1961-1962, may allow for longer siell growth seasons.

It is interesting to compare thesc results with earlicr isotopic studies on $S$. solidissima |Arthur et al., 1983: Jones et al., 1983. Krantz et al., 1987], a large, infaunal, and more rapidly growing bivalve, whose habitat is generally shallower but overlaps that of A. islandica [Aferrill and Ropes, 1969: Jones, 198()a, b] These studies have reported that $S$. solidissima shells do not record the coldest temperatures and displas an apparent shutdown temperature of $\sim)^{\circ}-11^{\circ} \mathrm{C}$. It is important to note here that these same isotope studies of $S$. solidissima shells contain an crror in their application of Cirossmanis $|1982| \delta^{14} \mathrm{O}$ temperature equation: when converting from SMOW to PI)I] scales, they incorrectly added rather than subtracted the approximate difference between the scales. This error has bet confirmed (D. S. Jones and 1:. I. Cirossman, personal communication, 1994) and when corrected. results in a lowering of their shutdown temperature estimate by $1^{\circ}-2^{\circ} \mathrm{C}$ for this species $\left(\right.$ to $\left.7-10^{\circ} \mathrm{C}\right)$. This corrected value is then $1^{\circ}-4^{\circ} \mathrm{C}$ warmer than the shutdown value determined for our $A$. islandica specimen and is consistent with the fact that $S$. solidissimas benthic habitat is shallower and geographically extends farther southward, thus reaching higher bottom temperature than those of the decper dwelling $A$. islandica. S. solidissima's peak

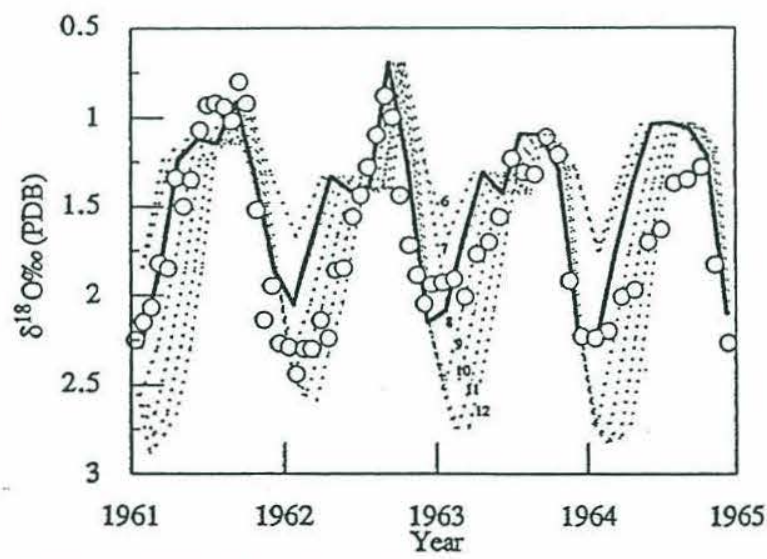

Figure 5. Shell $\delta^{18} O$ (1961-1964) (circles) data compared with predicted aragonite $\delta^{18} \mathrm{O}$ curves for shell growth seasons of different length (dashed and bold curves). The series of predicted $\delta^{18} 0$ curves are generated by successively eliminating the coldest months from the record (c.g., 12 = JanuaryDecember, $8=$ May-December). A least squares best fit is achieved between the shell $\delta^{18} \mathrm{O}$ data and the predicted $\delta^{18} \mathrm{O}$ curves for the 8 warmest months (May-December) (bold curve) when bottom temperatures are greater than $-6^{\circ} \mathrm{C}$. 
spawning period also occurs carlicr than A. islandica's by $\sim 2$ months (July-September) [Jones, 1980a, b]. In shallower regions of the shelf, bottom temperatures reach their maxima earlicr, and it is significant that $S$. solidissima, like $A$. islandica, also appears to deposit its annual growth mark (or thin growth increment I layer) at or near the time of maximum bottom temperature [Jones et al., 1983]. From this comparative evidence an apparent correlation between shell growth shutdown temperature and the general distribution of these two species on the shelf secms to exist, which potentially could be exploited to predict the occurrence of these species at particular locations as well as to estimate palcotemperature regimes on the continental shelf.

Using the evidence of an 8-month scasonal shell growth period and initially assuming a constant growth rate for each season, the shell data were arranged to estimate "monthly" $\delta^{18}(0)$ values for each growth year. To do this, the shell $\delta^{\text {th }}(\mathrm{O}$ data were first separated into individual growth years near the suasonal $\delta^{18} \mathrm{O}$ maxima. Each growth year's data were then divided into eight consecutive groups of nominally equal size, and the mean for each of these monthly groups was calculated. For the years 1966-1968, where only seven data points exist for each growth year, the fifth data point was chosen to represent the combined months of September and October. Unfortunately; the growth years 1969 and 1970 include ton few shell $\left.\delta^{18}\right)$ data points to calculate even approximate monthly values owing to reduced sampling resolution, and therefore they are excluded from further quantitative analysis.

In Figure 6 the monthly shell $\delta^{18}()$ values are plotted on the time axis for each year of record and are shown to the in good agreement with the predicted $\delta^{14}()$ signal for exich of the 8-

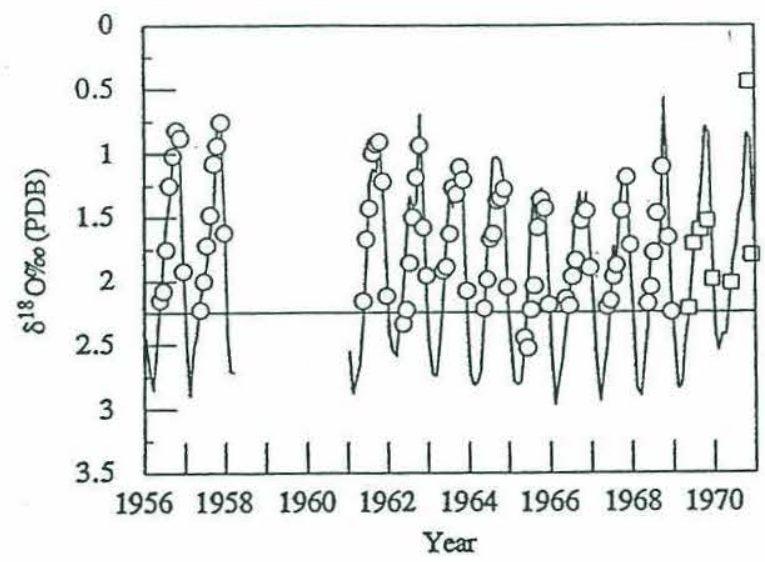

Figure 6. Predicted monthly aragonite values of $\delta^{18} \mathrm{O}$ for $1956-$ 1957 and 1961-1970 (solid curve) compared with measured "monthly" shell $\delta^{18} \mathrm{O}$ values for 1956-1957 and 1961-1968 (circles). The growth years 1969 and 1970 have too few data points to obtain a "monthly" resolution but are plotied (squares) for comparison. The horizontal line indicates the mean of the shell $\delta^{18} \mathrm{O}$ maxima $=+2.25 \%$, showing that the full seasonal $\delta^{18} \mathrm{O}$ signal is not recorded. The monthly shell $\delta^{18} \mathrm{O}$ values show good agreement with the predicted $\delta^{18} O$ record (with an average difference of $-0.07 \%$ (the shell values being more enriched) and an rms difference of $0.24 \%$ ), thus verifying that $A$. islandica deposits its shell in isotopic equilibrium with ambient conditions.

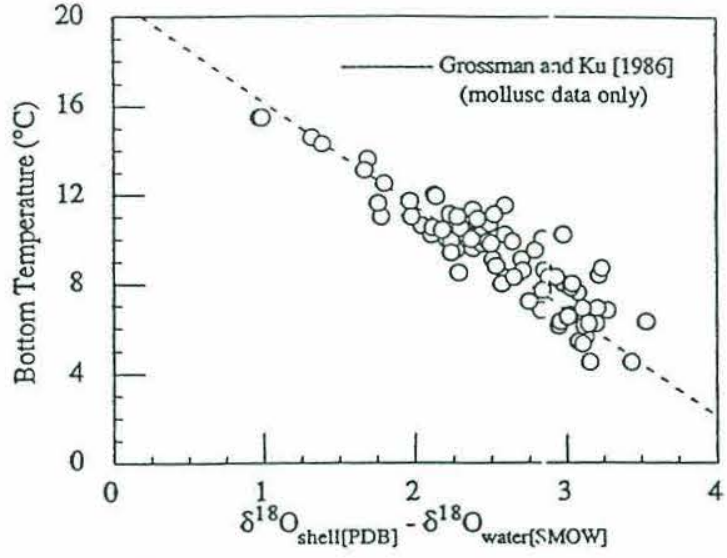

Figure 7. Observed mean monthly bottom temperatures (19561957 and 1961-1968) plotted against salinity-corrected "monthly" shell $\delta^{18} O$ values. The data cxhihit a close fit to Grossman and K'u's [1986] palcotemperature cquation (mollusc data only) (dashed line), with an average difierence of $+0.38^{\circ} \mathrm{C}$ (the shell-derived temperatures being cooler) and an nus difference of $1.10^{\circ} \mathrm{C}$.

month (May-December) periods during 195(-1957 and 19611968. Of particular importance is the finding that the seasonal $\delta^{18} \mathrm{O}$ minima for both the predicted and shell values follow the same interannual trend with depleted minima in the mid-1950): carly 1960s, and later 1960) and the most curiched minima $(\Delta \sim 1 \%)$ in 1965 and 1966 . The average difierence between the predicted (May-Docember) and shell monthly $\delta^{10}()$ values is $0.07 \%$ (the shell values being more curiched) with an mis difference of $0.24 \%$. Considering the uncertainty of the predicted values $( - \pm 0.2 \%)$, the quantitative agreement between the predicted and shell $\delta^{12} \mathrm{O}$ signals is quite good and indicatcs that $A$. islandica is depositing its aragonitic shell in isotopic equilibrium with the ambicnt conditions.

Analogously, this conclusion can also be demonstrated by comparing the monthly shell $\delta^{18} O$ valuos (corrected for $\delta^{18} \mathrm{O}_{\text {water }}$ using equation (3)) to the observed monthly bottom temperatures. Figure 7 shows these values closely fit Grossmum and Ku's [1986] paleotemperature equation (derived from mollusc data only) with an average difference of $0.38^{\circ} \mathrm{C}$ (the shell-derived temperatures being cooler than the obsicrved) and an rms difference of $1.10^{\circ} \mathrm{C}$.

For palcotemperature reconstructions, independent and detailed salinity records are unlikely to be available to constrain the $\delta^{18} \mathrm{O}_{\text {water }}$ and so to further examine the usefulness of $A$. islandica for this work, we first rearrange (1) to solve for temperature

$$
T_{b}=20.86-4.69\left(\delta^{18} \mathrm{O}_{\text {eragenite(PDB) }} \delta^{18} \mathrm{O}_{\text {waner(SMOW, }}\right)
$$

Equation (4) is then appliod to the monthly shell $\delta^{18} \mathrm{O}$ values along with a constant $\delta^{18} \mathrm{O}_{\text {water }}$ of $-0.88 \%$ to derive monthly (May-December) bottom temperatures for the years 1956-1957 and 1961-1968. These shell-derived monthly bottom temperatures are compared with the observed monthly bottom 
temperatures (Figure 8). Again, we include temperature calculations for the shell data for 1969 and 1970 for comparison, though the resolution for thesc ycars is much less than monthly. Despite the reduced constraint on the $\delta^{18} \mathrm{O}_{\text {water }}$ the agreement between the May-December monthly mean data sets (19561968 ) is lessened only slightly, with an average difference of $+0.41^{\circ} \mathrm{C}$ (the shell temperatures being cooler) and nns difference of $1.20^{\circ} \mathrm{C}$. As before, the interannual trend is preserved, reflecting the cooling of maximum bottom temperatures in the mid-1960s. The shell-derived record's maxima for the years 1956, 1957, 1961, 1963, and 1968 arc notably lower than the obscrved maxima for these years. The offsets, for all but 1968, are likely caused by the presence of $\delta^{18} \mathrm{O}$-enriched bottom waters which are indicated by the anomalously high salinities recorded during the autumns of these particular years (Figure $3 \mathrm{~b}$ ). The offset for 1968, however, is not explained by higher than nomal salinity, but is interpreted to be the result of a relatively short period of maximum bottom temperature. The 1968 shell-derived maximum monthly temperature is near in value to the combined September and October observed avcrage bottom temperature (observed $=11.7^{\circ} \mathrm{C}$ versus shell $=11.5^{\circ} \mathrm{C}$ ). Taken together, the evidence demonstrates that $A$. islandica is capable of estimating monthly shelf bottom temperatures with a precision of $-1.2^{\circ} \mathrm{C}$, even wisen applying a constant $\delta^{18} \mathrm{O}_{\text {water }}$

Deftman and Lohmann [1993] have suggested that if a mollusc species consistently ceases shell growth at a particular (cold) "shutdown" temperature, then this temperature might be used independently to constrain the $\delta^{18} \mathrm{O}_{\text {water }}$ and likewise to provide a method for determining the palcosalinity. For example, if the $6.2^{\circ} \mathrm{C}$ shutdown temperature determined for this

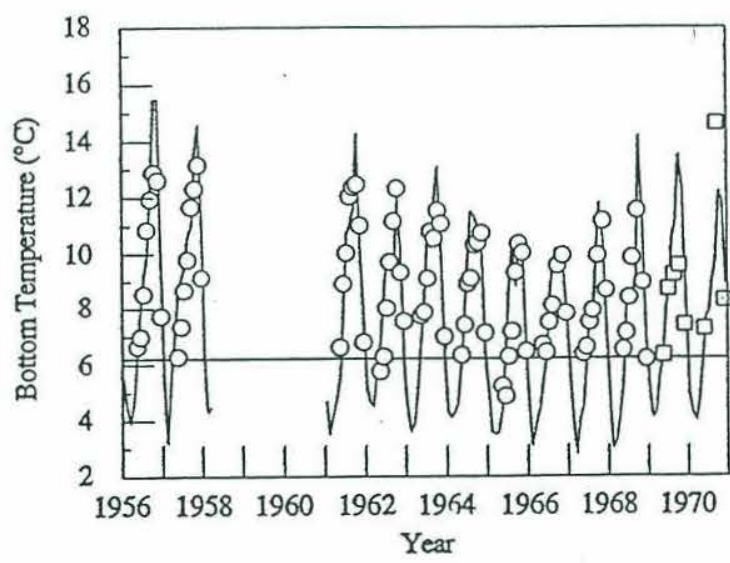

Figure 8. Observed mean monthly bottom temperatures (solid line) compared to "monthly" bottom temperatures derived from the shell $\delta^{18} \mathrm{O}$ data (1956-1957 and 1961-1968: open circles; 1969-1970: open squares). The shcll-derived temperatures were determined using equation (4) and a constant $\delta^{18} \mathrm{O}_{\text {water [SMow] }}$ value $(-0.88 \%)$ determined from the mean bottom salinity for 1956-1970. The horizontal line indicates the mean shutdown temperature $=6.2^{\circ} \mathrm{C}$ for shell growth. The shell-derived values are again in good agreement with the observed values for the months May-December with an average difference $=+() .41^{\circ} \mathrm{C}$ (the shell-derived temperatures being conler) and an rms difference $=1.20^{\circ} \mathrm{C}$, and reflect the observed mid-1960) cooling of maximum bottom tempieratures. specimen is characteristic of all $A$. islandica, then it could be used along with a specimen's scasonal $\delta^{18} \mathrm{O}$ maxima, in this case averaging $+2.25 \%$, to calculate (using (1)) a constant $\delta^{18} \mathrm{O}_{\text {waterismow }}=-0.88 \%$ and a corresponding salinity using a $\delta^{18} \mathrm{O}_{\text {wate }}$-salinity relationship. This cxample suggests that if the shutdown temperature can be further substantiated, then $A$. islandica's oxygen isotopic composition might be usod, even in the absence of other palconvironmental information, to reconstruct bottom palcotemperature and palcosalinity records. This would have important implications for the interpretation of oxygen isotopic records from fossil (or sub fossil) A. islandica shells. However, we add the important reminder that our evidence is derived, so far, from one specimen, and the shutdown charactcristic may vary among individuals, populations, with depth and latitude, and/or with food supply. For these reasons, as well as to better constrain the $\delta^{18} \mathrm{O}_{\text {sarapmite }}$ temperature relationship for A. islandica, we are currently growing $A$. islandica specimens under carefully monitored laboratory conditions and are analyzing specimens from different populations throughout the North Atlantic.

Because of its apparent winter shell growth shutdown, the $A$. islandica shell $\delta^{18} \mathrm{O}$ signal obviously cannot be used to reconstruct the full seasonal bottom temperature signal. However, as can be seen from the obscrved bottom temperature record (Figure 3a), the greatest intcrannual variation cxists between seasonal bottom temperature maxima (October mean ranges from $\sim 10^{\circ}$ to $15^{\circ} \mathrm{C}$ ) and not between seasonal bottom temperature minima (March mean ranges from $\sim 3^{\circ}$ to $4^{\circ} \mathrm{C}$ ). Since the maxima occur at the fall overturn, when conditions become isothermic (Figure 2), these values can be used for characterizing the seasonal heat budget for the shelf waters. So even though the full seasonal bottom temperature range is not recorded, the $A$. islandica shell does record the most important parameter for characterizing the intcrannual temperature ficld variability.

Most significant for its potential as a palcoclimate tool is the fact that the shell $\delta^{18} \mathrm{O}$ signal records the observed drop in the maximum bottom temperatures for the mid-1960s (Figure 3a). This cooling of maximum bottom temperatures at the Nantucket Shoals Lightship is also coincident with negative seawater temperature anomalies on the Newfoundland shelf [Petrie et al., 1992] as well as a reported interdecadal cooling of atmospheric temperatures in the northern hemisphere [Boden et al., 1990]. A comparison of the hydrographs of the seasonal temperature evolution for the years 1963 and 1966 (Figure 2) denonstrates a further importance of being able to reconstruct a record of bottom temperatures in shelf waters. These hydrographs show a very similar evolution of surface temperatures for 1963 and 1966 with nearly identical seasonal maximum SSTs of $19^{\circ} \mathrm{C}$ and $18^{\circ} \mathrm{C}$, respectively. However, bottom temperatures remain much coler during 1966, with the maximum bottom temperature being $4^{\circ} \mathrm{C}$ colder than 1963 , thus resulting in a much greater vertical thermal gradient on the shelf during colder 1966, than in warmer 1963. While SST records have been compiled for a number of locations on the contincntal shelves of the North Atlantic, bottom temperature records are comparatively rare. Therefore the ability to reconstruct time series of bottom temperatures at some of these same locations will allow for the development of stratification histories for these sheif regions.

Finally, although the present methods allow the slicll of this species to be used as a high temporal resolution recorder of ambient bottom temperatures, it still only permits a seasonal resolution to be obtained from the initial or "carliest" 10-20 
years of shell growth because of greatly reduced radial shell growth rates in the adult stage (Figure 4). However, hecause of A. islandica's longevity and abundance, $\delta^{18} \mathrm{O}$ profiles from the first decade or two of growth from several specimens of different ages, live collected from the same sitc, can be combined to reconstruct the interannual maximum bottom water temperatures for the past two centuries. Applying this strategy, we are currently AMS ${ }^{14} \mathrm{C}$-dating fossil (and sub fossil) sliclls and using them to develop bottom temperature records of the continental shelf for climatically important times during the Holocene.

\section{Conclusions}

The need for methods to reconstruct marine gencliemical records of meaningful length with scasonal, annual, and decadalscale resolution for the cold, higher-latitude oceans, has long been recognized. The recent availability of computer-aided micro sampling equipment and mictomass mass spectrometry now provides a way for long-lived, slow growth rate molluscs, such as $A$. islandica, to be used for this purpose. We provide the first oxygen isotopic evidence contirming that $A$. islandica deposits its growth bands anntally. The annual mark is deposited at or shortly after boltom temperatures reach their seasonal maximum, which occurs at Nantucket Shoals Lightship's location at the autumn overtum. Shell growth occurs only during the 8 warmest months of the year (May-December) and ceases during the 4 coldest months (January- $\wedge$ pril), with the transition occurring at ambicnt temperatures of $-6{ }^{\circ} \mathrm{C}$. The salinity-corrected shell $\delta^{18} \mathrm{O}$ data exhibit a relationship to the observed bottom temperatures not significantly different from that predicted using Grossman and Ku's [1986] palcotemperature equations for aragonite derived from mollusc data only: This evidence suggests that $A$. islandica deposits its aragonitc shell in oxygen isotopic equilibrium with the surrounding water and is an accurate $\left( \pm 1.2^{\circ} \mathrm{C}\right)$ monitor of Iocal botiom temperatures. The consistent shutdown temprerature in this specimen also suggests that A. islandica shells have the potential to independently determine the palco- $-{ }^{18}(0)$ composition and the palcosalinity of their growth environment. The significance of this possibility for palesenvironmental studics provides a strong motivation for further research to substantiatc this shutdown phenomenon. Finally, this study demonstrates wilat was recognized as a possibility nearly two decades ago by Thompson and Jones [1977], that Arctica islandica is "the tres of the North Atlantic."

Acknowledgments. All sampling and stable iscotope analyses for this study were performed in the Stable Isotope Laboratory of the University of Michigan. We thank Steve Murawski. Jim Weinberg. and others at NOAA's Northeast Center of the National Marine Fisheries Service at Wonds Ilole for critical help in this study. We also thank Doug Jones at the Forida Muscum of Natural Ilistory and an anonymous reviewer for thoughtful comments on an earlier version of this manuscript. This study was funded by DOF's Giobal Climatc Change Fellowship Program. NOMA grant NAIGRCO080-01. NSF grant OCE931015, and the WHOI Ocean Ventures Fund. This is WHOI contribution 8520 .

\section{References}

Arthur, M. A., D. F. Williams, and D. S. Jones, Seasonal temperaturesalinity changes and thermocline development in the mid-Atlantic Bight as recorded by the isotopic composition of bivalves, Geology, 11, 655-659, 1983.
Boden, T. A., P. Kancircuk. and M. P. Farrell, Trends 90: A compendium of data on global change. Carbon Dioxide Inf. Anal. Cent., Environ. Sci. Div.. Oak Ridge Natl Lab., Oak Ridgc, Tenn., 1990.

Broecker, W. S., The grcat occan convcyor, Oceanograplny., 4, 79-89, 1991.

Bumpus, D. F., Surface water temperatures along Atlantic and Gulf coasts of the United States, Rep. 214, U.S. Fish and WildI. Serv.. Washington, D.C., 1957a.

Bumpus, D. F. Occanographic observations, 1956, cast coast of the United States, Rep. 2jj, U.S. Fish and WildI. Serv.. Washington, D.C., $1957 \mathrm{~b}$.

Chase, J., Oceanographic observations. 1961. east coast of the United States, Rep. 1, U.S. Fish and Wildl. Scrv., Washington, D.C., 1964.

Chase, J., Occanographic observations, 1962, cast coast of the Unitod States, Rep. 9. U.S. Fish and Wildl. Service Report, Washington, D.C. 1965.

Chase. J., Oceanographic observations, 1963, cast coast of the Unitod States, Rep. 10. U.S. Fish and Wildl. Serv.. Washington. D.C.. 1966.

Chase, J., Occanographic obscrvations. 1964, cast coast of the United States, Rep. 18. U.S. Fish and Wildl. Serv., Washington. D.C., 1967.

Chase, J., Occanographic obscrvations. 1965, cast crast of the United States, Rep. 32. U.S. Fish and Wildl. Serv.. Washington, D.C.. 1969 a.

Chase. J., Occanographic observations, 1966, cast coast of the United States, Rep. 29. U.S. Fish and Wildl. Scrv., Washington. D.C.. $1969 \mathrm{~b}$.

Chase. J., Occanographic obscrvations. along the cast coast of the United States. January-December 1969. Rep. 46. U.S. Fish and Wildl. Scrv. Washington, D.C.. 1971a.

Chase. J., Occanographic obscrvations. along the cast coast of the United States. January-December 1967. Rep. 3S. U.S. Fish and Wildl. Serv.. Washington. D.C.. 1971b.

Chase, J.. Occanographic obscrvations, along the east coast of the United States, January-Docember 1968. Rep. 16. U.S. Fish and WildI. Serv., Washington. D.C.. 1971c.

Chase, J.. Occanographic observations. along the cast coast of the United States. January-December 1970, Rep. S3. U.S. Fish and Wildl. Serv.. Washington, D.C., 1972.

Day, C. G., Occanographic obscrvations, 1957. cast coast of the United States. Rep. 282. U.S. Fish and Wildl. Serv.. Washington. D.C., 1959 a.

Day, C. G., Occanographic observations, 1958. cast coast of the United States. Rep. 318. U.S. Fish and Wildl. Scrv.. Washington, D.C., $1959 b$.

Day, C. G., Occanographic obscrvations, 1959, east coast of the United States. Rep. 359. U.S. Fish and Wildl. Scrv.. Washington. D.C., 1960.

Day, C. G.. Occanngraphic obscrvations. 1960. cast coast of the United States, Rep. 406. U.S. Fish and WildI. Scrv., Washington, D.C., 1963.

Dettman, D. L., and K. C. Lohmann. Seasonal change in Paleogene surface water $\delta^{18} \mathrm{O}$ : Fresh-water bivalves of western North America, in Clinute Changes in Continental Isolopic Records, Geoplyys. Aonogr. Ser., vol. 78, odited by P. Swart, K. C. Lolumann, J. McKenzic, and S. Savin, pp. 153-163, AGU, Washingtor, D.C, 1993.

Druffel, E. M., Decade time scale variability of ventilation in the North Atlantic: High-precision measurements of bomb radiocarbon in banded corals, J. Geoplyys. Res., 94, 3271-3285, 1989.

Duplessy, J. C., Isotope studies, in Cliniale Change, editod by J. Gribben, pp. 46-67, Cambridge University Press, New York, 1978.

Epstein, S., R. Buchsbaum, H. A. Lowenstam, and H. C. Urcy, Revised carbonate-water isotopic temperature scale, Geol. Soc. Aml. Bull., 64, 1315-1326, 1953.

Fairbanks, R. G., The origin of continental shclf and slope water in the New York Bight and Gulf of Maine: Evidence from H2O-18/ 
H2O-16 ratio mcasurcments, J. Geoplyss. Res.. S7. 5796-5808, 1982.

Fritz, L. W. Scasonal condition change, morphometrics. growth and sex ratio of the scean quahog. Arctica islandica (Linncaus. 1767) off New Jersey. U.S.A., J. Shellfish Res.. 10, 79-88. 1991.

Grossman, E. L., Stable isotopes of live benthic foraninifera from the Southern California Borderland, Ph.D. dissertation. Univ, of South. Calif., Los Angcles, 1982.

Grossman, E. L.. and T. Ku. Oxygcri and carbon isotope fractionation in biogenic aragonite: Temperature cficets. Chem. Geol., 59, 5974, 1986.

Heller, J., Longevity in molluscs. Malacologia. 31. 259-295. 1990.

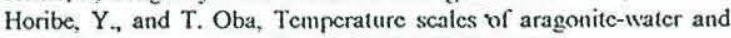
calcite-water systcms, Fossils. 23/24. 69-79. 1972.

Jones, D. S.. Annual cycle of shcll growth and repreduction in the bivalves Spisula solidissima and Arctica islandica. Ph.D. dissertation, Princeton Univ.. Princeton. N.J. 1980a.

Jones. D. S., Annual cycle of shell growth increment formation in two continental shelf bivalves and its palenecologic significance, Paleobiology.. 6. 331-340, 1980b.

Jones. D. S., Repating layers in the molluscan shell are not always periodic, J. Paleontol.. 55, 1076-1082. 1981.

Joncs, D. S., Sclerochironology: Reading the record of the molluscan shcll, Am. Sci., 71, 384-391. 1983.

Jones, D. S.. D. 1:. Williams. and M. A. Arthur. Growth history and ccology of the Atlantic surf clam. Spisula solidissima (Dillwy'n). as revealed by stable isotopes and annual shell increments. J. Mar. Biol. Ecol., 73. 225-242. 1983.

Krantz, D. E.. D. F. Williams, and D. S. Jones, Ecological and palconvironmental information using stable isotope profiles fron living and fossil molluscs. P'alakegreogr. P'alacoclimunol.. Palaeoecol.. 58. 249-266, 1987.

Lutz, R. A.. R. Mann. J. G. Gondsell, and M. Castagna. Larial and carly post-larval development of Arctica islumelica. I. Alar. Biol. Assoc. U.K. 62. 745-769. 1982.

Mann, R., The scasonal growth cycle of gonadal derclopment in Arctica islandica from the southern Ncw England Bight. Fish. Bull.. 80, 315-326. 1982.

Merrill. A. S.. and J. W. Ropes. The gencral distribution of the suri clam and occan quahog, Proc. Nall. Sluellfish. Assoc.. 59. 40-45. 1969.

Murawski, S. A.. J. W. Ropes, and F. M. Serchuk. Growth of the occan quahog. Arctica islandica, in the Middlc Atlantic Bight, Fish. Bull., 80. 21-34. 1982.

Petric. B., J. W. Loder, and J. Lazicr. Temperature and salinity variability on the castern Newfoundland shelf: The residual ficld. Atmos. Ocean, 30. 120-139. 1992.
Romanck, C. S.. D. S. Jones, D. F. Williams. D. E. Krantz and R. Radke. Stable isotopic investigation of physiological and environmental changes recorded in shell carbonate from the giant clam Tridacna nкаxima. A far. Biol.. 94. 385-393. 1987.

Ropes, J. W., D. S. Jones. S. A. Murawski, F. M. Serchuk, and A. Jearld, Documentation of annual growth lines in occan quahogs, Arctica islandica Linnć, Fis.l.. Bull.. 82. 1-19, 1984.

Sommer, M.A., and D. M. Rye, Oxygen arid carbon isotope internal thermometry using benthic calcitc and aragonite foraminifera pairs. in Short Papers 4th International Conference on Geochronology, Cosmochemistry, Isotope Goology, edited by R. E. Zartman, U. S. Geol. Surv. Open File Rep., 78-701. 408-410. 1978.

Tarutani. T, R. N. Clayton, and T. K. Mayoda. The eflocts of polymorphism and magnesium substitution on oxygen isotope fractionation between calcium carbonatc and water. Genchimt. Cosnochin. Acla. 33, 987-996. 1969.

Thompson, I., and D. S. Joncs. The nccan quahog. Arclica islandica. 'tree' of the North Allantic shelf. Geol. Soc. of Am. Abstr. Progranis. 9. 1199, 1977.

Thompson, I. D. S. Jones, and D. Dreibelbis, Annual internal growth banding and life history of the occan quahog Arctica islandica (Mollusca: Bivalvia). Mar. Biol.. 57. 25-34. 1980a.

Thompson, I.. D. S. Jones, and J. W. Ropes, Advanced age for sexual maturity in the occan quahog Arctica islandica (Mollusca: Bivalvia), Atar. Biol. 57, 35-39. 1980b.

Turekian. K. K., D. Cochran. Y. Nozaki. I. Thompson. and D. S. Jones. Determination of shell deposition rates of Arctica islandica from the New York 13ight using natural ${ }^{22} \mathrm{Ka}$ and ${ }^{22 \%} \mathrm{Th}$ and bombproduced ${ }^{14}$ C. I.inumol. ()ceumogr.. 27. 737-741. 1982.

Urey, H. C.. The thermedynamic properties of isotopic substances. $J$. Chemt. Soc.. S62-581, 1947.

Wefer, G., and W. H. Berger. Isotope palomtotogy: Growth and composition of cxtant calcarcous spocics. Mar. Geol.. 100. 207248. 1991

Wcidman. C. R.. and G. $\Lambda$. Jones. $A$ shell-derived time history of bomb ${ }^{14} \mathrm{C}$ on Georges Bank and its I abrador Sca implications. $J$. Geoplyys. Res.. 98. 14.577-14.588. 1993.

C.R. Weidman and G. A. Joncs. I 2 epartment of Marine Geology and Goophysics. Wonds IIole (Hccanographic Institution. Werds Holc, MA 02543. (c-mail cak'tiams245.whoi.cdu)

K. C. Ishmann. Goological Sciences I)epartment. University of Michigan, Ann Artor, MI $4810^{9}$.

(Received November 3. 1993: revised June 15. 1994:

acceptod Junc 28. 1994.) 


\section{Chapter 3}

\section{Stable Carbon and Oxygen Isotope Records from Arctica islandica Shells in a Monitored Laboratory Growth Experiment.}

\section{Introduction}

Stable oxygen $\left({ }^{18} \mathrm{O}\right)$ and carbon $\left({ }^{13} \mathrm{C}\right)$ isotope analysis of the carbonate skeletons of marine organisms is an important means of reconstructing past ocean climate and carbon cycle conditions [Wefer, \& Berger, 1991]. However, because these records are of biological origin, they can be biased by internal as well as external influences, and the former can vary among different phyla and species. Consequently, there is a prerequisite interest in verifying these skeletal isotope records with known ambient conditions. This can be done in the laboratory or in the field under natural conditions, both approaches having their advantages and disadvantages. In the previous chapter [Weidman, Jones, and Lohmann, 1994], a study was presented that compared a 12-year oxygen isotope record from a single shell with a predicted one derived from nearby lightship temperature and salinity records, an aragonite- $\delta{ }^{18} \mathrm{O}$ relationship from Grossman and Ku [Grossman, \& $\mathrm{Ku}$, 1986], and a $\delta^{18} \mathrm{O}-\mathrm{H}_{2} \mathrm{O} /$ salinity relationship for the Gulf of Maine from Fairbanks [Fairbanks, 1982]. That study concluded that the A. islandica 's shell isotope record was in close agreement with the predicted one assuming an eight-month shell growth period. However, some limitations of that field study were that: 1) the lightship and shell growth sites while close $(\sim 15 \mathrm{~km})$ (See Figure 1 in Chapter 2) were not identical allowing for possible differences in actual $\mathrm{T}$ and $\mathrm{S}$ properties, 2) the $\delta^{18} \mathrm{O}$-water was not measured directly but derived from salinity using a regional linear relationship, and finally, 3) no comparison was possible for the shell's $\delta^{13} \mathrm{C}$ record as no contemporary time series of the 
stable carbon isotope composition of the ambient dissolved inorganic carbon (DIC) exists for this shelf region. These deficiencies provide the motivation for the laboratory and monitored field study presented in this chapter, where Arctica islandica specimens were grown under closely monitored conditions in the laboratory and in several different substrates to compare the shells' carbon and oxygen isotope record with directly measured ambient properties. At the same time an offshore site was monitored, though less intensively, to record the natural variation of shelf water column properties.

\section{Methods}

\section{Laboratory Growth Experiment:}

Arctica islandica specimens representing a range of sizes/ages were captured live on June 4, 1993 from a location $5 \mathrm{~km}$ south of Moosepeak Light, Maine $\left(44^{\circ} 25^{\prime} \mathrm{N}, 67^{\circ} 32^{\prime}\right.$ W) at $70 \mathrm{~m}$ depth (Figure 1). Water samples for salinity and isotopic analysis were taken and bottom temperatures were measured at this site at the time of capture. Specimens were transported to a laboratory at the National Marine Fisheries Service Aquarium at Woods Hole, where individual shell heights were measured with a micrometer, each shell was indelibly marked with an ID number, and placed into one of three bins submerged in a tank $1.2 \mathrm{~m} \times 2.4 \mathrm{~m}$ in area with a water depth of $35 \mathrm{~cm}$. Each of the three bins contained a different substrate, medium/coarse sand of $\sim 0.5 \mathrm{~mm}$ diameter ( $15 \mathrm{~cm}$ deep), marine very fine sand/silt of $\sim 0.06 \mathrm{~mm}$ diameter $(15 \mathrm{~cm}$ deep), and no sediment at all. Unfiltered seawater from Woods Hole Harbor supplied the system which included a refrigerated recirculating loop to keep the tank's water temperature below $20^{\circ} \mathrm{C}$ during the warmest summer months. Tank inflow/outflow rate was maintained at about $20 \mathrm{l} / \mathrm{min}$ so that the residence time of the water in the tank was approximately 1 hour. This flow rate was chosen to exceed the maximum filtration rate determined for individual adult $A$. islandica 
(0.12 $1 / \mathrm{min})$ times the $\sim 100$ specimens that were placed in the tank [Winter, 1969][Kraus, Beal, Chapman, and McMartin, 1992].

Since Kraus, et al. [1992] have reported that handling strongly impacts shell growth rates for this species, the specimens, once placed in the bins, were not disturbed for the duration of the year-long calibration experiment. Tank temperature was recorded, almost daily, to the nearest tenth of a degree with a calibrated thermometer. Water samples were collected every two weeks for salinity and stable carbon and oxygen isotope analysis. During the warm summer months (July-September) when external seawater input was reduced and refrigerated recirculation increased, a commercially available invertebrate food supplement was added to the tank water once every two days.

In June 1994, just prior to harvesting the laboratory specimens, water column and pore water samples were collected from the two bins with the sand and mud substrate for carbon isotope analysis. In the case of the sand substrate this was accomplished using a syringe and extracting pore waters from three sediment depths of $1 \mathrm{~cm}, 3 \mathrm{~cm}$, and $6 \mathrm{~cm}$, respectively. In the case of the mud substrate this was done by coring the sediment with a 5 $\mathrm{cm}$ diameter plastic tube, removing three successively deep layers of mud at $1.4 \mathrm{~cm}$ intervals (total depth $0-4.2 \mathrm{~cm}$ ), and centrifuging them to separate the pore water.

All laboratory specimens were harvested on the same day on June 10, 1994, their ID numbers verified, and frozen. Later, selected specimens were thawed out, their shell heights measured, and a subset selected for isotopic analysis.

\section{Offshore Site Monitoring:}

A location $5 \mathrm{~km}$ south of Gay Head $\left(41^{\circ} 19^{\prime} \mathrm{N}, 70^{\circ} 50^{\prime} \mathrm{W}\right)$ and $34 \mathrm{~m}$ depth (Figure 1), referred to hereafter as the Devil's Bridge site, was revisited about once every month 
and a half for one year to record bottom temperature and take water samples for salinity and carbon and oxygen isotope analysis. This site was selected because it is the ocean quahog habitat nearest to Woods Hole. Although, A. islandica specimens were gathered from this site as well, the population at this site was too old/large and its growth rate too slow to be useful for this high-resolution laboratory growth study.

\section{Sample Preparation and Stable Isotope Analysis:}

Carbonate for isotopic analysis was obtained from selected shells using the microsampling techniques described in the previous chapter [Weidman, et al., 1994]. Oxygen and carbon isotopic analyses of the shell carbonate were performed on the VG Prism mass spectrometer with an automated on-line Isocarb extraction system at the Woods Hole Oceanographic Institution. For DIC carbon analysis, seawater was collected in $500 \mathrm{ml}$ borosilicate glass bottles, poisoned with $0.2 \mathrm{ml}$ of saturated $\mathrm{HgCl}_{2}$ solution to cease any further biological activity in the sample, and sealed with greased glass stoppers for later analysis. For oxygen analysis, seawater was collected in $100 \mathrm{ml}$ glass "salinity" bottles and sealed with airtight plastic screw caps for later analysis. $\mathrm{CO}_{2}$ extraction of the bi-monthly collected water samples for carbon isotope analysis was carried out using standard stripping methods described in McNichol, et al. [McNichol, Jones, Hutton, \& Gagnon, 1994]. Water samples collected for oxygen isotope analysis were prepared using a slight modification of methods first described in an unpublished report by T. Anderson [1983] at the University of Illinois and also later described by Allard [Allard, 1989] (see Appendix for details). These methods involve a freeze/thaw routine along with equilibrating an injected aliquot of $\mathrm{CO}_{2}$ of known volume and isotopic composition with a seawater sample. Isotopic analyses of bi-monthly and offshore site waters were performed (in duplicate) on the VG Optima mass spectrometer at the Woods Hole Oceanographic Institution. $\mathrm{CO}_{2}$ extraction of the pore waters and (simultaneously taken) ambient water column were carried out using methods developed by D. McCorkle for pore water $\delta^{13} \mathrm{C}$ analysis [McCorkle, 
Emerson, \& Quay, 1985][McCorkle, Keigwin, Corliss, \& Emerson, 1990][McCorkle, \& Keigwin, 1994], and isotopic analyses of these samples were performed on the VG 602 mass spectrometer at the Woods Hole Oceanographic Institution. All analyses on all three mass-spectrometers were calibrated against the simultaneously run NBS/NIST standards (NBS-19 and VSMOW) and in-house standards calibrated to these NBS/NIST standards. The analytical precision of carbon and oxygen analyses, for carbonate and DIC samples is approximately $\pm 0.1 \%$ o $(1 \sigma)$ and for oxygen analyses of water samples is $\pm 0.06 \%$ ( $r m s$ of duplicate differences). For reporting stable oxygen and carbon isotope compositions, the standard notation is used where

$$
\delta^{18} \mathrm{O}_{\text {sample }}(\mathrm{PDB})=\left[\left({ }^{18} \mathrm{O} /{ }^{16} \mathrm{O}_{\text {sample }} /{ }^{18} \mathrm{O} /{ }^{16} \mathrm{O}_{\text {standard(NBS-19=-2.20\%oc }}\right)-1\right] \mathrm{X} 1000
$$

and

$$
\delta^{13} \mathrm{C}_{\text {sample }}(\mathrm{PDB})=\left[\left({ }^{13} \mathrm{C} /{ }^{12} \mathrm{C}_{\text {sample }}{ }^{13} \mathrm{C} /{ }^{12} \mathrm{C}_{\text {standard(NBS-19=+1.95\%o] }}\right)-1\right] \mathrm{X} 1000
$$

and

$$
\delta^{18} \mathrm{O}_{\text {sample }}(\mathrm{SMOW})=\left[\left({ }^{18} \mathrm{O} /{ }^{16} \mathrm{O}_{\text {sample }}{ }^{18} \mathrm{O} /{ }^{16} \mathrm{O}_{\text {standard }}(\mathrm{VSMOW}=0.00 \% \mathrm{o}]-1\right] \mathrm{X} 1000\right.
$$

In this paper, Grossman and Ku's [1986] estimate of $\sim 0.2 \%$ for the difference between SMOW and PDB scales is assumed.

\section{Results}

\section{Water Column Properties}

\section{Temperature:}

The tank water temperature record shows a full annual cycle ranging from $0^{\circ}$ to $18^{\circ} \mathrm{C}$ with a mean of $10.8^{\circ} \mathrm{C}$ and standard deviation of $\pm 6.3^{\circ}$ (Figure 2a and Table 1). For

convenience, the bi-monthly temperatures, which were measured at the same time as the water sample collections, are shown in Table 1. Bottom temperature at the Maine capture 
site at the time of capture was $5.2^{\circ} \mathrm{C}(6 / 4 / 93)$. Captured specimens were introduced to the tank on June 5, 1993 (experiment day \# 33), at which time laboratory water temperatures were already greater than $15^{\circ} \mathrm{C}$. Water temperature reached a maximum in mid-September, dropped below $15^{\circ} \mathrm{C}$ in late October, reached a minimum in late January, and rose to just above $16^{\circ} \mathrm{C}$ at the experiment's termination on June $10,1994$.

\section{Salinity:}

Salinity in the laboratory tank ranged about $1 \%$ from $30.77 \%$ o to $31.78 \%$ with a mean of $31.30 \%$ and a standard deviation of $\pm 0.28 \%$ (Figure $2 b$ ). Bottom salinity at the capture site at the time of capture was $31.52 \%$. Highest laboratory salinities were recorded in the fall and early winter and lowest in the early spring. Temperature and salinity display only a weak positive correlation $(\mathrm{r}=+0.211)$.

\section{$\delta^{18} \mathbf{O}$-water:}

The $\delta^{18} \mathrm{O}$ (SMOW) of the tank water ranged about $0.4 \%$ from -1.59 to $-1.22 \%$ o with a mean of $-1.44 \%$ and standard deviation of $\pm 0.08 \%$. Bottom $\delta^{18} \mathrm{O}$-water value at the capture site at the time of capture was $-1.49 \%$ (Figure $2 \mathrm{c}$ ). As expected, $\delta^{18} \mathrm{O}$-water values correlate positively with salinity $(\mathrm{r}=+0.656)$. The linear $\delta^{18} \mathrm{O}$-salinity relationship for the tank water is: $\delta^{18} \mathrm{O}$-water $=0.190 * \mathrm{~S}-7.38$ (Standard Error of the Estimate $(\mathrm{SEE})=$ $0.07 \%$ ). This is similar in slope and intercept to Fairbanks' [1982] $\delta^{18} \mathrm{O}$-salinity relationship for the Mid-Atlantic Bight (+0.258 and -9.14). The intercept value of -7\%o indicates that the meteoric source of the fresh component in Woods Hole Harbor is local, based on Figure 1 in Fairbanks [1982].

\section{\$13C-DIC:}

$\delta^{13} \mathrm{C}$ (PDB) of the DIC ranged about $1 \%$ from $-0.2 \%$ to $+1.0 \%$ with a mean of $+0.62 \%$ and standard deviation of $\pm 0.35 \%$ (Figure $2 \mathrm{~d}$ ). Bottom DIC $\delta^{13} \mathrm{C}$ at the capture 
site at the time of capture was $0.4 \%$ o heavier than initial laboratory DIC. DIC $\delta^{13} \mathrm{C}$ reached a minimum in mid-summer and a maximum in late spring, and so is negatively correlated with temperature $(r=-0.582)$. This negative relationship may result from the dependence of the $\mathrm{CO}_{2}-\mathrm{HCO}_{3}$ equilibrium fractionation on temperature $\left(\sim-0.12 \%\right.$ / $\left./ \mathrm{C}^{\circ}\right)[$ Deuser and Degens, 1967][Mook, 1986]. The correlation between temperature and DIC $\delta^{13} \mathrm{C}$ data is weakened by the large $\delta^{13} \mathrm{C}$ scatter at temperatures above $15^{\circ} \mathrm{C}$. Deviation from equilibrium is likely for two reasons (Broecker and Peng, 1982): 1) carbon isotopic exchange is a rather slow process in seawater ( 1 year for full equilibration of a $10 \mathrm{~m}$ layer) and seasonal temperature changes are generally too rapid to allow for complete equilibrium, and 2) marine biological cycles are accompanied by carbon isotopic fractionations which can move the isotopic composition of the local DIC reservoir away from equilibrium with the atmosphere. For example, phytoplankton blooms in the spring and early summer can result in a ${ }^{13} \mathrm{C}$ enrichment of the DIC as ${ }^{12} \mathrm{C}$ is preferentially taken up by the organisms.

\section{Pore Water DIC:}

The pore waters of the sand and mud substrates are very enriched (by $\sim 65 \%$ ) in $\Sigma \mathrm{CO}_{2}$ and very depleted in $\delta^{13} \mathrm{C}$ (by $\sim 6 \%$ ) relative to the ambient water column above the sediment surface (Table 2). A sharp gradient in $\mathrm{\Sigma CO}_{2}$ and $\delta^{13} \mathrm{C}$ properties occurs in the top $1 \mathrm{~cm}$ of the sediment column of both sand and mud substrates. These conditions are characteristic of natural marine sediments due to the breakdown of organic matter within the upper sediment layers (marine organic carbon $\delta^{13} \mathrm{C} \sim-20 \%$ ) [McCorkle, 1985]. Surprisingly, mud and sand pore waters show no significant differences in their DIC properties, despite a difference in permeability of $\sim 10^{2}$ based on grain size [Inman, 1963] and the consequent potential difference in pore water exchange with the overlying water column. 


\section{Devil's Bridge Properties (natural cycle):}

Bottom temperature conditions at the Devil's Bridge site ranged from $-0.8^{\circ} \mathrm{C}$ to $13.8^{\circ} \mathrm{C}$ with a mean $9.1^{\circ} \mathrm{C}$ and standard deviation of $\pm 5.3^{\circ} \mathrm{C}$. Maximum temperatures were reached in late summer / early fall (Figure 3). Though no measurements were made during the winter months (Dec. - Feb.), temperatures could not have been much colder than $-0.8^{\circ}$ $\mathrm{C}$ recorded in early March, making that value a reasonable minimum for the year. In general, bottom temperatures at the Devil's Bridge site were cooler and had less range than in the laboratory tank. Salinity ranged $0.4 \%$ from $31.97 \%$ to $32.36 \%$ with a mean of $32.05 \%$ and standard deviation of $\pm 0.20 \%$. Like the laboratory conditions, lowest salinity occurred in the summer and spring with the highest values in the fall.

The $\delta^{18} \mathrm{O}$ (SMOW) of the bottom water ranged $0.25 \%$ from $-1.12 \%$ to $-1.37 \%$ with a mean of $-1.21 \%$ and standard deviation of $\pm 0.10 \%$. The $\delta^{18} \mathrm{O}$-water is correlated positively with salinity $(\mathrm{r}=+0.760)$. The linear $\delta^{18} \mathrm{O}$-salinity relationship for Devil's Bridge water is: $\delta^{18} \mathrm{O}$-water $=0.395 * \mathrm{~S}-13.86(\mathrm{SEE}=0.07 \%$ ). This is similar in slope and intercept to Fairbanks' [1982] $\delta^{18} \mathrm{O}$-salinity relationship for the Gulf of Maine $(+0.421$ and -14.66), and suggests a higher-latitude source for its fresh component.

DIC $\delta^{13} \mathrm{C}$ (PDB) ranged $\sim 0.7 \%$ from $+0.71 \%$ to $+1.39 \%$ with a mean of $+1.02 \%$ and standard deviation of $\pm 0.22 \%$. Maximum $\delta^{13} \mathrm{C}$ values were recorded in the first spring and early summer at the start of the monitoring program and reached a minimum in the early fall. $\delta^{13} \mathrm{C}$ rebounded again by late fall but remained at a low level during the following spring. DIC $\delta^{13} \mathrm{C}$ at the Devil's Bridge site is not significantly correlated to temperature $(\mathrm{r}=+0.235)$ and its trend is of the opposite sign from the laboratory DIC $\delta^{13} \mathrm{C}$ record. However, both laboratory and offshore $\delta^{13} \mathrm{C}$ profiles have minima when ambient temperatures are near their maxima, and both display maxima in the spring. 


\section{Shell Records}

Stable carbon and oxygen isotope records (Table 4) were obtained from the shells of three young A. islandica specimens, each approximately the same size/age (24-27 mm, / 7-9 yrs-old), and each grown in a different substrate medium (sand, mud, no sediment) in the laboratory for one year. Laboratory shell growth was very limited in older specimens (see Figure 4 in chapter 2), making it difficult to obtain a seasonal sampling resolution in their shells. For this reason, in this study we have limited our analysis to shells within the specified size/age range, which as a group showed the most shell growth and afforded the greatest sampling resolution. Figure 4a-c displays each shell's carbon and oxygen isotope record separately.

\section{Ring Structure and Shell Growth:}

In Figure 4a-c, the vertical cross-hatched lines superimposed on the profiles represent the internal "rings", which are visible in radial cross-sections of the shells as thin translucent layers between wider more opaque growth increments. In chapters one and two these rings were shown to be annual in nature and deposited in the autumn when bottom temperatures are highest and $\delta^{18} \mathrm{O}$ of the shell is most depleted. In the shell records shown here, the first $\sim 2 / 3$ of the isotope record is obtained from shell material that was deposited in the natural environment prior to capture, and the latter $\sim 1 / 3$ from material deposited in the laboratory setting over 1 year. The first two "rings" (from the left) are, thus, annual "rings", deposited in the fall of 1991 and 1992, respectively. The third "rings" are "disturbance rings", coincident with the start of the laboratory growth period (June 1993), and are, likely, related to the trauma experienced by the specimens at the time of their capture and/or subsequent sharp change in their ambient environment. The physical distance between the third and fourth rings is very small relative to the other bands, and in specimen qx102 it is just discernible. The fourth (or last) "rings" appear to have been 
deposited during the autumn of 1993 as they lie near the $\delta^{18} \mathrm{O}$-shell minima. However, the fourth ring of specimen $\mathrm{qx} 94$ (sand) is positioned just after the maximum $\delta^{18} \mathrm{O}$, though this is likely due to a placement error owing to the difficulty of visually gauging the actual position of the ring during micro-sampling. New radial shell growth for the three specimens averaged about $1.8 \mathrm{~mm}$. Shell growth was greatest for the specimen grown in sand $(2.15 \mathrm{~mm})$, and least for the specimen grown in "no sediment" $(1.39 \mathrm{~mm})$. The specimen grown in mud had about average growth $(1.83 \mathrm{~mm})$.

\section{$\delta^{18} \mathrm{O}$-shell record:}

Between 37 and 57 aragonite powder samples were obtained from outer portions of each of the three shells, of which between 15 and 21 samples were obtained from the laboratory grown portion of each shell. So the isotope records can be compared more closely, the sample positions are normalized by setting the pre-laboratory (pre-capture) growth run from -1 to 0 and the laboratory growth run from 0 to +1 (Figure $5 a-b)$. The oxygen isotope profiles of all three shells show strong similarities (Figure 5a). The prelaboratory part of the $\delta^{18} \mathrm{O}$-shell records display similar shapes and approximately equal values for minima and maxima. In these portions of the profiles, $\delta^{18} \mathrm{O}$ values range from about $+1 \%$ o to $+2 \%$ with a mean of $+1.4 \%$ ( $\pm 0.3 \%$ ). As described above, the minima occur at or near the annual "rings", and the maxima occur within a few samples after the annual "rings", so that the intra-band $\delta^{18} \mathrm{O}$ profiles are largely characterized by negative

trends. This is consistent with the seasonal $\delta^{18} \mathrm{O}$ profiles from the Nantucket Lightship specimen of the previous chapter (see Figure 4 in chapter 2).

The laboratory-grown portions of the record begin at the third "ring" where $\delta^{18} \mathrm{O}$ values are initially $\sim+1.2 \% \circ$ and are followed by a steep depletion. In this portion of the records, $\delta^{18} \mathrm{O}$ values range from about $0 \%$ to $+2 \%$ with a mean of $+0.7 \% \circ( \pm 0.7)$. The lab-grown segments exhibit a seasonal $\delta^{18} \mathrm{O}$ range about twice that of the pre-lab segments. 
Minima of about $0 \%$ occur within one or two samples after the disturbance ring. This sharp drop is consistent with the large temperature difference $\left(\Delta \sim 10^{\circ} \mathrm{C}\right)$ between the Maine capture site $\left(5^{\circ} \mathrm{C}\right)$ and the laboratory tank $\left(15^{\circ} \mathrm{C}\right)$. In all three shells, these first minima are confined within a very narrow sample space (1-2 samples), despite a prolonged period (5 months) of warm $\left(+15^{\circ} \mathrm{C}\right)$ tank temperatures, indicating very little shell growth during this time. These minima are followed by a sharp enrichment to maxima of $\sim+2 \%$. A rather linear negative trend characterizes the remaining $\delta^{18} \mathrm{O}$ data which reach terminal values of $0 \%$. This negative trending $\delta^{18} \mathrm{O}$ data comprises $60-85 \%$ of laboratory shell growth, and indicates that most of the new shell growth occurred during a few months in the winter/spring of 1994.

\section{$\delta^{13}$ C-shell record:}

Like the $\delta^{18} \mathrm{O}$ profiles, the pre-laboratory portion of the $\delta^{13} \mathrm{C}$-shell profiles display very similar shapes and values for minima and maxima (Figure 5b). In this portion of the shell, $\delta^{13} \mathrm{C}$ values range about $0.5 \%$ from about $+1.7 \%$ to $+2.2 \%$ with a mean of $+2.0 \%$ o $( \pm 0.2 \%)$. The annual $\delta^{13} \mathrm{C}$ minima occur within a few samples after the annual $\delta^{18} \mathrm{O}$ minima and before the next $\delta^{18} \mathrm{O}$ maxima. This observation demonstrates that seasonal shell growth continues after annual "ring" deposition and that the samples from the region between the $\delta^{18} \mathrm{O}$ minima and maxima are not simply a mixture of very enriched and depleted material divided by a hiatus in shell growth. If these samples were such a mixture of adjacent values, then no $\delta^{13} \mathrm{C}$ minima could occur in this region. The annual $\delta^{13} \mathrm{C}$ maxima occur near the latter part of each intra-band profile, but generally begin declining just before the annual "ring" is deposited, so that the intra-band $\delta^{13} \mathrm{C}$ profile is dominated by a positive trend.

The $\delta^{13} \mathrm{C}$ profiles of the lab-grown segments exhibit a much greater range and more variability between shells, than the pre-lab segments. In this portion of the shell, $\delta^{13} \mathrm{C}$ 
values range $\sim 2.0 \%$ from about $+0.2 \%$ to $+2.2 \%$ with a mean of $+1.5 \%$ ( \pm 0.5$)$. Like the $\delta^{18} \mathrm{O}$ data, the $\delta^{13} \mathrm{C}$ profiles show a large depletion at the disturbance "rings" to minima between $+0.7 \%$ and $-0.3 \%$. This $(\sim 2 \%)$ drop is consistent in sign, but larger than the difference in DIC $\delta^{13} \mathrm{C}$ between the laboratory minimum and capture site $(\Delta \sim 1 \%$ ). Like the pre-lab $\delta^{13} \mathrm{C}$ profiles, the laboratory $\delta^{13} \mathrm{C}$ minima occur near to, but after the $\delta^{18} \mathrm{O}$ minima. The $\delta^{13} \mathrm{C}$ minima are followed by an enrichment to maxima of $\sim+2.0 \%$ o that occur just prior to the end of each profile. The rate of this enrichment varies among the specimens; it is steep in the case of specimen qx94 (sand) and much less so in the case of qx156 (no sediment). The $\delta^{13} \mathrm{C}$ profiles again display a depletion just before the profiles'

terminations. The lab-grown segments show overall positive $\delta^{13} \mathrm{C}$ trends, which is consistent in sign, but greater than the similar trend in the DIC $\delta^{13} \mathrm{C}$.

\section{Discussion}

\section{I. $\delta^{18} \mathrm{O}$-aragonite}

The laboratory shell $\delta^{18} \mathrm{O}$ profiles are superimposed onto a predicted $\delta^{18} \mathrm{O}$ profile (Figure 6) for aragonite deposited in equilibrium with the laboratory tank water. This predicted profile was obtained by applying the tank's temperature and $\delta^{18} \mathrm{O}$-water data (Table 1) to the modified form of the Grossman and $\mathrm{Ku}$ (1986) paleotemperature equation (1a and 1b) (for mollusc data only) used in the previous chapter:

$$
\begin{aligned}
& \delta^{18} \mathrm{O}_{\text {aragonite }(\mathrm{PDB})}=4.45-0.213^{*} \mathrm{~T}\left(\mathrm{C}^{\circ}\right)+\delta^{18} \mathrm{O}_{\text {water }}(\mathrm{SMOW}) \\
& \mathrm{T}\left(\mathrm{C}^{\circ}\right)=20.86-4.69 *\left(\delta^{18} \mathrm{O}_{\text {aragonite }(\mathrm{PDB})}-\delta^{18} \mathrm{O}_{\text {water }(\mathrm{SMOW})}\right)
\end{aligned}
$$


The predicted $\delta^{18} \mathrm{O}$-aragonite curve has a range of $\sim 4 \%$ from $-1.0 \%$ to $+3.0 \%$ with a mean of $0.7 \%$ o $( \pm 1.3 \%$ ). The predicted range is about twice as large as that of the labgrown shell $\delta^{18} \mathrm{O}$ signals. In particular, the $\delta^{18} \mathrm{O}$-shell profiles do not become as enriched or as depleted as the predicted profile and neither are they in phase with each other, assuming continuous linear shell growth. The latter result alone implies that the shell growth rates must be variable. If the critical points (minima, maxima, and endpoints) of the predicted and shell records are assumed to coincide, then it becomes clear that most of the shell growth occurred during the last months of the experiment, and that little growth occurred during the first two-thirds of the experiment. This result may be due to a combination of physical shock associated with capture, resettling into the new laboratory environment, or the very warm tank temperatures during the first summer. As already mentioned, Kraus, et al. [1993], noted that handling the live $A$. islandica specimens during routine growth studies greatly reduces their growth rates, and so it is reasonable to suppose a period of convalescence after capture. If the validity of equation (1) for $A$. islandica is not assumed, and continuous (though non-linear) shell growth is assumed so that the entire temperature record is represented in the $\delta^{18} \mathrm{O}$-shell profiles, then a relationship can be derived from a fit of the tank temperature and shell's $\delta^{18} \mathrm{O}$ maxima and minima:

$$
\mathrm{T}=26.63-7.66^{*}\left(\delta^{18} \mathrm{O}_{\text {aragonite(PDB) }}-\delta^{18} \mathrm{O}_{\text {water(SMOW }}\right)
$$

This equation has roughly twice the negative slope as equation (1b). While this result cannot be justified as an equilibrium relationship based on thermodynamic arguments [O'Neil, Clayton, \& Mayeda, 1969], it is perhaps possible that it is the result of some unknown non-linear "vital" effect. This seems unlikely owing to the preponderance of evidence which indicates that bivalves generally deposit their carbonate in oxygen isotopic equilibrium with the ambient environment [Wefer, et al., 1991]. However, a point in favor of the higher-slope relationship is that it accurately hindcasts the Maine capture site 
temperature at the time of capture, whereas Grossman and Ku's relationship overestimates this value by $\sim 3^{\circ} \mathrm{C}$. While this could be taken as evidence of a disequilibrium effect, it may be that the instantaneous properties measured at this site at the time of capture were not characteristic over the period of shell deposition for these samples, which may represent one to several weeks of shell growth. For instance, the discrepancy might be explained by the presence of fresher or lighter $\delta^{18} \mathrm{O}$-water conditions existing just prior to capture. Salinity data for this area (MARMAP station \#141) do show a large ( 1\%o) freshening of this magnitude which occurs in the spring, and dissipates rapidly by early summer. In addition, the source of this springtime freshening seems to be a seasonal pulse of coastal Scotian Shelf water into the Gulf of Maine, which itself has its origins in the Gulf of Saint Lawrence [Smith, 1983]. This higher latitude source should also carry a lighter $\delta^{18} \mathrm{O}$-water component for a given salinity [Fairbanks, 1982], and taken along with a 1\%o drop in salinity (equivalent to $\sim 0.5 \%$ change in $\delta^{18} \mathrm{O}$-water) could account for the discrepancy between the predicted and observed values.

The more likely case, is that the $A$. islandica specimens deposited their aragonite in equilibrium with ambient conditions, and disparity between predicted $\delta^{18} \mathrm{O}$-aragonite and $\delta^{18} \mathrm{O}$-shell is the result of shell growth hiatuses. Shell growth cessation is common in bivalves during extremes in temperature, and has been reported in many species [Wilbur and Owen, 1964][Williams, Arthur, Jones, and Healy-Williams, 1982][Harrington, 1989][Wefer, et al., 1991]. More relevant, independent evidence exists from several studies for shell growth reduction or cessation in $A$. islandica during the coldest months [Jones, 1980a][Jones, 1980b][Lutz, Goodsell, Castagna, \& Stickney, 1983][Kraus, Beal, Chapman, \& McMartin, 1992]. In the previous chapter, the general validity of equation (1) was assumed, and bottom water $\mathrm{T}$ and $\mathrm{S}$ records from a nearby location along with Fairbanks' [1982] salinity- $\delta^{18} \mathrm{O}$-water relationship were used to predict a $\delta^{18} \mathrm{O}$-aragonite record. By comparing the shell and predicted records, a cold shutdown temperature of $\sim 6^{\circ} \mathrm{C}$ 
$\left( \pm 1^{\circ}\right)$ (at monthly resolution) was implied. No warm-end shutdown temperature was noted as the shell record $\delta^{18} \mathrm{O}$ minima corresponded with the predicted $\delta^{18} \mathrm{O}$ minima. However, Mann [1982] noted that the distribution of $A$. islandica on the eastern U. S. continental shelf shows a shoreward limit that corresponds to $\sim 16^{\circ} \mathrm{C}$ October (annual maximum) bottom isotherm. This suggests that temperatures greater than $16^{\circ} \mathrm{C}$ may be outside the normal temperature range of this species, and if so it would seem reasonable that they would respond poorly to temperatures exceeding this value.

Furthermore, in this chapter, the ambient temperature and $\delta^{18} \mathrm{O}$-water are specifically known throughout the period of calibration, which removes the uncertainty associated with these parameters present in the previous chapter. Assuming equilibrium deposition and applying the mean value of the lab-grown shells' $\delta^{18} \mathrm{O}$ minima and maxima $\left(-0.15 \% \circ \pm 0.2 \% o\right.$ and $+2.01 \% \circ \pm 0.3 \%$, respectively) and the mean $\delta^{18} \mathrm{O}$-water $(-1.44 \%$ $\pm 0.08 \%$ ) to equation (1), a mean cold and warm shutdown temperature are estimated to be $4.7^{\circ} \mathrm{C} \pm 1.8^{\circ}$ and $14.8^{\circ} \mathrm{C} \pm 1.3^{\circ}$, respectively. The cold shutdown temperature estimate of $\sim 5^{\circ} \mathrm{C}$ is slightly lower, though not significantly different than the $\sim 6^{\circ} \mathrm{C}$ estimate of the previous chapter. For the region near the Nantucket Lightship for the period from 19561971 , bottom temperatures annually dropped $1^{\circ}-2^{\circ} \mathrm{C}$ below the $5^{\circ} \mathrm{C}$ lower limit for about 3 to 4 months (January to April) on average, while the upper $15^{\circ} \mathrm{C}$ limit was exceeded only occasionally (twice by just $0.5^{\circ} \mathrm{C}$ in 14 years) and the mean annual maximum (October) bottom temperature for this period is fully $2^{\circ} \mathrm{C}$ below this cutoff.

Assuming that the shell growth hiatuses occur at the $\delta^{18} \mathrm{O}$-shell minima and maxima, then the $\delta^{18} \mathrm{O}$-shell profiles can be separated at these points and compared to different sections of the predicted $\delta^{18} \mathrm{O}$-aragonite curve (Figure 7 ). The growth periods of each of the shells can be determined by mapping the endpoints of each group onto the predicted curve. The data then fall into three groups. The first minima are arbitrarily 
assigned to the second or fall group. The hiatus between the second and third groups is made near the $\delta^{18} \mathrm{O}$ maxima but is also defined by a sharp increase in $\delta^{13} \mathrm{C}$.

The first group consists of the first 1-2 points from each shell's laboratory growth and represents a mix of pre-laboratory growth and early laboratory growth. As the change from one temperature regime to the other $\left(\Delta \sim 10^{\circ} \mathrm{C}\right)$ was essentially instantaneous, the data indicating in-between temperature states must be the result of mixing between material deposited under cold pre-laboratory conditions and warm laboratory conditions. This material was deposited sometime during the first four months or $35 \%$ of the experimental period and yet represents only about $10 \%$ of shell growth.

The second group, which includes the first summer minima, consists of 2-4 data points from each shell and represents autumn and early winter growth. This growth period lasted about two months from October to December or about $20 \%$ of the experiment's duration and represents approximately the same percentage of growth. In a recent $A$. islandica study, Witbaard, et al. [Witbaard, Jenness, Van Der Borg, \& Ganssen, 1994] suggest that seasonal shell growth stops at the annual ring and that the apparent fall growth in their $\delta^{18} \mathrm{O}$ profile may simply represent a sampling artifact caused by mixing the shell's $\delta^{18} \mathrm{O}$ minima and maxima. Although some smearing of the signal is inevitable during sampling, and already invoked here to explain the first group's "in-between" data, the $\delta^{13} \mathrm{C}$ minima that also occur within the second group argue against a simple mixing between $\delta^{18} \mathrm{O}$ minima and maxima, because these minima cannot be accounted for by a mixing of end members, and therefore indicate at least some real shell growth during this late autumn period.

The last group, or spring data, contain most of the shell data and represent most of the laboratory shell growth (70\%). This growth period began in mid-March and lasted until 
the experiment's termination in early June or approximately $20 \%$ of the experiment's duration. Figure 8 shows that the spring shell data, converted to temperature (using equation 1 and the mean $\delta^{18} \mathrm{O}$-water), closely follow the observed temperature curve indicating that shell growth is approximately linear over this time. The data from specimen qx94, grown in sand and having the most shell growth of the three shells, show the most deviation from the predicted curve, indicating a more variable shell growth rate for this faster growing individual.

\section{II. $\delta^{13} \mathrm{C}$-aragonite}

Currently, there is no consensus on the fractionation of aragonite deposited in equilibrium with the $\delta^{13} \mathrm{C}$-DIC of ambient waters. Figure 9 shows the results of applying the tank properties $\delta^{13} \mathrm{C}$-DIC and temperature to three recently published methods, all of which give disparate results. Mook [Mook, 1986] proposed the equation:

$$
\delta^{13} \mathrm{C} \text {-aragonite }=-4232 / \mathrm{T}\left(\mathrm{K}^{\circ}\right)+16.90+\delta^{13} \mathrm{C} \text {-DIC }
$$

This relationship describes $\delta^{13} \mathrm{C}$-aragonite as a positive function of temperature, with an approximate linear slope $\sim+0.05 /{ }^{\circ} \mathrm{C}$ in the range $0^{\circ}-20^{\circ} \mathrm{C}$. Grossman and $\mathrm{Ku}$ (1986) using mollusc data from their own study proposed the equation:

$$
\delta^{13} \mathrm{C} \text {-aragonite }=2.66-0.131^{*} \mathrm{~T}\left(\mathrm{C}^{\circ}\right)+\delta^{13} \mathrm{C} \text {-DIC }
$$

The relationship shows $\delta^{13} \mathrm{C}$-aragonite as a negative function of temperature. Most recently, Romanek, et al, [Romanek, Grossman, \& Morse, 1992] have performed inorganic precipitation experiments that show that $\delta^{13} \mathrm{C}$-aragonite has a constant offset of $+2.7 \%$ relative to ambient DIC with no significant temperature dependence. Hence, unlike 
$\delta^{18} \mathrm{O}$, there is no prior confidence in the predicted equilibrium curves as a baseline to compare the shell records.

The $\delta^{13} \mathrm{C}$ of the tank DIC averages $+0.6 \%$ while the lab-grown shell material averages $+1.6 \%$, for a mean difference of $1.0 \%$. This difference is much less than that expected from equilibrium using Romanek, et al.'s [1993] constant offset of $+2.7 \%$. For the mean tank temperature of $10.8^{\circ} \mathrm{C}$, it is also much less than the $+2.3 \%$ predicted from Mook's equation (3a), but it is only a bit less than the $\sim+1.2 \%$ predicted from Grossman and Ku's equation (3b).

The shell $\delta^{13} \mathrm{C}$ profiles do show a general similarity to the trend of the $\delta^{13} \mathrm{C}$-DIC signal (Figure 10), in that minima occur during the first summer and become more enriched in the winter and spring. Assuming continuous shell growth, this could be taken as evidence that the shell $\delta^{13} \mathrm{C}$ reflects the $\delta^{13} \mathrm{C}$ variations in the ambient DIC. However, the greater amplitude of the shell $\delta^{13} \mathrm{C}$ signals relative to the DIC signal suggests that the relationship between the $\delta^{13} \mathrm{C}$ of the water column DIC and shell carbonate cannot be attributed to a simple offset from $\delta^{13} \mathrm{C}$-DIC.

Using the shell growth periods determined from fitting the $\delta^{18} \mathrm{O}$ data onto the predicted $\delta^{18} \mathrm{O}$ record, the paired shell $\delta^{13} \mathrm{C}$ data can be assigned to a specific time of deposition (Figure 11). From this perspective, the variation in shell $\delta^{13} \mathrm{C}$ bears little relation to the $\delta^{13} \mathrm{C}$-DIC profile. For example, $\delta^{13} \mathrm{C}$-DIC remains rather constant during the fall and spring growth periods, while shell $\delta^{13} \mathrm{C}$ varies by about $1 \%$. Also, while spring DIC is $\sim 0.2 \%$ enriched in $\delta^{13} \mathrm{C}$ relative to the previous fall, the spring shell $\delta^{13} \mathrm{C}$ is approximately $1 \%$ enriched relative to the fall. However, the variation of shell data is similar to the variation predicted from Mook's [1986] positive temperature-dependent relationship (3a), although, the shell data are about $1 \%$ depleted relative to this predicted 
curve. Also, the offset between the fall and spring shell data $(\sim 1 \%)$ is not reflected in the predicted values from Mook's relationship which differ by only $\sim 0.2 \%$. Also not reflected in this predicted curve, is the shells' sharp depletion (0.3-1.7\%o) in the late spring. Finally, the absence of a clear dependence on temperature is shown by the poor correlation between the shell (laboratory) $\delta^{13} \mathrm{C}$ and $\delta^{18} \mathrm{O}(\mathrm{r}=-0.178)$ (Figure 12). These mixed results suggest that while the seasonal variation in A. islandica shell $\delta^{13} \mathrm{C}$ may be controlled at times by a positive dependence on temperature, there seems to be no dependence at other times.

\section{Microhabitat / Pore Water $\delta^{13} \mathrm{C}$ :}

Studies have shown that the depleted $\delta^{13} \mathrm{C}$-DIC environment of marine sediments [McCorkle, et al., 1985] can cause the tests of the infaunal benthic foraminifera to become depleted relative to tests of epifaunal species [Grossman, 1987][McCorkle, Keigwin, Corliss, and Emerson, 1990]. Analogously, Krantz, et al. [Krantz, Williams, \& Jones, 1987] offered the hypothesis that the $\delta^{13} \mathrm{C}$ composition of the shells of infaunal filterfeeding bivalves may be depleted relative to that of epifaunal species due to the uptake of pore water DIC. However, the $\delta^{13} \mathrm{C}$ composition of $A$. islandica shells does not appear to be dependent on the $\delta^{13} \mathrm{C}$ of ambient pore water DIC based on the results shown here. The mean $\delta^{13} \mathrm{C}$ of the shell grown in the water column or "no sediment" is actually more depleted $\left(\mathrm{qx} 156 \delta^{13} \mathrm{C}=+1.49 \%\right)$ than the shell grown in the mud $\left(\mathrm{qx} 102 \delta^{13} \mathrm{C}=\right.$ $+1.77 \%$ ) even though the latter specimen's ambient pore water $\delta^{13} \mathrm{C}$ was depleted by $\sim 6 \%$ relative to the overlying water column. The sand substrate's ambient pore water $\delta^{13} \mathrm{C}$ was as depleted as the mud substrate's pore water, and yet the mean $\delta^{13} \mathrm{C}$ of the shell grown in sand $(\mathrm{qx} 94=+1.46 \%$ ) is almost identical to that of the shell grown in the water column. These results indicate that the "microhabitat" analogy does not apply to the infaunal bivalve A. islandica, probably because this bivalve's internal fluid exchange with the overlying water column is rapid and overwhelms any external pore water influence. Based on studies that describe the significant influence of benthic megafauna on geochemical cycling in the 
sediments [Aller, 1978][Aller and Yingst, 1985], it is perhaps more likely that infaunal filter-feeding bivalves, such as $A$. islandica, rather than being passive inhabitants of their sediment environment, may act instead as primary transport pathways of overlying waters to the sediments, thus enriching the local pore water $\delta^{13} \mathrm{C}$ about the individual bivalves.

\section{Physiological (Vital) Effects:}

The strong similarity displayed among the shell's $\delta^{13} \mathrm{C}$ profiles, especially the prelaboratory growth portions, makes it difficult to discern whether the specimens are responding to environmental changes (external control) or a common physiological cycle (internal control). However, the absence of any consistent correspondence with ambient temperature and DIC variations and the greater contrast shown among the specimens' laboratory $\delta^{13} \mathrm{C}$ profiles hints that individual physiology may play an important role, at least during periods of greater physical stress (e.g., handling, extreme laboratory conditions, reproductive activity). Stable carbon isotope studies involving the carbonate shells of marine organisms, almost unanimously, have discussed the role of vital effect or physiological controls in interpreting their $\delta^{13} \mathrm{C}$ compositions, and most have concluded that it is a significant factor resulting in disequilibrium with ambient DIC (e.g., [Wefer and Berger, 1991]). The specific term "vital effect" is usually interpreted to mean the inclusion of metabolically-produced (internal respiration) $\mathrm{CO}_{2}$, which is usually isotopically lighter $(\sim-20 \%)$ than ambient DIC $(\sim 0 \%)$, into the carbonate shell of a marine organism causing this shell to become depleted relative to equilibrium [Grossman, 1987]. Tanaka, et al. [1986] have calculated that approximately $50 \%$ of the carbon in the shells of several coastal mollusc species is of metabolic origin. If we allow that the $A$. islandica shells are about $1 \%$ depleted relative to "equilibrium", based on the average difference with the predicted offsets $(0.2-1.7 \%$ ) derived from the three published relationships, then these shells require only a $5 \%$ uptake of metabolic- $\mathrm{CO}_{2}$ to cause this overall depletion. A fluctuation of $\sim \pm 5 \%$ about this metabolic uptake value would also explain the seasonal $\delta^{13} \mathrm{C}$ signal of $\sim 2 \%$ observed 
in the laboratory shell growth, though the pre-laboratory shell growth has a seasonal $\delta^{13} \mathrm{C}$ signal only about $1 / 4$ of this amplitude.

In this view, the shells' seasonal $\delta^{13} \mathrm{C}$ variation suggests variable metabolic activity or at least a variation in the supply of metabolic carbon to the shell. As the shell becomes most depleted in the autumn and most enriched in the mid-spring this model would suggest greatest metabolic activity or supply in the autumn and least in the spring. However, it would be reasonable to expect that increased shell growth, such as occurred during the spring in the laboratory, would parallel increased tissue growth and metabolic activity, but the spring is precisely when the shells are most enriched - not depleted. Perhaps, increased fluid exchange with the ambient water accompanies growth and overwhelms the metabolic effect on shell composition, but in any case this seems to add a complication and makes a direct metabolic effect less likely. McConnaughey [1989a, 1989b] suggested that kinetic effects, such as those that might be associated with rapid rates of carbonate deposition, would tend to cause offsets in both $\delta^{13} \mathrm{C}$ and $\delta^{18} \mathrm{O}$ and result in increased correlation between them. He also noted that based on the equilibration rates for the various DIC ions, that kinetic effects would be least likely in organisms with high flushing rates, low metabolisms, and slow shell growth rates. All three conditions, would seem to apply to $A$. islandica, and as Figure 12 shows no obvious correlation between $\delta^{13} \mathrm{C}$ and $\delta^{18} \mathrm{O}$, a kinetic effect related to shell growth rate seems implausible. McConnaughey [1989a] also discussed an indirect metabolic effect that would lead to a positive correlation between a photosynthetic organism's skeletal enrichment and that organism's tissue growth. He explained that if tissue growth dominated the draw down on an organism's carbon reservoir in the fluid between the skeleton and the membrane, then the residual pool available for shell formation, could be enriched in ${ }^{13} \mathrm{C}$ as tissue growth would preferentially incorporate ${ }^{12} \mathrm{C}$. However, this mechanism should not apply to nonphotosynthetic organisms, such as A. islandica, because their tissues receive their carbon 
from what they consume and supposedly do not draw on the ambient DIC. Nevertheless, it does seem that the $A$. islandica shell's pattern of springtime ${ }^{13} \mathrm{C}$ enrichment likely coincides with the period of increased tissue growth, for whatever reason.

Ontogenic depletion of shell $\delta^{13} \mathrm{C}$ has been reported in many bivalves [Wefer and Berger, 1991] and we have observed it consistently in A. islandica shells. In general, evidence of long term ${ }^{13} \mathrm{C}$ (and ${ }^{14} \mathrm{C}$ ) depletion in environmental records over the last century has attracted great interest because of the possibility that it might be tracking the uptake of $\mathrm{CO}_{2}$ from the combustion of fossil-fuels (which are very depleted in ${ }^{13} \mathrm{C}$ ) [Nozaki, Rye, Turekian, and Dodge, 1978][Quay, Tilbrook, and Wong, 1992]. However, owing to the absence of ambient records of DIC $\delta^{13} \mathrm{C}$ in most of the molluscan studies, it has not been clear that these $\delta^{13} \mathrm{C}$ depletions are of internal (ontogenic) or external (fossilfuel) origin. Overlapped records from $A$. islandica shells of different ages and from the same location near position of the former Nantucket Lightship (Figure 13), show a $\delta^{13} \mathrm{C}$ offset between them for the same time periods, demonstrating that these depletions are not the result of actual changes in the ambient environment and must be related to ontogeny. These records also show depletions of $1 \%$ or more during the first 15 years of growth. This corresponds approximately to the age when A. islandica reaches sexual maturity and also corresponds with a sharp reduction in growth rate [Thompson, Jones, and Ropes, 1980][Mann, 1982]. Again, these results appear consistent with a positive correlation between tissue growth and $\delta^{13} \mathrm{C}$ enrichment, with a reduction in the rate of tissue growth as bivalves age paralleling a depletion in their shells' $\delta^{13} \mathrm{C}$ composition. Alternately, increased metabolic activity associated with increased reproductive activity could also explain the ontogenic depletion trend. In either case, it is apparent that a physiological or vital effect plays a dominant role in the $\delta^{13} \mathrm{C}$ composition of $A$. islandica shells. 


\section{Summary}

$\delta^{18} \mathrm{O}$ and $\delta^{13} \mathrm{C}$ records were obtained from the aragonite shells of three $A$. islandica specimens grown in the laboratory in different substrates for 1 year, and compared with ambient conditions such as water temperature, salinity, $\delta^{18} \mathrm{O}$-water, water column DIC $\delta^{13} \mathrm{C}$, and pore water DIC $\delta^{13} \mathrm{C}$. Assuming $A$. islandica, like most bivalves, are depositing their shells in equilibrium with ambient conditions and using Grossman and Ku's [1986] aragonite paleotemperature equation, the shells' $\delta^{18} \mathrm{O}$ record indicates that shell growth occurred when water temperatures were between $5^{\circ} \mathrm{C}$ and $15^{\circ} \mathrm{C}$. No significant shell growth seemed to take place at higher or lower temperatures. Also, very little shell growth seems to have occurred during the first two-thirds of the experiment. Perhaps this is the result of a combination of physical shock associated with capture, resettling into a new environment, and excessively warm tank conditions during their first few months in the laboratory. Most (70\%) of shell growth occurred in the last two or three spring months of the experiment. The springtime shell $\delta^{18} \mathrm{O}$ data, converted to temperature, closely correspond to the observed temperature curve during this period, and indicate that shell growth was approximately linear for this period. These results suggest that $A$. islandica can be used to accurately reconstruct ambient temperatures within a $10^{\circ} \mathrm{C}$ range from $5^{\circ}$ to $15^{\circ} \mathrm{C}$.

The $\delta^{13} \mathrm{C}$ signals of $A$. islandica shells do not appear to be in "equilibrium" with ambient conditions, though exactly what constitutes $\delta^{13} \mathrm{C}$ equilibrium is still unsettled within the stable isotope community. Shell $\delta^{13} \mathrm{C}$ averages about $1 \%$ o heavier than ambient DIC, but is about $1 \%$ lighter than "equilibrium" based on three of the most recently published equilibrium relationships for aragonite. The shell's seasonal variation of $\sim 2 \%$ cannot be attributed, primarily, to seasonal $\delta^{13} \mathrm{C}$-DIC variations, which remained rather constant during the fall and spring periods of shell growth. Temperature trends in the fall and spring do correlate positively with shell $\delta^{13} \mathrm{C}$ trends as predicted by Mook's [1986] 
equilibrium relationship. However, there are significant deviations from this positive correlation as demonstrated by the poor correlation between $\delta^{13} \mathrm{C}$ and $\delta^{18} \mathrm{O}$ and the sharp drop in shell $\delta^{13} \mathrm{C}$ despite rising temperatures in the late spring. Pore water $\delta^{13} \mathrm{C}$ or the "microhabitat effect" is shown to have no obvious influence on the $\delta^{13} \mathrm{C}$ composition of $A$. islandica shells. An ontogenic $\delta^{13} \mathrm{C}$ depletion trend noted in A. islandica shells during their first $\sim 15$ years of growth cannot be accounted for by variations in the external environment. As external controls have not been identified to account for the shell $\delta^{13} \mathrm{C}$ variations, we suggest physiological controls.

This study reaffirms the conclusions of the previous chapter, that the $\delta^{18} \mathrm{O}$ composition of $A$. islandica 's annual bands can be used to reconstruct most of the ambient temperature record within the range of temperatures this species is naturally likely to encounter, except for the coldest winter months. In contrast, this study has shown that the $\delta^{13} \mathrm{C}$ composition of $A$ islandica's annual bands 1$)$ does not directly reflect ambient $\delta^{13} \mathrm{C}$ DIC and 2) displays seasonal and ontogenic variations that are more consistent with a physiological control, which, until further understood, precludes its use in reconstructing records of the ocean's carbon environment. 


\section{Acknowledgements:}

Financial support for this work was provided by NOAA grant \# NA36GPO291, Oak Ridge Associated Universities Global Climate Change Fellowship Program, and the WHOI Ocean Ventures Fund. I especially want to thank the personnel of the NOAA National Marine Fisheries Aquarium at Woods Hole for providing the laboratory space as well as their invaluable help in carrying out the experiment. I also want to thank Matthew Gould for skippering the Mytilus to and from the Devil's Bridge site on good days and bad, and Tuddy Erkhart of Jonesport, Maine for offering his boat, time, and friendly assistance in collecting the specimens for this experiment. Finally, I want to thank my son Dylan for filling in for me while I was away. 


\section{References:}

Allard, D. A., Masters Thesis, University of Rhode Island, 1989.

Aller, R. C., Experimental studies of changes produced by deposit feeders on pore water, sediment, and overlying water chemistry, Am. J. Sci., 278, 1185-1234, 1978.

Aller, R. C., and J. Y. Yingst, Effects of the marine deposit-feeders Heteromastus filiformis (polychaeta), Macoma balthica (bivalvia) and Tellina texana (bivalvia) on averaged sedimentary solute transport, reaction, and microbial distributions, J. Mar. Res., 43, 615-645, 1985.

Broecker, W. S., and T. H. Peng, Tracers in the Sea, Lamount-Doherty Geological Observatory Publication, Columbia University, Palisades, N.Y., 1982.

Deuser, W. G., and E. T. Degens, Carbon isotope fractionation in the system CO2(gas)CO2(aqueous)-HCO3-(aqueous), 215, 1033-1035, 1967.

Fairbanks, R. G., The origin of Continental Shelf and Slope Water in the New York Bight and Gulf of Maine: evidence from $\mathrm{H} 2 \mathrm{O}-18 / \mathrm{H} 2 \mathrm{O}-16$ ratio measurements, J. Geophys. Res., 87, 5796-5808, 1982.

Grossman, E. L., and T. Ku, Oxygen and carbon isotope fractionation in biogenic aragonite: temperature effects, Chem. Geol., 59, 59-74, 1986.

Grossman, E. L., Stable isotopes in modern benthic foraminifera: A study of vital effect, $J$. Foram. Res., 17, 48-61, 1987.

Harrington, R. J., Aspects of growth deceleration in bivalves: Clues to understanding the seasonal O-18 and C-13 record -- A comment on Krantz et al. (1987), Palaeogeogr., Palaeoclimatol., Palaeoecol., 70, 399-403, 1989.

Inman, D. L., Sediments: physical properties and mechanics of sedimentation, in: Submarine Geology, edited by F. P. Shepard, pp. 101-151, Harper's Geoscience Series, Harper and Row, New York, 1963.

Jones, D. S., Annual cycle of shell growth and reproduction in the bivalves-Spisula solidissima-\&-Arctica islandica-, PhD, Princeton University, 1980a.

Jones, D. S., Annual cycle of shell growth increment formation in two continental shelf bivalves and its paleoecologic significance, Paleobio., 6, 331-340, $1980 \mathrm{~b}$.

Krantz, D. E., D. F. Williams and D. S. Jones, Ecological and paleoenvironmental information using stable isotope profiles from living and fossil molluscs, Palaeogeogr., Palaeoclimatol., Palaeoecol., 58, 249-266, 1987.

Kraus, M. G., B. F. Beal, S. R. Chapman and L. McMartin, A comparison of growth rates in $A$. islandica (Linnaeus, 1967) between field and laboratory populations, $J$. Shellfish Res., 11, 289-294, 1992. 
Lutz, R. A., J. G. Goodsell, M. Castagna and A. P. Stickney, Growth of experimentally cultured ocean quahogs (Arctica islandica L.) in north temperate embayments, $J$. World Maricult. Soc., 14, 185-190, 1983.

Mann, R., The seasonal growth cycle of gonadal development in Arctica islandica from the southern New England Bight, Fish. Bull., 80, 315-326, 1982.

McConnaughey, T., $\mathrm{C} 13$ and $\mathrm{O} 18$ isotopic disequilibrium in biological carbonates: I. patterns, Geochim. Cosmichim., 53, 151-162, 1989a.

McConnaughey, T., C13 and $\mathrm{O} 18$ isotopic disequilibrium in biological carbonates: II. In vitro simulation of kinetic isotope effects, Geochim. Cosmichim., 53, 163-171, 1989b.

McCorkle, D. C., S. R. Emerson and P. D. Quay, Stable carbon isotopes in marine porewaters, Earth Planet. Sci. Lett., 74, 13-26, 1985.

McCorkle, D. C., and L. D. Keigwin, Depth profiles of d13C in bottom water and coretop C. wuellerstorfi on the Ontong-Java Plateau and Emperor Seamounts, Paleocean., 9, 197-208, 1994.

McCorkle, D. C., L. D. Keigwin, B. H. Corliss and S. R. Emerson, The influence of microhabitats on the carbon isotopic composition of deepsea benthic foraminifera, Paleocean., 5, 161-185, 1990.

McNichol, A. P., G. A. Jones, D. L. Hutton and A. R. Gagnon, The rapid preparation of seawater $\Sigma \mathrm{CO} 2$ for radiocarbon analysis at the National Ocean Sciences AMS Facility, Radiocarbon, 36, 237-246, 1994.

Mook, W. G., C13 in atmosphere CO2, Neth. J. Sea Res., 20, 211-223, 1986. O'Neil, J. R., R. N. Clayton and T. K. Mayeda, Oxygen isotope fractionation in divalent metal carbonates, J. Chem. Phys., 51, 5547-5558, 1969.

Nozaki, Y., D. M. Rye, K. K. Turekian and R. E. Dodge, C-13 and C-14 variations in a Bermuda coral, Geophys. Res. Lett., 5, No.10, 825-828, 1978.

Quay, P. D., B. Tilbrook and C. S. Wong, Oceanic uptake of fossil fuel CO2: carbon-13 evidence, Science, 256, 74-79, 1992.

Romanek, C. S., E. L. Grossman and J. W. Morse, Carbon isotopic fractionation in synthetic aragonite and calcite: effects of temperature and precipitation rate, Geochim. Cosmichim., 56, 419-430, 1992.

Smith, P. C., The mean and seasonal circulation off southwest Nova Scotia, J. Phys. Oceanogr., 13, 1034-1054, 1983.

Tanaka, N., M. C. Monaghan and D. M. Rye, Contribution of metabolic carbon to mollusc and barnacle shell carbonate, Nature, 320, 520-523, 1986.

Thompson, I., D. S. Jones and J. W. Ropes, Advanced age for sexual maturity in the ocean quahog Arctica islandica (Mollusca: Bivalvia), Mar. Biol., 57, 35-39, 1980. 
Weidman, C. R., G. A. Jones and K. C. Lohmann, The long-lived mollusc Arctica islandica: A new paleoceanographic tool for the reconstruction of bottom temperatures $\mathrm{f}$ or the continental shelves of the northern North Atlantic Ocean, J. Geophys. Res., 99, 18,305-18,314, 1994.

Wefer, G., and W. H. Berger, Isotope paleontology: growth and composition of extant calcareous species, Mar. Geol., 100, 207-248, 1991.

Wilbur, K. M., and G. Owen, Growth, in: Physiology of Mollusca, edited by K. M. Wilbur and C. M. Yonge, pp. 211-242, Academic Press, New York, 1964.

Williams, D. F., M. A. Arthur, D. S. Jones and N. Healy-Williams, Seasonality and mean annual sea surface temperatures from isotopic and sclerochronological records, Nature, 296, 432-434, 1982.

Winter, J. E., Uber den Einfluss der Nahrungkonzentration und anderer Faktoren auf Filtrierleistung und Nahrungsausnutzung der Mushcheln Arctica islandica und Modiolus modiolus, Mar. Biol., 4, 87-135, 1969.

Witbaard, R., M. I. Jenness, K. Van Der Borg and G. Ganssen, Verification of annual growth increments in Arctica islandica L. from the North Sea by means of oxygen and carbon isotopes, Neth. J. of Sea Res., 33, 91-101, 1994. 
Table 1: Ambient Water Properties-Initial Sites and Laboratory

\begin{tabular}{|c|c|c|c|c|c|}
\hline Date & $\begin{array}{c}\text { Experiment } \\
\text { Day \# }\end{array}$ & $\begin{array}{l}\text { Temperature } \\
\left(\mathrm{C}^{\circ}\right)\end{array}$ & $\begin{array}{l}\text { Salinity } \\
(\% 0)\end{array}$ & $\begin{array}{c}\delta^{180} \\
(\mathrm{SMOW})\end{array}$ & $\begin{array}{l}\delta^{13} \mathrm{C} \\
(\mathrm{PDB})\end{array}$ \\
\hline $\begin{array}{l}5 / 4 / 93 \\
6 / 4 / 93\end{array}$ & $\begin{array}{r}1 \\
32\end{array}$ & $\begin{array}{l}7.1 \\
5.2\end{array}$ & $\begin{array}{l}32.185 \\
31.521\end{array}$ & $\begin{array}{l}-1.13 \\
-1.49\end{array}$ & $\begin{array}{l}\text { 1.22 Devil's Bridge } \\
1.10 \text { Jonesport }\end{array}$ \\
\hline $\begin{array}{l}5 / 5 / 93 \\
6 / 3 / 93 \\
6 / 18 / 93 \\
7 / 1 / 93 \\
7 / 15 / 93 \\
7 / 28 / 93 \\
8 / 16 / 93 \\
8 / 30 / 93 \\
9 / 12 / 93 \\
10 / 6 / 93 \\
10 / 18 / 93 \\
11 / 6 / 93 \\
11 / 25 / 93 \\
12 / 10 / 93 \\
12 / 27 / 93 \\
1 / 13 / 94 \\
1 / 27 / 94 \\
2 / 10 / 94 \\
2 / 28 / 94 \\
3 / 18 / 94 \\
4 / 5 / 94 \\
4 / 24 / 94 \\
5 / 16 / 94 \\
6 / 4 / 94 \\
6 / 10 / 94\end{array}$ & $\begin{array}{r}2 \\
31 \\
46 \\
59 \\
73 \\
86 \\
105 \\
119 \\
132 \\
156 \\
168 \\
187 \\
206 \\
221 \\
238 \\
255 \\
269 \\
283 \\
301 \\
319 \\
337 \\
356 \\
378 \\
397 \\
403\end{array}$ & $\begin{array}{r}12.5 \\
15.8 \\
15.9 \\
15.2 \\
15.9 \\
16.2 \\
16.3 \\
17.3 \\
18.3 \\
16.5 \\
15.7 \\
12.6 \\
9.8 \\
8.5 \\
2.9 \\
1.5 \\
-0.0 \\
0.3 \\
1.7 \\
2.8 \\
6.6 \\
9.7 \\
12.6 \\
15.7 \\
16.3\end{array}$ & $\begin{array}{l}31.290 \\
31.286 \\
31.264 \\
31.222 \\
31.121 \\
31.190 \\
31.286 \\
31.439 \\
31.466 \\
31.628 \\
31.779 \\
31.670 \\
31.706 \\
31.418 \\
31.722 \\
31.200 \\
31.314 \\
31.221 \\
31.210 \\
30.798 \\
30.765 \\
30.860 \\
30.903 \\
31.174 \\
31.292\end{array}$ & $\begin{array}{l}-1.33 \\
-1.35 \\
-1.40 \\
-1.43 \\
-1.41 \\
-1.50 \\
-1.48 \\
-1.48 \\
-1.39 \\
-1.47 \\
-1.33 \\
-1.22 \\
-1.40 \\
-1.43 \\
-1.45 \\
-1.49 \\
-1.47 \\
-1.49 \\
-1.49 \\
-1.58 \\
-1.59 \\
-1.52 \\
-1.47 \\
-1.37 \\
-1.34\end{array}$ & $\begin{array}{r}0.89 \\
0.72 \\
0.18 \\
0.38 \\
0.19 \\
0.12 \\
-0.21 \\
0.54 \\
0.08 \\
0.35 \\
0.68 \\
0.76 \\
0.67 \\
0.54 \\
0.71 \\
---. \\
0.96 \\
0.99 \\
0.61 \\
0.92 \\
0.92 \\
0.99 \\
0.80 \\
0.95 \\
0.82\end{array}$ \\
\hline $\begin{array}{l}\text { Mean } \\
\pm \sigma\end{array}$ & & $\begin{array}{l}10.8 \\
\pm 6.3\end{array}$ & $\begin{array}{l}31.298 \\
\pm 0.282\end{array}$ & $\begin{array}{l}-1.44 \\
\pm 0.08\end{array}$ & $\begin{array}{c}0.62 \\
\pm 0.35\end{array}$ \\
\hline
\end{tabular}


Table 2: Ambient Pore Water and Water Column DIC Properties (Final State) 6/10/94

\begin{tabular}{llccc}
\hline ID & Substrate & $\begin{array}{c}\text { Depth } \\
(\mathrm{cm})\end{array}$ & $\begin{array}{c}\Sigma \mathrm{CO}_{2} \\
(\mu \mathrm{mol} / \mathrm{ml})\end{array}$ & $\begin{array}{c}\delta^{13} \mathrm{C} \\
(\% \circ)\end{array}$ \\
\hline BW-1 & Water & 0 & 2.011 & +0.99 \\
BW-2 & Water & 0 & 1.997 & +0.97 \\
BS1-1 & Sand & 1.0 & 3.204 & -4.56 \\
BS1-2 & Sand & 3.0 & 3.540 & -5.46 \\
BS1-3 & Sand & 6.0 & 3.373 & -4.73 \\
& & 1.0 & 3.164 & -5.05 \\
BS2-1 & Sand & 1.0 & 3.385 & -5.29 \\
BS2-2 & Sand & 3.0 & 3.520 & -4.36 \\
BS2-3 & Sand & 6.0 & & \\
& & $0.0-1.4$ & 2.944 & -3.75 \\
BM1-1 & Mud & $1.4-2.8$ & 4.815 & -8.51 \\
BM1-2 & Mud & & & \\
& & $0.0-1.4$ & 2.410 & -2.17 \\
BM2-1 & Mud & $1.4-2.8$ & 2.756 & -3.88 \\
BM2-2 & Mud & $2.8-5.6$ & 3.269 & -5.62 \\
BM2-3 & Mud & & & \\
\hline
\end{tabular}


Table 3: Devil's Bridge Bottom Water Properties

\begin{tabular}{|c|c|c|c|c|c|}
\hline Date & $\begin{array}{c}\text { Monitoring } \\
\text { Day \# }\end{array}$ & $\begin{array}{c}\text { Temperature } \\
\left(\mathrm{C}^{\circ}\right)\end{array}$ & $\begin{array}{l}\text { Salinity } \\
(\% 0)\end{array}$ & $\begin{array}{c}\delta^{180} \\
(\mathrm{SMOW})\end{array}$ & $\begin{array}{l}\delta^{13} \mathrm{C} \\
(\mathrm{PDB})\end{array}$ \\
\hline $\begin{array}{l}5 / 4 / 93 \\
6 / 8 / 93 \\
7 / 15 / 93 \\
8 / 31 / 93 \\
10 / 8 / 93 \\
11 / 10 / 93 \\
3 / 2 / 94 \\
4 / 25 / 94\end{array}$ & $\begin{array}{r}1 \\
32 \\
72 \\
119 \\
157 \\
190 \\
302 \\
356\end{array}$ & $\begin{array}{r}7.1 \\
12.1 \\
11.5 \\
13.8 \\
13.5 \\
11.9 \\
-0.8 \\
3.5\end{array}$ & \begin{tabular}{l}
32.185 \\
\hdashline 31.723 \\
31.998 \\
32.355 \\
32.045 \\
31.971 \\
32.076
\end{tabular} & $\begin{array}{l}-1.13 \\
-1.37 \\
-1.31 \\
-1.12 \\
-1.25 \\
-1.12 \\
-1.17\end{array}$ & $\begin{array}{l}1.22 \\
1.39 \\
1.06 \\
1.09 \\
0.71 \\
1.01 \\
0.93 \\
0.80\end{array}$ \\
\hline $\begin{array}{l}\text { Mean } \\
\pm \sigma\end{array}$ & & $\begin{array}{l}9.07 \\
\pm 5.3\end{array}$ & $\begin{array}{l}32.050 \\
\pm 0.195\end{array}$ & $\begin{array}{l}-1.21 \\
\pm 0.1\end{array}$ & $\begin{array}{l}1.02 \\
\pm 0.22\end{array}$ \\
\hline
\end{tabular}


Table 4: Shell Isotope Raw Data

\begin{tabular}{|c|c|c|c|c|c|c|c|c|c|}
\hline \multirow[b]{2}{*}{ \# } & \multicolumn{2}{|c|}{$\mathrm{gx} 156$ (no sed) } & \multicolumn{3}{|c|}{$\mathrm{gx} 94$ (sand) } & \multirow[b]{2}{*}{ \# } & \multicolumn{2}{|c|}{$\mathrm{gx} 102$ (mud) } & \\
\hline & $\delta^{18} \mathrm{O}$ & $\delta^{13} \mathrm{C}$ & \# & $\delta^{18} \mathrm{O}$ & $\delta^{13} \mathrm{C}$ & & $\delta^{18} \mathrm{O}$ & $\delta^{13} \mathrm{C}$ & \\
\hline 1 & 1.35 & 1.90 & 1 & 1.19 & $2.01^{*}$ & 1 & $0.98^{*}$ & 2.09 & \\
\hline 2 & 1.21 & 1.98 & 2 & 1.15 & 1.81 & 2 & 1.03 & $2.10 *$ & \\
\hline 4 & 1.05 & $2.17 *$ & 3 & 0.93 & 1.72 & 3 & 1.05 & 2.09 & \\
\hline 5 & 1.22 & 1.95 & 4 & 0.97 & 1.73 & 4 & 1.15 & 2.05 & \\
\hline 7 & 0.90 & 1.90 & 5 & 1.00 & 1.73 & 5 & 1.10 & 1.91 & \\
\hline 8 & $0.78^{*}$ & 1.93 & 6 & 0.96 & 1.83 & 6 & 1.46 & $1.74 *$ & \\
\hline 9 & 0.93 & 1.96 & 7 & 0.96 & 1.77 & 7 & $1.96^{*}$ & 1.99 & \\
\hline 10 & 0.93 & 1.91 & 8 & $0.88^{*}$ & 1.73 & 8 & 1.85 & 2.04 & \\
\hline 11 & 0.90 & 1.90 & 9 & 0.91 & 1.65 & 9 & 1.78 & 2.01 & \\
\hline 12 & 0.90 & 1.85 & 10 & 1.34 & $1.55^{*}$ & 10 & 1.57 & 2.07 & \\
\hline 13 & 1.10 & $1.74 *$ & 11 & 1.68 & 1.86 & 11 & 1.63 & 2.10 & \\
\hline 14 & 1.42 & 1.79 & 12 & 1.65 & 1.87 & 12 & 1.59 & $2.15^{*}$ & \\
\hline 15 & 1.69 & 1.82 & 13 & $1.81^{*}$ & 1.79 & 13 & 1.35 & 2.10 & \\
\hline 16 & $1.89^{*}$ & 1.94 & 14 & 1.45 & 1.89 & 14 & 1.43 & 2.13 & \\
\hline 17 & 1.64 & 1.93 & 15 & 1.48 & 1.93 & 15 & 1.51 & 2.12 & \\
\hline 18 & 1.76 & 1.96 & 16 & 1.23 & 1.89 & 16 & 1.43 & 2.08 & \\
\hline 19 & 1.71 & 1.97 & 17 & 1.42 & 1.94 & 17 & 1.37 & 2.00 & \\
\hline 20 & 1.67 & 2.05 & 18 & 1.42 & 1.90 & 18 & $1.21^{*}$ & $1.71^{*}$ & \\
\hline 21 & 1.59 & 1.99 & 19 & 1.27 & 1.93 & 19 & $1.81^{*}$ & 1.87 & \\
\hline 22 & 1.49 & 2.03 & 20 & 1.40 & 1.95 & 20 & 1.47 & 2.10 & \\
\hline 23 & 1.58 & 2.04 & 21 & 1.37 & $2.13^{*}$ & 21 & 1.32 & 2.30 & \\
\hline 24 & 1.50 & 2.07 & 22 & 1.43 & 2.09 & 22 & 1.20 & $2.30^{*}$ & \\
\hline 25 & 1.52 & 2.04 & 23 & 1.17 & 2.03 & 23 & 0.63 & 1.88 & \\
\hline 26 & 1.52 & 2.02 & 24 & 1.20 & 1.95 & 24 & $0.05^{*}$ & $0.58 *$ & \\
\hline 27 & 1.37 & 2.09 & 25 & $0.93 *$ & 1.88 & 25 & $2.22 *$ & 0.59 & \\
\hline 28 & 1.43 & $2.19 *$ & 26 & 1.45 & $1.66^{*}$ & 26 & 2.05 & 1.02 & \\
\hline 29 & 1.34 & 2.18 & 27 & 1.63 & 1.89 & 27 & 2.02 & 1.66 & \\
\hline 30 & $1.30 *$ & 2.16 & 28 & $1.65^{*}$ & 2.01 & 28 & 1.49 & 1.94 & \\
\hline 31 & 1.40 & 2.09 & 29 & 1.49 & 2.05 & 29 & 1.38 & 2.09 & \\
\hline 32 & 1.38 & 2.07 & 30 & 1.48 & 2.14 & 30 & 1.20 & 2.04 & \\
\hline 33 & 1.47 & 2.03 & 31 & 1.25 & 2.19 & 31 & 1.06 & 2.14 & \\
\hline 34 & 1.52 & 1.74 & 32 & 1.24 & 2.19 & 32 & 0.80 & 2.12 & \\
\hline 35 & 1.52 & $1.73^{*}$ & 33 & 1.19 & 2.30 & 33 & 0.75 & $2.26^{*}$ & \\
\hline 36 & $1.80^{*}$ & 1.85 & 34 & 1.21 & 2.26 & 35 & 0.41 & 2.15 & \\
\hline 37 & 1.74 & 1.94 & 35 & 0.98 & 2.23 & 36 & 0.32 & 1.99 & \\
\hline 38 & 1.61 & 2.02 & 36 & 1.04 & $2.30^{*}$ & 37 & 0.13 & 1.96 & \\
\hline 39 & 1.42 & 2.11 & 37 & 0.98 & 1.95 & 38 & -0.08 & 1.63 & \\
\hline 40 & 1.49 & 2.18 & 38 & 0.34 & 1.61 & & & & \\
\hline 41 & 1.46 & 2.22 & 39 & $-0.45^{*}$ & 0.45 & & & & \\
\hline 42 & 1.35 & $2.22 *$ & 40 & 0.40 & 0.31 & & & & \\
\hline 43 & 0.84 & 2.03 & 41 & $2.13 *$ & $-0.31 *$ & & & & \\
\hline 44 & 0.21 & 1.80 & 42 & 1.58 & 0.76 & & & & \\
\hline 45 & $-0.26 *$ & 1.39 & 43 & 1.27 & 1.42 & & & & \\
\hline 46 & 0.00 & 1.17 & 44 & 1.04 & 1.69 & & & & \\
\hline 47 & 0.93 & 0.90 & 45 & 0.85 & 1.77 & & & & \\
\hline 48 & 1.55 & $0.78 *$ & 46 & 0.86 & 1.50 & & & & \\
\hline 49 & $1.67 *$ & 0.98 & 47 & 0.81 & 1.59 & & & & \\
\hline 50 & 1.34 & 1.17 & 48 & 0.78 & 1.76 & & & & \\
\hline 51 & 1.29 & 1.39 & 49 & 0.70 & 1.63 & & & & \\
\hline 52 & 1.04 & 1.57 & 50 & 0.37 & 1.62 & & & & \\
\hline 53 & 0.91 & 1.72 & 51 & -0.06 & $2.33 *$ & & & & \\
\hline 54 & 0.78 & 1.80 & 52 & -0.12 & 2.05 & & & & \\
\hline 55 & 0.57 & $1.85^{*}$ & 53 & -0.10 & 2.19 & & & & \\
\hline 56 & 0.46 & 1.55 & 54 & -0.23 & 2.13 & $*$ & Critical & Points & (Max, Min) \\
\hline 57 & 0.17 & 1.56 & 55 & 0.03 & 1.59 & & & & \\
\hline & & & 56 & -0.30 & 1.34 & & & & \\
\hline & & & 57 & -0.25 & 0.65 & & & & \\
\hline
\end{tabular}




\section{Figure Captions}

Figure 1. Location Map

Figure 2. Laboratory Tank Water Properties: a) temperature; b) salinity; c) $\delta^{18} \mathrm{O}$-water; d) $\delta^{13} \mathrm{C}-\mathrm{DIC}$.

Figure 3. Devil's Bridge Water Properties: a) temperature; b) salinity; c) $\delta^{18} \mathrm{O}$-water; d) $\delta^{13} \mathrm{C}-\mathrm{DIC}$.

Figure 4. Individual shell oxygen (solid line) and carbon (dashed line) stable isotope profiles versus sample sequence. The double vertical lines represent the growth "ring" locations. The pre-laboratory growth / laboratory growth parts of the profiles are separated by the third "ring" from the left, with pre-laboratory growth to the left and laboratory growth to the right. a) specimen qx156 grown in no sediment, b) specimen qx94 grown in medium/coarse sand, c) specimen qx102 grown in mud (very fine sand/silt).

Figure 5. Comparative a) oxygen and b) carbon stable isotope profiles versus normalized shell growth. The "0" normalized growth position separates the pre-laboratory profile (-1 to 0 ) from the laboratory profile $(0$ to +1$)$. The specimens' substrate types are indicated by solid line (no sediment), dashed line (sand), and dotted line (mud). Note that the prelaboratory growth profiles display much less variation both individually and collectively than to the laboratory growth profiles.

Figure 6. Predicted laboratory $\delta^{18} \mathrm{O}$-aragonite profile (dashed) compared with $\delta^{18} \mathrm{O}$-shell profiles (solid). The profiles are plotted assuming constant continuous growth. The horizontal lines indicate the mean maximum and mean mininum $\delta^{18} \mathrm{O}$-shell values. Note that the amplitude of the $\delta^{18} \mathrm{O}$-shell profiles is approximately half that of the predicted profile, and suggests that either 1) the shells did not grow during the coldest and the warmest periods, or 2) that the specimen's were not depositing their aragonite in equilibrium. Also, note the profiles are not in phase indicating variable growth rates including, perhaps, periods of shell growth cessation. 
Figure 7. Predicted $\delta^{18} \mathrm{O}$-aragonite profile and $\delta^{18} \mathrm{O}$-shell data. The $\delta^{18} \mathrm{O}$-shell data are plotted in time by matching up their maxima and minima with corresponding predicted $\delta^{18} \mathrm{O}$-aragonite values, and assuming periods of no shell growth. The double vertical lines represent the shell growth hiatuses. The substrate type of the $\delta^{18} \mathrm{O}$-shell data is indicted by: 1) 'o' no sediment; 2) '+' sand; and 3) '*' mud.

Figure 8. Spring tank temperature versus shell-derived temperature data for the same period. The shell-derived temperatures closely correspond to the actual $\left(\mathrm{SEE}= \pm 0.95^{\circ} \mathrm{C}\right)$, and indicate that the shell growth is aproximately linear during this period.

Figure 9. Tank $\delta^{13} \mathrm{C}$-DIC (solid) and three predicted $\delta^{13} \mathrm{C}$-aragonite profiles (dashed): 1 ) Romanek, et al.'s [1992] constant offset relationship (Ro); 2) Mook's [1986] positive temperature-dependent relationship (equation 3a) (Mo); 3) Grossman and Ku's [1986] negative temperature-dependent relationship (equation 3b) (Gr). Currently, there in no consensus on "equilibrium" fractionation between aragonite and ambient DIC.

Figure 10. Laboratory $\delta^{13} \mathrm{C}$-DIC profile (dashed) compared with $\delta^{13} \mathrm{C}$-shell profiles (solid). The profiles are plotted assuming constant continuous growth. The shells are more enriched than the DIC by about $1 \%$ on average and the shell profiles show some phase similarity to the DIC profile. However, the $\delta^{13} \mathrm{C}$-shell signals have a larger amplitude than the $\delta^{13} \mathrm{C}$-DIC signal. The $\delta^{13} \mathrm{C}$ profile of the specimen grown in the water column (no sed) is actually lighter than that of the specimens grown in substrates whose pore waters are considerably lighter, indicating that pore water composition does not influence the shells' carbon isotope composition.

Figure 11. Laboratory $\delta^{13} \mathrm{C}$-DIC profile (solid), predicted $\delta^{13} \mathrm{C}$-aragonite profile (dashed) [Mook, 1986], and $\delta^{13} \mathrm{C}$-shell data. The $\delta^{13} \mathrm{C}$-shell data are plotted in time according to the same scheme used for their $\delta^{18} \mathrm{O}$-shell pairs in Figure 7. The vertical lines separate periods of growth and no growth. The substrate type of the $\delta^{13} \mathrm{C}$-shell data is indicted by: 1) 'o' no sediment; 2) ' + ' sand; and 3) '*' mud. Taken all together the fall shell and DIC data have about the same average value, while the spring shell data are about $1 \%$ heavier than the DIC. While the $\delta^{13} \mathrm{C}$-DIC remains rather constant during each growth period the $\delta^{13} \mathrm{C}$-shell shows variation. The trend of some of this variation is similar to Mook's [1986] predicted $\delta^{13} \mathrm{C}$-aragonite indicating a positive temperature dependence, however the sharp depletion trend near the shell profiles termination runs counter to this interpretion. 
Figure 12. Laboratory shell $\delta^{13} \mathrm{C}$ versus $\delta^{18} \mathrm{O}$. No significant correlation exists between shell $\delta^{13} \mathrm{C}$ versus $\delta^{18} \mathrm{O}$.

Figure 13. Overlapped long term $\delta^{13} \mathrm{C}$ records from two shells of different ages livecaptured at the same time and at the same location on Nantucket Shoals. The first $\sim 15$ years of growth in each shell show a 1-1.5\%o depletion. The records overlap the years 19461956. The overlapping part of the record of the older specimen (solid line) averages about $+1.8 \%$ and shows only a slight negative trend, while the overlapping part of the record of the younger specimen (dashed) averages about $+2.3 \%$ and shows a steep negative trend. These results are interpreted as evidence of a strong physiological control on the $\delta^{13} \mathrm{C}$ composition of $A$. islandica shells. 


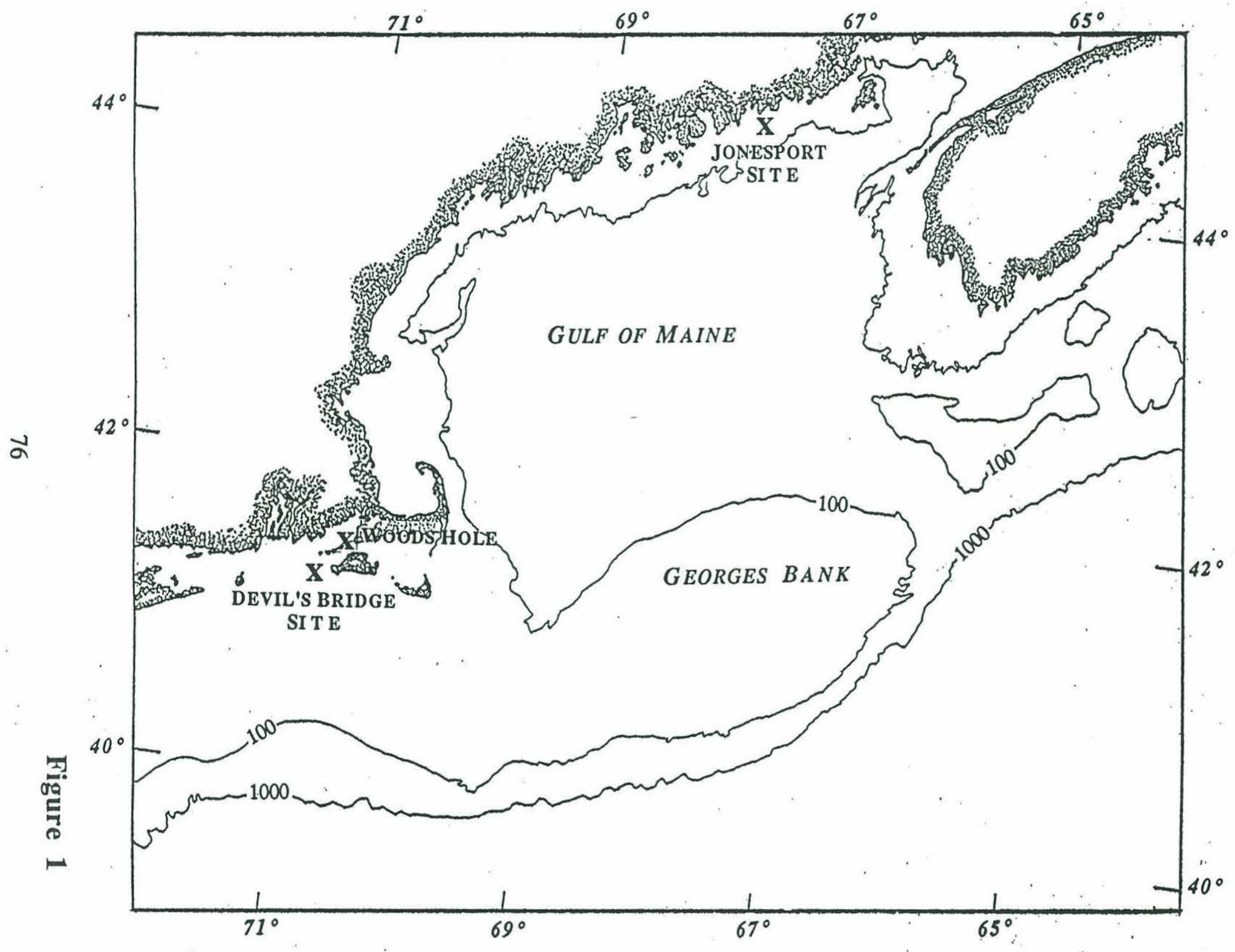




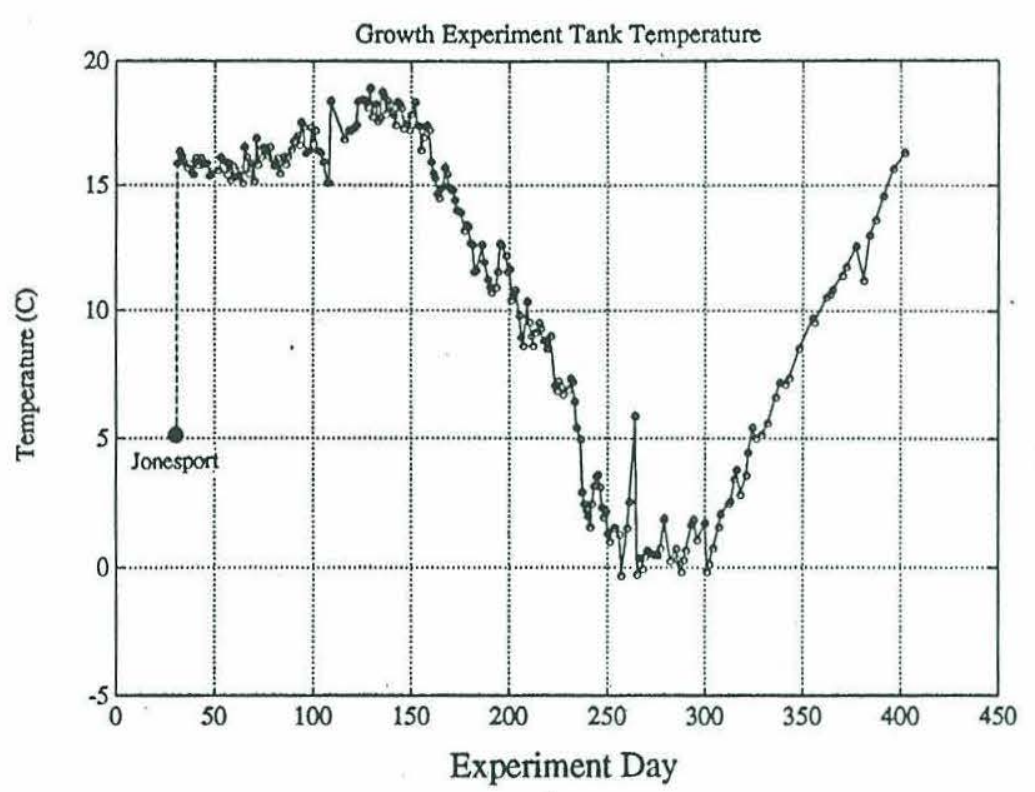

B
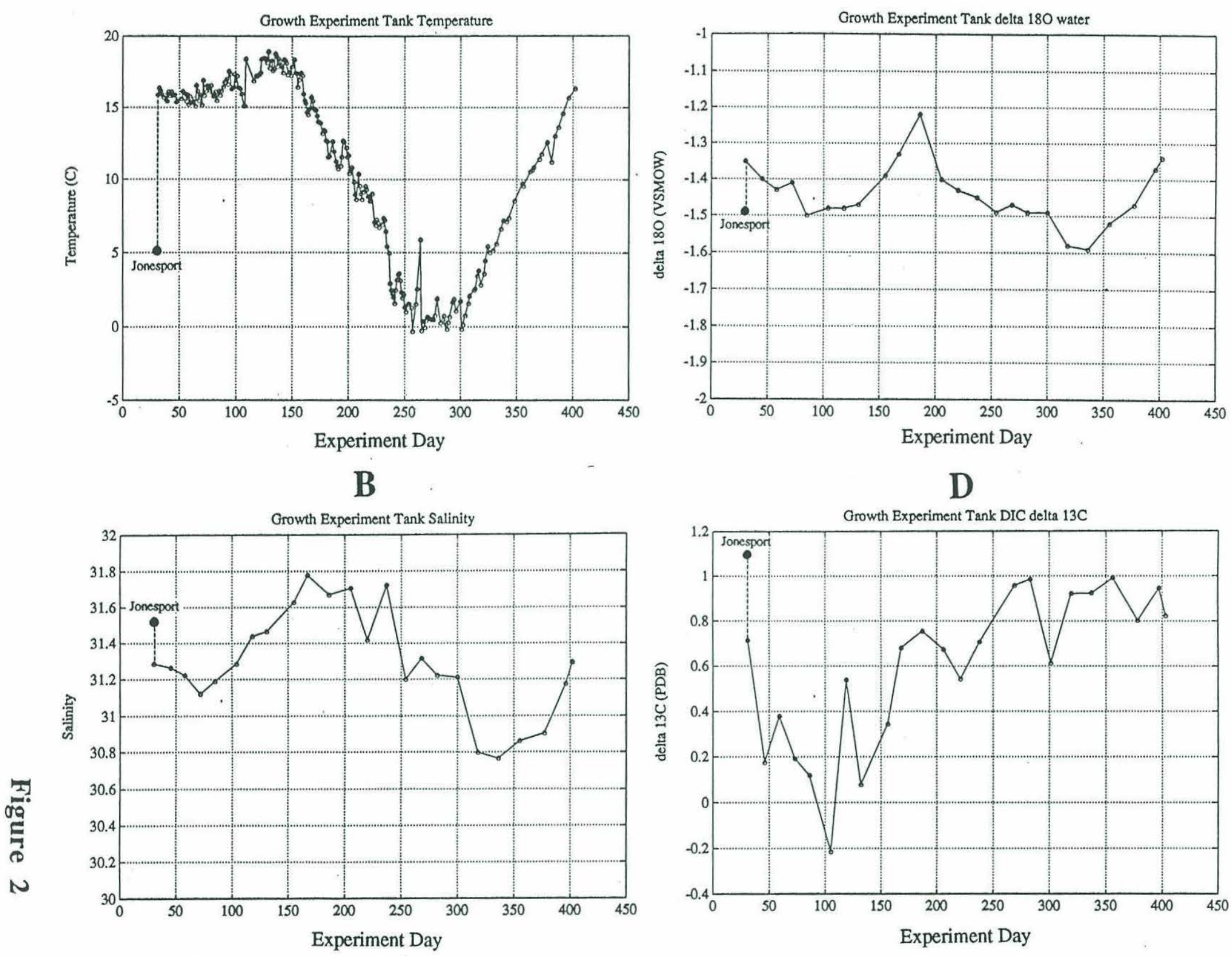

D

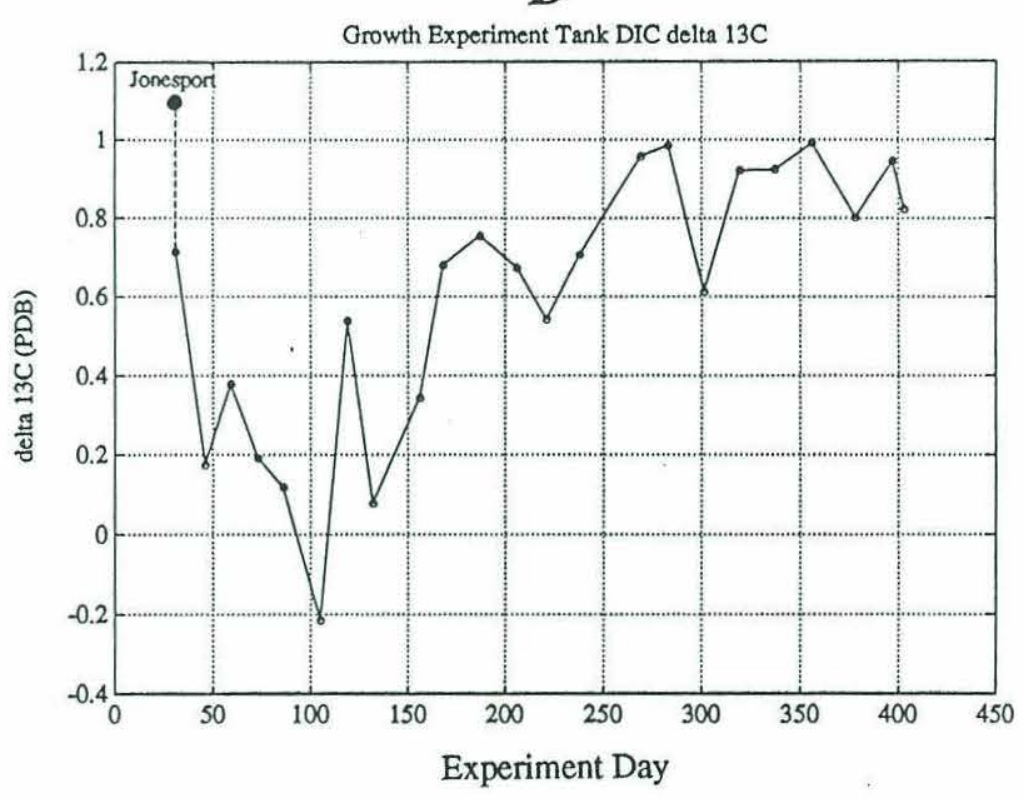


A

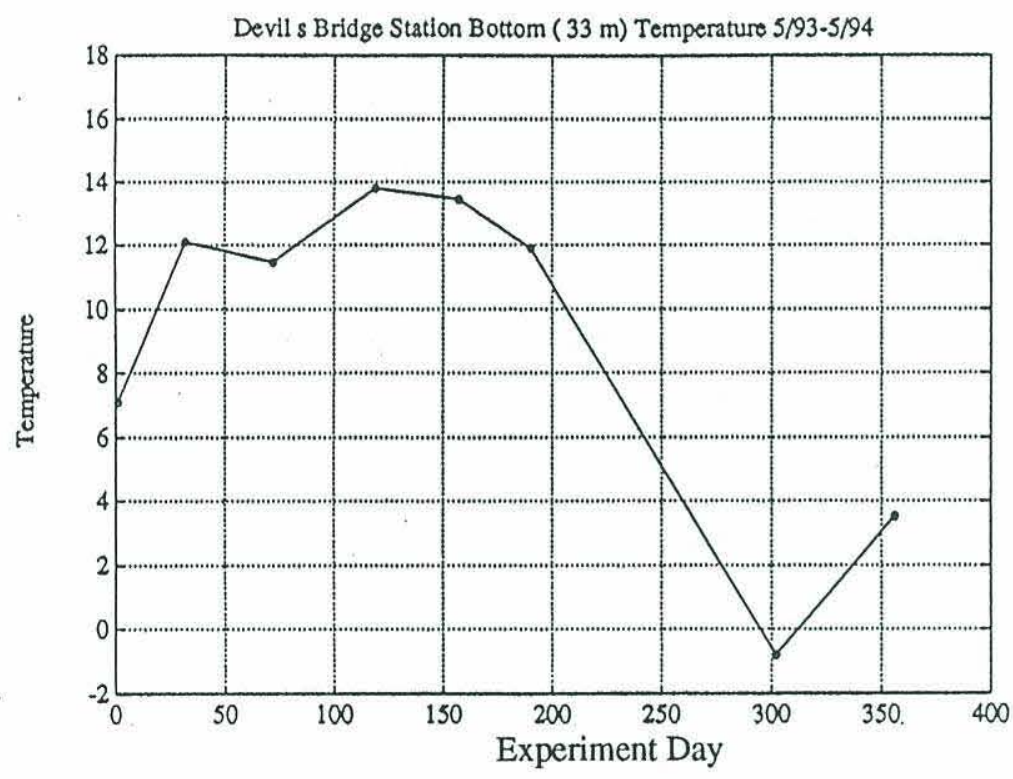

$\vec{\infty}$

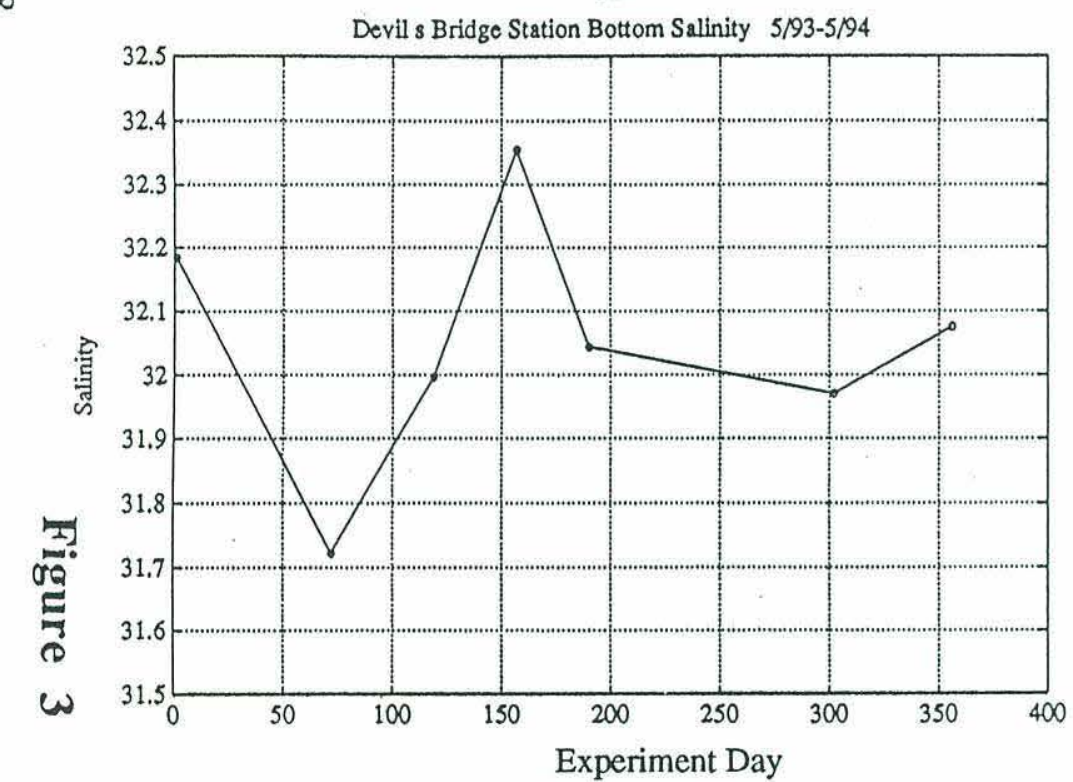

C

Devil s Bridge Station delta 180 5/93-5/94

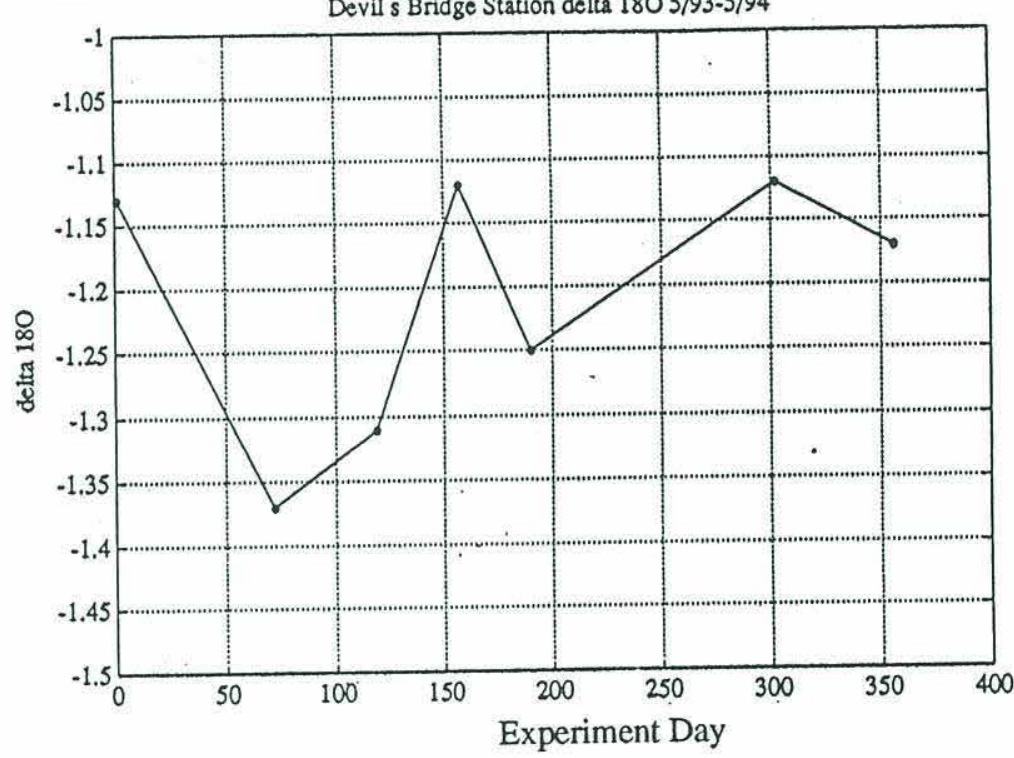

D

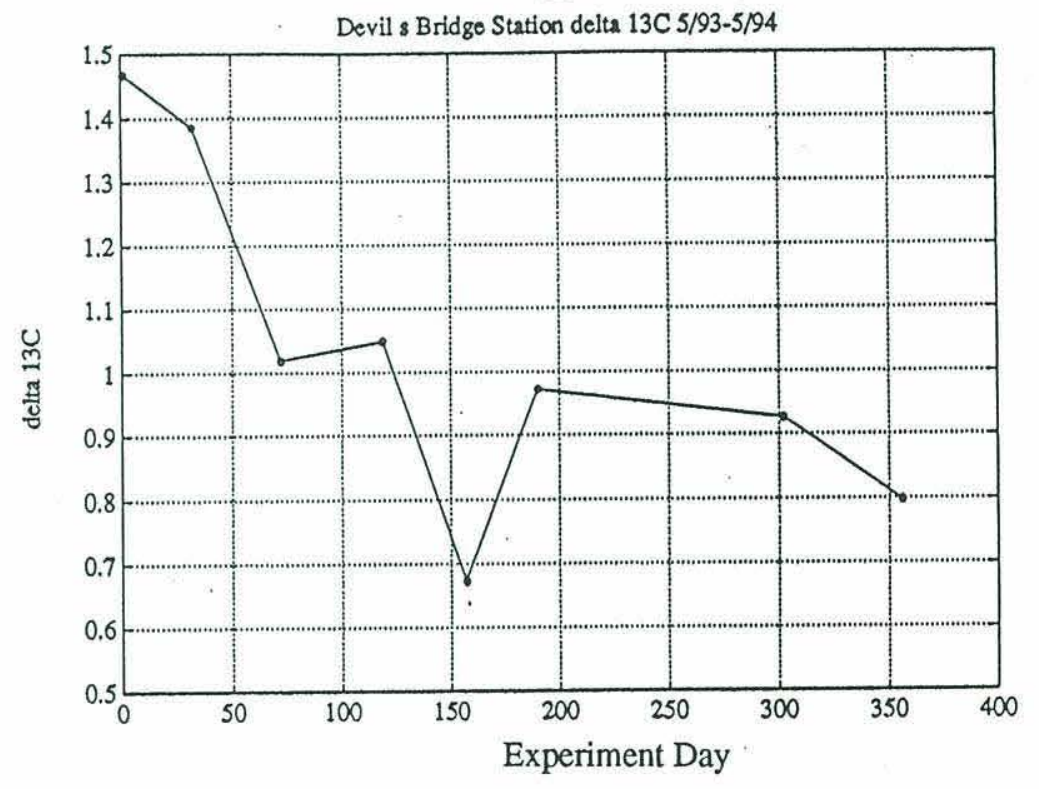



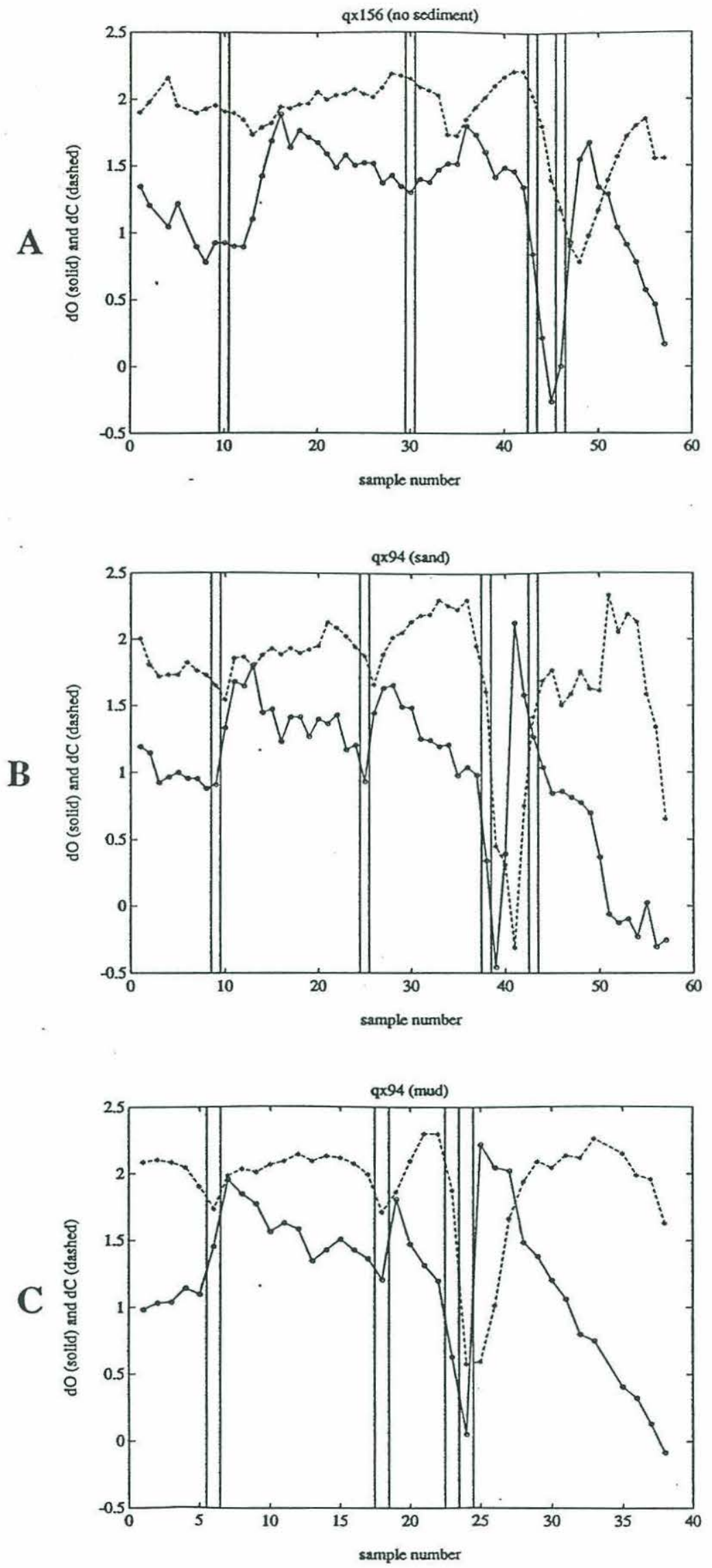

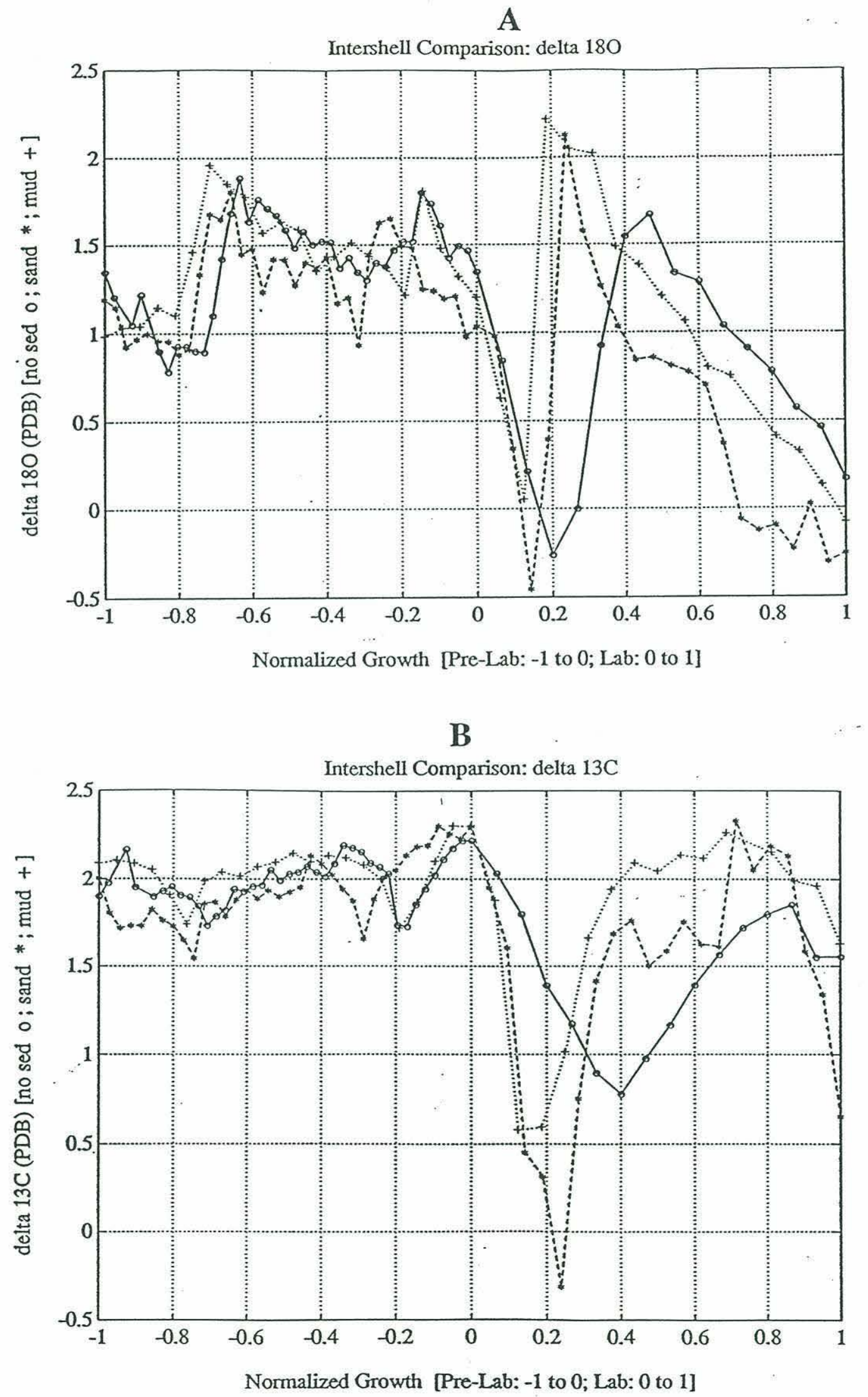

Figure 5 


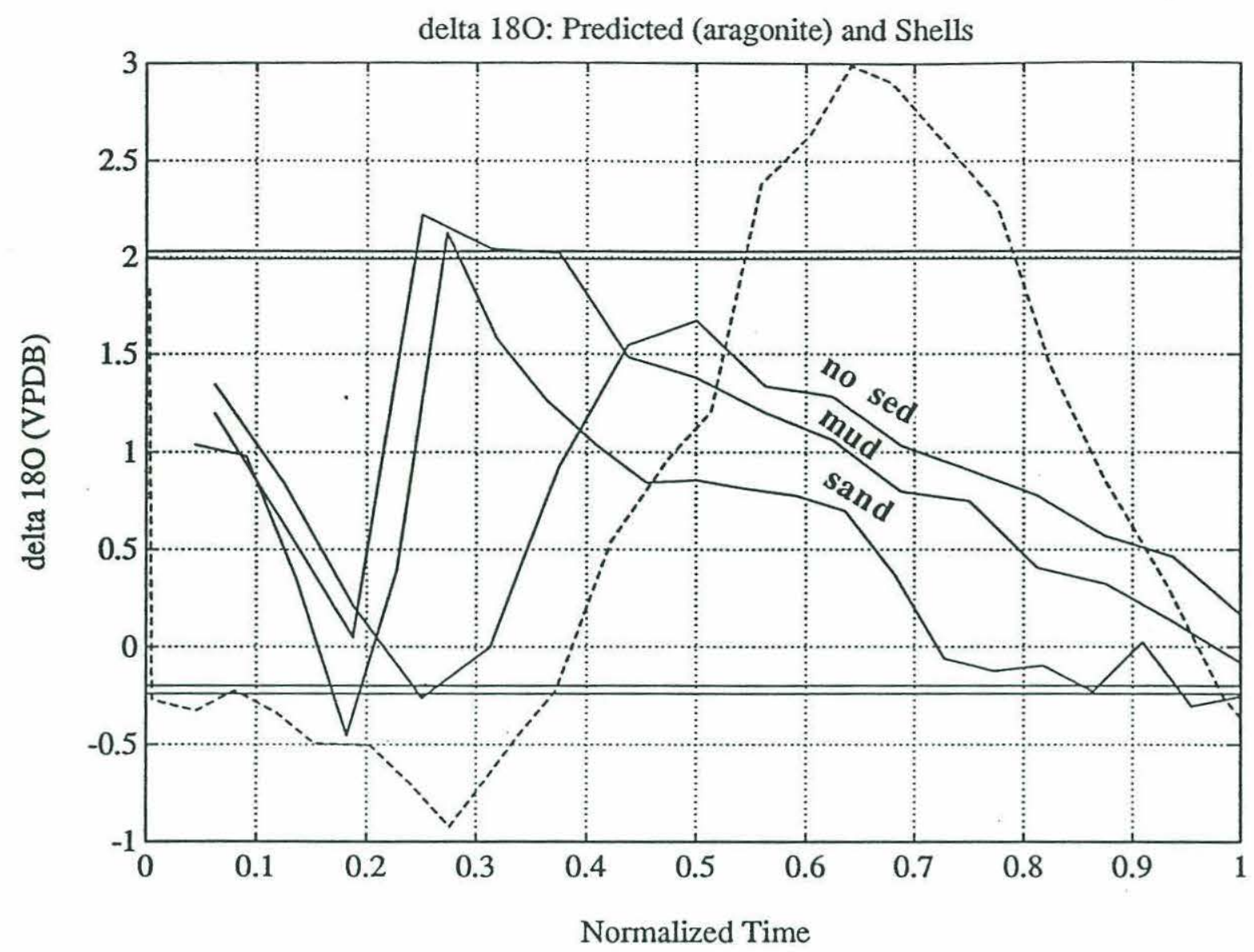

Figure 6 


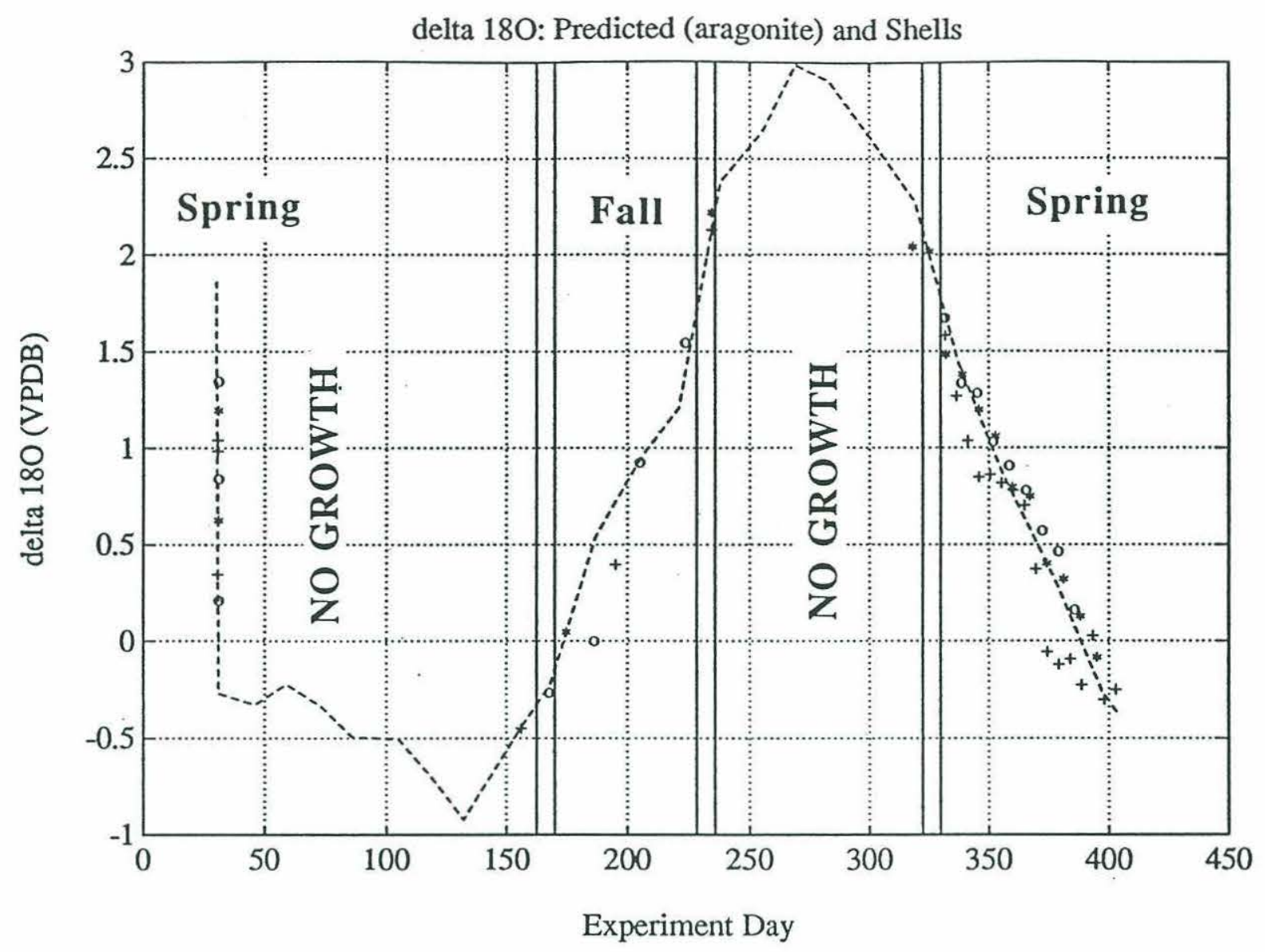

Figure 7 


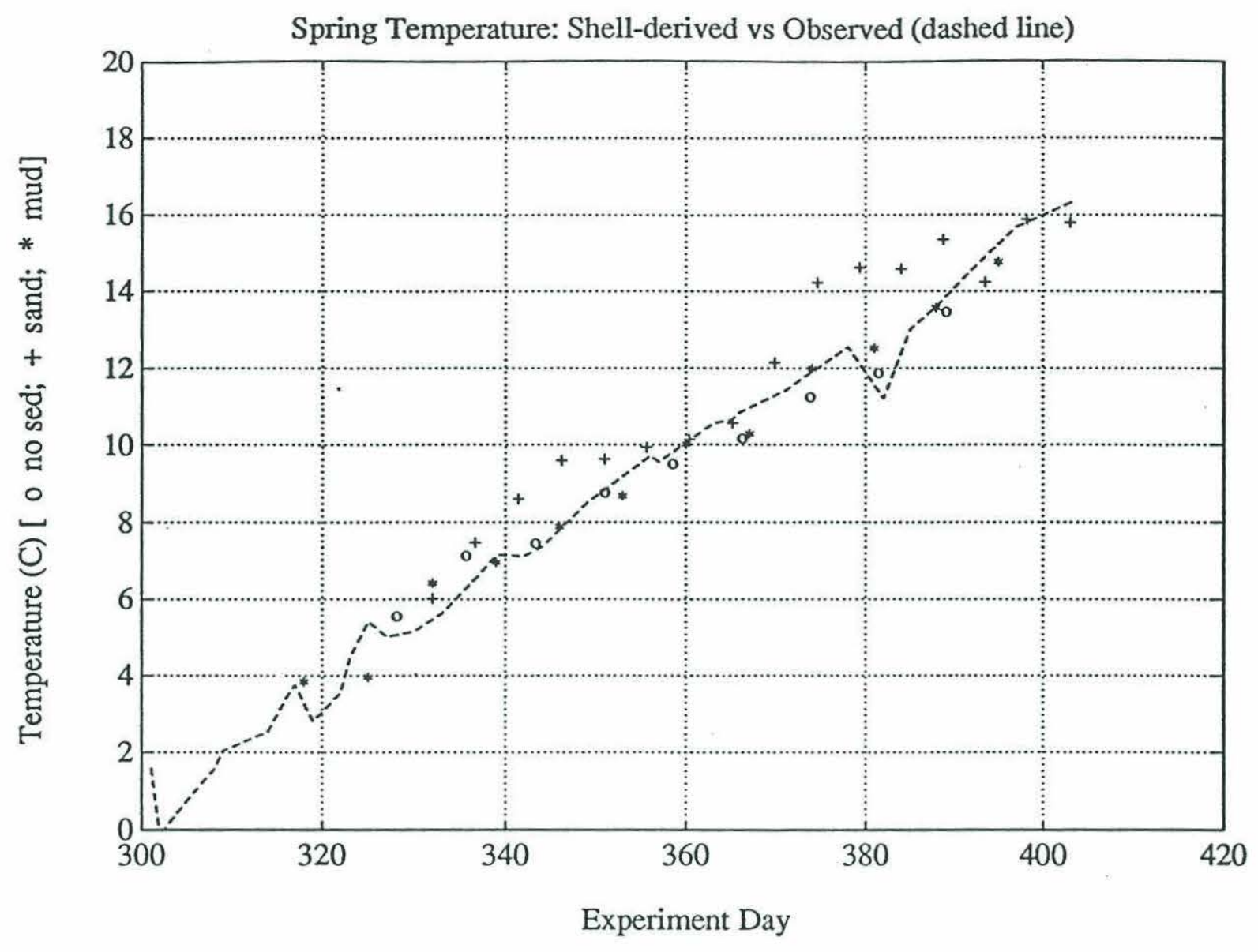

Figure 8 


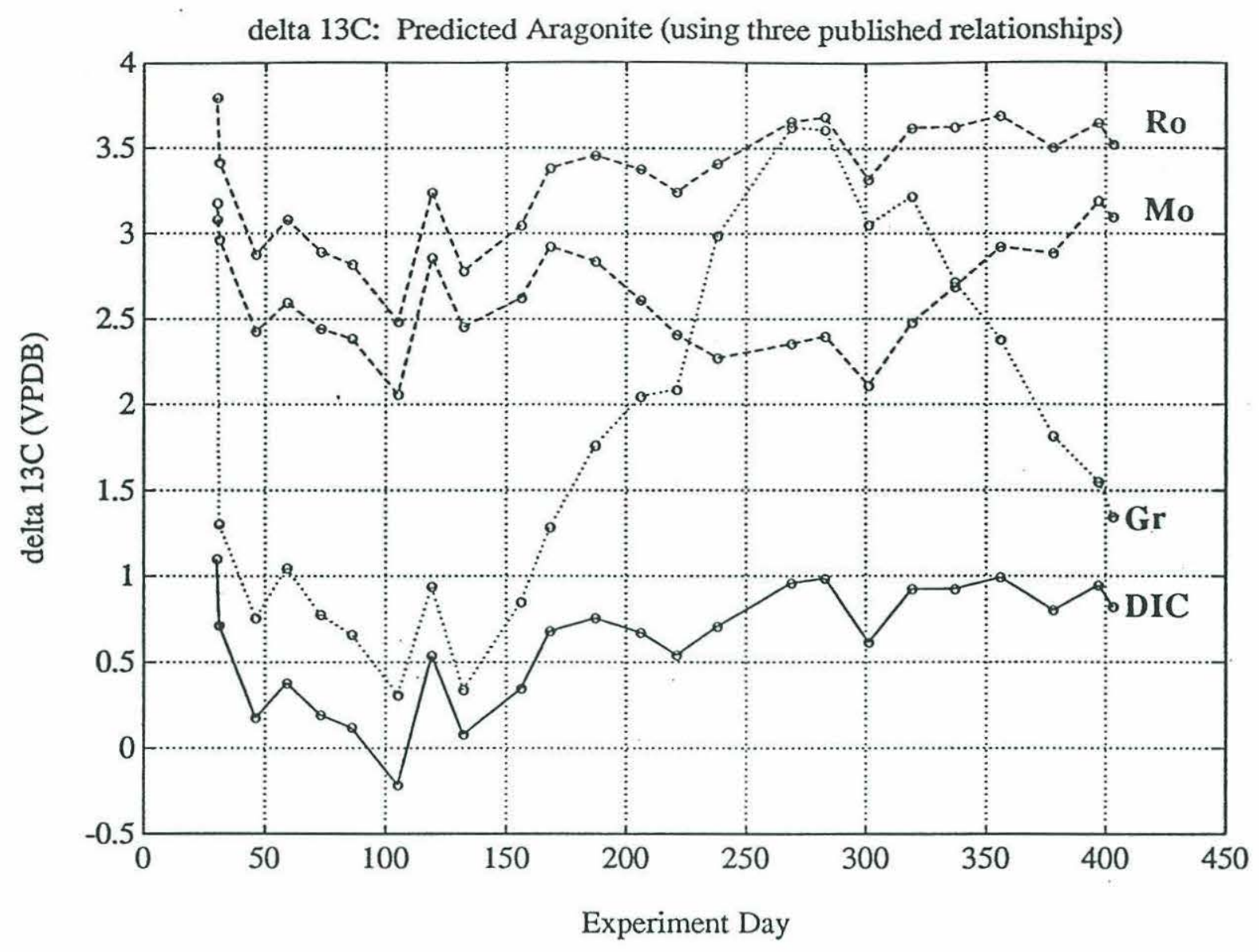

Figure 9 


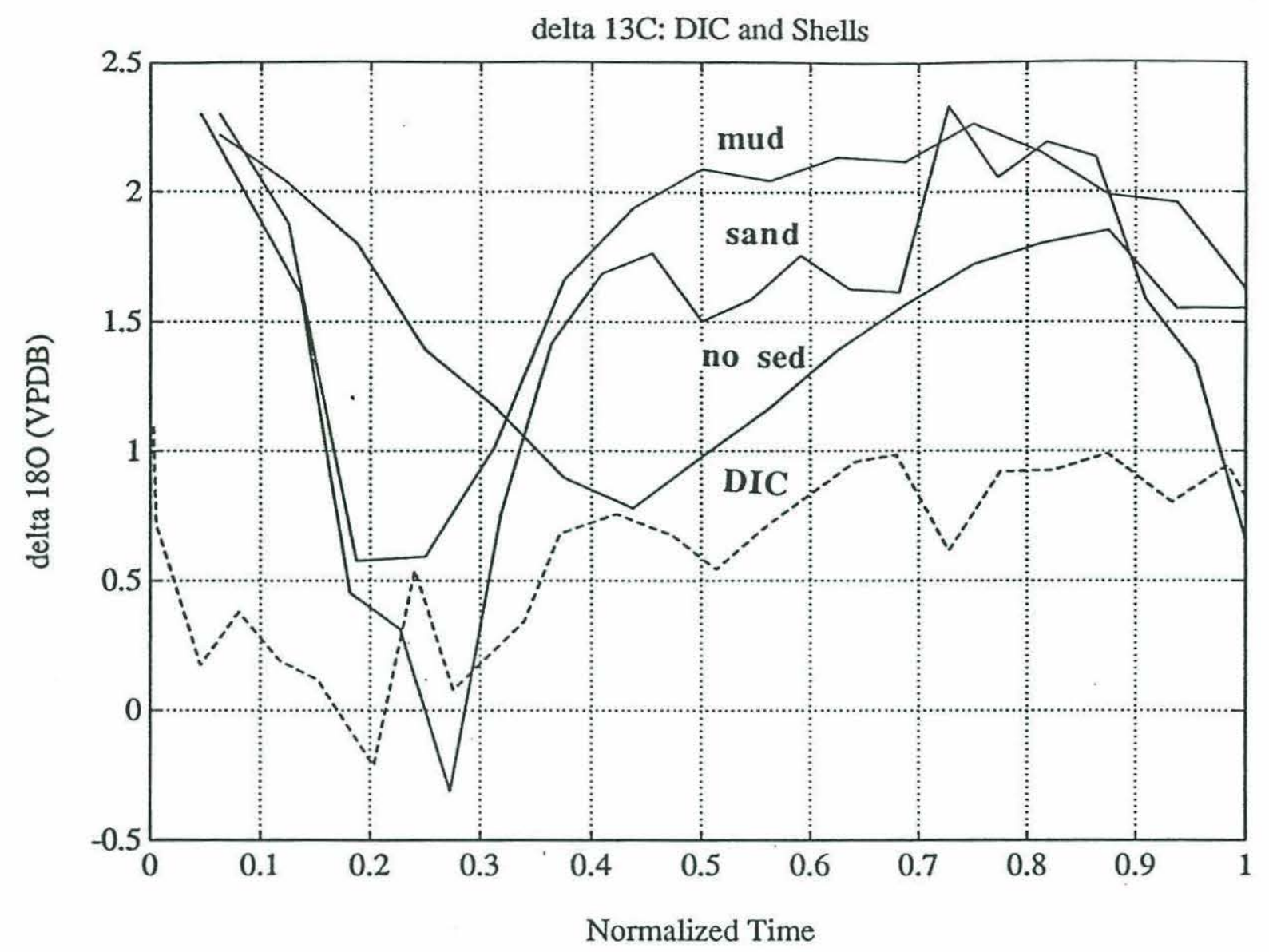

Figure 10 


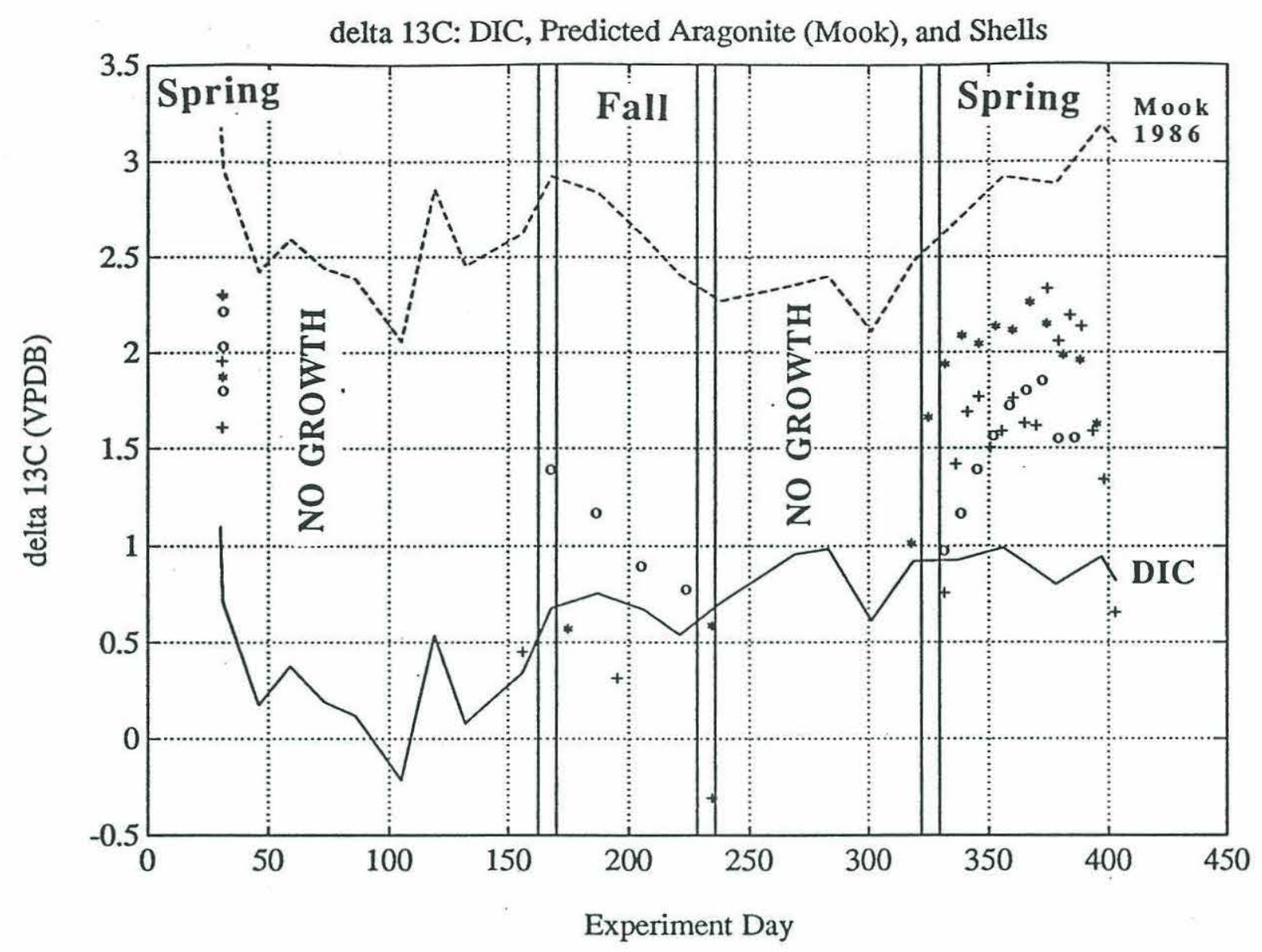

Figure 11 


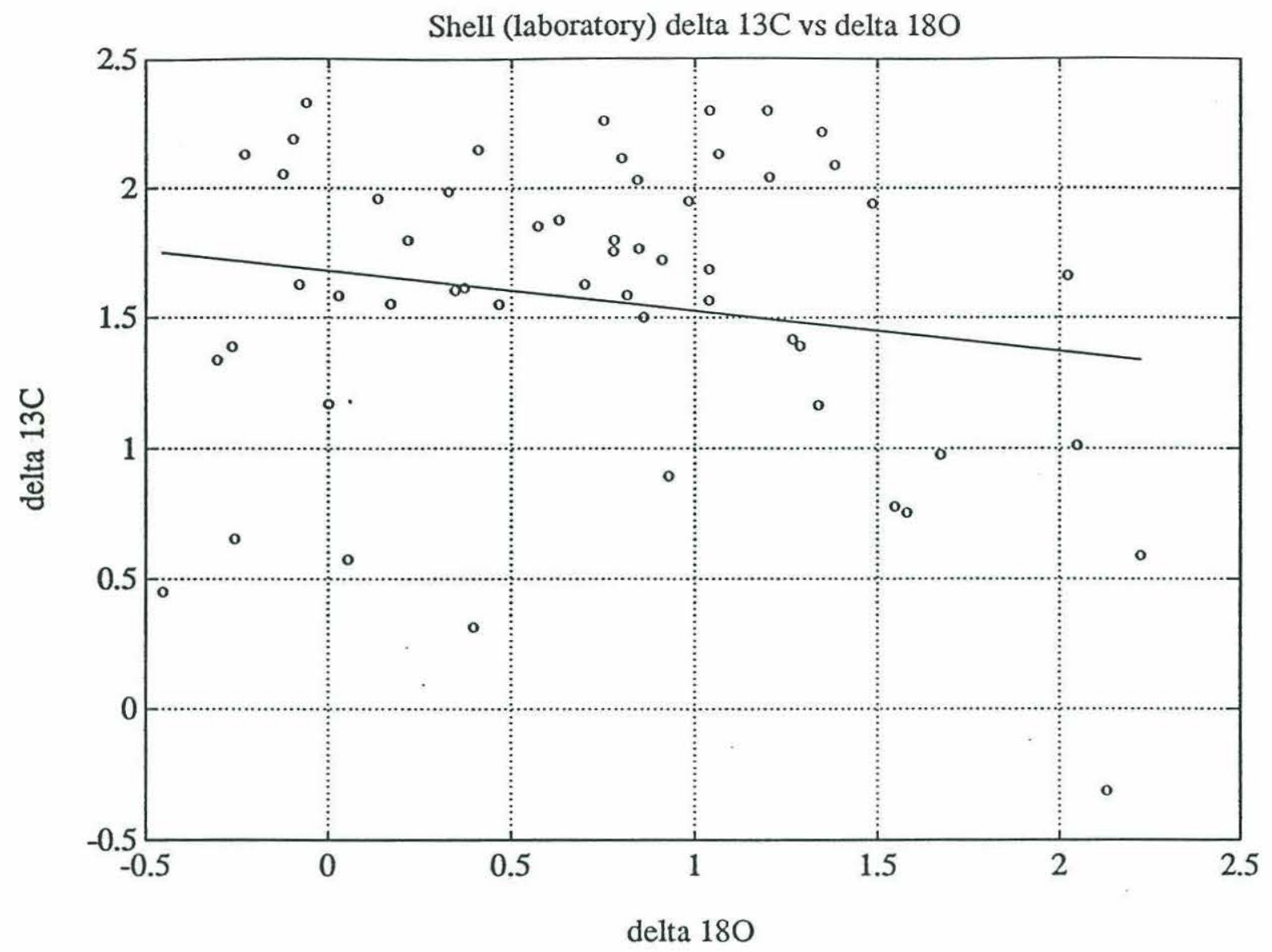

Figure 12 


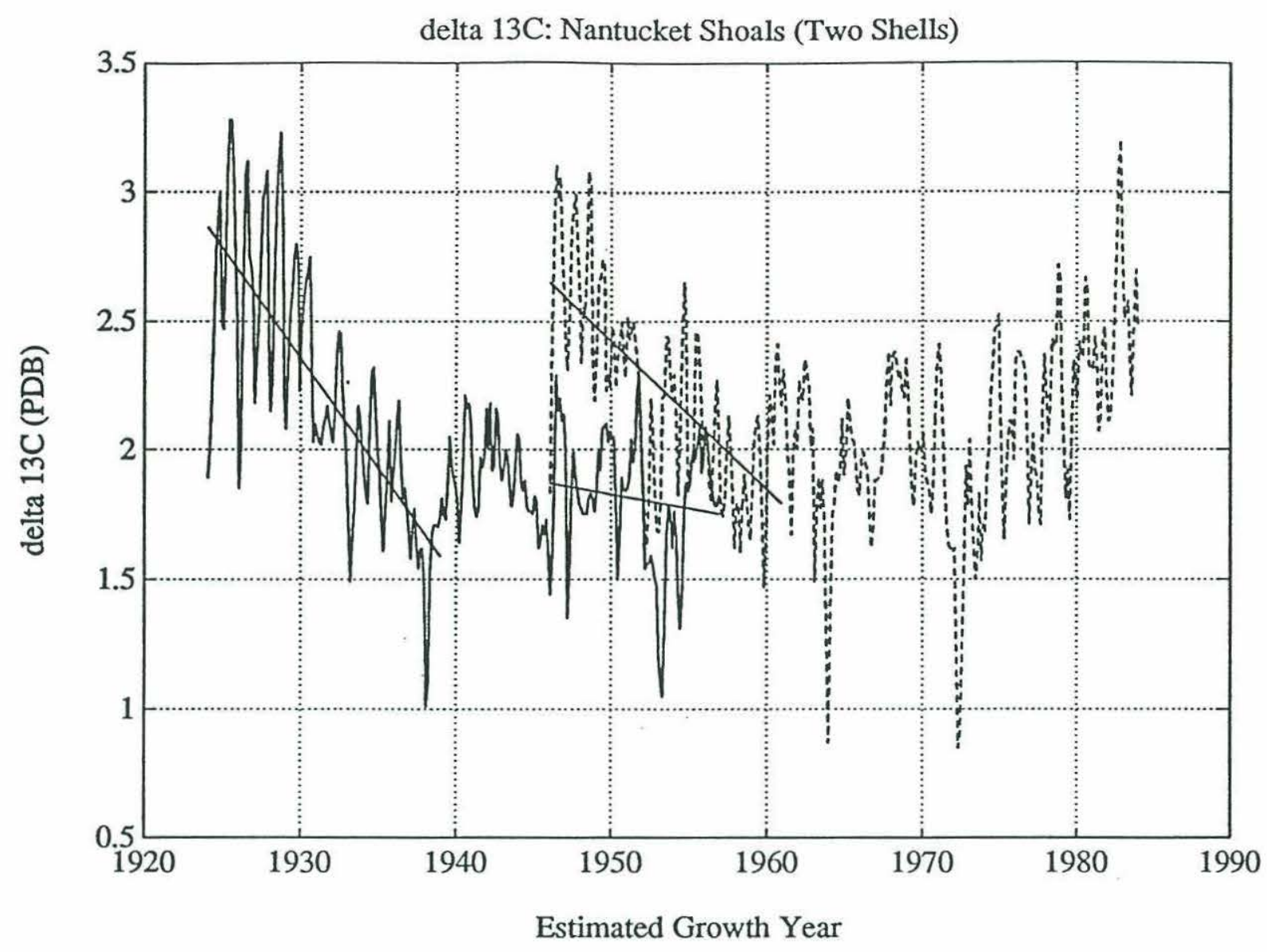




\section{Chapter 4}

\section{Time History of $\Delta^{14} \mathrm{C}$ in the Surface North Atlantic Ocean}

\section{Introduction}

The northern North Atlantic Ocean is thought to play a critical role in the regulation of global climate and ocean circulation [Broecker, 1991][Keigwin and Jones, 1994][Stocker and Broecker, 1994][Dickson and Brown, 1994]. This role is characterized by a large net meridional transport of heat from the lower-latitude ocean to the higherlatitude atmosphere and, as a result of this oceanic heat-loss to the atmosphere, the production of a large share of the world ocean's deep water and the warming of northern Europe's climate [Stommel, 1957][Worthington, 1970][Warren, 1981]. In addition, deepwater production provides a mechanism for sequestering anthropogenic $\mathrm{CO}_{2}$ [Broecker, \& Peng, 1992], and hence the character of this region's circulation provides important constraints on global climate changes associated with the "green-house" effect. In the last four decades, one of the most important techniques used to understand oceanographic processes has been the measurement of ocean radiocarbon $\left(\Delta^{14} \mathrm{C}\right)$. As a time-dependent tracer, $\Delta^{14} \mathrm{C}$ provides oceanographers with a method of determining the structure and rates of the ocean's steady state physical circulation [Broecker, \& Peng, 1982][Toggweiler, Dixon, \& Bryan, 1989a] [Maier-Reimer, \& Bacastow,

1990][Schlosser, et al., 1995] as well as the ocean's steady state absorption of atmospheric carbon dioxide [Revelle and Suess, 1957]. Although confounding steady state applications, nuclear bomb-produced ${ }^{14} \mathrm{C}$ has become a valuable tracer for measuring the ocean's transient uptake of atmospheric $\mathrm{CO}_{2}$, as well as a means of measuring water mass transport in the ocean [Broecker, et al., 1982][Quay, Stuiver, \& Broecker, 1983][Toggweiler, Dixon, \& Bryan, 1989b][Broecker, 1991]. In particular, global and regional ocean 
sampling programs, such as GEOSECS (1970s), TTO (1980s), and WOCE (1990s), have provided snapshots of these tracers' ocean distribution. The temporal evolution of the ocean's bomb- ${ }^{14} \mathrm{C}$ signal has been more difficult to assess owing to the global scope and cost of seawater sampling programs. But since the late 1970s, beginning with Nozaki et al. [Nozaki, Rye, Turekian, \& Dodge, 1978] and Druffel and Linick [Druffel, \& Linick, 1978a], long, high-resolution time-series of surface ocean $\Delta^{14} \mathrm{C}$ have been reconstructed from banded corals. These records have provided important pre-bomb (before 1958) information concerning the ocean's uptake of fossil-fuel produced $\mathrm{CO}_{2}$, as well as postbomb information useful in studying the nature of upper ocean circulation [Toggweiler, Dixon, \& Broecker, 1991] [Druffel, 1989]. However, these time-series have been limited to the warm subtropical oceans, the habitat of fast-growing banded-corals, and there is still a near absence of comparable records for the high-latitude oceans, and a corresponding lack of insight that radiocarbon time-series could provide for the globally important circulation processes operating in these regions.

Only recently has the reconstruction of high-resolution $\Delta^{14} \mathrm{C}$ records for the highlatitude oceans become practical with the introduction of AMS-radiocarbon dating technology [Linick, Damon, Donahue, \& Jull, 1989], which has enabled the analysis of very small samples $(\sim 10 \mathrm{mg})$ from the skeletal remains of cold ocean marine organisms, such as otoliths and the shells of slow-growing, long-lived molluscs. For example, Kalish [1993] employed AMS-dating of fish otoliths to reconstruct a 70-year radiocarbon timehistory for New Zealand $\left(39^{\circ} \mathrm{S}\right)$ coastal waters. Weidman and Jones [1993] used microsampling methods to extract carbonate samples from the shells of the long-lived mollusc Arctica islandica and AMS-analysis to reconstruct a 50-year radiocarbon time history for Georges Bank on the northeastern $\left(41^{\circ} \mathrm{N}\right)$ U.S. continental shelf. Also, Jones and Weidman (in preparation) have similarly obtained a 70-year radiocarbon time-series from a long-lived mollusc collected on South Georgia Island shelf $\left(55^{\circ} \mathrm{S}\right)$ within the Antarctic 
Circumpolar Current. These studies have initiated the application of AMS-dating and micro-sampling methods to obtain cold ocean radiocarbon time-series. This paper builds on our earlier work on Georges Bank, by applying these techniques to obtain a set of radiocarbon time histories for the northeastern North Atlantic Ocean. These records are combined with Druffel's two coral-derived records from Bermuda and Florida [Druffel, 1989] to obtain a more complete picture of the evolution of the ${ }^{14} \mathrm{C}$ signal in the surface North Atlantic Ocean over the last century than has previously been possible.

\section{General circulation of the North Atlantic and the surface $\Delta^{14} \mathrm{C}$ signal:}

The three new shell-derived time-histories presented here are all located in the eastern North Atlantic, while three previously published time histories, represented here, are from the western North Atlantic (Figure 1a). The three eastern North Atlantic shell collection sites are 1) southern North Sea $\left(54^{\circ} 24^{\prime} \mathrm{N}, 6^{\circ} 30^{\prime} \mathrm{E}\right)$ at $37 \mathrm{~m}$ depth, 2) Siglufjordur on the north coast of Iceland $\left(66^{\circ} 10^{\prime} \mathrm{N}, 18^{\circ} 53^{\prime} \mathrm{W}\right)$ at $22 \mathrm{~m}$ depth, and 3) Troms $\varnothing y$ sund, on the northern coast of Norway $\left(69^{\circ} 38^{\prime} \mathrm{N}, 18^{\circ} 57^{\prime} \mathrm{E}\right)$ at $3 \mathrm{~m}$ depth. The three western North Atlantic shell and coral collection sites are 1) Georges Bank $\left(41^{\circ} \mathrm{N}\right.$, $\left.67^{\circ} \mathrm{W}\right)$ at $76 \mathrm{~m}$ depth [Weidman and Jones, 1993], 2) Florida $\left(24^{\circ} \mathrm{N}, 81^{\circ} \mathrm{W}\right)$ at $4 \mathrm{~m}$ depth [Druffel, 1989], and 3) Bermuda $\left(32^{\circ} \mathrm{N}, 65^{\circ} \mathrm{W}\right)$ at $\sim 10 \mathrm{~m}$ depth [Druffel, 1989]. These coastal and shelf locations are adjacent to large-scale features of the North Atlantic's general surface circulation that will be described next, in broad terms, to provide a general oceanographic context for the radiocarbon time histories.

Although many quantitative aspects are still uncertain, the overall qualitative view of the North Atlantic's surface circulation is not very different from that proposed by Sverdrup, et al. [Sverdrup, Johnsen, \& Fleming, 1942] (Figure 1a). In this simple view, two coupled basin-wide systems dominate the surface circulation in the North Atlantic described by an anti-cyclonic subtropical gyre and a cyclonic subpolar gyre [McCartney 
and Talley, 1982][Schmitz, \& McCartney, 1993]. In this paper, the term "subpolar gyre" refers to the greater subpolar gyre, in the manner of Dickson, et al. [1988] and Ellet [1993], which includes the Nordic Seas (e.g., the path of the Great Salinity Anomaly), as opposed to the lesser subpolar gyre, which refers only to the cyclonic recirculating flows of the Labrador Sea and Irminger Sea. The two systems are connected by a continuous northward surface flow along the western side of the subtropical gyre (Gulf Stream) and the south side of the subpolar gyre (North Atlantic Current). This northward surface flow is thought to largely balance the sub-surface southward flow of North Atlantic Deep Water (NADW), and together constitute the principal features of the North Atlantic's thermohaline circulation cell. The two North Atlantic surface gyres also can be described roughly by their mean temperature fields at $150 \mathrm{~m}$ depth [Robinson, Bauer, \& Schroeder, 1979] (Figure 1b). The subtropical gyre region is defined by a zone with temperatures above $15^{\circ} \mathrm{C}$, and the subpolar gyre region is defined by a zone with temperatures below $10^{\circ} \mathrm{C}$. The zone between $10^{\circ} \mathrm{C}$ and $15^{\circ} \mathrm{C}$, which incorporates much of the central eastern North Atlantic, has been described as a transition area between subpolar and subtropical waters [Krauss, 1986]. Another, subdivision can be made by separating the subpolar region into an eastern section with warmer temperatures between $5^{\circ}-10^{\circ} \mathrm{C}$ and a western section with colder temperatures below $5^{\circ} \mathrm{C}$. The eastern section includes the poleward flowing Atlantic waters of the Irminger Current on its west side and the North Atlantic Current and its extension the Norwegian Current on its east side. The western section includes the southward flowing polar waters of the East Greenland Current, the Arctic waters of the Greenland Sea, and the Labrador Sea. Lastly, due to strong seasonal cooling and increased cyclone frequency, the higher-latitude regions, especially in the west, experience much greater convective mixing than the lower-latitudes, expressed by a general deepening of the winter mixed-layer from south to north [Robinson, et al., 1979] (Figure 1c). 
Broecker and Peng [1982] presented a latitudinal profile of surface $\Delta^{14} \mathrm{C}$ for the Atlantic Ocean from GEOSECS and pre-bomb ocean water data (Chapter 1, Figure 1). The salient features of this profile are higher $\Delta^{14} \mathrm{C}$ in the mid-latitudes and lower $\Delta^{14} \mathrm{C}$ in the equatorial regions and the high-latitudes. The cause of the latitudinal $\Delta^{14} \mathrm{C}$ variations are ascribed to ocean circulation processes, such as upwelling in the equatorial ocean which brings deep (low $\Delta^{14} \mathrm{C}$ ) waters to the surface, subtropical convergence of surface (high $\Delta^{14} \mathrm{C}$ ) waters, which have had a longer time to equilibrate with the atmosphere, and deep convective mixing in the high-latitudes which overturns the surface and deep layers and thus lowers the surface $\Delta^{14} \mathrm{C}$.

\section{Coastal environments and $\Delta^{14} \mathrm{C}$ signal:}

Within this ocean circulation framework, each of the six sites is also located within a shelf environment, and so its $\Delta^{14} \mathrm{C}$ signal may differ from that of the adjacent ocean. The evolution of the surface ocean's $\Delta^{14} \mathrm{C}$ concentration at any one location is a function of its initial value, the difference between the surface ocean and atmosphere $\Delta^{14} \mathrm{C}$ concentrations, the $\mathrm{CO}_{2}$ air-sea surface gas transfer rate (usually treated as a function of the regional mean wind speed), mixed-layer depth, vertical mixing/exchange rates with deeper ocean layers, and horizontal advection. These parameters have important ramifications for the $\Delta^{14} \mathrm{C}$ signals of shelf waters. For example, mixed-layer depth is limited to the shelf depth, vertical exchange with deeper layers cannot occur, and the longer ocean water is isolated on the shelf, the more it will equilibrate with the atmosphere.

The German Bight region of the southern North Sea is primarily (90-95\%) supplied by waters from the English Channel [Reid, Taylor, \& Stephens, 1988], which itself is fed by surface waters from the central eastern North Atlantic [Pingree and Le Cann, 1989][Pingree, 1993]. The shelf pathway for waters from the English Channel to the German Bight site is shallow $(<50 \mathrm{~m})$, and waters at the North Sea site have a residence 
time estimated to be $~ 4-6$ months from the Dover Straits, as well as additional time in the shelf regions (English Channel and Celtic and Armorican Shelfs) to the west [Reid, et al., 1988]. These factors suggest a strong shelf influence on the North Sea's $\Delta^{14} \mathrm{C}$ signal relative to that of its central eastern North Atlantic source.

Iceland is near the center of the greater subpolar gyre with southward flowing Arctic waters to its north and west and northward flowing Atlantic waters to its south and east. The northern Icelandic shelf waters are generally supplied by Atlantic water of Irminger Current origin (the north Icelandic Irminger Current), however considerable mixing with waters of Arctic origin occurs during the winter [Stefansson, 1962][Johannessen, 1986]. In addition, the Atlantic versus Arctic component can vary widely from year to year as the result of climatic variations [Stefansson, \& Olafsson, 1991]. Although, the Siglufjordur site is relatively shallow $(\sim 20 \mathrm{~m})$, it is on a narrow part of the shelf adjacent $(\sim 10 \mathrm{~km})$ to a deep region (Skagafjardar-Djup) and its $\Delta^{14} \mathrm{C}$ signal might therefore show only slight modification from that of the adjacent ocean.

The Tromsøysund, Norway site is adjacent to the offshore Norwegian Current which is the northern extension of the eastern limb of the subpolar gyre as we have defined it. However, this site is within a complex fjord system ( $\sim 50 \mathrm{~km}$ inland) fed by shelf waters which are part of the Norwegian Coastal Current, a relatively fresh current extending northward from the Skaggerat at the mouth of the Baltic Sea to the Barent's Sea [Johannessen, 1986][Gade, 1986]. In the northern Norwegian shelf region considerable mixing occurs between the offshore (Norwegian Current) and the inshore Norwegian Coastal Current waters [Rey, 1981]. Despite these complexities, tidal currents within Troms $\emptyset$ sund are strong and the hydrography (salinity and temperature) shows strong continuity and little modification from the shelf waters of the adjacent western coast [Normann, 1992]. These observations imply that the Tromsøysund $\Delta^{14} \mathrm{C}$ record probably 
reflects that of the shelf waters with little modification, but the influence of the coastal current (with its Baltic and runoff sources) may cause it to vary from that of the adjacent Norwegian Sea.

The Bermuda and Florida sites are both within the western region of the North Atlantic encompassed by the subtropical gyre. Druffel [1989] makes the reasonable assumption that the shallow waters of Bermuda's reef platform ( $15 \mathrm{~km}$ at greatest extant) exchange rapidly with the surrounding Sargasso Sea surface. Thus, Bermuda's coralderived $\Delta^{14} \mathrm{C}$ signal is not expected to differ significantly from the adjacent oceanic $\Delta^{14} \mathrm{C}$ signal, and should be representative of the mid-subtropical gyre region. The Florida coral was also obtained from a shallow reef platform and Druffel and Linick [1978] noted slightly lower salinity here than for the offshore Gulf Stream, and allowed for some slight Florida Bay influence. However, this site is located on a very narrow part of the shelf and only $\sim 15 \mathrm{~km}$ from the center line of the Florida Current so that it is reasonable to assume, as Druffel [1989] did, that the Florida coral $\Delta^{14} \mathrm{C}$ signal is essentially the same as that of the surface Gulf Stream.

The upstream source region for shelf water on Georges Bank is thought to be the Labrador Sea [Chapman, \& Beardsley, 1989]. From estimates of the mean alongshelf velocity $(\sim 10 \mathrm{~cm} / \mathrm{s})$ the shelf water residence time (relative to the Labrador Sea) for water on Georges Bank is estimated to be about 1 year. Although the site where the shell was collected is relatively deep $(76 \mathrm{~m})$ and overlying waters in this region of Georges Bank are stratified during the warmer months of the year, complete vertical mixing occurs during the colder months of the year. It was argued in Weidman and Jones [1993] (Chapter 1) that the ${ }^{14} \mathrm{C}$ signal on Georges Bank is modified relative to the Labrador Sea $\Delta^{14} \mathrm{C}$ signal due to enhanced atmospheric equilibration of the shelf waters. 


\section{Methods}

All shells used in this study were obtained from live-captured specimens collected from dredge hauls. Shell samples were prepared by slicing each shell radially from the umbo through the ventral edge along the axis of maximum growth (see Chapter 1, Figure

3) using a slow-speed petrographic saw with twin diamond-edged blades. A shell slice $\sim 2$ $\mathrm{mm}$ thick was obtained this way and then epoxied onto a petrographic slide. The slide was mounted on an automated 3-axis stage and the outer shell layer of the slice was subsectioned into samples comprised of one or more annual bands with an ultra-thin $(150 \mu \mathrm{m})$ diamond saw. Care was taken to extract only carbonate from the outer shell layer, and not from the adjacent inner nacreous layer which represents material deposited at a later time. Also, the periostracum (or outer organic layer) was removed, along with part of the outer prismatic layer just below the periostracum, in order to eliminate inclusion of surface contaminants or material affected by early diagenesis. The number of annual bands comprising a sample was constrained only by the minimum amount of aragonite required for a single AMS radiocarbon analysis ( $10 \mathrm{mg})$. The shell of any one specimen contains a continuous record for the period of its life-span, however, since shell growth slows as the bivalve ages, sampling-resolution, and likewise temporal-resolution, is reduced in the later (more recent) stages of shell growth. Sometimes to overcome this handicap, samples from the inner, faster growth intervals from two or more shells of different ages were analyzed to produce a higher-temporal resolution record than otherwise would be obtainable from a single shell. Samples weighed from $\sim 10-80 \mathrm{mg}$ and integrated from 1 to 10 years (Table 1).

Samples were prepared for AMS analysis by first etching them in $10 \% \mathrm{HCl}$ for 30 seconds to remove surface contaminants, followed by conversion to $\mathrm{CO}_{2}$ in anhydrous phosphoric acid at $60^{\circ} \mathrm{C}$ (overnight), and finally conversion to graphite using a hydrogen 
reduction and iron catalytic process [Gagnon and Jones, 1993]. Graphite targets were analyzed at the National Ocean Sciences AMS Facility at Woods Hole Oceanographic Institution, Woods Hole, Massachusetts. Analytical $\Delta^{14} \mathrm{C}$ error for these samples ranged from $\pm 3.0 \%$ o to $\pm 13.5 \%$ with a mean of $\pm 5.7 \%$ o. All $\Delta^{14} \mathrm{C}$ data are age-corrected to 1950 and normalized to $\delta^{13} \mathrm{C}$ (PDB) value of $-25 \%$, according to methods outlined by Stuiver and Pollach [1977]. To correct for fractionation, $\delta^{13} \mathrm{C}$ values were obtained either from sub-samples of the same material analyzed for $\Delta^{14} \mathrm{C}$, interpolation with adjacent samples from within the same shell, or the mean $\delta^{13} \mathrm{C}$ of other $A$. islandica shells in the region. $A$. islandica shell $\delta^{13} \mathrm{C}$ values averaged $\sim+2 \%$.

\section{Results}

The time histories for the eastern North Atlantic (the new results) are described first, but all six North Atlantic records (from 1940 on) are shown in Figure 2(a-f). Shellderived data are also shown in Table 2(a-d). Coral-derived data are tabulated in Druffel [1989].

\section{Eastern Atlantic $\Delta^{\mathbf{1 4}} \mathrm{C}$ Time Histories (New Results) North Sea:}

The German Bight $\Delta^{14} \mathrm{C}$ record spans from 1948 to 1990 (Figure 2a, Table 1a) and is a composite of two overlapping shell records. This record has a minimum value of $-83.3 \%$ in 1954 , and a maximum value of $+239.3 \%$ in $1967-1968$, for an amplitude of $323 \%$. The pre-bomb (before 1958) data have a mean value of $-65.8 \%$, and show a large depletion of $\sim 33 \%$ o between 1948 and 1954. The first definite bomb influence (significant rise above previous levels) in the shell record occurred in 1959. The steepest signal increase occurred between the years 1961 and 1966. The North Sea $\Delta{ }^{14} \mathrm{C}$ signal remained 
near its maximum value for about 7 years until 1974-1975, and afterwards decayed by $\sim 100 \%$ o until the early 1980 s, but has changed little since then.

\section{Iceland:}

The Siglufjordur $\Delta^{14} \mathrm{C}$ time-history spans from 1872 to 1991 (Figure $2 \mathrm{~b}$ and Table $1 \mathrm{~b}$ ), is composed of samples from three shells, and is the longest shell-derived $\Delta^{14} \mathrm{C}$ record obtained thus far. This record has a minimum value of $-59.5 \%$ in $1912-1921$, and a maximum value of $+56.9 \%$ in $1970-1971$, for an amplitude of $116 \%$ o. The pre-bomb (before 1958) data have a mean value of $-55.8 \%$, and show no significant trend. The first definite bomb influence in the shell record occurred in 1960. The steepest signal increase occurred between the years 1960 and 1964. After the peak in 1970-1971, the signal dropped to a local minimum in the mid-1970s, and rose to a second local maximum in the late 1970s. The signal declined slightly in the early 1980s and changed very little for the rest of the decade.

\section{Norway:}

The Tromsøysund $\Delta^{14} \mathrm{C}$ time-history spans from 1940 to 1993 (Figure 2c and Table 1c) and is from a single shell. This record has a minimum value of $-82.3 \%$ in $1956-$ 1957 , and a maximum value of $+132.2 \%$ o in $1969-1970$, for an amplitude of $215 \%$. The pre-bomb (before 1958) data have a mean value of $-60.9 \%$, and show a large depletion of $\sim 36 \%$ o between 1940 and 1956-1957. The first definite bomb influence in the shell record occurred in 1959-1960. The steepest signal increase occurred between the years 1957 and 1970. After the peak, the signal dropped sharply in the mid-1970s, but rose again to a second local maximum in the later 1970s. Between 1977 and 1988 the signal decayed by $\sim 60 \%$, but has changed little since 1988 . 


\section{Western North Atlantic $\Delta^{\mathbf{1 4}} \mathrm{C}$ Time Histories (Previously Published)}

\section{Bermuda:}

Druffel's [1989] coral-derived Bermuda $\Delta{ }^{14} \mathrm{C}$ time history spans from $1950-1983$ (Figure 2d). The Bermuda coral record has a minimum value of $-54.8 \%$ in 1951 , and a maximum value of $+159.2 \%$ in 1977 , for an amplitude of $214 \%$. The pre-bomb (before 1958) data have a mean value of $-46.7 \%$, but this record does not extend far enough back to calculate a pre-bomb trend. However, Nozaki, et al. [1978] showed a depletion of $25 \%$ o between 1900 to 1950 from their coral-derived Bermuda record. The first definite bomb influence appears in the coral record in 1959. The steepest signal increase occurs between the years 1962 and 1964. Though the peak value occurs in 1977, the bomb-signal also shows an earlier local maximum of almost equal magnitude $(+157.6 \%$ ) in 1973 , and otherwise remains within $\sim 10 \%$ of its maximum value for the decade from 1971 to 1981 . The signal drops sharply in the early 1980s and the record ends in 1983, so no comparison can be made with the shell-derived records for the last decade.

\section{Florida:}

Druffel's [1989] coral-derived Florida $\Delta^{14} \mathrm{C}$ time history spans from $1951-1983$ (Figure 2e). The Florida coral record has a minimum value of $-66.0 \%$ in 1952 , and a maximum value of $+156.0 \%$ in 1970 , for an amplitude of $222 \%$. The pre-bomb (before 1958) data have a mean value of $-58.9 \%$. This particular record also does not extend far enough back to calculate a pre-bomb trend, but Druffel and Linick [1978] published a longer record from this same site which showed a depletion of $~ 12 \%$ between 1900 and 1955. The first definite bomb influence occurred in 1958, and the steepest signal increase occurred between 1962 and 1965. The bomb signal remained near its maximum value for about 6 years, then dropped sharply in 1976, but changed little until 1983 when it dropped sharply again. 


\section{Georges Bank:}

The Georges Bank $\Delta^{14} \mathrm{C}$ time-history spans from 1939 to 1990 (Figure $2 \mathrm{f}$ and Table 1d) and is from a single shell. This record has a minimum value of $-74.6 \%$ in $1951-$ 1952 , and a maximum value of $+77.0 \%$ in $1973-1975$, for an amplitude of $152 \%$. The pre-bomb (before 1958) data have a mean value of $-67.2 \%$, and show a depletion of 13\%o between 1939 and 1951-1952. The first definite bomb influence in the shell record occurred in 1959-1960. The steepest signal increase occurred between 1960 and 1965 . The signal dropped off sharply after 1973-1975, but remained nearly constant throughout the 1980s.

\section{Discussion}

\section{North Atlantic Pre-Bomb $\Delta^{\mathbf{1 4}} \mathrm{C}$}

\section{Time History Comparison:}

Table 2 contains a summary of important parameters for each of the six $\Delta^{14} \mathrm{C}$ timehistories. Pre-bomb $(<1958)$ values range from $-83 \%$ o to $-45 \%$, and average $-58 \%$. Norway and North Sea sites have unusually low minima $<-80 \%$ in the mid-1950s, which may be anomalous or represent unusual conditions (and will be discussed in a later section), and so the pre-bomb data for the period just from 1940 to 1951 ( 1950) are also compared in Table 2. Bermuda and Georges Bank have the highest and lowest pre-bomb ( 1950) values, respectively. This contrast is consistent with latitudinal position (see

Chapter 1, Figure 1), Bermuda being in a region of low vertical exchange and converging surface flows, and Georges Bank having its source in the Labrador Sea where deep convective mixing occurs. The Florida pre-bomb $(\sim 1950)$ value is intermediate between Bermuda and Georges Bank. Druffel [1989] has explained this depletion in the Florida prebomb signal relative to Bermuda as evidence of an equatorial (upwelled) component in the 
Florida Current. The eastern North Atlantic ( 1950) pre-bomb mean values (Norway, Iceland, and the North Sea) are all approximately the same -55\%o, showing less regional contrast than western North Atlantic sites. Also, despite their higher-latitude location these sites are more enriched than the Georges Bank region.

\section{Comparison with other pre-bomb $\Delta^{14} \mathrm{C}$ measurements:}

Pre-bomb ocean water $\Delta^{14} \mathrm{C}$ data for the North Atlantic were obtained by Broecker, et al. [Broecker, Gerard, Ewing, \& Heezen, 1960] (see Chapter 1, Figure 1) in the mid1950s and their results show a North Atlantic mean surface water $\Delta^{14} \mathrm{C}$ value of $-49 \%$ $(\mathrm{n}=18)$, ranging from a high of $-33 \%$ to a low of $-65 \%$. While that study noted no significant relationship between North Atlantic surface radiocarbon concentrations and specific hydrographic features, their sampling in the North Atlantic was limited to the subtropical gyre and no samples were taken north of $39^{\circ} \mathrm{N}$. Fonselius and Ostlund [Fonselius, \& Ostlund, 1959] obtained five pre-bomb (1957) surface ocean radiocarbon values averaging $-43 \%$ for the northern North Atlantic above latitude $60^{\circ} \mathrm{N}$. Results from the Denmark Strait ( $\mathrm{n}=3$ ) west of Iceland, averaged $-48 \%$, while two samples taken within the Norwegian Current averaged -35\%. Broecker, et al. [1960] suggested a slight negative correction of about $-3 \%$ to their own and Fonselius and Ostlund's data, owing to some initial bomb enrichment of the atmosphere by 1956 . From the results of these two early ocean radiocarbon studies Broecker, et al., [1960] concluded that surface $\Delta^{14} \mathrm{C}$ waters in the northern North Atlantic $\left(60^{\circ}-80^{\circ} \mathrm{N}\right)$ were more enriched $(+14 \%$ ) than subtropical gyre $\left(15^{\circ}-40^{\circ} \mathrm{N}\right)$ surface waters, which fit broadly with the idea that the former were being

replenished by the latter as part of the Atlantic's thermohaline circulation and by continued enrichment from contact with the atmosphere.

Druffel's [1989] Florida and Bermuda pre-bomb data average is $-53 \%$, which is effectively identical to Broecker, et al.'s [1960] average value of -52\%o for the subtropical 
gyre region (using Broecker, et al.,'s 3\%o correction). However, Fonselius and Ostlund's northern North Atlantic data are quite enriched (by $~ 15 \%$ ) compared to the shell-derived pre-bomb records for the four northern North Atlantic sites discussed here, which yield an average of $-59 \%$. Pre-bomb $\Delta^{14} \mathrm{C}$ data for the surface Nordic Sea regions also have been compiled from whole-shell analysis of selected museum shells [Mangerud, 1972][Mangerud and Gulliksen, 1975]. For the Norwegian Sea region, Mangerud and Gulliksen [1975] gave pre-anthropogenic means of $-52 \%$, $-57 \%$, and $-61 \%$ o for the southern and northern coasts of Norway and Spitzbergeb, respectively. They interpreted the northward depletion trend in their data as evidence of the increasing influence of Norwegian Current (lower $\Delta^{14} \mathrm{C}$ ) and the decreasing influence of the northward flowing Norwegian Coastal Current (higher $\left.\Delta^{14} \mathrm{C}\right)$, implying a relatively depleted core $(<-60 \%$ ) for the Norwegian Current. Their Norwegian Sea values are in close agreement with this study's pre-1950 time history data for northeastern North Atlantic (North Sea, Norway, and Iceland). For the Greenland Sea and Denmark Strait region, these same studies showed shell-derived pre-bomb data with means of $-69 \%$ and $-68 \%$ o from the east coast of Greenland (from Hjort, 1973) and from the southwest coast of Iceland (from Broecker and Olson, 1961), respectively. These values are more depleted than Iceland's north coast record (the nearest time history location), but are similar to the Georges Bank pre-bomb data (and our estimate for the Labrador Sea region in Chapter 1) as well as Broecker's [1979] estimate of $-70 \%$ for the initial source of North Atlantic Deep Water (NADW).

It would appear then that Fonselius and Ostlund's [1959] ocean water data for the Nordic Sea regions are too enriched, perhaps because of bomb contamination, to represent mean pre-bomb surface conditions, and that the pre-bomb $\Delta^{14} \mathrm{C}$ data from the shell records presented in this study are more in line with other regional pre-bomb data. In contrast, then to Broecker, et al.'s [1960] assessment, the shell pre-bomb results from this study show that the northern North Atlantic surface waters, on average, are more depleted than 
subtropical gyre surface waters, and that the western part of this northern region is the most depleted region in the North Atlantic. While the difference between mid- and high latitude regions in the North Atlantic $(\Delta \sim 20 \%)$ is not nearly as great as in the South Atlantic and Pacific Oceans $\left(\Delta \sim 70 \%\right.$ ), the conclusion that no surface $\Delta{ }^{14} \mathrm{C}$ gradient exists between the subtropical and subpolar North Atlantic [Bard, 1988][Bard, et al., 1994] appears incorrect. The gradient disappears when the radiocarbon signature of the surface subpolar regions is blended out by combining data (including the Fonselius and Ostlund [1959] data) from the same latitudes, and thus masking the east/west asymmetry of the pre-bomb $\Delta^{14} \mathrm{C}$ data. However, it is critical not to ignore this asymmetry because, as Bard, et al. [1994] have recently pointed out in their discussion of the Younger Dryas ( 10 kyr B.P.) period, the presence and magnitude of the meridional surface $\Delta^{14} \mathrm{C}$ gradient has important implications for the thermohaline circulation of the North Atlantic.

The pre-bomb north-south contrast in $\Delta^{14} \mathrm{C}$ is at least partly explainable by the difference in winter mixed-layer depth and the consequent difference in surface residence time between these regions, which, in a one-dimensional sense, should allow the subtropical gyre waters to become more equilibrated with the atmosphere than the higherlatitude waters. However, because subpolar waters are thought to be largely replenished by surface waters of subtropical origin, and transport to these northern regions, via the North Atlantic Current system, should allow for further enrichment as a result of additional surface residence time, there is a need for a counterbalancing depleted source(s) to account for the lower $\Delta^{14} \mathrm{C}$ of northern surface waters. In addition, the flushing times for the Nordic Seas and Labrador Sea basins are on the order of a decade or two [Broecker, 1979][Schlosser, et al., 1995][Bonisch and Schlosser, 1995], and so the $\Delta^{14} \mathrm{C}$ depletion caused by radioactive decay is negligible $(\sim 1-3 \%)$ and should be more than compensated by the atmosphere-derived $\Delta^{14} \mathrm{C}$ enrichment ( 4-9\%o). 
The particularly low values $(\sim-70 \%$ ) of the western subpolar region highlight the problem and motivate the need for a significant deepwater source. Based on GEOSECS tritium data, Broecker [1979] calculated that the deep overflows from the Greenland and Norwegian Seas were contributing waters with an estimated pre-bomb-value of $-68 \%$ o to the NADW, and as mentioned, Mangerud and Gulliksen [1979] reported pre-anthropogenic shell values comparable to this for the Greenland Sea and Denmark Strait surface waters. Broecker [1979] further showed that, because of the short residence in the Nordic basins, the inflow $\Delta^{14} \mathrm{C}$ concentration must approximately equal the outflow $\Delta^{14} \mathrm{C}$ concentration. These combined results imply that the full water column within the subpolar gyre region south and west of Iceland may have carried a pre-bomb value of -70\%o. The problem is how to achieve a $\Delta^{14} \mathrm{C}$ of $-70 \%$ for this subpolar region if its only major sources are 1 ) equilibrated surface waters ( -50\%) of subtropical origin and 2) Polar waters of the East Greenland Current ( -70\%o). Either, another depleted source(s) exists or subtropical surface waters do not contribute to the subpolar gyre. Since much evidence has been compiled to reject the latter option $\left(\mathrm{i}_{\mathrm{r}} \mathrm{e}\right.$, [Lazier, 1973][McCartney and Talley, 1982][McCartney and Talley, 1984][Schmitz and McCartney, 1993]), a depleted source must be sought.

Two potential sources of the depleted waters are the intermediate and deep water reservoirs existing along the southern limits of the subpolar gyre that might be accessed by intense winter convection. Convection, here and northward, can extend to depths of 1000 m or more [McCartney and Talley, 1982]. Broecker [1979], argued that an important contributor to NADW and its $\Delta^{14} \mathrm{C}$ composition was the underlying Antarctic Bottom Water (mid-latitude $\mathrm{AABW}: \Delta^{14} \mathrm{C} \sim-100 \%$ at $\sim 4000 \mathrm{~m}$ ) which extends northward at least to mid-latitude in the North Atlantic. However, while he showed that the uptake of AABW quite successfully accounts for the downstream evolution of the NADW $\Delta^{14} \mathrm{C}$ composition, it is more difficult to account for its presence in the surface subpolar waters. A second, 
more viable potential source for the depleted component in northern North Atlantic surface waters is Antarctic Intermediate Water (mid-latitude AAIW: $\Delta^{14} \mathrm{C} \sim-90 \%$ at $\sim 1000 \mathrm{~m}$ ), which Tsuchiya [Tsuchiya, 1989] showed, through its silica signature, being transported well into the high-latitude $\left(60^{\circ} \mathrm{N}\right)$ North Atlantic by the Gulf Stream-North Atlantic Current and extending along the subpolar front (Figure 3). McCartney and Talley [1982] have shown that the intense winter convection along the axis of the North Atlantic Current, Irminger Current, and the Labrador Sea allows for the formation of thick (500-1000 m) vertically homogeneous upper ocean water masses referred to as Subpolar Mode Water (SPMW). They showed that these upper ocean waters continue to evolve in temperature and salinity, increasing in density along their trajectories, and ultimately form the core waters of the Norwegian Current and Labrador Sea Water. These same processes potentially could mix surface subtropical waters with an initial (mid-latitude) value of $-50 \%$ o and underlying intermediate waters (AAIW) with an initial (mid-latitude) value $-90 \%$ to form SPMW with a $\Delta^{14} \mathrm{C}$ of $-70 \%$. In such a scheme, the contribution of Arctic water from the East Greenland Current with a similar value of $-70 \%$ would not alter the $\Delta^{14} \mathrm{C}$ composition of subpolar gyre water.

The presence of AAIW in the northern North Atlantic waters has been reported previously by others. Sverdrup, et al. [1942], in a simple schematic of North Atlantic intermediate water masses showed AAIW flowing northward as the underlying part of the western boundary current (Figure 188, p. 685). Broecker's [1979] paper, while focusing on the role of $A A B W$, listed the very similar $\Delta^{14} \mathrm{C}$, silica, and nitrate properties of Circumpolar intermediate waters, and did not preclude an important role for them in the make up of (upper) NADW. Broecker and Takahashi [1981] traced the influence of AAIW up to about $40^{\circ} \mathrm{N}$ in the central North Atlantic using GEOSECS results for ${ }^{14} \mathrm{C},{ }^{226} \mathrm{Ra}$, silica, oxygen, nitrate, potential temperature, and salinity. Tanaka, et al. [1990], calculated that the Gulf of Maine $\Delta^{14} \mathrm{C}$ budget required relatively equal inputs of AAIW (40\%) and 
Gulf Stream/ Sargasso Sea Water (60\%). Following their arguments it was shown in chapter one [Weidman and Jones, 1993] that a 50:50 mixture of AAIW and Gulf Stream (or Sargasso Sea) Water could also account for the $\Delta^{14} \mathrm{C}$ budget of the Labrador Sea. Maier-Reimer and Bacastow's [1990] pre-bomb $\Delta{ }^{14} \mathrm{C}$ tracer results from their ocean global circulation model (OGCM) show the northward penetration of an AAIW analog that results in northwestern North Atlantic surface values of $-70 \%$ (Figure 4a). Alternately, it is the absence of this northward penetration of an AAIW analog in Toggweiler, et al.'s [1989a] OGCM pre-bomb $\Delta^{14} \mathrm{C}$ results that allows for a more enriched (-40\%) northwestern North Atlantic (Figure 4b), which is at odds with the observed pre-bomb values in the western subpolar region. The introduction of this intermediate water component into the surface waters along the subpolar front about the south of the Labrador Sea and Iceland, would account for the lower radiocarbon concentrations of the northern North Atlantic waters in general, and the even more depleted conditions of the Labrador and Irminger Seas in particular.

A third possible source for depleted waters for the Labrador Sea region is Arctic waters from the Canadian Archipelago. Chapman and Beardsley [1989], suggested that continuity exists between the East Greenland, West Greenland, and Labrador Currents through westward flows across the Davis Strait (see Chapter 1, Figure 2). The coastal and inshore parts of these currents, being fresher and less dense than offshore Labrador Sea Water, remain somewhat distinct [Lazier, 1973] and therefore may carry the initial radiocarbon signature of the East Greenland Current (-70\%o) relatively undiluted (in prebomb times) all the way to the Georges Bank region. Chapman and Beardsley [1989] also suggested that Arctic waters flowing southward through the Davis Strait are a major contributor ( 2 Sv) to this flow, and Lazier [1973] indicated that waters from this same source (albeit through the Canadian Archipelago) form the major supply of low-salinity water to the surface of the Labrador Sea. This is significant in light of the fact that 
Mangerud and Gulliksen [1975] reported three shell values from the southern coast of Ellesmere Island with a very depleted pre-bomb mean $\Delta^{14} \mathrm{C}$ of $-89 \%$. However, this value is much lighter than the $\sim-50 \%$ estimated by Ostlund et al. [1987], for pre-bomb Arctic surface waters of the Eurasian basin. Mangerud and Gulliksen [1975] suggest that the strong salinity stratification of the upper Arctic Ocean water effectively prevents significant exchange with the deeper waters (Canadian basin deep water $\Delta^{14} \mathrm{C} \sim-105 \%$ ) and explain their low Arctic shell values as either owed to a Pacific (Bering Strait) origin $\left(\Delta^{14} C<\right.$ $-100 \%$ ) or a local depleted source. Granting these uncertainties, if the $-89 \%$ value is typical of pre-bomb Arctic waters transported southward through the Canadian Archipelago, then these waters might be an important source of depleted waters for the Labrador Sea.

\section{Suess Effect:}

The "Suess effect" refers to the reservoir depletion caused by the dilution of atmospheric $\mathrm{CO}_{2}$ from the combustion of $\left({ }^{14} \mathrm{C}\right.$-free) fossil fuels [Suess, 1953]. Tans, et al. [Tans, De Jong, \& Mook, 1979] have shown a 20\%o depletion in tree-ring $\Delta^{14} \mathrm{C}$ from northern Europe between 1900 and 1950. The ocean's uptake of this atmospheric fossilfuel $\mathrm{CO}_{2}$, has similarly caused a $\Delta^{14} \mathrm{C}$ depletion in the ocean surface waters as recorded by corals [Druffel and Suess, 1983]. The magnitude of this depletion in the ocean over the same pre-bomb period averages $\sim 10 \%$ or about half that of the atmosphere. However, as shown by Druffel and Suess [1983] the size of this ocean Suess effect varies widely from place to place owing to differing oceanographic processes, such as the rate of deep water renewal to the local surface waters and differences in regional air-sea gas exchange rates. For instance, the Suess effect derived from a Bermuda coral is $\sim 25 \%$ [Nozaki, et al., 1978] or almost the same as Tans, et al.'s [1979] tree-ring value, while a Florida coral shows $\sim 11 \%$ o [Druffel and Linick, 1978] and a Galapagos coral measured only 6\%o [Druffel, 1981]. Most of the ocean $\Delta^{14} \mathrm{C}$ depletion exhibited in these coral records has 
occurred since about 1930, so that if just the period from about 1940 to 1955 is considered, in order to be comparable with the shorter shell-derived records, most of the Suess effect should still be detectable in the northern North Atlantic records (shown in Table 2). For this shorter period, the magnitude of the Suess effect for Bermuda and Florida is approximately $18 \%$ and $11 \%$, respectively. The depletion for Georges Bank is $\sim 13 \%$, or intermediate between that of Bermuda and Florida. In contrast, the Norway and North Sea records exhibit depletions greater than $\sim 30 \%$, though this calculation is based on the very low values occurring at both sites in the mid-1950s. In contrast, the Iceland record spans almost the entire anthropogenic period, though with low-temporal resolution for the pre-bomb period, but surprisingly shows no significant depletion and perhaps even enrichment in the latter part of this signal. Corroborating this result, pre-bomb whole shell data from the southwest coast of Iceland [Broecker and Olson, 1961] do not show a Suess effect depletion either and actually indicate an $8 \%$ enrichment between the 1840s and the 1940s. Perhaps, convective and deep-water formation processes in the subpolar regions or episodic shifts between Arctic and Atlantic water masses on Iceland's north coast [Stefansson and Olafsson, 1991] result in ocean $\Delta^{14} \mathrm{C}$ changes that overwhelm the Suess effect in this region. Taken together, these pre-bomb results display a great deal of variability concerning the size of the Suess effect in the North Atlantic, and suggest that reservoir corrections [Mangerud and Gulliksen, 1975][Bard, 1988] and regional fossil-fuel $\mathrm{CO}_{2}$ uptake calculations based on a modelled 0-10\% Suess effect for the surface North Atlantic possess a large uncertainty.

\section{0s Extrema: Norway and North Sea:}

The very depleted minima $(<-80 \%)$ in the North Sea and Norway in the mid-1950s are difficult to explain, because there is no other evidence of a surface source this low in the eastern North Atlantic. Since, they represent only two data points and the North Sea value has a large precision error $( \pm 13 \%$ ), it is possible that they are simply the result of analytical 
error. However, these two points also roughly coincide with the rather low minimum in the Georges Bank record, and the 1950s is the period of maximum Suess effect. Tree-ring records from northern Europe do not indicate "clean-air" $\Delta^{14} \mathrm{C}$ values much lower than $-30 \%$ o by 1950 [Tans, et al., 1979], and atmospheric values of at least -80\%o would be required to account for these extreme ocean minima. The Norway site is adjacent to a small city and within a fjord with steep mountains to the east, and perhaps it is possible that nearby fossil-fuel $\mathrm{CO}_{2}$ emissions resulted in locally depleted atmospheric conditions. Meijer, et al. [in press] have recently shown a seasonal $\Delta^{14} \mathrm{C}$ depletion of $40 \%$ for atmospheric $\mathrm{CO}_{2}$ during the period 1974-1993 caused by local fossil-fuel burning at a sampling station near Groningen, Netherlands. Cain and Suess [1976] also showed that trees in New York City had values close to $-90 \%$ in the 1940 s. Further, two studies have shown that the highly industrialized Rhine Valley region of northern Germany displays atmospheric $\Delta^{14} \mathrm{C}$ depletions greater than $100 \%$ relative to "clean air" during winter-time due to increased pollution and lower atmosphere inversions [Levin, Munnich, \& Weiss, 1980][Segl, et al., 1983]. However, this local pollution explanation seems unreasonable as a cause for the North Sea anomaly since that site is about $100 \mathrm{~km}$ offshore, and should not be subject to such a large local anthropogenic effect.

Unusually strong upwelling of intermediate waters along the subpolar front, perhaps in response to increased deepwater production, might have provided a source for such depleted values. Evidence of deep convective mixing in the central eastern North Atlantic to depths of $\sim 1000 \mathrm{~m}$ has been reported and invoked to explain the ventilation of the intermediate depth waters of the eastern subtropical gyre region [Arhan, Colin de Verdiere, \& Memery, 1994]. In the northwest Atlantic, Tanaka, et al. [1990] discussed the possibility of episodic upwelling of AAIW near the Labrador Sea and southwards along the shelf to explain unusually low pre-bomb $\Delta^{14} \mathrm{C}$ values in Long Island Sound in the mid1950s. Also, Dickson, et al. [1975, 1988] have reported significant climate reversals in the 
northern North Atlantic, which could provide the mechanisms for unusual upwelling events and frontal shifts of subpolar and arctic water masses. The $\Delta^{14} \mathrm{C}$ minima at Georges Bank, North Sea, and Norway differ in time from each other by the approximate water mass travel times between these locales estimated from the mean residual velocity of the subpolar gyre circulation $\sim 1000 \mathrm{~km} / \mathrm{yr}$ [Dickson, et al., 1988]. If these anomalous observations are not merely coincidental and are unrelated to the Suess effect, it might suggest that unusual upwelling occurred in the northern North Atlantic in the early 1950s forming very depleted surface water which migrated about the greater subpolar gyre in the 1950s. Though, the Iceland record does not show a similar anomaly, its only 1950s data are a decadal average for 1942-1951 and the year 1958, and so it may simply be undetected. A higher resolution $\Delta^{14} \mathrm{C}$ time-series for the 1950 s from these same locations might help to resolve this issue.

\section{North Atlantic Post-Bomb $\Delta^{14} \mathrm{C}$}

\section{Time History Comparison:}

The first certain appearance of bamb- ${ }^{14} \mathrm{C}(1959 \pm 1$ year $)$ as well as the period of steepest ${ }^{14} \mathrm{C}$ signal increase (1960-1966) are nearly synchronous in all six time-histories. These results reflect the hemispheric homogeneity of the atmospheric bomb- ${ }^{14} \mathrm{C}$ signal, which reached a maximum in 1964-1965 [Levin, et al., 1985] (Figure 5). However, large variations in signal amplitude exist among the different sites. The North Sea signal has the largest amplitude $\sim 300 \%$. The Florida, Bermuda, and Norway signal amplitudes are intermediate $\sim 200 \%$, while the Georges Bank and Iceland signals have the smallest amplitudes $\sim 110-150 \%$. Phase differences exist regarding the timing of the signal maxima. The North Sea signal maximum occurs earliest about 1966-1968, only 1-3 years after the atmospheric signal peak, while Bermuda's broad peak is the most delayed, occurring in the mid- to late-1970s. The rest of the records display a greater phase similarity with their maxima occurring in the early 1970s. The decay of the bomb-signal, shown in Table 2 as a percentage reduction of the total bomb-signal amplitude by 1990, also varies among sites. 
The North Sea record shows the largest signal decay, whereas the Iceland record exhibits only a slight decline over two decades.

In general, these observations are consistent with the broad-scale oceanographic conditions, of which perhaps the most important factor is the winter mixed-layer depth. To illustrate this, Figure 5 shows the effect of depth changes on an idealized mixed-layer ocean in response (solid lines) to the atmospheric bomb- ${ }^{14} \mathrm{C}$ signal (dashed line). The essential observation from this exercise is that shallower mixed layers equilibrate with the atmosphere more rapidly. Alternatively, increased gas exchange rates have the same proportional effect as decreased mixed-layer depth. As gas exchange rates increase northward over the North Atlantic as a function of increasing mean wind-speed [Toggweiler, et al., 1989a] they should tend to cancel the effect of increased mixed-layer depth. However, in the North Atlantic gas-transfer rates vary by a factor of two (Figure 6), while the winter mixed-layer depth varies by a factor of 5 or more (Figure 1c), thus making mixed-layer depth the more critical parameter. Since subtropical regions (Bermuda and Florida) have shallower mixed-layers relative to subpolar regions (Georges Bank, Iceland), their $\Delta^{14} \mathrm{C}$ signal amplitudes should tend to be greater. The North Sea and Norway records do not fit this generalization since both have rather large amplitudes and yet are near regions of deep mixing. However, this discrepancy serves as an indication of the shelf modification of these ocean $\Delta^{14} \mathrm{C}$ signals [Weidman and Jones, 1993].

Shallower mixed-layers also should produce an earlier phase (maximum) and a more rapid signal decay (Figure 5). However, four of the profiles reach their peak at about the same time in the early 1970s, and a clear relation between mixed-layer depth and phase is not apparent in the data. This is partly because the broad peaks of the bomb signals, defined by a decade long period (from the late 1960s to the late 1970s) when $\Delta^{14} \mathrm{C}$ fluctuated within $\sim 10 \%$ of the maxima, make it difficult to determine precisely the phase of 
these ${ }^{14} \mathrm{C}$ signals. Regional oceanographic processes, operating on interannual and decadal scales and resulting even in minor $\Delta^{14} \mathrm{C}$ fluctuations could produce apparent phase shifts of several years. The North Sea record with its very early peak follows a shallow pattern, while Bermuda with its very late peak follows a deep pattern, which is opposite to what might be expected based on the mixed-layer depths of their source regions. The North Sea signal's early phase is again consistent with a strong shelf influence. Druffel [1989] explained Bermuda's delayed phase relative to Florida's as the result of deeper winter mixing in the Sargasso Sea. However, winter mixing at Bermuda is still much shallower than that taking place in any of the subpolar regions and yet Bermuda's peak occurs later, suggesting that the mixed-layer depth is not the sole factor in determining the phase of the bomb-signal. Druffel and Suess [1983], in discussing the Galapagos coral record, noted that the supply of intermediate or deep water to surface waters should cause a phase shift in the surface $\Delta^{14} \mathrm{C}$ signal towards that of the atmospheric $\Delta^{14} \mathrm{C}$ signal, as the depleted component (relatively unaffected by bomb input) would tend to drive down the concentration as soon as the atmospheric, peak input passed. The advanced phase of the northern North Atlantic signals relative to Bermuda is also consistent with the other evidence of a deep depleted source for the northern surface waters. Signal decay is difficult to assess for the subtropical sites as both records end in 1983, but Druffel [1989] has explained the more rapid dropoff of the Florida signal relative to the Bermuda signal as evidence of the presence of upwelled waters in the Gulf Stream precursor. As seen in Table 2 , the Georges Bank and Iceland signals decay at about half the rate ( $20 \%$ drop relative to bomb-signal amplitude) as the North Sea and Norwegian signals ( $\sim 35 \%$ drop relative to bomb-signal amplitude). This contrast could be the result of greater mixed-layer depths in the western subpolar source regions and/or greater shelf influence in the two eastern sites. 


\section{Comparison with Other Post-bomb $\Delta^{14} \mathrm{C}$ Measurements:}

Figure 7 shows GEOSECS [Stuiver and Ostlund, 1980] and TTO [Ostlund and Grall, 1987] North Atlantic surface data versus winter mixed-layer depth (using Robinson, et al. [1979]) at each GEOSECS and TTO site and Table 3 compares the regional mean GEOSECS and TTO values with the time-history data for years $\sim 1972$ and $~ 1981$, and also shows the winter (February) mixed-layer depth for each region. These comparisons again demonstrate that the post-bomb surface $\Delta^{14} \mathrm{C}$ in the North Atlantic during these periods can be seen largely as a function of mixed-layer depth, which is in line with Broecker and Peng's [1982] interpretation of the poleward depletion of surface $\Delta^{14} \mathrm{C}$ in the North Atlantic. Possibly aliasing this relationship, however, is the presence of an intermediate/deep water component, whose $\Delta^{14} \mathrm{C}$ composition would be relatively uninfluenced yet by bomb- ${ }^{14} \mathrm{C}$ and would thus dilute the bomb input in the surface waters. Table 3 also shows that the Florida, Bermuda, and Iceland data closely match their GEOSECS and TTO regional means, while the North Sea, Norway, and Georges Bank data are higher than their regional means. While, it cannot be certain that the regional means derived from GEOSECS and TTO data are representative of the ocean areas adjacent to the time-history sites, this comparison suggests that the former three records are not significantly modified by shelf influences, while the latter three records may have been altered by shelf influences.

\section{Determining the Offshore $\Delta^{\mathbf{1 4}} \mathrm{C}$ Signal:}

In chapter one [Weidman and Jones, 1993] it was shown that the Georges Bank's $\Delta^{14} \mathrm{C}$ signal could be viewed as a shelf-modified Labrador Sea $\Delta^{14} \mathrm{C}$ signal. The shelf effect can be summarized as the importation and isolation of ocean water on a shallow shelf, the essential effect of which is to enhance the equilibration of this water's $\Delta^{14} \mathrm{C}$ concentration with the atmosphere relative to its ocean source. In this way the "shelf effect" results in the bomb-signal's amplification, an advancement of its phase towards that of the 
atmosphere's signal. The resultant $\Delta^{14} \mathrm{C}$ of shelf waters are thus a combination of the offshelf $\Delta^{14} \mathrm{C}$ which is presumably characteristic over a wide ocean region (such as the Labrador Sea or Norwegian Sea) and local shelf water depth and residence time. The ocean record can be estimated from an adjacent shelf record by inverting this relationship. A similar approach was used in chapter one to obtain a $\Delta^{14} \mathrm{C}$ record for the Labrador Sea from the Georges Bank data, and is now used to reconstruct $\Delta^{14} \mathrm{C}$ time histories for the central eastern North Atlantic and the Norwegian Sea. A simple model describes the relationship between a shelf site's $\Delta^{14} \mathrm{C}$ signal and that of its offshore ocean source:

$$
\Delta^{14} C_{\text {shelf }(+R)}=\Delta^{14} C_{\text {ocean }}+U_{\text {shelf }} *\left(\Delta^{14} C_{\text {atmosphere }}-\Delta^{14} C_{\text {ocean }}\right)
$$

The shelf uptake rate $\mathrm{U}_{\text {shelf }}=\mathrm{R} * \mathrm{I} /\left(\mathrm{h}_{\text {shelf }} * \Sigma \mathrm{CO}_{2}\right)$, where $\mathrm{R}$ is the shelf residence time, $\mathrm{I}$ is the air-sea $\mathrm{CO}_{2}$ invasion rate, $\mathrm{h}_{\text {shelf }}$ is the mean shelf depth, and $\Sigma \mathrm{CO}_{2}$ is total DIC (which is assumed here for simplicity to be the same for both ocean and shelf). Rewriting (1) to solve for the ocean signal we obtain:,

$$
\Delta^{14} C_{\text {ocean(-R) }}=\left(\Delta^{14} C_{\text {shelf }}-U_{\text {shelf }}{ }^{*}{ }^{14} C_{\text {atmosphere }}\right) /\left(1-U_{\text {shelf }}\right)
$$

Given the shelf and atmospheric record, we can solve (2) by determining a value for $\mathrm{U}_{\text {shelf }}$ in two ways: 1) directly from estimates of the parameters $\mathrm{R}, \mathrm{I}, \mathrm{h}_{\text {shelf }}$, and $\Sigma \mathrm{CO}_{2}$, and 2) indirectly by finding a $U_{\text {shelf }}$ that fits the regional ocean GEOSECS and TTO data. The latter method can be expressed as

$$
\mathrm{U}_{\text {shelf }}=\left(\Delta^{14} \mathrm{C}_{\text {shelf }}-\Delta^{14} \mathrm{C}_{\text {GEOSECS or TTO }}\right) /\left(\Delta^{14} \mathrm{C}_{\text {atmosphere }}-\Delta^{14} \mathrm{C}_{\text {GEOSECS or TTO }}\right)
$$




\section{North Sea:}

A determination of the uptake coefficient $U_{\text {shelf }}$ for the North Sea region can be made directly. A residence time of 4-6 months has been calculated for the waters of English Channel origin in the German Bight region of the North Sea [Reid, et al., 1988]. A quantitative estimate is not available for the residence time of waters of central eastern North Atlantic origin in the English Channel and Celtic shelf, but based on Pingree and Le Cann's [1989] study of residual currents $(\sim 1-3 \mathrm{~cm} / \mathrm{s})$ on the Celtic and Armorican shelves an additional 8-12 month period does not seem unreasonable. This gives a total shelf residence time (from the central eastern North Atlantic to the German Bight) of 12-18 months or $\mathrm{R} \sim 1.25$ year. A value of $20 \mathrm{~mol} \mathrm{CO}_{2} \mathrm{~m}^{-2} \mathrm{yr}^{-1}$ is assumed for the $\mathrm{CO}_{2}$ invasion rate I, which is the approximate value that Broecker, et al. [1985] determined for the Atlantic Ocean. For $h_{\text {shelf }}$ we assume an average value of $50 \mathrm{~m}$. A value of $2 \mathrm{~mol} \mathrm{~m}^{-3}$ is used for $\Sigma \mathrm{CO}_{2}$. From these estimates we obtain $\mathrm{U}_{\text {shelf }} \sim 0.25$ for the North Sea. Alternately, using the indirect method (3), the regional TTO surface value from the central eastern North Atlantic for 1981 of $\sim+109 \%$, and an atmospheric value for 1981 of $+240 \%$ [Levin, et al., 1985] we obtain an estimate of $\mathrm{U}_{\text {shelf }} \sim 0.19$ for the North Sea.

Figure 8 shows several estimates of the $\Delta^{14} \mathrm{C}$ signal in the North Sea using (2) the North Sea record, the atmospheric record, and several $\mathrm{U}_{\text {shelf }}$ values from 0.20 to 0.35 . From this analysis a $\Delta^{14} \mathrm{C}$ signal with a $\mathrm{U}_{\text {shelf }} \sim 0.22$ is adopted for the shelf regions west of the German Bight (Table 4a). The estimated central eastern North Atlantic record peaks about 1974 with a maximum of $\sim+160 \%$. The phase and amplitude of this signal are similar to that of the Bermuda signal, peaking in the mid-1970s, and showing a slow decay rate (drop of $\sim 15 \%$ of total bomb-signal amplitude). The estimated pre-bomb record is dependent on our assumptions about the nature of the extreme 1950s minimum in the North Sea. Since no unusual atmospheric depletion is assumed in the model, then very depleted ocean waters for the 1950 s are predicted. Alternately, if the 1950 s ocean source water were 
to be fixed at a low but reasonable value of $-65 \%$, then an atmospheric value of $\sim-140 \%$ is still required to fit the North Sea minimum. While this level of depletion is similar to that found in the nearby industrialized Rhine valley, it seems too extreme to maintain over large areas of the English Channel and North Sea shelf, which makes the idea for an ocean source of the 1950 s anomaly seem the more probable cause.

\section{Norway:}

The direct method cannot be used at present to determine $\mathrm{U}_{\text {shelf }}$ for the Norway site because an independent estimate of the shelf residence time (R) for water in Tromsøysund is not available, nor is there a quantitative estimate of relative mixing between the Norwegian Coastal Current and offshore Norwegian Current waters (which would affect our estimate of R). Using the indirect method (equation 3), the atmospheric values of $+465 \%$ o (1972) and $+240 \%$ (1981), the Troms $\varnothing y$ sund data for $\sim 1972$ and $~ 1981$ (from Table 1c), and the regional GEOSECS and TTO data for the eastern subpolar region of $+54 \%$ (1972) and $+63 \%$ (1981), we obtain $U_{\text {shelf }}$ values of 0.16 (1972) and 0.20 (1981).

Figure 9 shows the several estimates of the $\Delta^{14} \mathrm{C}$ signal in the Norwegian Sea using (2) and the Tromsøysund record, the atmospheric record, and an array of $U_{\text {shelf }}$ values from .10 to .20 . From this analysis a $\Delta^{14} \mathrm{C}$ signal with a $\mathrm{U}_{\text {shelf }} \sim 0.15$ is adopted as the estimate for the $\Delta^{14} \mathrm{C}$ signal of the Norwegian Sea (Table $4 \mathrm{~b}$ ). This $\Delta^{14} \mathrm{C}$ signal has a similar, but slightly larger, amplitude than the Iceland signal, peaks in the mid-1970s, and slowly decays (drop of $\sim 16 \%$ of total bomb-signal amplitude). A larger $\mathrm{U}_{\text {shelf }}$ value is not chosen, despite a better fit with GEOSECS and TTO data, because it produces a large local minimum in the mid-1960s bomb-curve which seems unrealistic since this is the time of peak atmospheric $\Delta^{14} \mathrm{C}$, unless unusually deep mixing was occurring in the ocean source region. There is some evidence for this latter hypothesis. The mid-1960s was a time of unusual cooling in the northern North Atlantic [Dickson, et al., 1975] and records from the 
north coast of Iceland show a sharp change to a regime of colder springtime ocean temperatures $\left(\Delta \sim 4^{\circ} \mathrm{C}\right)$ and lower salinities $(\Delta \sim 0.5 \%)$ at this time [Stefansson and Olafsson, 1991]. Recently, Bonisch and Schlosser [1995] have shown results from a tracer and box modeling study of the Greenland/Norwegian Seas and Nansen Basin, which suggest that deep water production in this region was fives times greater between the mid1960s and 1980 than since that time. Also, Druffel [1989] has shown, from modeling results, that the upper ocean ventilation rates in the Sargasso Sea (mid-subtropical gyre) appeared to be at a 15 -year maximum in the mid-1960s. Alternately, as the rate of change of atmospheric $\Delta^{14} \mathrm{C}$ was greatest in the early to mid-1960s, our model and time-history may simply have too coarse a resolution to accurately reconstruct this sensitive part of the bomb-curve.

As in the North Sea case, the pre-bomb estimate for the offshore source region is dependent on our assumptions about the cause of the 1950s anomaly. As this site is quite shallow and within a few hundred meters of a small city, it is not unreasonable to suspect a strong anthropogenic (fossil-fuel combustion) effect. However, even if offshore waters are assumed to be as low $-65 \%$, a back estimate requires local atmosphere $\Delta^{14} \mathrm{C}$ of $\sim-185 \%$, which seems impossible to maintain over an area wide enough to affect the Tromsøysund surface water. This analysis adds weight to the alternative hypothesis of an offshore origin for the 1950s anomaly.

\section{The Evolution of the bomb- ${ }^{14} \mathrm{C}$ signal in the North Atlantic:}

In Figure 10, three estimated time histories for the Labrador Sea (from Chapter 1, Table 2), Norwegian Sea, and central eastern North Atlantic (derived from the Georges Bank, Norway, and North Sea records, respectively, and corrected for shelf effects) are combined with the time-histories for Iceland, Bermuda, and Florida, to present an overview of the evolution of the bomb- ${ }^{14} \mathrm{C}$ signal in the North Atlantic Ocean. A sharp 
contrast in amplitudes is apparent between northern (subpolar) and southern (subtropical) regions with remarkable conformity within each region. Florida, Bermuda, and the central eastern North Atlantic have similar amplitudes of $\sim 220 \%$ and maxima of $\sim+160 \%$ o. These radiocarbon results add support to other evidence (i.e., McCartney and Talley, 1982) that suggest the surface waters in the transitional region south of the subpolar front, including those that feed the central eastern North Atlantic and the southern North Sea, generally share a more distinct connection with the subtropical gyre than with the subpolar gyre. The Bermuda and central eastern North Atlantic records also share a delayed phase relative to the Florida signal. Druffel [1989] has explained the phase difference between Bermuda and Florida as the result of deeper mixing in the Sargasso $(\sim 200 \mathrm{~m})$ relative to the Florida Current $(\sim 100 \mathrm{~m})$. However, this explanation still contains a discrepancy since both Florida and Bermuda have similar amplitudes which should also vary with mixed-layer depth. One solution to this problem is that the dilution of the atmospheric input resulting from a deeper mixed-layer in the Sargasso Sea is balanced by horizontal advection from converging surface waters.

The Labrador Sea, Iceland Sea, and Norwegian Sea have amplitudes of $\sim 120 \%$ and maxima +60\%. All reached their maxima in the mid-1970s and have decayed only by about $15 \%$ of their total bomb-signal amplitudes over 15 years (about $1 / 6$ the atmospheric bomb-signal decay rate). These results are consistent with the deep winter mixed-layers $(500-1000 \mathrm{~m})$ of these northern areas that dilute the bomb- ${ }^{14} \mathrm{C}$ inventory and slow the ocean's equilibration with the atmosphere. The results, also, are consistent with a $\Delta^{14} \mathrm{C}$ depleted intermediate or deepwater contribution to the subpolar regions. The slow signal decay rates of the northern North Atlantic time histories might be partly owed to the sharply reduced convection and deep water production since $\sim 1980$ indicated by a number of multitracer studies (e.g., [Schlosser, et al., 1991][Bonisch and Schlosser, 1995]). Also, because surface waters in these subpolar regions are, presently, more depleted than the 
atmosphere, these regions should still be increasing their inventory of atmospheric bomb${ }^{14} \mathrm{C}$ or maintaining a balance with regional loss through deep water production. These results support Toggweiler, et al.'s [1989b] modeling results which predicted increasing inventories for northern North Atlantic and decreasing inventories for the subtropical North Atlantic during the 1980s. The estimated Iceland Sea and Labrador Sea bomb-signals are very similar, though the Labrador Seas pre-bomb data are $\sim 20 \%$ o lower, indicating a deepwater component (such as AAIW) in the Labrador Sea surface waters absent in the surface waters of the Iceland Sea. A small east-west difference is shown in the relative enrichment of the Norwegian Sea signal versus the Labrador Sea and Iceland Sea signals. This difference is in agreement with deeper mixing in the western section of the subpolar gyre and Nordic Seas, and the poleward advection of surface Atlantic water into the Norwegian Sea.

\section{Summary}

Three shell-derived $\Delta^{14} \mathrm{C}$ time-histories from the eastern North Atlantic were combined with three previously published $\Delta^{14} \mathrm{C}$ records from the western North Atlantic to investigate the temporal and spatial evolution of the $\Delta^{14} \mathrm{C}$ in the surface North Atlantic Ocean. Pre-bomb conditions are more enriched in the subtropical regions than the subpolar regions, and most depleted in the Labrador Sea and most enriched in the Sargasso Sea. This contrast can be explained by 1) deeper convective mixing in the higher-latitude regions, and 2) a depleted source for the subpolar gyre waters of intermediate (AAIW) southern ocean origin, or possibly of Arctic origin via the Davis Strait. The high-latitude time-histories generally show pre-bomb depletions that are consistent with the Suess effect recorded by subtropical North Atlantic corals, but the magnitude of this effect varies greatly, and is much larger on the European shelf than in the western North Atlantic. Very low pre-bomb values $(<-80 \%$ ) in the North Sea and Norway in the 1950s, cannot be 
explained easily by a Suess effect depletion of the overlying atmosphere, and most likely are the result of unusually strong convection / upwelling in the northern North Atlantic during this time.

Initial appearance of the bomb- ${ }^{14} \mathrm{C}$ is synchronous in all North Atlantic $\Delta^{14} \mathrm{C}$ records about 1959 ( \pm 1 year). All North Atlantic $\Delta^{14} \mathrm{C}$ records show a steep rise during the the early to mid-1960s and reach maxima in the late 1960s to late 1970s. The North Sea record has the largest amplitude $(\sim 320 \%)$ and the Iceland record has the smallest $(\sim 120 \%)$. The bomb- ${ }^{14} \mathrm{C}$ signal amplitude and maxima are seen largely as a function of local and regional mixed-layer depth. The southern North Sea record's extremely large amplitude and advanced phase indicates enhanced equilibration owing to local shelf influence. By comparing regional GEOSECS and TTO surface $\Delta^{14} \mathrm{C}$ data to the time history records, the degree of shelf influence can be recognized, corrected for, and used to derive estimated regional surface ocean time histories. The Georges Bank, Norway, and North Sea records have been corrected in this way to produce the first regional $\Delta^{14} \mathrm{C}$ time-series for the Labrador Sea (done in chapter one), Norwegian Sea, and the central eastern North Atlantic. The "corrected" bomb- ${ }^{14} \mathrm{C}$ signals show a sharp contrast between northern (subpolar gyre) and southern (subtropical gyre) regions with remarkable conformity within each of these regions. Despite its high-latitude position, the southern North Sea is clearly more linked with subtropical gyre regions. Florida, Bermuda, and the central eastern North Atlantic have amplitudes and maxima that are double those of the Labrador Sea, Iceland Sea, and Norwegian Sea. These results are consistent with the deeper convection of the high-latitude regions as well as the likely contribution of an intermediate source to the subpolar gyre.

Despite the global climatic and oceanographic importance of high-latitude ocean regions, such as the northern North Atlantic, these areas still remain relatively devoid of radiocarbon data. This study has begun the process of closing this gap by taking advantage 
of $A$. islandica's longevity and wide geographic distribution to compile several radiocarbon time-histories throughout the northern North Atlantic Ocean. The results of this study demonstrate the utility of this new paleoceanographic tool and suggest that its further application combined with denser spatial coverage and higher-temporal resolution can be used to yield a more detailed history of North Atlantic circulation for the past century.

\section{Acknowledgements}

Financial support for this work was provided by NOAA grant \# NA36GPO291, NSF grant \# OCE9301015, Oak Ridge Associated Universities Global Climate Change Fellowship Program, and the WHOI Ocean Ventures Fund. All new radiocarbon analyses for this study were done at the National Ocean Sciences AMS Facility at WHOI. For critical help in collecting specimens, I would like to thank: Steve Murawski and Frank Almeida at the NOAA Northeast Center of National Marine Fisheries Service at Woods Hole for the North Sea specimens; Rindy Ostermann at WHOI, and Jon Olafsson and Hrafnkell Eiriksson, both at the Marine Research Institute in Reykjavik, Iceland for the Iceland specimens; and Jan Sundet of the Norwegian Institute of Fisheries and Aquaculture, Troms $\varnothing$, Norway for the Norway specimens. I would also like to thank Bill Schmitz, Lynne Talley, and Mike McCartney for helping me to understand North Atlantic Ocean circulation. 


\section{References}

Arhan, M., A. Colin De Verdiere and L. Memery, The eastern boundary of the subtropical North Atlantic, J. Phys. Ocean., 24, 1295-1316, 1994.

Bard, E., Correction of accelerator mass spectrometry C14 ages measured in planktonic foraminifera: Paleoceanographic implications, Paleoceanogr., 3, 635-645, 1988.

Bard, E., M. Arnold, J. Mangerud, M. Paterne, L. Labeyrie, J. Duprat, M. A. Melieres, E. Sonstegaard and J. C. Duplessy, The North Atlantic atmosphere-sea surface 14C gradient during the Younger Dryas climatic event, Earth and Planet. Sci. Let., 126, 275287, 1994.

Bonisch, G., and P. Schlosser, Deep water formation and exchange rates in the Greenland/Norwegian Seas and the Eurasian Basin of the Arctic Ocean derived from trace balances, Prog. Oceanog., 35, 29-52, 1995.

Broecker, W. S., A revised estimate for the radiocarbon age of North Atlantic Deep Water, J. Geophys. Res., 84, 3218-3226, 1979.

Broecker, W. S., The great ocean conveyor, Oceanogr., 4, 79-89, 1991.

Broecker, W. S., R. Gerard, M. Ewing and B. C. Heezen, Natural radiocarbon in the Atlantic Ocean, J. Geophys. Res., 65, 2903-2931, 1960.

Broecker, W. S., and E. A. Olson, Lamont radiocarbon measurements VIII, Radiocarbon, 3, 176-204, 1961.

Broecker, W. S., and T. H. Peng, Tracers in the Sea, Lamount-Doherty Geological Observatory Publication, Columbia University, Palisades, N.Y., 1982.

Broecker, W. S., and T. S. Peng, Interhemispheric transport of carbon dioxide by ocean circulation, Nature, 356, 587-589, 1992.

Broecker, W. S., and T. Takahashi, Hydrography of the central Atlantic-IV. Intermediate waters of Antarctic origin, Deep-Sea Res., 28A, 177-193, 1981.

Chapman, D. C., and R. C. Beardsley, On the origin of shelf water in the Middle Atlantic Bight, J. Phys. Ocean., 19, 384-391, 1989.

Dickson, R. P., and J. Brown, The production of North Atlantic Deep Water: sources, rates and pathways, J. Geophys. Res., 99, 12,319-12,341, 1994.

Dickson, R. R., H. H. Lamb, S.-A. Malmberg and J. M. Colebrook, Climatic reversal in northern North Atlantic, Nature, 256, 479-482, 1975.

Dickson, R. R., J. Meincke, S. Malmberg and A. J. Lee, The "Great Salinity Anomaly" in the Northern North Atlantic 1968-1982, Prog. Oceanog., 20, 103-151, 1988. 
Druffel, E. M., Decade time scale variability of ventilation in the North Atlantic: Highprecision measurements of bomb radiocarbon in banded corals, J. Geophys. Res., 94, 3271-3285, 1989.

Druffel, E. M., Radiocarbon in annual coral rings from the eastern tropical Pacific, Geophys. Res. Lett., 8, 59-62, 1981.

Druffel, E. M., and T. W. Linick, Radiocarbon in annual coral rings, Geophys. Res. Lett., 5, 913-916, 1978.

Druffel, E. M., and H. E. Suess, On the radiocarbon record in banded corals: exchange parameters and net transport of $14 \mathrm{CO} 2$ between atmosphere and surface ocean, $J$. Geophys. Res., 88, 1271-1280, 1983.

Ellett, D. J., The north-east Atlantic: A fan-assisted storage heater?, Weather, 48, 118-126, 1993.

Fonselius, S., and G. Ostlund, Natural radiocarbon measurements on the surface water from the North Atlantic and Arctic Sea, Tellus, 11, 77-82, 1959.

Gade, M., Features of fjord and ocean interaction, in: The Nordic Seas, edited by B. G. Hurdle, pp. 183-189, Springer-Verlag, New York, 1986.

Gagnon, A. R., and G. A. Jones, AMS-graphite target production methods at the Woods Hole Oceanographic Institution between 1986-91, Radiocarbon, 35, 301-310, 1993.

Hjort, C., A sea correction for East Greenland, Geologiska Foreningens i Stockholm Forhandlingar, 95, 132-134, 1973.

Johannessen, O. M., Brief overview of the physical oceanography, in: The Nordic Seas, edited by B. G. Hurdle, pp. 103-127, Springer-Verlag, New York, 1986.

Kalish, J. M., Pre- and Post-bomb radiocarbon in fish otoliths, Earth Planet. Sci. Lett., 1993.

Krauss, W., The North Atlantic Current, J. Geophys. Res., 91, 5061-5074, 1986.

Keigwin, L. D., and G. A. Jones, Western North Atlantic evidence for millennial-scale changes in ocean circulation and climate, J. Geophys. Res., 35, 12-397-12,410, 1994.

Lazier, J. R. N., The renewal of the Labrador Sea water, Deep-Sea Res., 20, 341-353, 1973.

Levin, I., B. Kromer, H. Schoch-Fischer, M. Bruns, M. Munnich, D. Berdau, J. C. Vogel and K. O. Munnich, 25 years of Tropospheric 14C Observations in Central Europe, Radiocarbon, 27, 1-19, 1985.

Levin, I., K. O. Munnich and W. Weiss, The effect of anthropogenic CO2 and 14C sources on the distribution of $14 \mathrm{C}$ in the atmosphere, Radiocarbon, 22, 379-391, 1980.

Linick, T. W., P. E. Damon, D. J. Donahue and A. J. T. Jull, Accelerator mass spectrometry: the new revolution in radiocarbon dating, Quat. Internat., 1, 1-6, 1989. 
Maier-Reimer, E., and R. Bacastow, Modelling of geochemical tracers in the ocean, in: Climate-Ocean Interaction, edited by M. E. Schlesinger, pp. 233-267, Kluwer Academic Publishers, Netherlands, 1990.

Mangerud, J., Radiocarbon dating of marine shells, including a discussion of apparent age of Recent shells from Norway, Boreas, 10, 143-172, 1972.

Mangerud, J., and S. Gulliksen, Apparent radiocarbon ages of Recent marine shells from Norway, Spitzbergen, and Arctic Canada, Quatern. Res., 5, 263-273, 1975.

McCartney, M. S., and L. D. Talley, The subpolar Mode Water of the North Atlantic Ocean, J. Phys. Oceanogr., 12, 1169-1188, 1982.

McCartney, M. S., and L. D. Talley, Warm-to-cold conversion in the northern North Atlantic Ocean, J. Phys. Oceanogr., 14, 922-935, 1984.

Meijer, H. A. J., J. V. D. Plicht, J. S. Gislefoss and R. Nydal, Long-time atmospheric $14 \mathrm{C}$ and $3 \mathrm{H}$ record near Groningen (Netherlands) and comparison with the Fruholmen (Norway) and Izana (Canary Islands) 14C stations, Radiocarbon, in press.

Normann, U., Havnmiljødata fra nord-norske fjorder 1991, Fiskeriforskning-Norges fiskerihøgskole, Troms $\varnothing, 1992$.

Nozaki, Y., D. M. Rye, K. K. Turekian and R. E. Dodge, C-13 and C-14 variations in a Bermuda coral, Geophys. Res. Lett., 5, No.10, 825-828, 1978.

Ostlund, H. G., and C. Grall, TTO: Tritium Laboratory Data Report, 16, University of Miami, 1987.

Ostlund, H. G., G. Possnert and J. H. Swift, Ventilation rate of the deep Arctic Ocean from Carbon 14 data, J. Geophys. Res., 92, 3769-3777, 1987.

Pingree, R. D., Flow of surface waters to the west of the British Isles and in the Bay of Biscay, Deep-Sea Res., 40, 369-388, 1993.

Pingree, R. D., and B. Le Cann, Celtic and Armorican slope and shelf residual currents, Prog. Oceanog., 23, 303-338, 1989.

Quay, P. D., M. Stuiver and W. S. Broecker, Upwelling rates for the equatorial Pacific Ocean derived from bomb 14C distribution, J. Mar. Res., 41, 769-792, 1983.

Reid, P. C., A. H. Taylor and J. A. Stephens, The hydrography and hydrographic balances of the North Sea, in: Pollution of the North Sea, edited by W. Salomons, B. L. Bayne, E. K. Duursma and U. Forstner, pp. 3-19, Springer-Verlag, Heidelberg, Germany, 1988.

Revelle, R., and H. E. Suess, Carbon dioxide exchange between atmosphere and ocean and the question of an increase of atmospheric CO2 during the past decades, Tellus, 9, 18-27, 1957.

Rey, F., The development of the spring phytoplankton outburst at selected sites off the Norwegian coast, in: The Norwegian Coastal Current, edited by R. Saetre and M. Mork, pp. 649-680, The University of Bergen, Bergen, 1981. 
Robinson, M. K., R. A. Bauer and E. H. Schroeder, Atlas of North Atlantic - Indian Ocean Monthly Mean Temperatures and Mean Salinities of the Surface Ocean, Naval Oceanographic Office Reference Publication 18, Naval Oceanographic Office, 1979.

Schlosser, P., G. Bonisch, B. Kromer, H. H. Loosi, R. Buhler, R. Bayer, G. Bonani and K. P. Koltermann, Mid-1980s distribution of tritium, 3He, 14C and 39Ar in the Greenland/Norwegian Seas and the Nansen Basin of the Arctic Ocean, Prog. Oceanog., $35,1-28,1995$.

Schlosser, P., G. Bonisch, M. Rhein and R. Bayer, Reduction of deep water formation in the Greenland Sea during the 1980s: evidence from tracer data, Science, 251, 10541056, 1991.

Schmitz, W. J., and M. S. McCartney, On the North Atlantic circulation, Rev. Geophys., 31, 29-49, 1993.

Segl, M., I. Levin, H. Schoch-Fischer, M. Munnich, B. Kromer, J. Tschiersch and K. O. Munnich, Anthropogenic 14C variations, Radiocarbon, 25, 583-592, 1983.

Stefansson, U., North Icelandic Waters, Leiftur Ltd, Reykjavik, 269 p., 1962.

Stefansson, U., and J. Olafsson, Nutrients and fertility of Icelandic waters, J. Mar. Res. Inst. Reykjavik, 12, 1-56, 1991.

Stocker, T. F., and W. S. Broecker, Observation and Modeling of the North Atlantic Deep Water Formation and its Variability: Introduction, J. Geophys. Res., 99, 12,317, 1994.

Stommel, H., A survey of ocean current theory, Deep-Sea Res., 4, 149-184, 1957.

Stuiver, M., and H. G. Ostlund, GEOSECS Atlantic radiocarbon, Radiocarbon, 22, 1-24, 1980.

Stuiver, M., and H. A. Polach, Discussion: Reporting of 14C Data, Radiocarbon, 19, 355363, 1977.

Suess, H. E., Natural radiocarbon and the rate of exchange of $\mathrm{CO} 2$ between the atmosphere and the sea, Proc. of the Conf. on Nuclear Processes in Geological Settings, University of Chicago Press, Chicago, Ill., 52-56, 1953.

Sverdrup, H. V., M. W. Johnson and R. H. Fleming, The Oceans, Prentice-Hall, 1087p., 1942.

Tanaka, N., M. C. Monaghan and K. K. Turekian, C14 balance for the Gulf of Maine, Long Island Sound and the northern Middle Atlantic Bight: evidence for the extent of the Antarctic Intermediate Water contribution, J. Mar. Res., 48, 75-87, 1990.

Tans, P. P., A. F. M. De Jong and W. G. Mook, Natural atmospheric $14 \mathrm{C}$ variation and the Suess effect, Nature, 280, 826-828, 1979.

Toggweiler, J. R., K. Dixon and W. S. Broecker, The Peru upwelling and the ventilation of the South Pacific thermocline, J. Geophys. Res., 96, 20,467-20,497, 1991. 
Toggweiler, J. R., K. Dixon and K. Bryan, Simulations of radiocarbon in a coarseresolution world ocean model, 1, steady state prebomb distributions, J. Geophys. Res., 94, 8217-8242, 1989a.

Toggweiler, J. R., K. Dixon and K. Bryan, Simulations of radiocarbon in a coarseresolution world ocean model, 2, distributions of bomb-produced carbon 14, J. Geophys. Res., 94, 8243-8264, 1989 b.

Tsuchiya, M., Circulation of the Antarctic Intermediate Water in the North Atlantic Ocean, J. Mar. Res., 47, 747-755, 1989.

Warren, B. A., Evolution of Physical Oceanography, MIT Press, Cambridge, Mass., 1981.

Weidman, C. W., and G. A. Jones, A shell-derived C14 Time History on Georges Bank and its Labrador Sea Implications, J. Geophys. Res., 98, 14,577-14588, 1993.

Worthington, L. V., The Norwegian Sea as a mediterranean basin, Deep-Sea Res., 17, 7784, 1970. 
Table 1. North Atlantic $\Delta^{14} \mathrm{C}$ Time Histories derived from Arctica islandica shells.

A. North Sea-German Bight $\left(54^{\circ} \mathrm{N}, 6^{\circ} \mathrm{E}\right) \sim 37 \mathrm{~m}$ depth

\begin{tabular}{|c|c|c|c|c|c|}
\hline Year & $\Delta^{14} \underline{C}$ & $\pm \varepsilon$ & \multicolumn{2}{|c|}{$\delta^{13} \underline{C}^{1}$ Shell ID } & Accession ID \\
\hline 1948* & -50.0 & 3.9 & 2.0 & $\mathrm{~N}-8 \mathrm{~A}$ & OS-0093 \\
\hline $1950 *$ & -64.1 & 12.2 & 2.0 & $\mathrm{~N}-8 \mathrm{~A}$ & OS-0094 \\
\hline 1954* & -83.3 & 13.2 & 2.0 & $\mathrm{~N}-8 \mathrm{~A}$ & rec \#1018 \\
\hline 1959* & -24.2 & 3.9 & 2.0 & $\mathrm{~N}-8 \mathrm{~A}$ & OS-0090 \\
\hline 1960 & +9.5 & 7.8 & 2.0 & N-8A II & OS-1351 \\
\hline 1961-1963* & +26.2 & 4.3 & 2.0 & $\mathrm{~N}-8 \mathrm{~A}$ & OS-0089 \\
\hline 1963-1964 & +116.6 & 9.1 & 2.0 & $\mathrm{~N}-8$ A II & OS-1349 \\
\hline 1966 & +234.2 & 8.5 & 2.0 & $\mathrm{~N}-1 \mathrm{~B}$ & OS- 0130 \\
\hline 1967-1968 & +239.3 & 13.3 & 2.0 & N-8A II & OS- 1350 \\
\hline 1969 & +222.8 & 7.6 & 2.0 & $\mathrm{~N}-1 \mathrm{~B}$ & OS- 0128 \\
\hline 1969-1971* & +210.7 & 4.1 & 2.0 & $\mathrm{~N}-8 \mathrm{~A}$ & OS-0091 \\
\hline 1970 & +228.4 & 5.0 & 2.0 & $\mathrm{~N}-1 \mathrm{~B}$ & OS-0642 \\
\hline $1971-1972$ & +216.7 & 3.8 & 2.0 & $\mathrm{~N}-8 \mathrm{~A}$ II & OS-1424 \\
\hline 1974 & +220.4 & 6.2 & 2.0 & $\mathrm{~N}-1 \mathrm{~B}$ & OS-0099 \\
\hline 1974-1975* & +216.0 & 10.5 & 2.0 & $\mathrm{~N}-8 \mathrm{~A}$ & OS- 0088 \\
\hline 1976 & +186.7 & 3.7 & 2.0 & $\mathrm{~N}-8 \mathrm{~A}$ II & OS-1400 \\
\hline 1980-1981 & +173.0 & 5.4 & 2.0 & $\mathrm{~N}-1 \mathrm{~B}$ & OS-0097 \\
\hline 1979-1983* & +133.7 & 13.5 & 2.0 & $\mathrm{~N}-8 \mathrm{~A}$ & OS-0087 \\
\hline 1982-1987 & +137.2 & 6.1 & 2.0 & $\mathrm{~N}-1 \mathrm{~B}$ & OS-0096 \\
\hline $1989-1990$ & +126.4 & 7.0 & 2.0 & $\mathrm{~N}-1 \mathrm{~B}$ & OS-0131 \\
\hline
\end{tabular}

* these dates have been lagged by 7 years from those originally logged because of an error in logging these samples. Samples from N-8A II (adjacent slice from same shell) were later run to corroborate this 7-year shift.

1. $\delta^{13} \mathrm{C}$ assumed from mean of the Iceland and Notway shells

B. Iceland-Siglufjodur $\left(66^{\circ} \mathrm{N}, 19^{\circ} \mathrm{W}\right) 22 \mathrm{~m}$ depth

\begin{tabular}{llllll} 
Year & $\Delta^{14} \mathrm{C}$ & $\pm \varepsilon$ & $\delta^{13} \mathrm{C}$ & Shell ID & Accession ID \\
\cline { 5 - 6 } $1872-1876$ & -55.0 & 3.5 & 2.6 & $\mathrm{I}-1-1 \mathrm{~A}$ & OS-2667 \\
$1892-1896$ & -53.8 & 3.3 & 2.5 & $\mathrm{I}-1-1 \mathrm{~A}$ & OS-2666 \\
$1912-1921$ & -59.5 & 3.5 & 1.9 & $\mathrm{I}-1-1 \mathrm{~A}$ & OS-2665 \\
$1942-1951$ & -54.8 & 3.8 & 1.8 & $\mathrm{I}-1-1 \mathrm{~A}$ & OS-2664 \\
1958 & -44.4 & 3.6 & 1.9 & $\mathrm{I}-1-13 \mathrm{~B}$ & OS-2736 \\
1960 & -22.3 & 5.3 & 1.8 & $\mathrm{I}-1-13 \mathrm{~B}$ & OS-2733 \\
1964 & +22.9 & 4.9 & 2.6 & $\mathrm{I}-1-13 \mathrm{~B}$ & OS-2731 \\
$1968-1969$ & +41.1 & 4.3 & 2.3 & $\mathrm{I}-1-13 \mathrm{~B}$ & OS-2734 \\
$1970-1971$ & +56.9 & 7.3 & 2.0 & $\mathrm{I}-1-13 \mathrm{~B}$ & OS-2730 \\
$1972-1973$ & +44.2 & 4.4 & 1.8 & $\mathrm{I}-1-13 \mathrm{~B}$ & OS-2735 \\
$1974-1975$ & +47.8 & 4.8 & 1.3 & $\mathrm{I}-1-6 \mathrm{~B}$ & OS-2672 \\
1976 & +40.8 & 4.1 & 1.7 & $\mathrm{I}-1-6 \mathrm{~B}$ & OS-2671 \\
$1974-1979$ & +53.3 & 4.8 & 1.7 & $\mathrm{I}-1-13 \mathrm{~B}$ & OS-2732 \\
1979 & +51.9 & 5.5 & 1.9 & $\mathrm{I}-1-6 \mathrm{~B}$ & OS-2669 \\
$1982-1983$ & +34.9 & 6.1 & 1.9 & $\mathrm{I}-1-6 \mathrm{~B}$ & OS-2673 \\
1987 & +43.7 & 4.4 & 1.8 & $\mathrm{I}-1-6 \mathrm{~B}$ & OS-2670 \\
1991 & +35.7 & 4.2 & 1.6 & $\mathrm{I}-1-6 \mathrm{~B}$ & OS-2668
\end{tabular}


Table 1. North Atlantic $\Delta{ }^{14} \mathrm{C}$ Time Histories derived from Arctica islandica shells.

C. Norway, Tromso $\left(70^{\circ} \mathrm{N}, 19^{\circ} \mathrm{E}\right) 3 \mathrm{~m}$ depth

\begin{tabular}{lrrlll} 
Year & $\Delta^{14} \mathrm{C}$ & $\pm \varepsilon$ & $\delta^{13} \mathrm{C}$ & Shell ID & Accession ID \\
\hline 1940 & -44.5 & 3.0 & 2.5 & $\mathrm{~T}-2 \mathrm{~A}$ & OS-3019 \\
1945 & -62.2 & 5.8 & 2.4 & $\mathrm{~T}-2 \mathrm{~A}$ & OS-3018 \\
$1951-1952$ & -54.7 & 3.1 & 2.5 & $\mathrm{~T}-2 \mathrm{~A}$ & OS-3017 \\
$1956-1957$ & -82.3 & 5.0 & 2.5 & $\mathrm{~T}-2 \mathrm{~A}$ & OS-3016 \\
$1959-1960$ & -34.2 & 3.5 & 1.8 & $\mathrm{~T}-2 \mathrm{~A}$ & OS-3015 \\
$1962-1963$ & +8.0 & 3.2 & 1.9 & $\mathrm{~T}-2 \mathrm{~A}$ & OS-2865 \\
$1965-1966$ & +61.9 & 10.7 & 2.1 & $\mathrm{~T}-2 \mathrm{~A}$ & rec \#-6163 \\
$1969-1970$ & +132.2 & 4.3 & 1.8 & $\mathrm{~T}-2 \mathrm{~A}$ & OS-2864 \\
$1973-1974$ & +105.3 & 3.8 & 2.1 & $\mathrm{~T}-2 \mathrm{~A}$ & OS-2863 \\
$1976-1977$ & +122.3 & 3.3 & 1.8 & $\mathrm{~T}-2 \mathrm{~A}$ & OS-2852 \\
$1979-1980$ & +100.0 & 5.4 & 1.7 & $\mathrm{~T}-2 \mathrm{~A}$ & OS-2851 \\
$1982-1984$ & +97.0 & 4.0 & 1.7 & $\mathrm{~T}-2 \mathrm{~A}$ & OS-3527 \\
$1988-1990$ & +62.4 & 4.0 & 1.52 & $\mathrm{~T}-2 \mathrm{~A}$ & OS-2738 \\
$1992-1993$ & +64.6 & 4.5 & 1.3 & $\mathrm{~T}-2 \mathrm{~A}$ & OS-2737
\end{tabular}

$2 . \delta^{13} \mathrm{C}$ linearly interpolated from adjacent values

D. Georges Bank $\left(41^{\circ} \mathrm{N}, 67^{\circ} \mathrm{W}\right) 76 \mathrm{~m}$ depth

\begin{tabular}{lllllll} 
Year & $\Delta^{14} \mathrm{C}$ & $\pm \varepsilon$ & & $\delta^{13} \underline{C}^{3}$ & Shell ID & Accession ID \\
\hline & & & & & & \\
1939 & -61.3 & 6.2 & 2.3 & GB61-7-1B & AA 6922 \\
1942 & -64.4 & 6.1 & 2.3 & GB61-7-1B & AA 6923 \\
$1945-1946$ & -70.6 & 6.2 & 2.3 & GB61-7-1B & AA 6924 \\
$1948-1949$ & -65.3 & 6.3 & 2.3 & GB61-7-1B & AA 6925 \\
$1951-1952$ & -74.6 & 6.2 & 2.3 & GB61-7-1B & AA 6927 \\
$1954-1955$ & -66.0 & 6.2 & 2.3 & GB61-7-1B & AA 6928 \\
$1959-1960$ & -34.4 & 6.4 & 2.3 & GB61-7-1B & AA 6929 \\
$1963-1965$ & +32.3 & 6.7 & 2.3 & GB61-7-1B & AA 6930 \\
$1968-1970$ & +74.8 & 7.4 & 2.3 & GB61-7-1B & AA 6932 \\
$1973-1975$ & +77.0 & 7.6 & 2.3 & GB61-7-1B & AA 6933 \\
$1978-1980$ & +47.7 & 7.5 & 2.3 & GB61-7-1B & AA 6934 \\
$1983-1985$ & +51.1 & 7.7 & 2.3 & GB61-71B & AA 6935 \\
$1988-1990$ & +42.8 & 7.4 & 2.3 & GB61-7-1B & AA 6936
\end{tabular}

3. $\delta^{13} \mathrm{C}$ assumed from mean of 214 analysis from specimen from Nantucket Shoals 
Table 2: North Atlantic ${ }^{14} \mathrm{C}$ Time History Summary

\begin{tabular}{lcclcccc} 
Location & (Lat., Long) & $\begin{array}{c}\text { Pre-Bomb } \\
(<1958 / \sim 1950)\end{array}$ & $\begin{array}{l}\text { Pre-Bomb } \\
\text { Minimum }(Y)\end{array}$ & $\begin{array}{c}\text { Post-Bomb } \\
\text { Maximum (Yr) }\end{array}$ & $\begin{array}{c}\text { Amplitude } \\
\text { Suess Effect } \\
\sim 1940+\end{array}$ & $\begin{array}{c}\text { Decay } \\
(\% \text { amplitude })\end{array}$ \\
\hline Florida & $\left(25^{\circ} \mathrm{N}, 83^{\circ} \mathrm{W}\right)$ & $-59 /-65$ & $-66(1952)$ & $+156(1970)$ & 222 & $-11 \% 0$ & -- \\
Bermuda & $\left(32^{\circ} \mathrm{N}, 64^{\circ} \mathrm{W}\right)$ & $-47 /-49$ & $-55(1952)$ & $+159(1977)$ & 214 & $-18 \%$ & -- \\
Georges Bank $\left(41^{\circ} \mathrm{N}, 67^{\circ} \mathrm{W}\right)$ & $-75 /-70$ & $-75(1951-52)$ & $+77(1973-75)$ & 152 & $-13 \% 0$ & 22 \\
North Sea & $\left(54^{\circ} \mathrm{N}, 6^{\circ} \mathrm{E}\right)$ & $-66 /-57$ & $-83(1954)$ & $+239(1967-68)$ & 322 & $-33 \%$ & 35 \\
Iceland & $\left(66^{\circ} \mathrm{N}, 19^{\circ} \mathrm{W}\right)$ & $-56 /-55$ & $-60(1912-21)$ & $+57(1970-71)$ & 117 & $\sim 0 \% 0$ & 18 \\
Norway & $\left(70^{\circ} \mathrm{N}, 19^{\circ} \mathrm{E}\right)$ & $-61 /-55$ & $-82(1956-57)$ & $+132(1969-70)$ & 214 & $-36 \% 0$ & 32 \\
\hline
\end{tabular}


Table 3: North Atlantic ${ }^{14} \mathrm{C}$ Time History and Ocean Data Summary

\begin{tabular}{lccc} 
Location & $\sim 1972$ (GEOSECS) & $\sim 1981$ (TTO) & TC Depth \\
\hline Sub-Trop & $139 \% 0$ & $131 \% 0$ & 208 \\
Florida & $155 \% 0$ & $128 \% 0$ & \\
Bermuda & $154 \% 0$ & $148 \% 0$ & \\
\hline Transitional & --- & $109 \% 0$ & 303 \\
North Sea & $218 \% 0$ & $153 \% 0$ & \\
\hline W. Sub-Pol & $54 \% 0$ & $46 \% 0$ & 701 \\
Georges Bank & $76 \% 0$ & $49 \% 0$ & \\
Iceland & $44 \% 0$ & $43 \% 0$ & \\
\hline E. Sub-Pol & $54 \% 0$ & $63 \% 0$ & 563 \\
Norway & $119 \% 0$ & $99 \% 0$ & \\
\hline
\end{tabular}


Table 4a: Estimated $\triangle 14 \mathrm{C}$ Time History for the Central Eastern North Atlantic

\begin{tabular}{lcc}
\hline Date & Atmosphere & \\
& $\Delta 14 \mathrm{C}$ & Estimated Ocean \\
& & $\Delta 14 \mathrm{C}$ \\
\hline & & \\
1947 & -30 & -56 \\
1949 & -30 & -74 \\
1953 & -30 & -98 \\
1958 & +130 & -68 \\
1959 & +227 & -52 \\
$1960-1962$ & +266 & -41 \\
$1962-1963$ & +537 & -2 \\
1965 & +755 & +87 \\
$1966-1967$ & +658 & +121 \\
1968 & +564 & +127 \\
$1968-1970$ & +543 & +117 \\
1969 & +544 & +139 \\
$1970-1971$ & +510 & +134 \\
1973 & +429 & +162 \\
$1973-1974$ & +415 & +160 \\
1975 & +361 & +138 \\
$1979-1980$ & +263 & +129 \\
$1978-1982$ & +256 & +109 \\
$1981-1986$ & +199 & +120 \\
$1988-1989$ & +148 & +120 \\
& & \\
\hline
\end{tabular}

Table 4b: Estimated $\Delta 14 \mathrm{C}$ Time History for the Norwegian Sea

\begin{tabular}{lcc}
\hline Date & $\begin{array}{c}\text { Atmosphere } \\
\Delta 14 \mathrm{C}\end{array}$ & $\begin{array}{c}\text { Estimated Ocean } \\
\Delta 14 \mathrm{C}\end{array}$ \\
& & \\
\hline 1939 & -30 & -47 \\
1944 & -30 & -68 \\
$1950-1951$ & -30 & -59 \\
$1955-1956$ & +30 & -102 \\
$1958-1959$ & +179 & -72 \\
$1961-1962$ & +292 & -42 \\
$1964-1965$ & +795 & -67 \\
$1968-1969$ & +554 & +58 \\
$1972-1973$ & +447 & +45 \\
$1975-1976$ & +346 & +83 \\
$1978-1979$ & +287 & +67 \\
$1981-1983$ & +220 & +75 \\
$1987-1989$ & +153 & +46 \\
$1991-1992$ & +114 & +56 \\
& & \\
\hline
\end{tabular}

* Atmospheric record is shown in Figure 3 and is a compilation of pre-bomb data from Tans, et al. [1979], and post-bomb data from Levin, et al. [1985] and Meijer, et al. [in press]. 


\section{Figure Captions}

Figure 1a. General surface circulation patterns of the surface North Atlantic Ocean (after Sverdrup, et al., 1942) and radiocarbon time history locations $(\Delta)$.

Figure 1b. Mean February water temperatures at $150 \mathrm{~m}$ depth (after Robinson, et al., 1979 ) and radiocarbon time history locations $(\Delta)$. These isotherm patterns vary very little throughout the year.

Figure 1c. Mean February depth to thermocline ( annual maximum mixed-layer depth defined here by the depth where temperature is $1.1^{\circ} \mathrm{C}$ less than that of the surface) (after Robinson, et al., 1979) and radiocarbon time history locations $(\Delta)$.

Figure 2(a-f). Radiocarbon time histories for six locations in the North Atlantic Ocean. Eastern North Atlantic shell-derived records (new results): a) North Sea; b) Iceland; c) Norway. Western North Atlantic shell- and coral-derived records (previously published results): d) Bermuda (Druffel, 1989); e) Florida (Druffel, 1989); f) Georges Bank (Weidman and Jones, 1993).

Figure 3. Antarctic Intermediate Water Distribution in the North Atlantic: a) Silica $(\mu \mathrm{mol} / \mathrm{l})$ on the isopycnal whose depth is shown in b) Depth (x $100 \mathrm{~m}$ ) of AAIW core as identified by Tsushiya [1989] (from Tsushiya, 1989). Note that this surface outcrops in the Labrador and Irminger Seas. Comparing (b) with Figure 1c note that this core is accessible to convection almost everywhere north of the subpolar front.

Figure 4. a) Steady state OGCM $\Delta^{14} \mathrm{C}$ results from a) Maier-Reimer and Bacastow, 1990, and b) Toggweiler, et al., 1989. The Maier-Reimer and Bacastow results reproduce a more realistic surface northern North Atlantic than Toggweiler's results owing to what appears to be the greater northward penetration of the former's AAIW analog (centered at $\sim 1000 \mathrm{~m}$ at the equator).

Figure 5. Atmospheric bomb- ${ }^{14} \mathrm{C}$ signal (dashed line) modelled ocean bomb- ${ }^{14} \mathrm{C}$ signals (solid lines) in a simple mixed-layer ocean as a function of layer depth (or gas exchange rate). Shallower depths (or increased gas exchange rates) result in a reduced signal amplitude and earlier phase shift.

Figure 6. Distribution of wind speed dependent gas exchange rates ( $\mathrm{mol} / \mathrm{m} 2 / \mathrm{yr}$ ) (from Toggweiler, et al., 1989a).

Figure 7. North Atlantic surface $\Delta^{14} \mathrm{C}$ (GEOSECS (stars) and TTO (circles) data) versus February ( annual maximum) mean depth to thermocline at those same locations. There is a strong correlation (GEOSECS:dashed line; TTO: solid line) between surface $\Delta^{14} \mathrm{C}$ and winter mixed-layer depth.

Figure 8. Estimated central eastern North Atlantic $\Delta^{14} \mathrm{C}$ signals (dashed lines) based on the North Sea ${ }^{14} \mathrm{C}$ time history (solid line) and back-corrected for shelf influence using various uptake coefficients from 0.20 to 0.35 . The $\Delta^{14} \mathrm{C}$ time history estimates are compared to the regional mean for the central eastern North Atlantic (solid circle) for $\sim 1981$ (TTO). 
Figure 9. Estimated Norwegian Sea $\Delta^{14} \mathrm{C}$ signals (dashed lines) based on the Troms $\varnothing y$ sund $\Delta^{14} \mathrm{C}$ time history (solid line) and back-corrected for shelf influence using various uptake coefficients from 0.10 to 0.20 . The $\Delta^{14} \mathrm{C}$ time history estimates are compared to the regional means for the Norwegian Sea (solid circles) for $\sim 1972$ (GEOSECS) and 1981 (TTO).

Figure 10. Combined North Atlantic Ocean $\Delta^{14} \mathrm{C}$ Time Histories (corrected for shelf effects). A strong signal contrast exists between subpolar and subtropical gyre influenced regions and close agreement among the signals within these regions. The subtropical gyre region signals have a much larger amplitude than the subpolar region signals. 


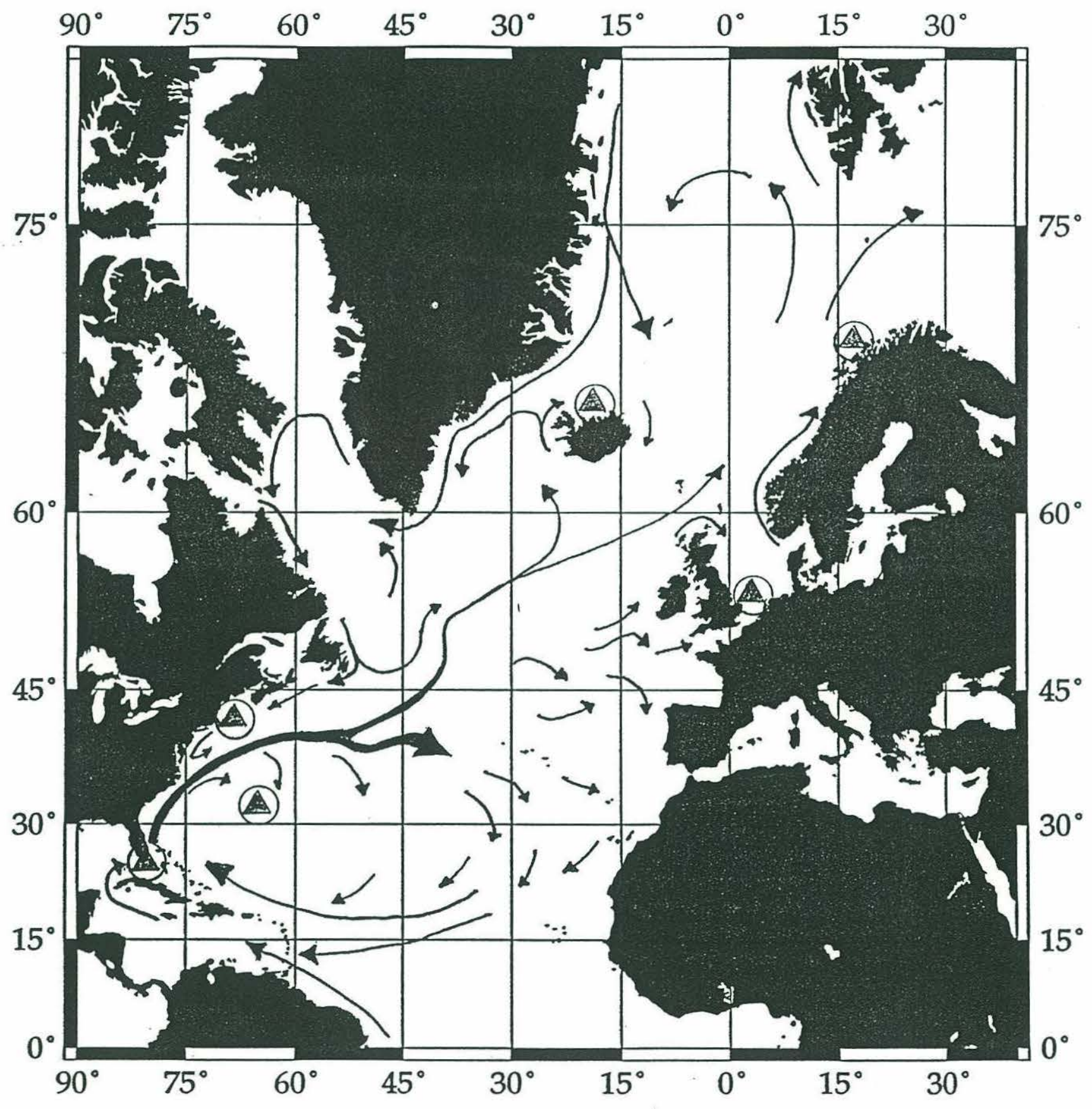

Figure 1a 


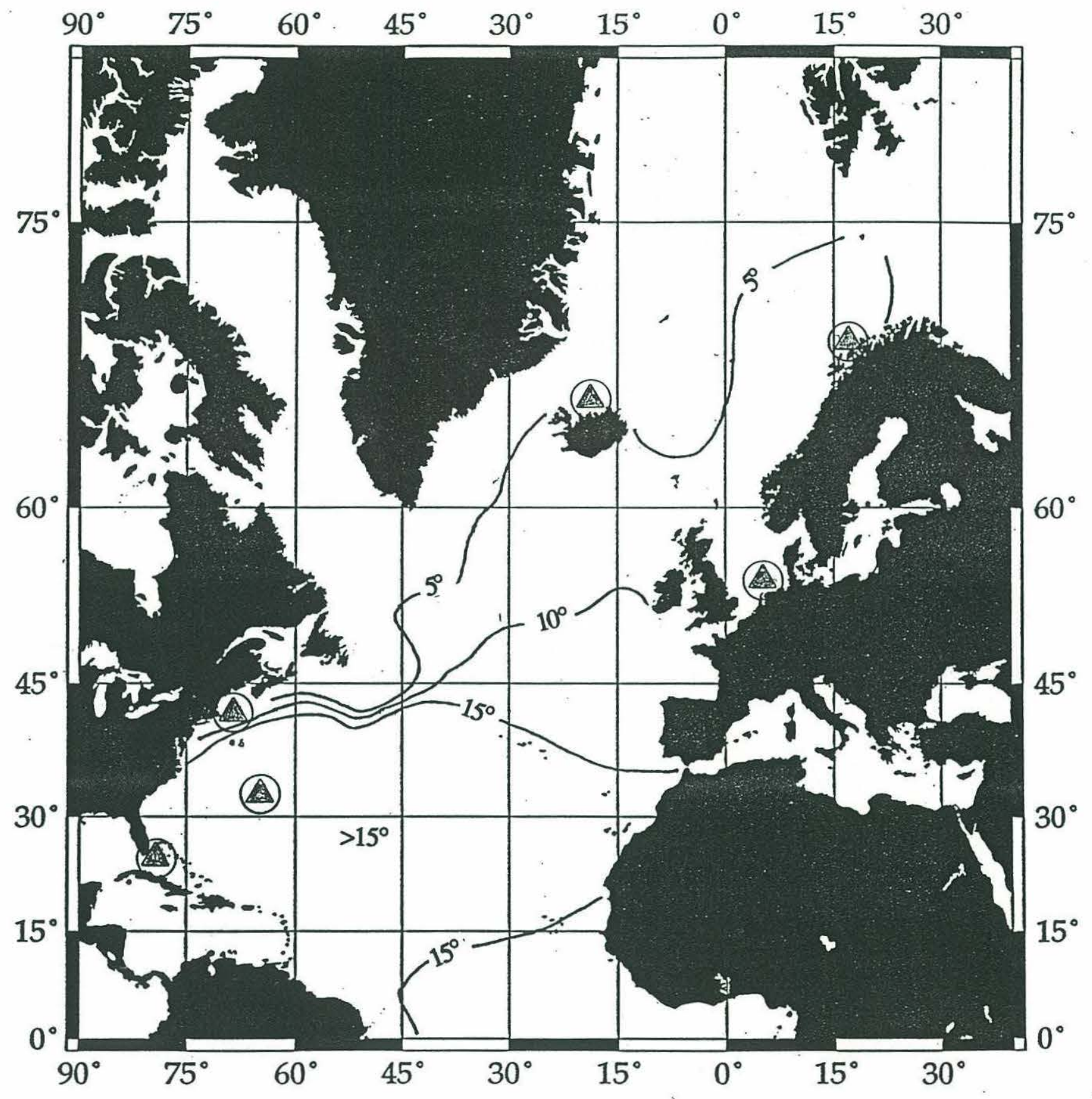




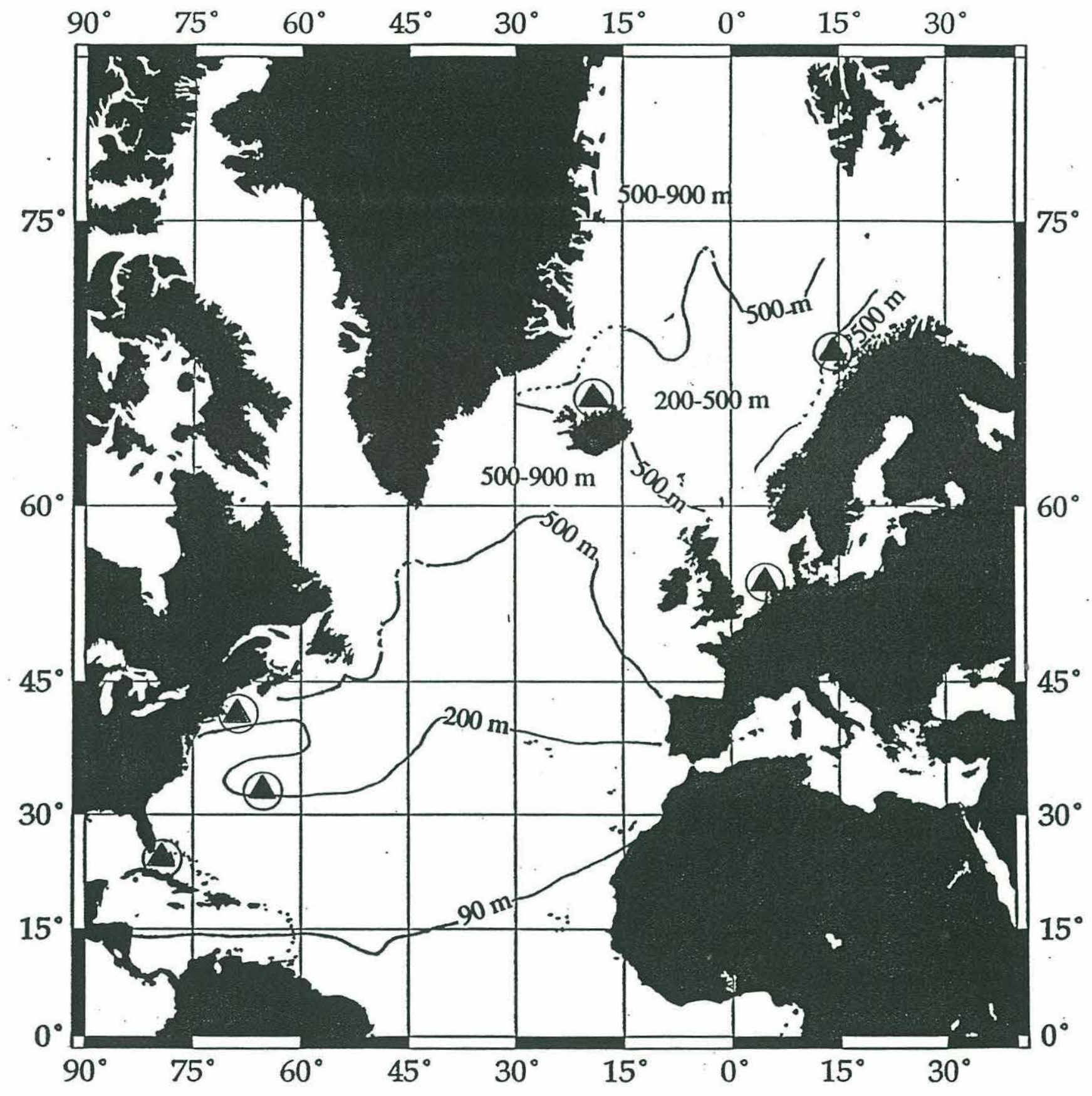

Figure 1c 
A) North Sea

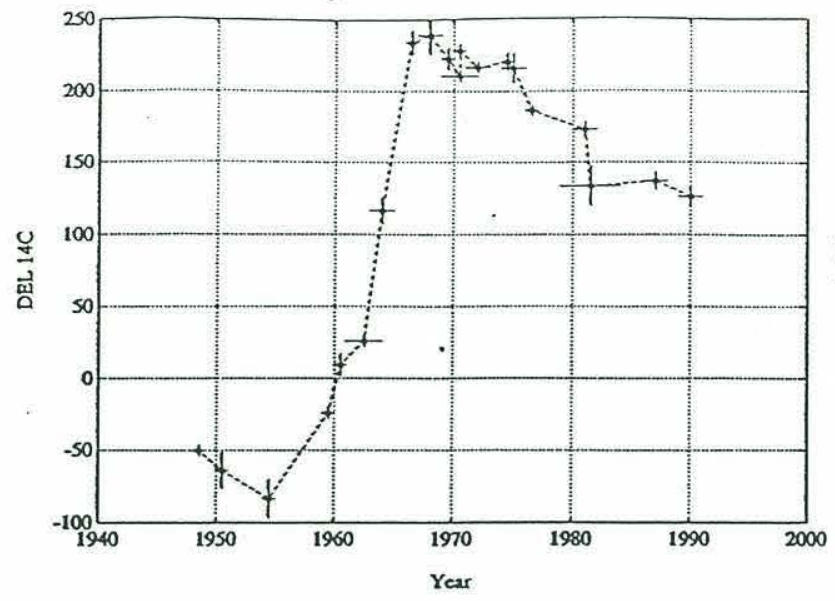

B) Iceland

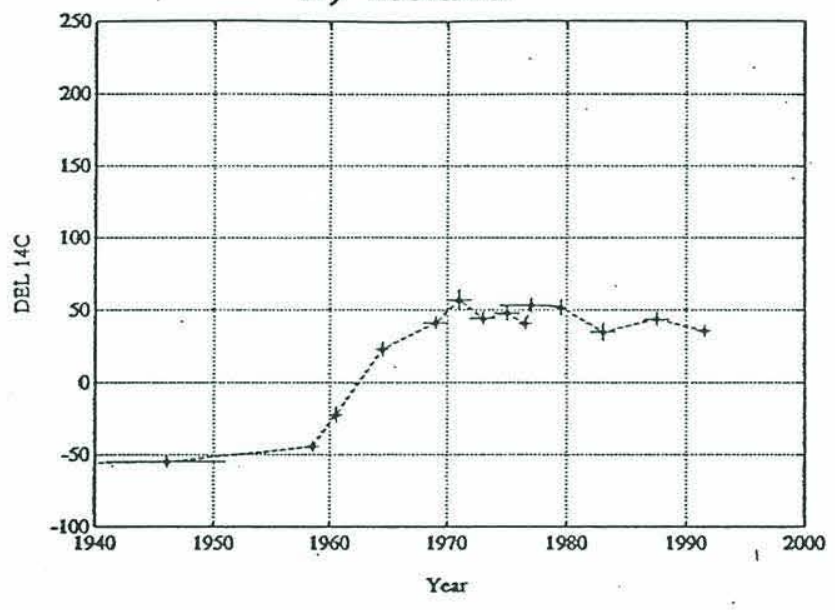

C) Norway

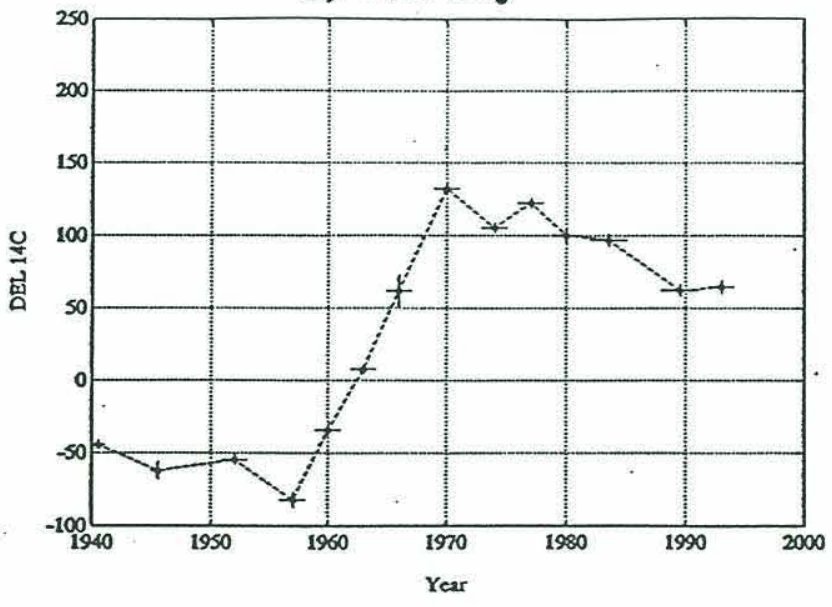

D) Bermuda

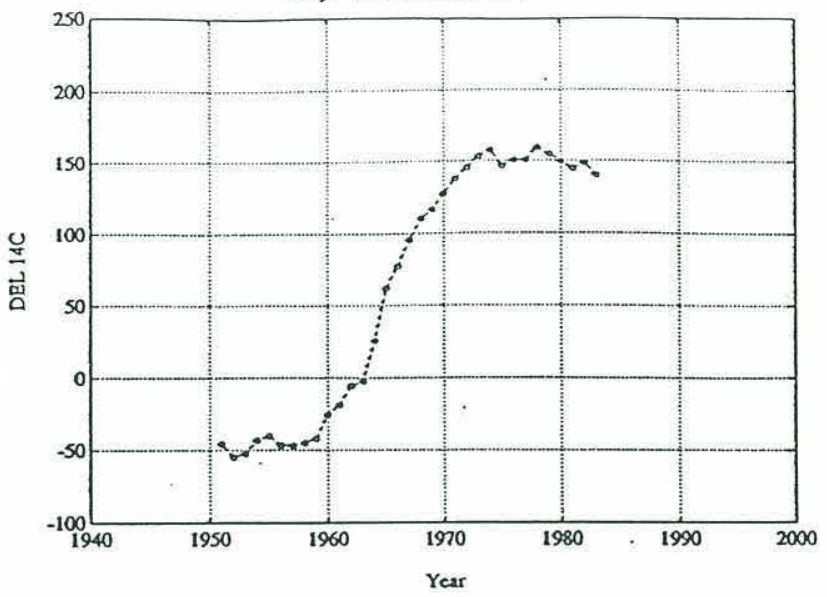

E) Florida

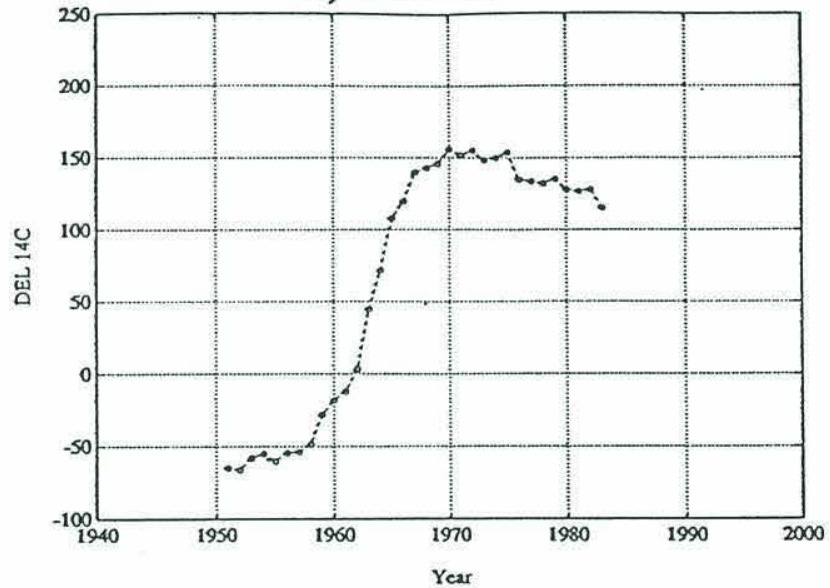

F) Georges Bank

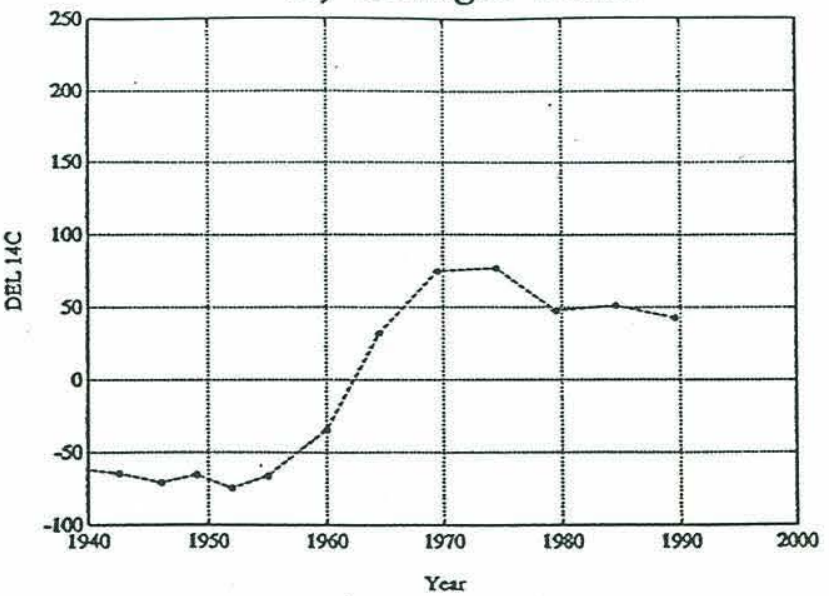



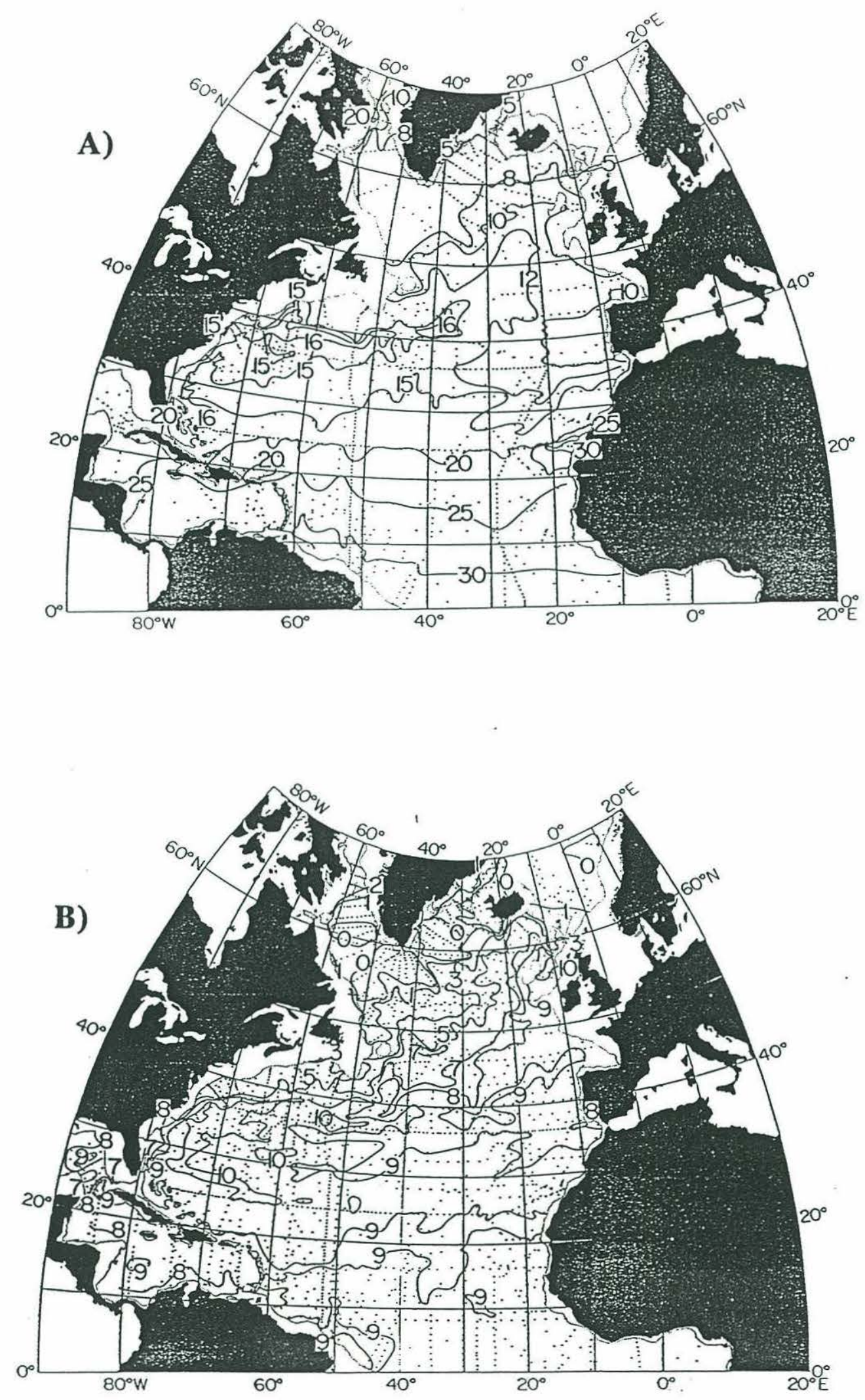

Figure 3 
OGCM results (steady state) ${ }^{14} \mathrm{C}$ Distribution (from Maier-Reimer and Bacastow, 1990)
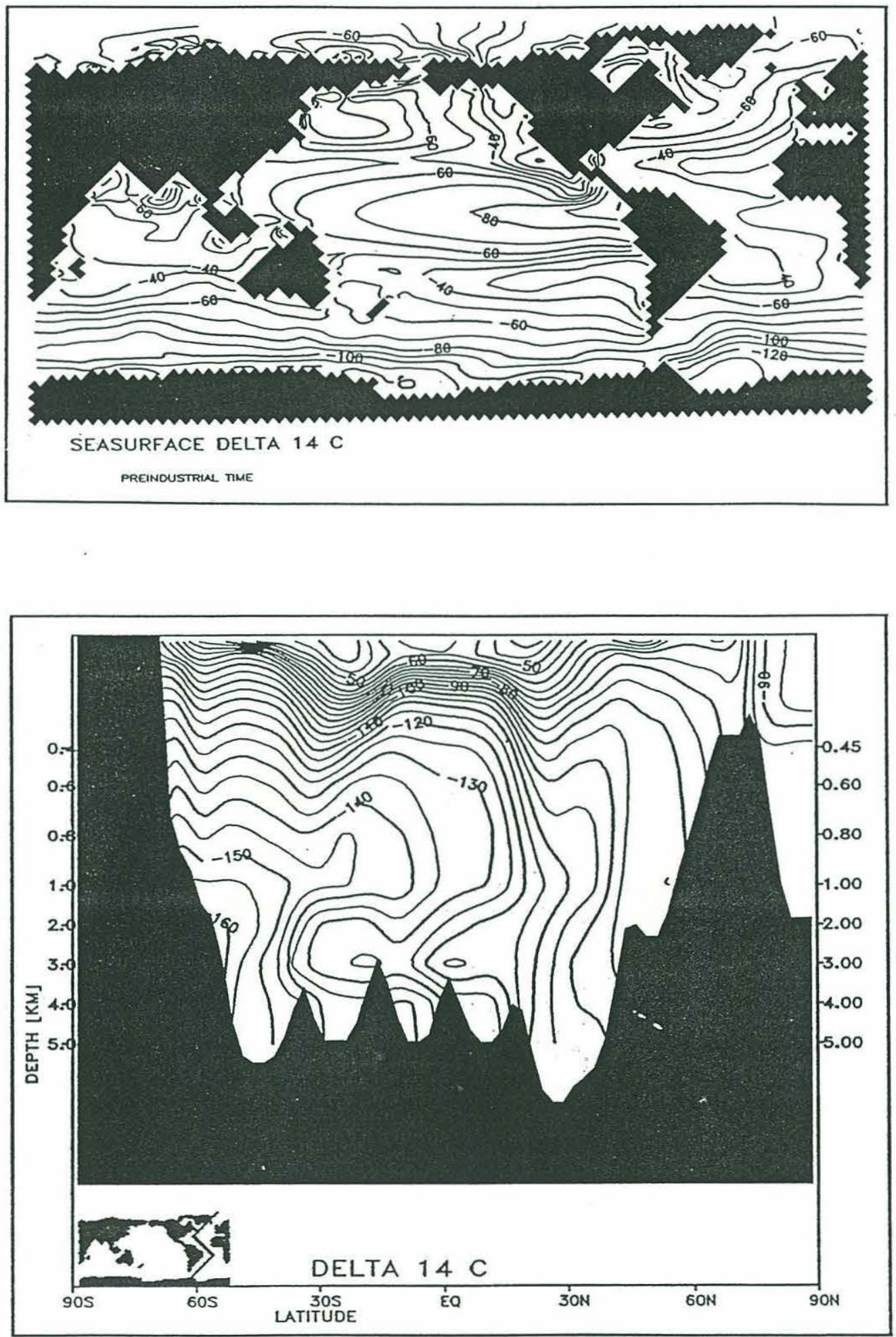

Figure $4 a$ 


\section{OGCM results (steady state) ${ }^{14} \mathrm{C}$ Distribution (from Toggweiler, et al., 1989)}
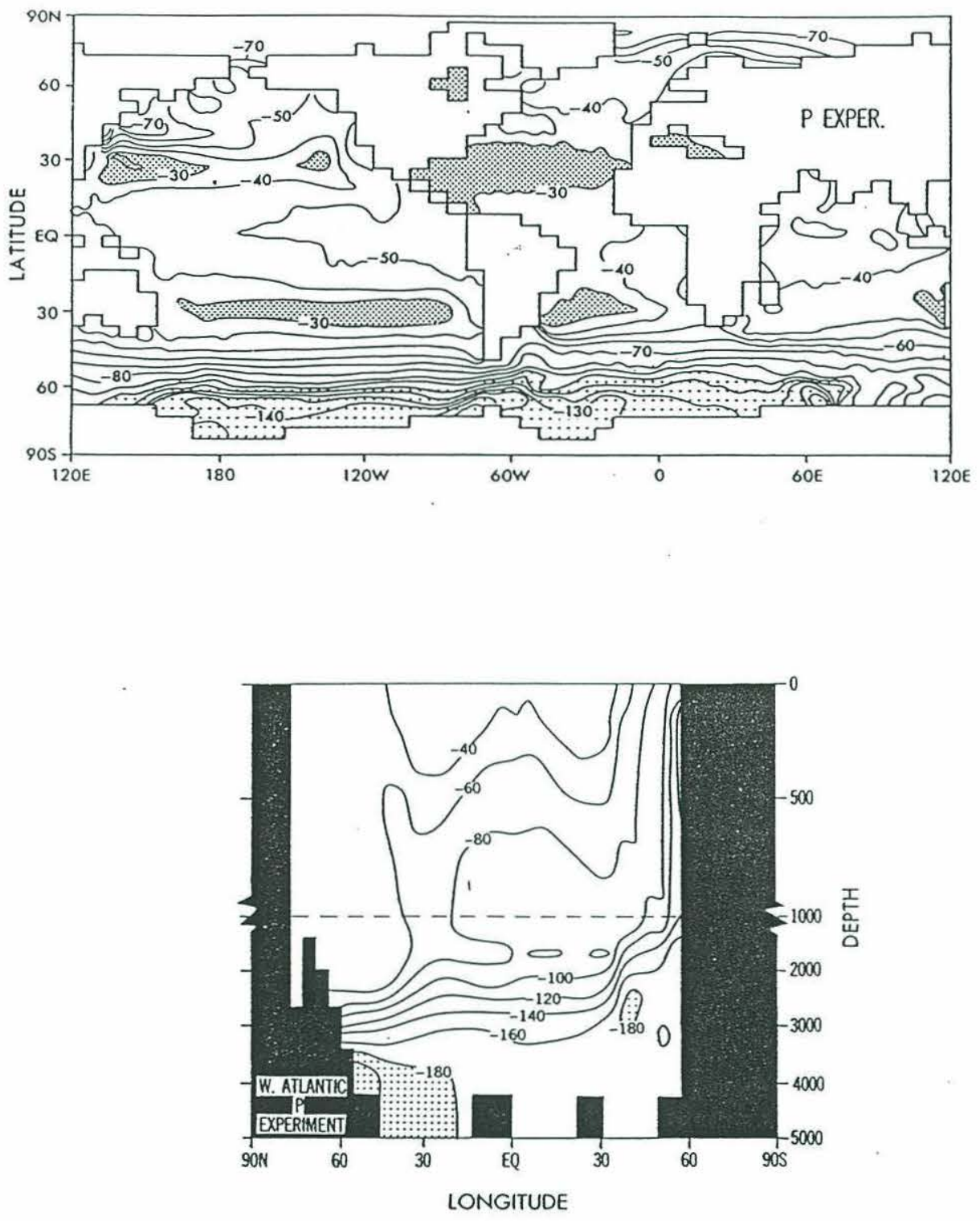


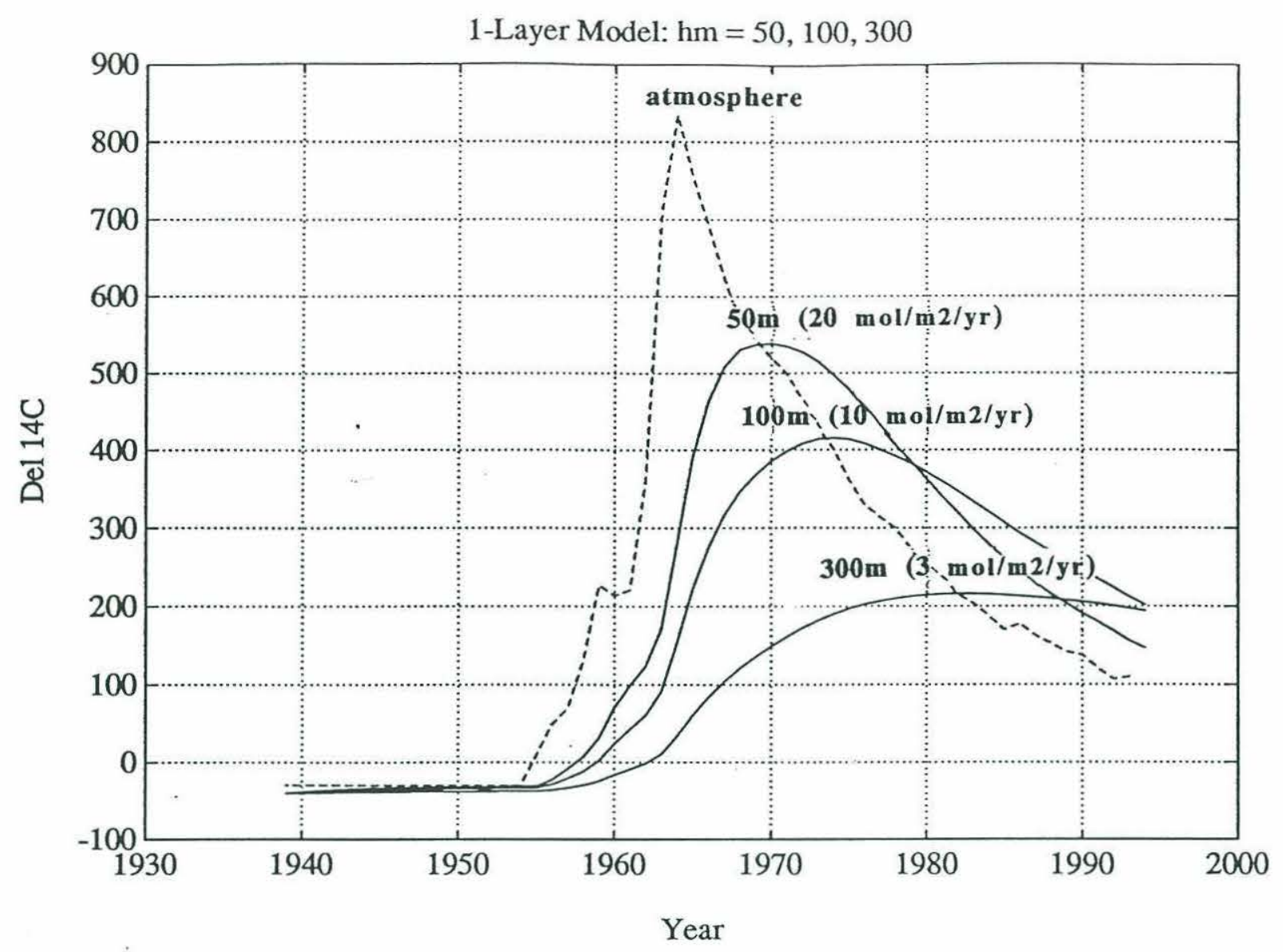

Figure 5 


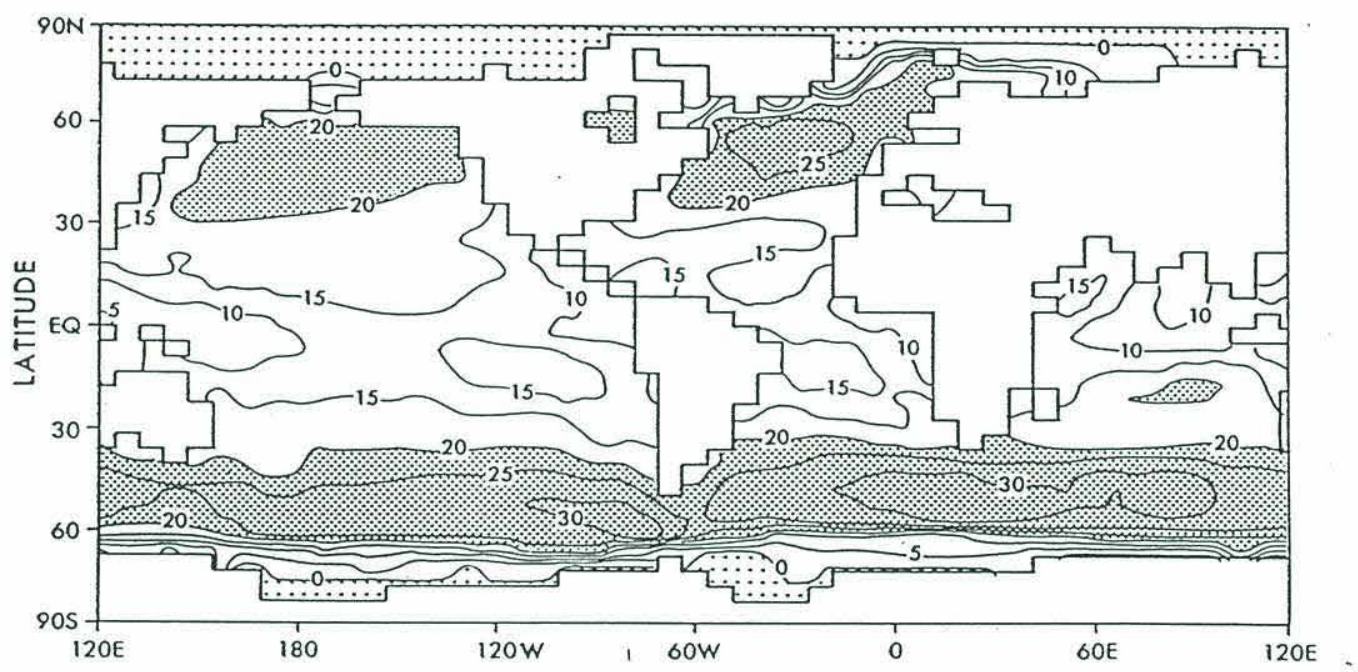

Figure 6 


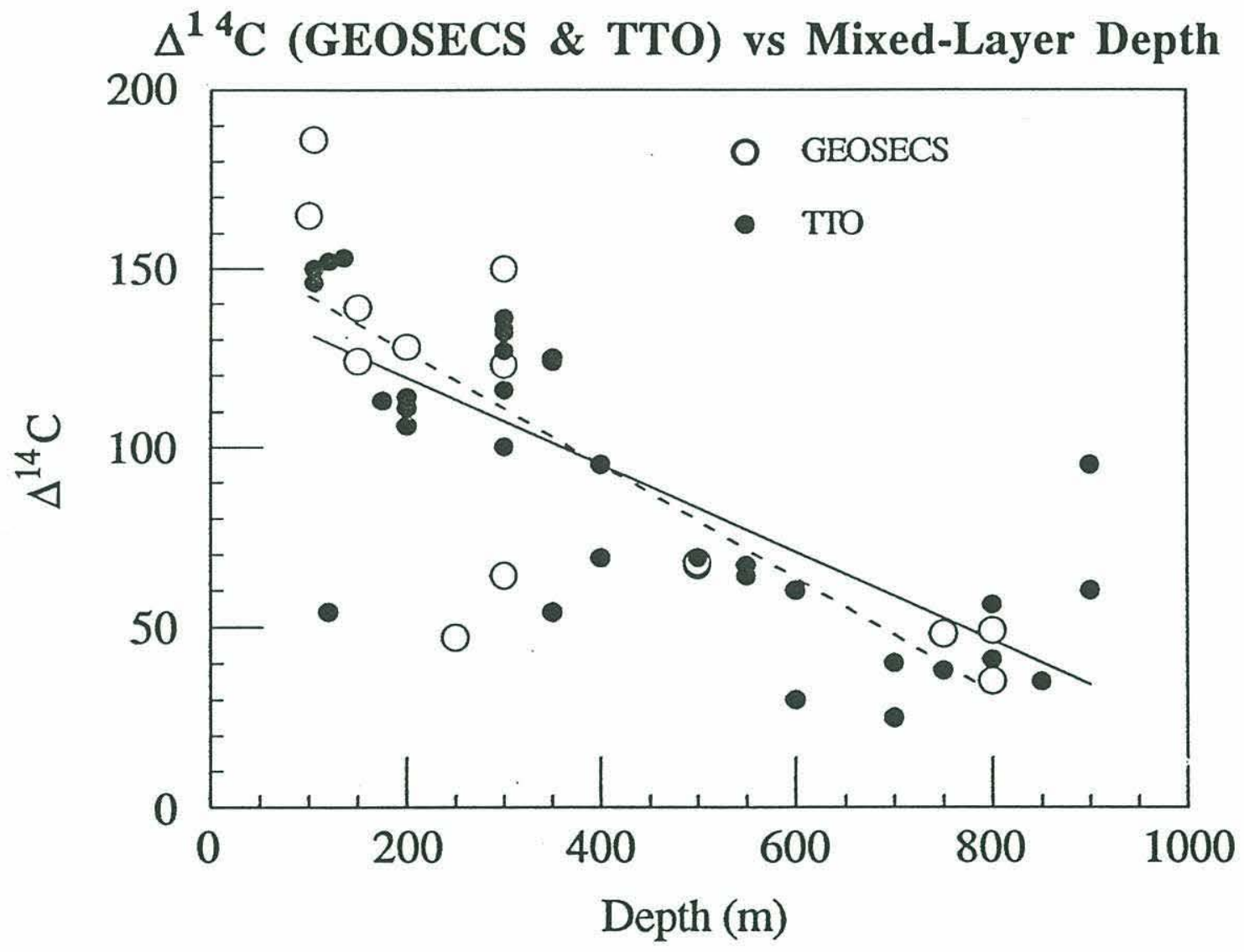

Figure 7 


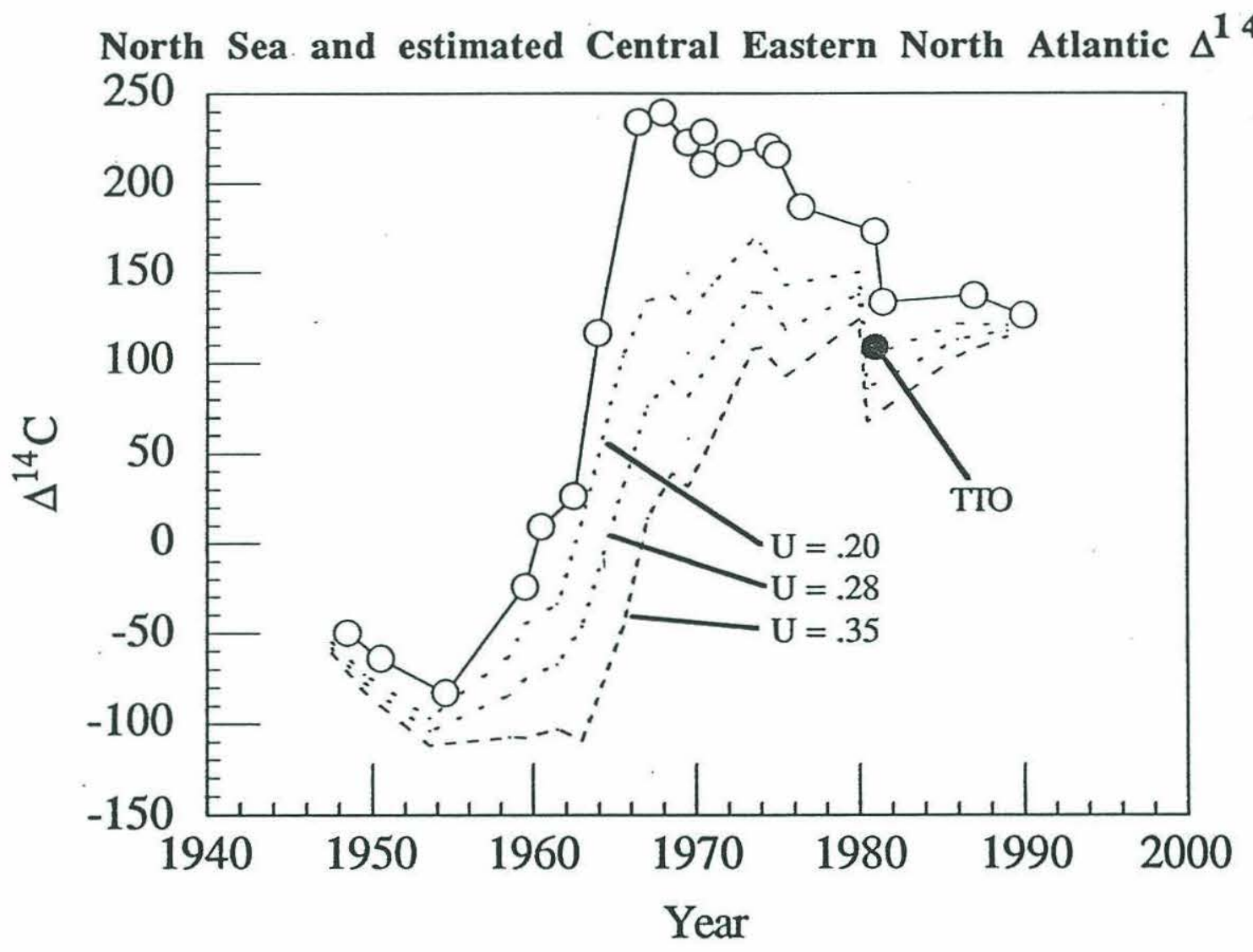

Figure 8 


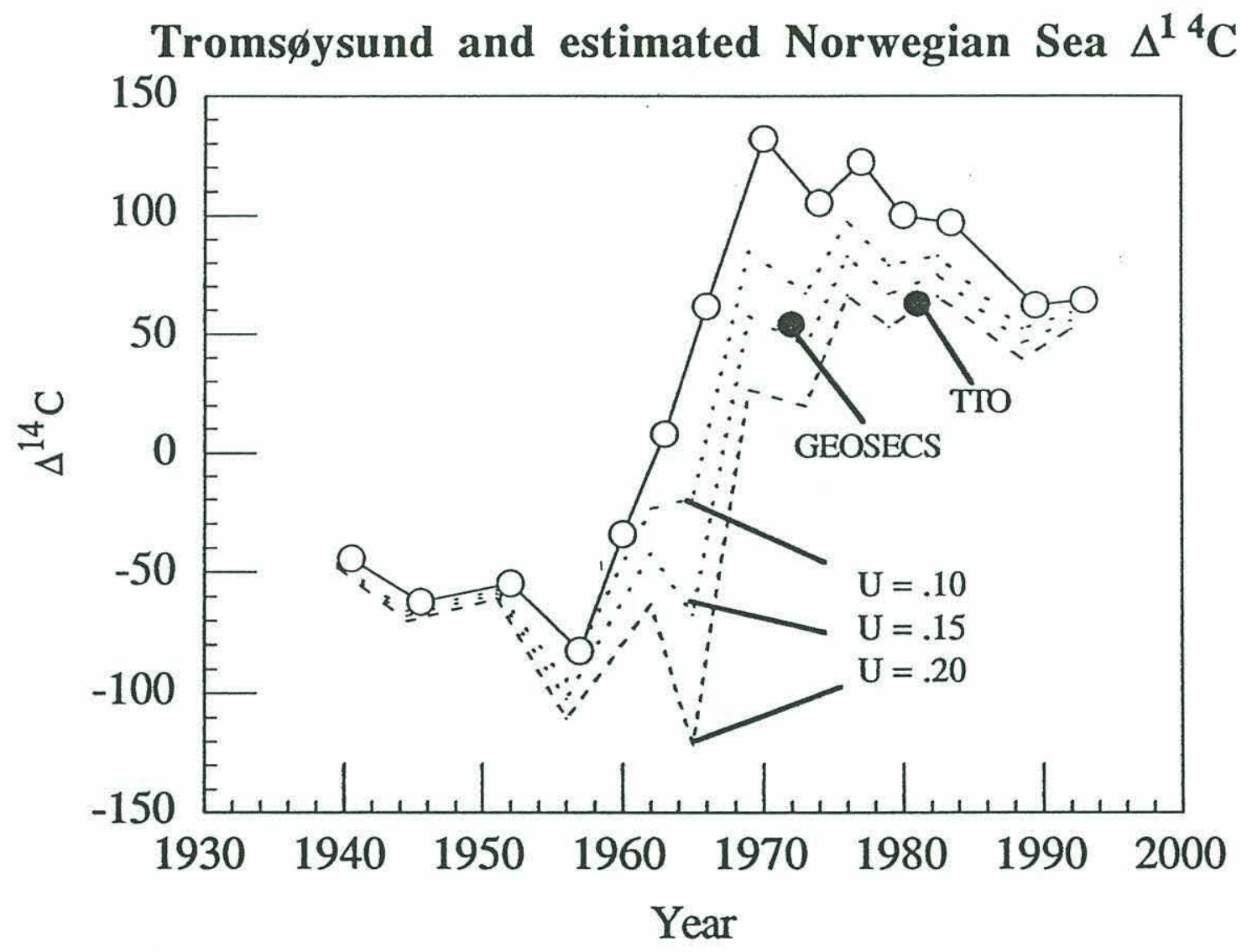

Figure 9 


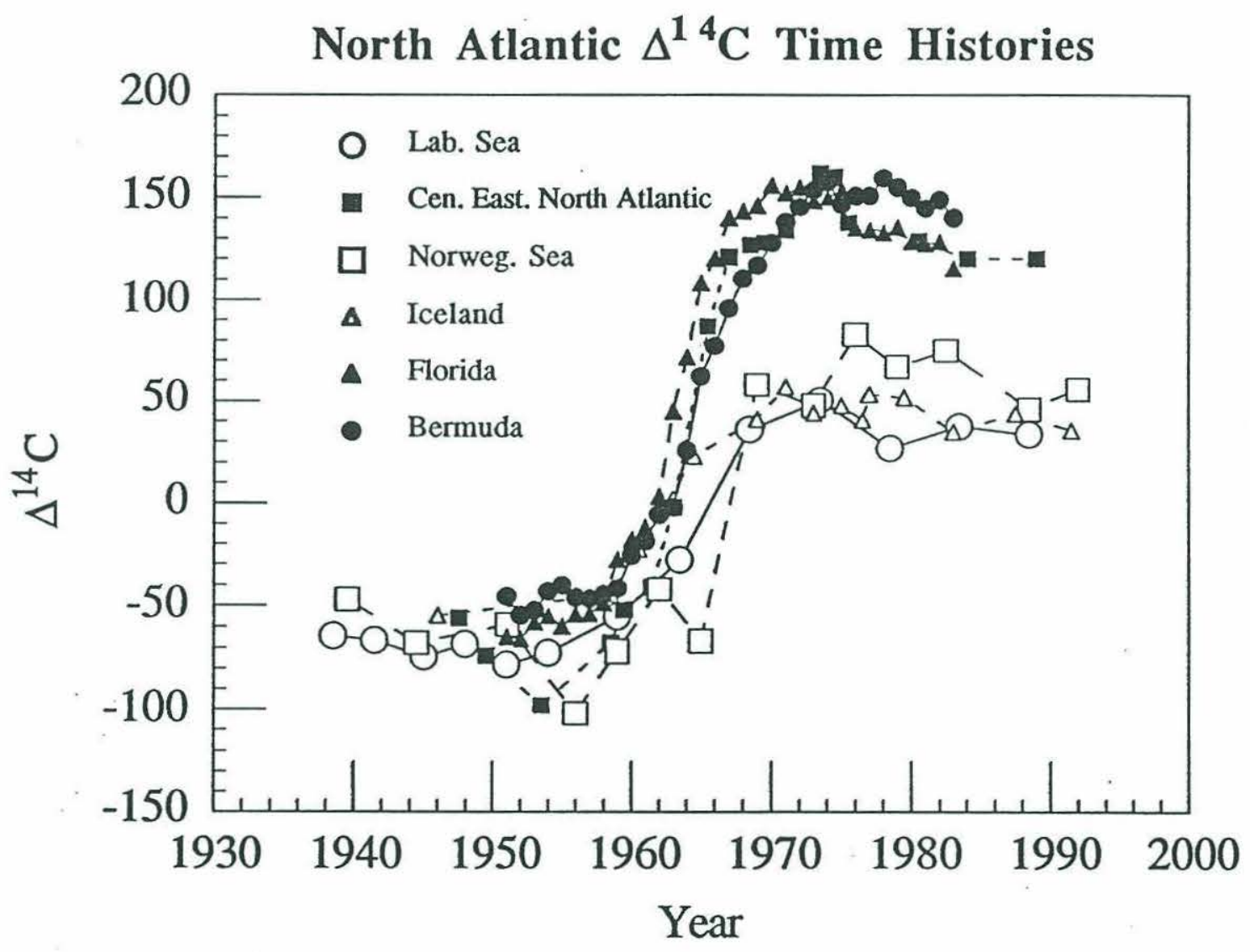

Figure 10 


\section{Chapter 5}

\section{A Century-Long Record of Bottom Temperatures Near Nantucket Shoals from Stable Oxygen Isotopic Analysis of Arctica islandica Shells}

\section{Introduction}

The method for deriving past ocean temperatures from the oxygen isotope composition of biogenic carbonates is a commonly used paleoceanographic technique with a four decade-long history [Urey, Lowenstam, Epstein, \& McKinney, 1951][Epstein, Buchsbaum, Lowenstam, \& Urey, 1953][Duplessy, 1978][Grossman, \& Ku, 1986][Wefer, \& Berger, 1991]. In particular, oxygen isotope studies of the shells of bivalved molluscs have been used to obtain information on shell growth banding and paleoenvironmental conditions [Rhoads, \& Lutz, 1980][Arthur, Williams, \& Jones, 1983][Jones, Williams, Arthur, \& Krantz, 1984][Romanek, Jones, Williams, Krantz, \& Radke, 1987][Krantz, Williams, \& Jones, 1987]. However, because most bivalves have relatively short lives [Heller, 1990], isotope records generated from them have been limited to a decade or so in length, and the few long-lived species have slow shell growth rates, which has precluded the application of conventional sampling methods. The recent development of micro-sampling techniques [Dettman, \& Lohmann, 1993] and low-sample weight mass spectrometry have advanced the potential of the field of stable isotope sclerochronology, by enabling the precise sampling of very small seasonal growth increments in long-lived bivalves. The specific methods as applied to the bivalve species Arctica islandica (longevity +200 years) were validated in an earlier study [Weidman, Jones, \& Lohmann, 1994] which compared a 12-year oxygen isotope record in a single shell with bottom $\mathrm{T}$ and $\mathrm{S}$ data from the nearby Nantucket Lightship. 
In this paper, a 109-year record (1875-1983) of bottom temperatures near the former location of the Nantucket Lightship has been compiled using stable oxygen isotopic analysis on the annual bands of shells of the bivalve mollusc Arctica islandica, more commonly known in this region as the ocean quahog. This record is the longest seasonal mollusc-derived paleotemperature record compiled to date and provides the first centurylong seasonal record of bottom temperatures (from any source) on the North Atlantic continental shelves. Banded corals have been used previously to reconstruct ocean climate records for the warm sub-tropical regions (e.g.,[Druffel, 1985][Aharon, 1991]), but only now, with this study, has reconstruction begun of century-length climate records for the colder high-latitude oceans, regions thought to be intimately linked with the regulation of global climate and ocean circulation. The ability to reconstruct these longer high-resolution records also provides a means of investigating historical climate events and monitoring synoptic oceanographic processes. To demonstrate this, the shell-derived climate record is compared to other historical air and sea surface data, enabling us to explore the relationship between atmosphere / sea surface temperatures and outer shelf bottom temperatures, and the temporal variability of this relationship from the intra-seasonal to the century-scale.

\section{Methods}

\section{Location:}

The century-long temperature record is derived from the oxygen isotope records of four A. islandica shells. All four specimens were live-captured from the same dredge haul during the 1992 NMFS Clam Survey (Leg II) in June, 1992 from station \# 315 at $40^{\circ} 28^{\prime}$ $\mathrm{N}, 69^{\circ} 29^{\prime} \mathrm{W}$ and $65 \mathrm{~m}$ depth (Figure 1 ). This location is approximately $9 \mathrm{~km}$ south of the former position of the Nantucket Lightship ( $40^{\circ} 33^{\prime} \mathrm{N}, 69^{\circ} 28^{\prime} \mathrm{W}$ and $59 \mathrm{~m}$ water depth). From lightship records [Weidman, et al., 1994] and hydrographic survey data [Flagg, 
1987], it is known that the water column near the capture site locale is isothermic from about November through March, and stratified during the warmer months of the year (see Chapter 2, Figure 2). For the period 1956-1957 and 1960-1971, when full water column temperature (T) and salinity (S) measurements were regularly performed at the lightship, bottom temperatures ranged from winter minima averaging $3.6^{\circ} \mathrm{C}\left( \pm 0.9^{\circ}\right)$ to autumn maxima averaging $12.9^{\circ} \mathrm{C}\left( \pm 1.6^{\circ}\right)$. Salinity averaged $32.72 \%$ o $( \pm 0.37 \%$ ) (see Chapter 2, Figure 3). The site is centered within a shelf water mass referred to as the "cold pool", which is a seasonally persistent subsurface band of relatively cold water situated between the $50 \mathrm{~m}$ and $80 \mathrm{~m}$ isobaths on the continental shelf, and extending from the southern flank of Georges Bank to the southern reaches of the Mid-Atlantic Bight [Houghton, Schlitz, Beardsley, Butman, \& Chamberlin, 1982] (Figure 2).

\section{Sampling and Stable Isotope Analysis:}

The micro-sampling methods used to obtain carbonate samples from the annual growth bands of A. islandica shells have been detailed in earlier studies (Chapters 2 and 3). In Chapter 2 it was shown that shell growth did not occur during the coldest months of the year, and that the growth period corresponded to about an eight-month (May-December) growing season. For this reason, a target minimum resolution of eight samples per annual growth band was chosen so that each sample would represent approximately one month of shell growth (assuming a constant seasonal growth rate). Sampling generally began within the 3rd annual band, as the earlier (outer layer) shell material was usually too eroded to sample. The ontogenic decrease in seasonal shell growth currently limits the sampling to the inner (earliest) 20 to 50 annual bands of each shell. A longer record was thus reconstructed by overlapping the individual isotope records (with about a decade of overlap on average) from specimens of different ages. 
The aragonite samples weighed $\sim 50 \mu \mathrm{g}$ on average (ranging from 10 to $200 \mu \mathrm{g}$ ), and were roasted (along with aragonite standards) in vacuo for 1 hour at $200^{\circ} \mathrm{C}$ to volatilize any organic matter. A VG Prism mass spectrometer with an on-line VG Isocarb extraction system was used for the analyses, which were performed at the Woods Hole Oceanographic Institution. The overall analytical precision reported for this instrument for oxygen isotopes, based on the daily analysis of four or more powdered National Institute of Standards and Technology carbonate standards, is $\sim \pm 0.1 \%$ o $(1 \sigma)$.

\section{Chronology:}

The specimen ages were determined by counting the internal bands in thin-sections made from radial slices of shell. In Table 1 are shown the specimen ages $( \pm$ uncertainty in years), number of bands sampled in each shell, and the estimated chronology of the sampled bands. Specimen ages range from 48 to 119 years-old. The banding in the two youngest shells was clear and unambiguous, but the two older shells had some growth disturbance features in their shells resulting in some uncertainty in their age estimates. Later, the shell chronologies were further checked by correlating the overlap section isotope signals and adjusting them, within the band count uncertainty range, only if it significantly improved the correlation (details discussed in next section). The specimen ages and chronologies shown in Table 1 are the adjusted and final ones.

\section{Results}

\section{Data:}

A total of 1579 samples were successfully analyzed from 139 bands obtained from the four shells, with sampling resolution ranging from 5 to 33 samples per growth band $(\sim 11.5$ samples/band). For quantitative convenience, each growth year was defined as ending on the seasonal minimum $\delta^{18} \mathrm{O}$ value and beginning on the sample following the 
previous year's minimum $\delta^{18} \mathrm{O}$ value. This method was synchronous with the visually identified growth bands, as in almost all years the seasonal $\delta^{18} \mathrm{O}$ minimum occurred on or adjacent to the annual "ring" position (the "rings" being defined as the thin translucent layers which form the boundaries of each wider, opaque, annual growth increment). The data were then normalized to "monthly" values so that each year band was represented by eight values (our target minimum sampling resolution). Finally, as a simplification the "monthly" data are statistically arranged in three forms: 1) annual maximum (Omax); 2) annual minimum Omin); and 3) annual mean (Omean).

Table 2 provides a statistical summary of each shell record and Figure 3 shows all the monthly data along with linear fits of their Omean, Omax, and Omin (slopes are summarized in Table 2). The mean ( \pm standard deviation) of Omean, Omax, and Omin are $+1.86 \%$ o $( \pm 0.18 \% \circ),+2.31 \%$ ( $\pm 0.21 \%$ ) , and $+1.32 \%$ o $(0.25 \% \circ)$, respectively. The mean seasonal amplitude (Omax - Omin) is $0.99 \%$. The Omin data show a positive (enriching) trend with age in all four shells. The trends of the Omean and Omax data vary consistently in sign with each other, but unlike the Omin data, do not trend in a consistent way in all shells. In each shell record, the seasonal amplitude (Omax - Omin) gets smaller with age, with the enrichment trend of Omin contributing the greatest part of this signal reduction. In each shell record, the Omin always has the largest standard deviation relative to Omax and Omean, although the difference among all three parameters is not large indicating a similar amount of interannual variation.

\section{Overlap Comparison and Chronology Check:}

The fidelity of the shell-derived $\delta^{18} \mathrm{O}$ signals and relative chronologies was tested by comparing each of the three overlapped sections and performing standard correlation and lag tests. Figure 4 and Table 3 display the results of this comparison and correlation. The first $(3 \mathrm{~B} / 12 \mathrm{~B}, \mathrm{n}=5)$ and third $(28 \mathrm{~A} / 4 \mathrm{~B}, \mathrm{n}=11)$ overlaps had high and significant 
correlations $(\alpha \sim .05)$, without any adjustment of their relative (band-count) chronologies. Lag tests resulted in reduced correlation in all cases. The second $(12 \mathrm{~B} / 28 \mathrm{~A}, \mathrm{n}=14)$ overlap showed a very poor correlation with the original (band-count) chronology (Omin: $\mathrm{r}$ $=-0.16$, Omean: $\mathrm{r}=-0.256$, Omax: $\mathrm{r}=+0.199$ ). However, a shift of +1 year (reducing 12B's estimated age by 1 year) significantly improved the fit, though the correlation is less significant $(\alpha \sim .10)$ than that of the other two overlap sections. The lag test for the second overlap also identified two other equally significant fits, requiring shifts of -4 and -5 years (increasing the estimated age of $12 \mathrm{~B}$ ), but they were rejected since these shifts were beyond the uncertainty ( \pm 1 year) range estimated for the shell. Also, since the first overlap (3B / 12B) showed a high correlation, their relative chronologies were assumed to be "locked",

and so reduced the estimated age of specimen 3B by 1 year as well. As the chronologies of 3B and $12 \mathrm{~B}$ are considered "locked", their combined uncertainty was estimated to be \pm 1 year (the same as the uncertainty of $12 \mathrm{~B}$ ). These slight adjustments result in the "final" chronologies presented in the tables and figures.

\section{Band Width/ Age Corrections:}

In Figure 4 and Table 3, it appears that the greater the age difference between the overlapping shells, the larger the positive offset is between their Omin data. An alternate view is that the smaller the mean band widths of the older shells of the overlap pairs, the larger the offset. These alternate perspectives are obviously interrelated and may be explained as an age and/or sampling-precision effect. In the first case, it may be that there is an ontogenic shortening of the seasonal growth period or reduced autumn shell growth rates as a result, perhaps, of metabolic changes or increased reproductive activity, so that the warmest ambient temperatures are less represented in the shell's seasonal growth with age. This would account for a reduced seasonal $\delta^{18} \mathrm{O}$ amplitude with age. This effect has been suggested for bivalves in general [Harrington, 1989] and for Spisula solidissima in particular [Williams, Arthur, Jones, and Healy-Williams, 1982]. 
In the second case, as the band widths decrease with shell age, there would be an increased tendency to mechanically smear the seasonal signal as the precision limits of the sampling process are approached. This mixing effect would be negligible when the band widths are large, but cause a small progressive reduction in signal amplitude as the band widths narrowed with shell age. This effect would be most pronounced in the Omin data, as the $\delta^{18} \mathrm{O}$ minima (warmest temperatures of autumn) occur in the shell just prior to the $\delta^{18} \mathrm{O}$ maxima (cold temperatures of early winter). The shells' $\delta^{18} \mathrm{O}$ maxima would be less affected since the direction of sampling is chronological, and the bottom waters warm much more slowly in the spring than they cool in the autumn. Also, the Omean data would be little affected. Indeed, the offset differences for Omean and Omax are either small or not consistent with age/band width difference.

The age / band width effect can be corrected by calibrating the Omin overlap offsets with their age and band width differences. A linear fit between age differences and Omin offsets results in the age correction: Age Correction $\left(\Delta \delta^{18} \mathrm{O}\right)=0.011 \mathrm{y}^{-1}+0.143$. Since the 0 -intercept is about 13 years, this relationship implies that an age correction need not be applied to data from bands which are less than 13 years-old. Interestingly, this is also the approximate mean age of sexual maturity for A. islandica [Mann, 1982].

If a band width effect is assumed instead, a similar bandwidth correction can also similarly derived: Band Width Correction $\left(\Delta \delta^{18} \mathrm{O}\right)=-0.558$ (bandwidth $\left.(\mathrm{mm})\right)+0.204$. In this case, the 0 -intercept is about $0.4 \mathrm{~mm}$, and suggests that the correction should be applied to data from bands with widths smaller than this value. A more rigorous approach to correcting the sampling-precision effect can be done by using a mixing model, where each sample is treated as a combination of itself and a small amount of its neighbor. The 
overlap offsets can be used to estimate the size of this mixing term, and the "true" sample values can be "unmixed" by inverting the model,

1) $\delta^{18} \mathrm{O}_{\text {unmixed }}=\delta^{18} \mathrm{O}_{\text {mixed 1 }}-\left[(\mathrm{MIX}) *\left(\delta^{18} \mathrm{O}_{\text {unmixed 2 }}-\delta^{18} \mathrm{O}_{\text {unmixed } 1}\right)\right] /(\mathrm{RES}+\mathrm{MIX})$

where RES is the sample resolution ( $\mathrm{mm})$, MIX is the mixing term (mm), and unmixed 1 and 2 are adjacent samples (and their $\delta^{18} \mathrm{O}$ difference is approximately the same as that between mixed samples). Using this last approach, we calculated a MIX $\sim 25 \mu \mathrm{m}$ and used it to correct the Omin data for this sampling-precision effect (average correction $\sim 0.15 \%$ ). No correction was applied to the Omean or Omax data.

\section{$\mathrm{T} / \delta^{18} \mathrm{O}_{\text {aragonite }}$ and $\mathrm{T} / \mathrm{S} / \delta^{18} \mathrm{O}_{\text {water }}$ Relationships:}

As in chapters 2 and 3, a modified form of Grossman and Ku's [Grossman, et al., 1986] aragonite- $\delta^{18}$ O equilibrium equation (for mollusc data only) is used to convert the shells' $\delta^{18} \mathrm{O}_{\text {aragonite }}$ records to bottom temperature $\left(\mathrm{T}_{\mathrm{b}}\right)$,

2) $\mathrm{T}_{\mathrm{b}}=20.86-4.69\left(\delta^{18} \mathrm{O}_{\mathrm{arag}}(\mathrm{PDB})-\delta^{18} \mathrm{O}_{\text {water }}(\mathrm{SMOW})\right)$

The equation has been modified from the original to include the approximate difference $(\Delta \sim$ $0.2 \%$ ) between $\mathrm{CO}_{2}$ equilibrated with standard mean ocean water ( $\mathrm{SMOW}$ ) and $\mathrm{CO}_{2}$ generated from the hydrolized carbonate standard Pee Dee belemnite (PDB). The standard notation for oxygen isotopic composition is used, where $\delta^{18} \mathrm{O}_{\text {sample }}(\mathrm{PDB})=$ $\left[{ }^{18} \mathrm{O} /{ }^{16} \mathrm{O}_{\text {sample }}{ }^{18} \mathrm{O} / 16 \mathrm{O}_{\text {standard }}(\mathrm{PDB})^{-1}\right] \times 1000$.

In equation 2 , the term $\delta^{18} \mathrm{O}_{\text {water }}$ is the isotopic composition of the ambient water, which can be estimated using Fairbanks' [Fairbanks, 1982] salinity- $\delta^{18} \mathrm{O}_{\text {water }}$ relationship for the Gulf of Maine, 
Rather than use a single mean value for our estimate of salinity (S), we use a variable one derived from a polynomial (2nd order) fit to $\mathrm{T}$ and $\mathrm{S}$ data for the period 1956-1971 (equation 4) when bottom data were recorded at the lightship (Figure 5). A quadratic relationship was chosen over a linear one because it captures the double maximum in the seasonal salinity cycle, the largest one at the autumn overturn when bottom temperatures are at a maximum and a smaller one in the late winter / early spring when bottom temperatures are coldest. This $\mathrm{T} / \mathrm{S}$ function allows salinity (and thus $\delta^{18} \mathrm{O}_{\text {water }}$ ) to be treated as a function of temperature,

$$
\mathrm{S}=0.018 \mathrm{~T}^{2}-0.277 \mathrm{~T}+33.625 \quad(\mathrm{SEE}=0.322)
$$

Substituting (4) into (3) to obtain

$$
\delta^{18} \mathrm{O}_{\text {water }}(\mathrm{SMOW})=0.008 \mathrm{~T}^{2}-0.117 \mathrm{~T}-0.504
$$

Substituting (5) into (2) to obtain

$$
\mathrm{T}_{\mathrm{b}}=21.98-\left[133.3\left(\delta^{18} \mathrm{O}_{\text {aragonite }}\right)-43.1\right]^{0.5}
$$

Note that (6) works only for $\mathrm{T}_{\mathrm{b}}<\sim 22^{\circ} \mathrm{C}$, which is well above recorded maximum bottom temperatures for this deep water area of the shelf. This relationship also suggests that as

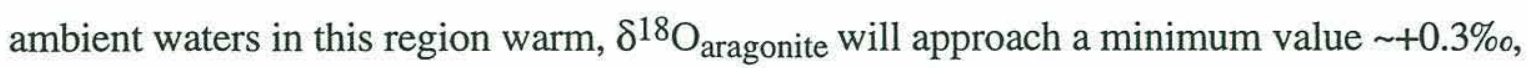
because the ambient $\delta^{18} \mathrm{O}_{\text {water }}$ would be getting heavier at the opposite rate from the equilibrium fractionation between aragonite and water. Hydrographically, this also implies that as bottom temperatures become $>17^{\circ} \mathrm{C}$ their $\mathrm{S}$ and $\delta^{18} \mathrm{O}_{\text {water }}$ properties approach 
those of slope water $\left(\mathrm{S}>34 \%\right.$ and $\delta^{18} \mathrm{O}_{\text {water }}>+0.0 \%$ ) [Fairbanks, 1982]. This result is supported by hydrographic data [Flagg, 1987] which shows that the nearest source of very warm bottom water is upper slope water, which can intrude landward along the outer shelf bottom during late summer and autumn.

\section{The Combined Shell-Derived Temperature Records:}

Equation (6) was used to convert the shell Omean, Omax, and Omin data to bottom temperatures. The individual shell records were combined to form three 109-year annual temperature records from 1875 to 1983 (Table 4 and Figure 6). The overlap data are averaged to obtain a single temperature value for each year. We estimate no uncertainty in the chronology from 1924 to 1983 and a \pm 1 year uncertainty for the period from 1875 to 1923. The shell-derived bottom temperatures, like the shell $\delta^{18} \mathrm{O}$ data, are described by the three parameters: 1) annual mean (BTmean); 2) annual "monthly" maximum (BTmax); and an 3) annual "monthly" minimum (BTmin). Ten-year running means are also calculated and plotted in Figure 6 for each of the three records.

In chapter 2 [Weidman, et al., 1994], it was argued that A. islandica shells' $\delta^{18} \mathrm{O}$ composition can be used to estimate "monthly" bottom temperatures of ambient waters with an accuracy of $\pm 1.2^{\circ} \mathrm{C}$, but since shell growth ceases during the winter at temperatures below $\sim 6^{\circ} \mathrm{C}$, the coldest temperatures cannot be determined. In addition, in chapter 3 , it was shown that shell growth seems to occur between ambient temperatures of $5^{\circ}$ to $15^{\circ} \mathrm{C}$, but not much above or below these cutoffs. As bottom temperatures at the Nantucket Lightship appear to rarely exceed $15^{\circ} \mathrm{C}$, this upper limit should not usually constrain the shell's recording of annual maximum temperatures (BTmax). In contrast, BTmin and to some extent BTmean should tend to be biased towards warmer values than the corresponding statistics for ambient waters because of the cold end cutoff, which is $1-2^{\circ} \mathrm{C}$ warmer than average minimum bottom temperatures in this region (see Chapter 2, Figure 
3). However, the shell growth shutdown/turn on may not be entirely temperature driven, as suggested by the greater variability of the annual minimum temperature $\left(5.7^{\circ} \mathrm{C} \pm 0.9^{\circ} \mathrm{C}\right)$ in this study's much larger data set than exhibited in the 12-year record $\left(6.0^{\circ} \mathrm{C} \pm 0.6^{\circ} \mathrm{C}\right)$ discussed in chapter two (using equation 6 in this study to calculate both). The seasonal shell growth shutdown/turn on may be indirectly related to temperature through food or light availability and thus coupled to a particular time of year. For example, Figure 7 (from O'Reilly, Evans-Zetlin, and Busch, 1987] shows a time-series of seasonal primary production for the stratified region on the southern flank of Georges Bank. Note the large increase which occurs in May (spring phytoplankton bloom) and and the sharp decline after November, so that the period of peak food availability (for a filter-feeder) is roughly coincident with $A$. islandica's seasonal growth cycle.

\section{BTmean:}

BTmean values are not likely to be true annual means for the reasons discussed above, but they should provide a measure of the mean temperature during the shell growth season ( May-December). However, the mean of BTmean $\left(7.64^{\circ} \mathrm{C} \pm 0.90^{\circ} \mathrm{C}\right)$ is very close to the Nantucket Lightship annual mean bottom temperature of $\left(7.58^{\circ} \mathrm{C} \pm 0.50^{\circ} \mathrm{C}\right)$ for the period 1960-1971, but shows more variability. The coldest year of the mean shell record is $1977\left(5.30^{\circ} \mathrm{C}\right)$ and the warmest is $1898\left(9.88^{\circ} \mathrm{C}\right)$. Linear regression of the data produces a slope of $-0.010^{\circ} \mathrm{C}^{-1}\left( \pm 0.003^{\circ} \mathrm{C}\right)$, indicating that mean annual bottom temperatures in the "cold pool" region south of Nantucket Shoals have cooled $\sim 1.1^{\circ} \mathrm{C}$ over the past century. The mid-1960s and mid-1970s are periods of sustained cold bottom temperatures. Sharp coolings $\left(\sim-2^{\circ} \mathrm{C} \mathrm{y}^{-1}\right)$ occur after some of BTmean's warmest periods near the years 1880 , 1905, and 1920. The 10-year running mean exhibits two peak warm periods centered about 1900 and 1919, with a cold period between them, and cold periods in the 1880s, and after 1960 until the end of the record in the late 1970s. The 10-year running mean shows a flat trend from 1925 to 1960. 


\section{BTmax:}

The BTmax record represents the annual maximum "monthly" bottom temperatures, which generally occur in this region at the autumn overturn in late October and November. The mean of $\mathrm{BTmax}\left(11.47^{\circ} \mathrm{C} \pm 1.69^{\circ} \mathrm{C}\right)$ is about $1^{\circ} \mathrm{C}$ lower than the Nantucket Lightship mean annual monthly maximum bottom temperature of $\left(12.59^{\circ} \mathrm{C} \pm 1.37^{\circ} \mathrm{C}\right)$ for the period 1960-1971, and exhibits similar variability. The coldest year of the maximum record is $1976\left(8.14^{\circ} \mathrm{C}\right)$ and the warmest is $1878\left(15.60^{\circ} \mathrm{C}\right)$. Linear regression of the data produces a slope of $-0.027^{\circ} \mathrm{C}^{-1}\left( \pm 0.005^{\circ} \mathrm{C}\right)$, indicating that the annual maximum "monthly" bottom temperatures at this site have cooled a surprising $\sim-2.9^{\circ} \mathrm{C}$ over the past century. In particular, the mid-1960s and mid-1970s are the longest sustained cold periods of the century, with maximum bottom temperatures dropping about $4^{\circ} \mathrm{C}$ between warmer peaks in the early 1960s, late 1960s-early 1970s, and late 1970 s. In the 1880 s, there is a similar decade long reduction of about $4^{\circ} \mathrm{C}$ between peak warm annual maximum temperatures in the early 1880 s and early 1890 s, but in an absolute sense this "cold" period is warmer by about $1^{\circ} \mathrm{C}$ than a century later. Similar to the BTmean data, the 10 -year running mean rises from the cold decade of the 1880 s to two peak warm periods centered about 1900 and 1915 with a colder period between them. There follows a more or less continuous cooling until the end of the record in the late 1970s, with the most rapid reduction in maximum bottom temperatures occurring after 1945.

\section{BTmin:}

As discussed above, the BTmin record cannot represent the actual annual minimum "monthly" bottom temperature as the shells do not grow during the coldest months (when T $\left.<\sim 5^{\circ}-6^{\circ} \mathrm{C}\right)$, and it is still unclear whether a shutdown/turn on temperature or time is the

more important factor controlling the seasonal cessation and commencement of shell deposition. However, this record should at least reflect the rate of springtime warming if a shutdown temperature is operating, with years having more rapid rates of warming 
reflected in warmer minima. If seasonal shell growth is more of a time-controlled phenomenon, then the interannual variations will reflect real differences in temperature at a particular time in the spring, and need not be constrained to temperatures greater than $\sim 5^{\circ}$ $6^{\circ} \mathrm{C}$. The mean of $\mathrm{BTmin}\left(5.65^{\circ} \mathrm{C} \pm 0.90^{\circ} \mathrm{C}\right)$ is only slightly colder than the mean bottom temperature $\left(5.90^{\circ} \mathrm{C} \pm 0.82^{\circ} \mathrm{C}\right)$ for the month of May at the Nantucket Lightship for the period 1960-1971, and exhibits the same variability. The coldest year of the minimum record is $1881\left(3.48^{\circ} \mathrm{C}\right)$ and the warmest year is $1898\left(7.34^{\circ} \mathrm{C}\right)$. Linear regression of the data produces a slope of $-0.004^{\circ} \mathrm{C}^{-1}\left( \pm 0.003^{\circ} \mathrm{C}\right)$, indicating that the annual minimum ( May) "monthly" bottom temperatures at this site have cooled only $\sim 0.4^{\circ} \mathrm{C}$ over the past century. The 1880s and 1960s stand out as the most persistent coldest periods of the past century. The 10 -year running mean shows a $1^{\circ} \mathrm{C}$ warming from the early 1880 s to 1900 which is a characteristic of all three shell-derived bottom temperature records. The 10-year running mean shows almost no trend for the next 60 years from 1900 to about 1960, and then drops off sharply by $\sim 1^{\circ} \mathrm{C}$ for the rest of the record.

\section{Discussion}

\section{Nantucket Lightship Bottom Temperature Records:}

A comparison of the shell-derived bottom temperature records with the Nantucket Lightship bottom temperature records for the continuous period 1960-1971 shows a strong qualitative and quantitative fit (Figure 8). The lightship data are similarly divided into the annual mean, annual maximum, and the mean May bottom temperature (representing a comparable "minimum"). The period 1960-1971 is particularly distinctive because of the extreme and sustained drop in bottom temperatures which occurred in the mid-1960s. The magnitude and phase of this low-temperature anomaly recorded at the lightship are reflected in all three shell-derived records. The means of each of the shell-derived records as 
compared to the lightship records for the same period are: shell $/$ lightship mean $=7.20^{\circ} \mathrm{C} /$ $7.58^{\circ} \mathrm{C}$; shell $/$ lightship maximum $=10.37^{\circ} \mathrm{C} / 12.59^{\circ} \mathrm{C}$; shell $/$ lightship "minimum" = $5.27^{\circ} \mathrm{C} / 5.90^{\circ} \mathrm{C}$. The shell-derived temperatures are always colder, though the offset is small in the mean and minimum data, but a significant $\sim 2^{\circ} \mathrm{C}$ colder in the maximum data. Also, the mean and minimum records are much better correlated $(r=+0.653$ and +0.710 , respectively) than the maximum records $(r=+0.265)$. The weaker fit of the maximum data may indicate that the annual maximum bottom temperature is a more spatially heterogeneous phenomenon on the outer shelf, as it is synchronous with the autumn overturn, a convective (vertical) process of short duration. The lower annual maximum is consistent with the greater depth of the shell site and its more centered position within the "cold pool" (see Figure 2), and also the autumn overturn may be delayed relative to the shallower lightship position allowing for an even colder annual maximum to be experienced at the deeper site.

\section{Nantucket Lightship Sea Surface ,Temperature Records:}

The Nantucket Lightship sea surface temperature (SST) records are more temporally extensive (1878-1971) than the bottom temperature (BT) records, but are less satisfactory to use as a comparison data set. This is true largely because the Nantucket lightships were relocated a number of times over the period from 1878 to 1971 . In addition, the records are not continuous, having gaps as long as 12 years. However, SST records from the same 1960-1971 period when bottom temperatures were logged, offer insight into the relationship between bottom and surface temperatures at this outer shelf region. The SST data are arranged into annual means, maxima, and minima (using the May SSTs as the comparable minima) (Figure 8). Like the lightship and shell-derived bottom temperatures, the lightship SSTs show a large cooling in the mid-1960s. During this period, overall cooling at the surface has almost the same magnitude as the cooling at the bottom, but there are important differences between surface and bottom temperature 
signals. For example, the surface and bottom lightship data are strongly correlated when comparing their May data $(\mathrm{r}=+0.855)$, while their annual mean and maximum data are more weakly correlated ( $\mathrm{r}=+0.533$ and +0.338 , respectively). This result is consistent with the idea that stratification during summer isolates the bottom waters from surface heating. By the time overturn occurs in the autumn, the magnitude of the summer surface anomaly is often modified considerably. In fact, the offset between the lightship's annual maximum bottom and sea surface temperatures tends to be greatest during years when either the bottom maxima are coldest or surface maxima are warmest, indicating that the bottom and surface anomalies are often out of phase with each other. A lag test confirms this phase difference in the annual maximum signal by showing improved correlations when the bottom signal precedes the surface signal by 1 year or when the surface signal precedes the bottom signal by 2 years. These observations demonstrate that bottom and sea surface temperature anomalies can vary from each other significantly, even at the same location on the outer shelf.

\section{Brenton Reef Lightship and Boothbay Harbor SST Records:}

Two coastal SST time-series from the New England region are compared with the shell-derived bottom temperatures (Figure 9). The Boothbay Harbor, Maine $\left(\sim 43^{\circ} 45^{\prime} \mathrm{N}\right.$, $69^{\circ} 40^{\prime}$ W) SST record from 1906 to 1995 [Lazzari, 1995] is the longest, most continuous SST record on the U. S. east coast, and can be compared to the later 78 years of the shellderived record (1906-1983). The Brenton Reef Lightship ( $\left.41^{\circ} 20^{\prime} \mathrm{N}, 71^{\circ} 30^{\prime} \mathrm{W}\right) \mathrm{SST}$ record from 1879 to 1941 [Bumpus, 1957] is one of longest and oldest continuous SST records on the southern New England coast, and can be compared with most of the earlier portion of the shell-derived record. Both records overlap a 36-year period from 1906 to 1941. For comparison, these records are arranged into annual mean, maximum, and April (comparable minimum) records, and 10-year running means are computed for each parameter. The mean April SSTs are used here instead of May SSTs as was done for the 
Nantucket Lightship records, because significant warming of nearshore coastal waters occurs during May, making the April coastal SSTs more reflective of the spring offshore conditions. The Brenton Reef April and maximum records are several years shorter than the annual mean record because of missing monthly data for the late 1930 s.

A basic contrast between the two coastal temperature records is that Brenton Reef has a mean about $2^{\circ} \mathrm{C}$ warmer than the Boothbay Harbor $\left(10.4^{\circ} \mathrm{C}\right.$ versus $\left.8.3^{\circ} \mathrm{C}\right)$. A linear fit to the Brenton Reef records show that both the annual mean and April data have positive slopes $\left(\right.$ mean $=+0.005 \mathrm{y}^{-1} \pm 0.006$, April $\left.=+0.016 \mathrm{y}^{-1} \pm 0.009\right)$, while the annual maximum data have a slight negative slope (maximum $=-0.001 \mathrm{y}^{-1} \pm 0.007$ ). Similarly, a linear fit to the Boothbay Harbor records also show that the annual mean and April data have positive slopes $\left(\right.$ mean $=+0.017 \mathrm{y}^{-1} \pm 0.004$, April $\left.=+0.013 \mathrm{y}^{-1} \pm 0.006\right)$, while the annual maximum data have a negative slope (maximum $=-0.016 \mathrm{y}^{-1} \pm 0.004$ ). Therefore the coastal sea surface records indicate a mean warming of $\sim 0.3^{\circ} \mathrm{C}\left( \pm 0.4^{\circ} \mathrm{C}\right)$ for the period between 1879 and 1941 and $\sim 1.3^{\circ} \mathrm{C}\left( \pm 0.3{ }^{\circ} \mathrm{C}\right)$ for the period between 1906 and 1983 . The equally strong warming trends indicated for the month of April of $\sim 1^{\circ} \mathrm{C}\left( \pm 0.5^{\circ} \mathrm{C}\right)$ for each period contrast with the cooling indicated for the annual maximum temperatures, implying that the mean annual warming trend is primarily a winter/spring phenomenon and not a summer feature. The summer temperature records at Boothbay Harbor prior to 1941 may be artificially high due to an instrumentation change in that year (K. Drinkwater, pers. comm., 1995), so that the slope of the annual maximum data may be biased. Correlation of the 1906-1941 overlapped section of these two coastal SST records reflects a significant ( $\alpha$ $=.05$ ) coherence between the two records (annual mean: $\mathrm{r}=+0.492$, annual maximum: $\mathrm{r}$ $=+0.323$, April: $\mathrm{r}=+0.438$ ). However, these $\mathrm{r}$ coefficients also indicate a good deal of local variation, especially between the annual maximum SSTs, which demonstrates that coastal SST anomalies within the same general region can differ substantially. 
The 10-year running means of the Brenton Reef records, trend flat or downward for the 40 -year period from the early 1880 s to the early 1920 s, and afterwards rise to record warming in the mid-1930s. The 10-year running means of the Boothbay Harbor records, trend flat or downward for the 30-year period from about 1910 to the early 1940 s, rise sharply to maxima in the early 1950 s, and then decline steeply to minima in the mid1960s. The Boothbay Harbor running mean also shows a rise again in the 1970s. An obvious contrast between the running means in the overlapping period is the absence of a significant warming in the mid-1930s in the Boothbay Harbor records.

A comparison of these two SST records with the shell-derived bottom temperature record, shows aspects of agreement and disagreement. Correlation between the SST and the shell BT records reveals a poor coherence between the data sets ( $\mathrm{r}$ coefficients between Brenton Reef and shell: annual mean $=-0.126$, annual maximum $=+0.009$, and spring minimum $=+0.327$; and Boothbay Harbor and shell: annual mean $=+0.031$, annual maximum $=+0.283$, and spring minimum $=+0.260)$. The overall warming $\left(\Delta \sim+1^{\circ} \mathrm{C}\right)$ displayed in the SST mean record is in contrast to the overall cooling $\left(\Delta \sim-1^{\circ} \mathrm{C}\right)$ displayed in the shell-derived BT mean record. The warming trend $\left(\Delta \sim+1^{\circ} \mathrm{C}\right)$ from 1880 to 1900 indicated in the shell BT records, is not apparent during the same period in the records from Brenton Reef. The warmest part of the shell BT records are centered between 1900 and 1920, while the warmest parts of the SST mean records are later during mid-century. The shell BT records do not show any significant warming trend in mid-century, neither the 1930s maximum of the Brenton Reef record nor the 1950s maximum of the Boothbay Harbor record. Common to the SST and shell BT records is a sharp cooling trend from the 1950s until the late 1960s. In contrast, the 1970s are a period of warming in the SST records, but continued cooling in the shell BT records. Another shared characteristic of both SST and shell-derived BT records is that their annual maximum data all trend downward indicating long-term cooling of seasonal maximum temperatures over the past 
century. This result reaffirms the notion that whatever warming may have occurred on the northeastern U.S. continental shelf over the last century, it has not been a summer phenomenon.

\section{Coastal Northeast U. S. Air Temperature Record:}

A composite air temperature record for northeastern U.S. coastal locations for the period from 1901 to 1983 [Boden, Kaiser, Sepanski \& Stoss, 1994](Figure 10) is compared to the coastal SST and shell-derived BT records. The air temperature record is divided into annual mean, summer (maximum), and spring (comparable minimum) values. Linear fits of these data show positive slopes for all three parameters (mean: $=+0.010^{\circ} \mathrm{C} \mathrm{y}^{-}$ ${ }^{1} \pm 0.003^{\circ} \mathrm{C}$; summer $+0.013^{\circ} \mathrm{C} \mathrm{y}^{-1} \pm 0.003^{\circ} \mathrm{C}$; spring $\left.=+0.008^{\circ} \mathrm{C} \mathrm{y}^{-1} \pm 0.004^{\circ} \mathrm{C}\right)$, indicating a regional mean atmospheric warming of $\sim+0.8^{\circ} \mathrm{C}$ over the first 80 years of this century. Correlation of the air temperature records with the SST data generally show a good coherence (Brenton Reef, Boothbay Harbor: annual means: $r=+0.685,+0.581$; annual maximum: $\mathrm{r}=+0.532,+0.029$; April: $\left.\mathrm{r}_{1}=+0.599,+0.541\right)$ with the exception of the Boothbay Harbor maximum. The 10-year running means of the air temperatures are similar to those of the Boothbay Harbor SSTs, showing a warm peak in the 1950s and a cold period in the mid-1960s. Correlation of the air temperature records with the shell-derived BT data show a poor coherence (annual means: $r=+0.080$; annual maximum: $r=-0.115$; April: $r=+0.060)$. From this perspective, the SSTs at the coastal sites clearly seem to reflect atmospheric forcing, but the shell-derived BTs do not, with the exception of the extreme mid-1960s cold period.

\section{Comparison of Detrended Records:}

The mid-1960s exception suggests that perhaps a large measure of the inconsistency between the surface data (air and sea surface) and shell-derived bottom data 
is in the long-term trends. To investigate this hypothesis the data sets were detrended by subtracting out the 10-year running means and intercomparing their normalized residuals or deviations (residual / SD(residuals)). These deviation records display a much improved positive coherence between the shell-derived data and surface records (Figure 11). The correlation is most significantly ( $\alpha \sim .01$ ) improved between the shell BT and Boothbay Harbor SST deviation data (mean: $\mathrm{r}=+0.435$; maximum: $\mathrm{r}=+0.211$; minimum: $\mathrm{r}=$ +0.456 ), in fact, being slightly more significant than the correlation between the Boothbay Harbor and Brenton Reef SST records. The correlation is still quite significant $(\alpha \sim .05)$ with the atmospheric data (mean: $r=+0.236$; maximum: $r=+0.185$; minimum: $r=$ +0.245 ), but less so with the Brenton Reef data $(\alpha \sim .10)$ (mean: $r=+0.169$; maximum: $r$ $=-0.030$; minimum $\mathrm{r}=+0.429$ ). The annual mean and minimum (spring) data show the strongest coherence, while the annual maximum data remain only weakly correlated. These results show that much of the short-term (decade-scale) interannual variation in the bottom temperature record is in phase and proportional to the short-term SST and air temperature anomalies, and therefore suggests that the short term shell-derived bottom temperature anomaly pattern can be used to infer SST and air temperature anomalies in the region. However, this positive relationship seems to break down on longer time-scales.

\section{The Long-Term Trend Problem:}

The disparity between the long-term shell-derived bottom temperature and surface temperature (air and sea) trends poses an important question. Are these opposing temperature trends real or is the difference an artifact of our assumptions? The assumptions fall into two categories: unaccounted for 1) biological processes affecting the shells' oxygen isotope chemistry or 2) water mass changes affecting the $\delta^{18} \mathrm{O}$ properties of the ambient waters. The overlapped shell isotope records provided a means of detecting differences between individual specimens and bias due to "vital" effects. Small offsets were observed in the seasonal minimum $\delta^{18} \mathrm{O}$ data that appeared to be ontogenic in nature, and 
would have the effect of deriving colder annual maximum temperatures by $\sim 1^{\circ} \mathrm{C}$ in the later (more recent growth) portions of the longer shell records. However, the mean and minimum temperature data are unaffected and the maximum data have been corrected for these effects, and so a biological cause for the long-term trend difference is ruled out.

It is possible that as the result of undetected changes in shelf circulation over the last century, there has been a gradual enrichment of the ambient $\delta^{18} \mathrm{O}_{\text {water }}$ of outer shelf waters, which is aliased in our isotope-derived record as an apparent long-term cooling trend. This effect would be difficult to sort out, because circulation changes large enough to affect the $\delta^{18} \mathrm{O}_{\text {water }}$ properties of shelf water might just as easily affect its temperature properties as well. If an enrichment of ambient $\delta^{18} \mathrm{O}_{\text {water }}$ has occurred, one way this could have happened is indicated by three shelf circulation studies [Fairbanks, 1982] [Chapman, Barth, Beardsley, \& Fairbanks, 1986] [Chapman, \& Beardsley, 1989]. These studies describe shelf water as essentially a two component mixture of fresher Scotian shelf water $\left(\delta^{18} \mathrm{O}_{\text {water }} \sim-1.09 \%\right.$ ) and saltier Slope, water $\left(\delta^{18} \mathrm{O}_{\text {water }} \sim+0.75 \%\right.$ ), whose relative proportions can vary both spatially and temporally. Using their model, a $10 \%$ increase in the relative proportion of Slope water would cause a $+0.5 \%$ salinity increase and a $+0.2 \%$ o $\delta^{18} \mathrm{O}_{\text {water }}$ enrichment, or the equivalent of a $1^{\circ} \mathrm{C}$ cooling in temperature if unaccounted for in estimating shelf $\delta^{18} \mathrm{O}_{\text {water }}$. However, if this mechanism is invoked as the cause of the long-term temperature trend difference between shell-derived BTs and SSTs, it simply shifts the problem, for it implies that shelf waters were a surprising $\sim 1 \%$ fresher a century ago to account for the $2^{\circ} \mathrm{C}$ relative difference $\left(1^{\circ} \mathrm{C} \mathrm{SST}\right.$ warming $+1^{\circ} \mathrm{C} \mathrm{BT}$ cooling). This conclusion, while pointing up the uncertainty of the absolute temperature estimate from $\delta^{18} \mathrm{O}$ data, would still motivate the need to understand how such a significant shelf circulation change occurred, and if that change was related to air and sea surface warming. 
The other option is to assume that the shell-derived bottom temperature trends are real, and to look for oceanographic mechanisms to explain the contrast with coastal surface temperature trends. The simplest explanation may be that higher sea surface temperatures in the New England region lead directly or indirectly to greater stratification of adjacent deep shelf waters and increased volume and isolation of cold bottom waters on the outer shelf. This explanation has support in Houghton et al.'s [1983] study of the "cold pool" and its seasonal persistence in the Mid-Atlantic Bight. They suggest that the prime source of "cold pool"water is the large volume of very cold dense water formed in the winter over the Nantucket Shoals due to strong tidal mixing. As surface heating increases in the late spring and summer this same mechanism produces a large volume of warm, less dense water which then spreads out as a near-surface layer over the colder denser bottom waters. Further surface heating increases this stratification, which reduces vertical mixing and heat flux between the warm mixed-layer and the cold bottom waters. If surface temperatures were to rise, or seasonal warming were to begin earlier in the spring or end later in the fall, a consequence would be reduced vertical mixing, an increase in the initial volume of cold bottom water, and a persistence of cold bottom temperatures. Other indirect causes that have been associated with reduced vertical mixing and increased stratification are increased precipitation and local runoff at certain times of year (warm/wet versus cold/dry climate patterns), decreased wind stress, or changes in storm frequency and intensity patterns. In support of the latter of these, Dickson and Namias [1976] showed that decreased cyclone frequencies and intensities for the period 1948-1957 were coupled with warming along the U. S. eastern seaboard, while increased storminess for the period (1958-1969) was linked with a strong cooling trend in this region. These ideas on a cause for bottom cooling synchronous with surface warming, are purely speculative, but they demonstrate that oceanographic mechanisms, similar to those used to explain the existence of the "cold pool", may be operating to create this contrast. 


\section{Conclusions}

A 109-year annual time-series (1875-1983) of bottom temperatures has been reconstructed for a location (at $65 \mathrm{~m}$ depth) near the former Nantucket Lightship from the oxygen isotope records of four shells of the long-lived mollusc species Arctica islandica. This site is centered within a seasonal hydrographic feature referred to as the "cold pool", and so these records provide a century-long thermal history of this outer continental shelf subsurface water mass. The method of establishing the chronology by annual band counting, and using the overlapped isotope records from several shells of different ages to reconstruct a longer record was validated by the strong correlations between the overlapped portions of the four shell records. The shell-derived bottom temperature record is presented as three annual records: annual mean, annual maximum, and annual minimum. The annual means represent the means of the shell growth seasons, average $7.6^{\circ} \mathrm{C}\left( \pm 0.9^{\circ} \mathrm{C}\right)$, and indicate a century-long cooling of $\sim 1.1^{\circ} \mathrm{C}$. The annual maxima represent bottom temperatures at about the time of the autumn overturn, average $12.6^{\circ} \mathrm{C}\left( \pm 1.3^{\circ} \mathrm{C}\right)$, and indicate a large century-long reduction of $\sim 2.9^{\circ} \mathrm{C}$ in the autumn bottom temperature. The annual minima represent the spring or May bottom temperatures, average $5.7^{\circ} \mathrm{C}\left( \pm 0.9^{\circ} \mathrm{C}\right)$ and indicate a modest reduction of $\sim 0.4^{\circ} \mathrm{C}$ in spring bottom temperatures over the last century. The shell records describe a $\sim 1^{\circ} \mathrm{C}$ warming from a cold period in the 1880 s to a record warm period centered about 1900 . A cold period $~ 1905-1910$ is followed by another peak warming about 1915, after which there is general decline in temperatures for the rest

of the record. A steeper decline in temperature occurs after 1960. All records indicate that the 1880 s, 1960s, and 1970 s were the three most prolonged, coldest periods of the past century.

Shell-derived bottom temperature records show a strong similarity with the Nantucket Lightship bottom temperature records for the period 1960-1971, reconfirming 
that the shell-derived temperatures are accurately reflecting bottom temperatures on the outer shelf. The coherence between these records is strongest between the mean and minimum records and weakest between the maximum records. The latter result may indicate greater horizontal heterogeneity in bottom waters on the outer shelf at the autumn overturn. Long records of sea surface temperature from two coastal locations in New England and an air temperature record from the northeast U.S. coastal region show a strong positive correlation with each other, though there are significant local variations among these records at both short and long time-scales. Coastal air and sea surface records indicate a long-term $\sim 1^{\circ} \mathrm{C}$ warming over the last century with peak warming occurring in mid-century, most apparent in their annual mean and spring records. The shell-derived bottom temperature records show a poor correlation with the surface temperature records. However, detrending the records of their 10-year running means, greatly improves the correlation between these records, and indicates that the short-term temperature anomaly patterns are similar, while the long-term temperature trends differ.

One primary contrast between the long-term trends is that the shell-derived records indicate a mean century-long cooling of $\sim 1^{\circ} \mathrm{C}$, while mean air and sea surface records describe a century-long warming of equal magnitude. We have considered whether this contrast is a real temperature difference or an artifact. A biological or "vital effect" cause for this disparity has been rejected because the overlapping shell records provide a constraint on individual and ontogenic variation. It is possible that shelf water $\delta^{18} \mathrm{O}$ has become more enriched over the past century, owing to changes in shelf water circulation. For example, a $10 \%$ increase in the amount of Slope water relative to Scotian shelf water would produce an apparent $1{ }^{\circ} \mathrm{C}$ cooling if not accounted for. However, this explanation would also imply that the shelf waters have become $\sim 0.5 \%$ saltier over the past century as well. While, this hypothesis may be correct, it merely shifts the problem, from one of a significant temperature change to one of a significant salinity change (or some of both) either of which 
would have broad implications for shelf circulation. Finally, it seems equally possible that the shell-derived bottom temperature trends are real and of opposite sign to surface temperature trends. To explain this contrast, it is suggested that increased surface warming is directly or indirectly related to increased or prolonged stratification of shelf waters, which leads to a net reduction in vertical mixing and heat flux into the bottom waters of the "cold pool" and thus, an increase in the seasonal persistence of this continental hydrographic feature over the past century. 


\section{Acknowledgements}

Financial support for this work was provided by NOAA grant \# NA36GPO291 and Oak Ridge Associated Universities Global Climate Change Fellowship Program. All sampling and stable isotope analyses for this study were performed at the Woods Hole Oceanographic Institution. Specimen collections were carried out during the 1992 NMFS Clam Survey with the invaluable assistance of crew of the R/V Delaware II and the Survey Group at NOAA's Northeast Center of the National Marine Fisheries Service at Wood Hole. 


\section{References}

Arthur, M. A., D. F. Williams and D. S. Jones, Seasonal temperature-salinity changes and thermocline development in the mid-Atlantic Bight as recorded by the isotopic composition of bivalves, Geology, 11, 655-659, 1983.

Boden, T. A., D. P. Kaiser, R. J. Sepanski and F. W. Stoss, Trends '93: A compendium of data on global change, Carbon Dioxide Information Analysis Center, Environmental Sciences Division, Oak Ridge National Laboratory, ESD Publication No. 4195, 1994.

Bumpus, D. F., Surface water temperatures along Atlantic and Gulf Coasts of the United States, 214, U.S. Fish and Wildlife Service, 1957.

Chapman, D. C., J. A. Barth, R. C. Beardsley and R. G. Fairbanks, On the continuity of mean flow between the Scotian Shelf and the Middle Atlantic Bight, J.Phys.Oceanog, 16, 758-772, 1986.

Chapman, D. C., and R. C. Beardsley, On the origin of shelf water in the Middle Atlantic Bight, J. Phys. Ocean., 19, 384-391, 1989.

Dettman, D. L., and K. C. Lohmann, Seasonal change in Paleogene surface water d180: fresh-water bivalves of wertern North America, in Climate Changes in Continental Isotopic Records, Geophys. Monogr. Ser., vol. 78, edited by P. Swart, K. C. Lohmann, J. McKenzie, and S. Savin, pp. 153-163, AGU, Washington, D. C., 1993.

Dickson, R. R., and J. Namias, North American influences on the circulation and climate of the North Atlantic sector, Mon. Weather Rev., 104, 1255-1265, 1976.

Druffel, E. R. M., Detection of El Nino and decade scale variations of sea surface temperature from banded coral records: Implications for the carbon dioxide cycle, in: The Carbon Cycle and Atmospheric CO2: Natural Variations Archaean to Present, edited by E. T. Sundquist and W. S. Broecker, pp. Geophysical Monograph 32, American Geophysical Union, Washington, D.C., 1985.

Duplessy, J. C., Isotope Studies, in: Climate Change, edited by J. Gribben, pp. 46-67, Cambridge University Press, New York, 1978.

Epstein, S., R. Buchsbaum, H. A. Lowenstam and H. C. Urey, Revised carbonate-water isotopic temperature scale, Bull. Geol. Soc. Am., 64, 1315-1326, 1953.

Fairbanks, R. G., The origin of Continental Shelf and Slope Water in the New York Bight and Gulf of Maine: evidence from $\mathrm{H} 2 \mathrm{O}-18 / \mathrm{H} 2 \mathrm{O}-16$ ratio measurements, J. Geophys. Res., 87, 5796-5808, 1982.

Flagg, C. N., Hydrographic structure and variability, in: The Georges Bank Book, edited by R. H. Backus, pp. 108-124, MIT Press, Cambridge, MA, 1987.

Grossman, E. L., and T. Ku, Oxygen and carbon isotope fractionation in biogenic aragonite: temperature effects, Chem. Geol., 59, 59-74, 1986.

Harrington, R. J., Aspects of growth deceleration in bivalves: Clues to understanding the seasonal O-18 and C-13 record -- A comment on Krantz et al. (1987), Palaeogeogr., Palaeoclimatol., Palaeoecol., 70, 399-403, 1989. 
Heller, J., Longevity in molluscs, Malacol., 31, 259-295, 1990.

Houghton, R. W., R. Schlitz, R. C. Beardsley, B. Butman and J. L. Chamberlin, The Middle Atlantic Bight Cold Pool: evolution of the temperature structure during summer 1979, J. Phys. Ocean., 12, 1019-1029, 1982.

Jones, D. S., Annual cycle of shell growth and reproduction in the bivalves-Spisula Solidissima-\&-Arctica islandica-, $\mathrm{PhD}$, Princeton University, 1980.

Jones, D. S., D. F. Williams, M. A. Arthur and D. E. Krantz, Interpreting the Palaoenvironmental, paleoclimatic and life history records in mollusc shells, Geobios. Mem., 8, 333-339, 1984.

Krantz, D. E., D. F. Williams and D. S. Jones, Ecological and paleoenvironmental information using stable isotope profiles from living and fossil molluscs, Palaeogeogr., Palaeoclimatol., Palaeoecol., 58, 249-266, 1987.

Lazzari, M. A., Monthly and annual means of sea surface temperature, Boothbay Harbor, Maine, 1905 through 1994, Research Reference Document 95/1, Maine Department of Marine Resources, Environmental Monitoring Project at the Marine Sciences Laboratory, West Boothbay Harbor, Maine, 1995.

Mann, R., The seasonal growth cycle of gonadal development in Arctica islandica from the southern New England Bight, Fish. Bull., 80, 315-326, 1982.

O'Reilly, J. E., C. Evans-Zetlin and D. A. Busch, Primary production, in: The Georges Bank Book, edited by Backus, pp. MIT Press, Cambridge, MA, 1987.

Rhoads, D. C., and R. A. Lutz, Skeletal Growth of Aquatic Organisms, New York and London, Plenum Press, 1980.

Romanek, C. S., D. S. Jones, D. F. Williams, D. E. Krantz and R. Radke, Stable isotopic investigation of physiological and environmental changes recorded in shell carbonate from the giant clam Tridacna maxima, Mar. Biol., 94, 385-393, 1987.

Urey, H. C., H. A. Lowenstam, S. Epstein and C. R. McKinney, Measurement of paleotemperatures and temperatures of the Upper Cretaceous of England, Denmark, and Southeastern United States, Bull. Geol. Soc. Am., 62, 399-416, 1951.

Wefer, G., and W. H. Berger, Isotope paleontology: growth and composition of extant calcareous species, Mar. Geol., 100, 207-248, 1991.

Weidman, C. R., G. A. Jones and K. C. Lohmann, The long-lived mollusc Arctica islandica: A new paleoceanographic tool for the reconstruction of bottom temperatures $\mathrm{f}$ or the continental shelves of the northern North Atlantic Ocean, J. Geophys. Res., 99, 18,305-18,314, 1994.

Williams, D. F., M. A. Arthur, D. S. Jones and N. Healy-Williams, Seasonality and mean annual sea surface temperatures from isotopic and sclerochronological records, Nature, 296, 432-434, 1982. 
Table 1. Specimen Band Chronology Data

\begin{tabular}{lccc}
$\begin{array}{l}\text { Specimen } \\
\text { ID }\end{array}$ & $\begin{array}{l}\text { Age }( \pm \text { uncertainty) } \\
\text { (years) }\end{array}$ & Bands sampled & $\begin{array}{c}\text { Chronology } \\
\text { (years) }\end{array}$ \\
\hline CS92-315-3B & $119( \pm 2)$ & 45 & $1875-1919$ \\
CS92-315-12B & $79( \pm 1)$ & 23 & $1915-1937$ \\
CS92-315-28A & $70( \pm 0)$ & 33 & $1924-1956$ \\
CS92-315-4B & $48( \pm 0)$ & 38 & $1946-1983$
\end{tabular}


Table 2: Shell $\delta^{18} \mathrm{O}$ Summary

\begin{tabular}{lllllllll}
\hline Specimen & $\begin{array}{l}\text { Mean } \\
\text { Mean }(\sigma)\end{array}$ & $\begin{array}{l}\text { Mean } \\
\text { Max }(\sigma)\end{array}$ & $\begin{array}{l}\text { Mean } \\
\text { Min }(\sigma)\end{array}$ & $\begin{array}{l}\text { Mean } \\
\text { Amp }\end{array}$ & $\begin{array}{l}\text { Slope } \\
\text { Mean }\end{array}$ & $\begin{array}{l}\text { Slope } \\
\text { Max }\end{array}$ & $\begin{array}{l}\text { Slope } \\
\text { Min }\end{array}$ & $\begin{array}{c}\text { Slope } \\
\text { Amp }\end{array}$ \\
\hline 3B & $1.82(.18)$ & $2.30(.25)$ & $1.22(.24)$ & 1.08 & -0.003 & -0.007 & +0.003 & -0.010 \\
\hline 12B & $1.78(.19)$ & $2.31(.17)$ & $1.18(.31)$ & 1.13 & +0.010 & +0.006 & +0.015 & -0.009 \\
\hline 28A & $1.83(.13)$ & $2.23(.16)$ & $1.35(.24)$ & 0.88 & -0.002 & -0.004 & +0.007 & -0.011 \\
\hline 4B & $1.97(.20)$ & $2.40(.22)$ & $1.49(.24)$ & 0.90 & +0.011 & +0.010 & +0.013 & -0.003 \\
\hline Mean & $1.86(.18)$ & $2.31(.21)$ & $1.32(.25)$ & 0.99 & +0.004 & +0.001 & +0.010 & -0.008 \\
\hline
\end{tabular}


Table 3. Overlap Comparison

\begin{tabular}{|c|c|c|c|c|c|c|c|c|c|c|}
\hline $\begin{array}{l}\text { Overlap } \\
\text { ID }\end{array}$ & $\begin{array}{l}\text { Overlap Size } \\
\text { (years) }\end{array}$ & $\begin{array}{l}\text { Chronology } \\
\text { (years) }\end{array}$ & $\begin{array}{c}\Delta \\
\text { mean }\end{array}$ & $\underset{\max }{\Delta}$ & $\underset{\min }{\Delta}$ & $\begin{array}{c}\mathrm{r} \\
\text { mean }\end{array}$ & $\stackrel{r}{\max }$ & $\stackrel{\mathrm{r}}{\mathrm{min}}$ & $\begin{array}{l}\text { Age } \Delta \\
\text { (years) }\end{array}$ & $\begin{array}{l}\text { Band Width (mm) } \\
\text { Young / Old }\end{array}$ \\
\hline $3 B / 12 B$ & 5 & $1915-1919$ & +0.12 & -0.02 & +0.26 & 0.84 & 0.62 & 0.95 & 40 & $6.61 / 0.23$ \\
\hline $12 \mathrm{~B} / 28 \mathrm{~A}$ & 14 & $1924-1937$ & -0.03 & +0.08 & -0.08 & 0.60 & 0.43 & 0.35 & 9 & $2.77 / 0.29$ \\
\hline $28 \mathrm{~A} / 4 \mathrm{~B}$ & 11 & $1946-1956$ & 0.00 & -0.08 & +0.15 & 0.74 & 0.62 & 0.80 & 23 & $3.61 / 0.27$ \\
\hline
\end{tabular}

그 
Table 4. Combined Shell-Derived Bottom Temperature Record

\begin{tabular}{|c|c|c|c|c|}
\hline Year & & Mean & Max & Min \\
\hline $\begin{array}{l}1875 \\
1876 \\
1877 \\
1878 \\
1879\end{array}$ & . & $\begin{array}{l}6.46 \\
6.76 \\
7.57 \\
9.88 \\
8.78\end{array}$ & $\begin{array}{l}11.53 \\
11.66 \\
14.52 \\
15.60 \\
11.81\end{array}$ & $\begin{array}{l}4.06 \\
3.77 \\
4.86 \\
6.80 \\
6.41\end{array}$ \\
\hline $\begin{array}{l}1880 \\
1881 \\
1882 \\
1883 \\
1884 \\
1885 \\
1886 \\
1887 \\
1888 \\
1889\end{array}$ & & $\begin{array}{l}8.23 \\
6.37 \\
7.71 \\
6.94 \\
7.71 \\
7.20 \\
7.57 \\
6.67 \\
7.16 \\
8.18\end{array}$ & $\begin{array}{l}11.50 \\
10.60 \\
15.12 \\
12.16 \\
11.02 \\
10.87 \\
10.07 \\
10.61 \\
11.90 \\
11.74\end{array}$ & $\begin{array}{l}6.50 \\
3.48 \\
5.66 \\
4.06 \\
5.30 \\
4.90 \\
4.75 \\
4.59 \\
4.55 \\
6.89\end{array}$ \\
\hline $\begin{array}{l}1890 \\
1891 \\
1892 \\
1893 \\
1894 \\
1895 \\
1896 \\
1897 \\
1898 \\
1899\end{array}$ & & $\begin{array}{l}8.14 \\
8.04 \\
8.04 \\
7.39 \\
7.80 \\
7.66 \\
8.23 \\
9.56 \\
9.08 \\
8.09\end{array}$ & $\begin{array}{l}10.29 \\
13.96 \\
10.99 \\
13.03 \\
12.91 \\
10.99 \\
13.09 \\
14.77 \\
12.06 \\
11.97\end{array}$ & $\begin{array}{l}6.72 \\
6.72 \\
6.07 \\
5.34 \\
6.07 \\
5.10 \\
5.38 \\
6.89 \\
7.34 \\
6.07\end{array}$ \\
\hline $\begin{array}{l}1900 \\
1901 \\
1902 \\
1903 \\
1904 \\
1905 \\
1906 \\
1907 \\
1908 \\
1909\end{array}$ & . & $\begin{array}{l}7.66 \\
8.78 \\
9.29 \\
9.45 \\
7.99 \\
6.85 \\
8.63 \\
6.94 \\
6.67 \\
6.07\end{array}$ & $\begin{array}{r}11.70 \\
14.27 \\
13.20 \\
14.31 \\
12.40 \\
10.15 \\
13.15 \\
9.74 \\
9.78 \\
13.16\end{array}$ & $\begin{array}{l}6.07 \\
6.76 \\
7.20 \\
7.30 \\
5.10 \\
4.55 \\
6.33 \\
5.26 \\
5.54 \\
4.48\end{array}$ \\
\hline $\begin{array}{l}1910 \\
1911 \\
1912 \\
1913 \\
1914 \\
1915 \\
1916 \\
1917 \\
1918 \\
1919\end{array}$ & . & $\begin{array}{l}8.43 \\
8.18 \\
7.80 \\
7.71 \\
7.80 \\
8.52 \\
8.00 \\
8.19 \\
8.66 \\
9.54\end{array}$ & $\begin{array}{l}13.44 \\
12.22 \\
11.34 \\
13.30 \\
12.10 \\
13.50 \\
10.67 \\
15.35 \\
13.53 \\
14.43\end{array}$ & $\begin{array}{l}6.59 \\
6.67 \\
5.74 \\
6.33 \\
6.63 \\
6.31 \\
5.87 \\
5.06 \\
6.26 \\
6.93\end{array}$ \\
\hline
\end{tabular}




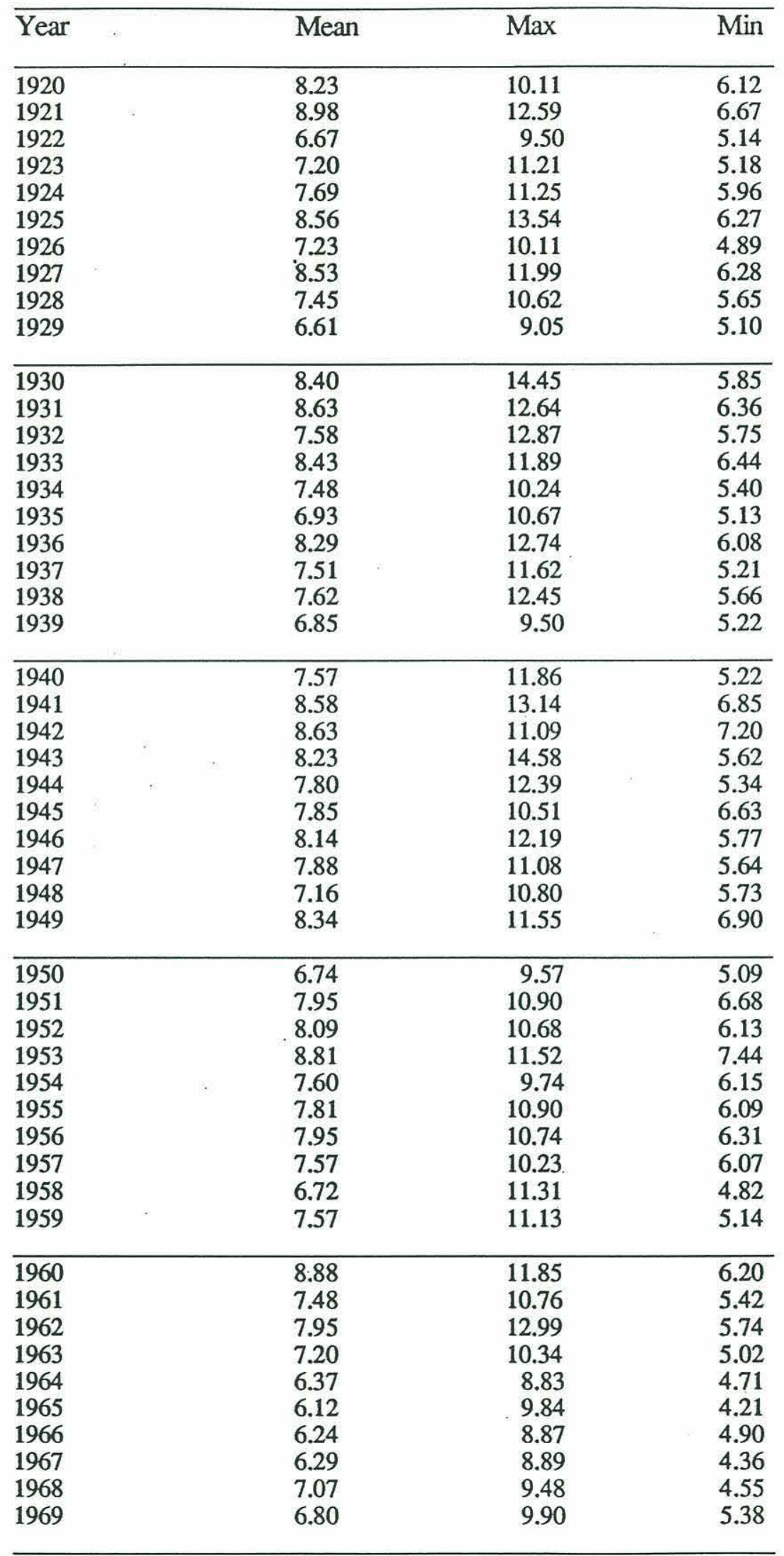




\begin{tabular}{llcl}
\hline Year & Mean & Max & Min \\
\hline & & & \\
1970 & 8.14 & 12.54 & 6.24 \\
1971 & 7.90 & 10.12 & 6.54 \\
1972 & 7.20 & 9.82 & 5.91 \\
1973 & 6.54 & 8.49 & 5.87 \\
1974 & 6.54 & 9.73 & 4.75 \\
1975 & 6.20 & 10.11 & 4.44 \\
1976 & 6.03 & 8.14 & 5.38 \\
1977 & 5.30 & 8.75 & 3.81 \\
1978 & 7.43 & 11.12 & 5.87 \\
1979 & 6.37 & 8.58 & 4.59 \\
\hline 1980 & & & \\
1981 & 5.74 & 8.43 & 4.06 \\
1982 & 5.99 & 9.53 & 3.92 \\
1983 & 6.80 & 9.77 & 5.22 \\
& 7.43 & 11.48 & 4.75 \\
\hline Mean & & 11.47 & \\
$( \pm 1 \sigma)$ & 7.64 & $( \pm 1.69)$ & $( \pm 0.90)$ \\
Minimum & $( \pm 0.90)$ & 8.14 & 3.48 \\
(Year) & & $(1976)$ & $(1881)$ \\
Maximum & 5.30 & 15.60 & 7.34 \\
(Year) & $(1977)$ & $(1878)$ & $(1898)$ \\
\hline
\end{tabular}




\section{Figure Captions}

Figure 1. Nantucket Shoals and Georges Bank. Specimen collection site is approximately nine kilometers south of the former position of the Nantucket Lightship.

Figure 2. Figures from Houghton, et al.'s [1982] Mid-Atlantic Bight (MAB) "Cold Pool" study showing the specimen collection site (solid triangle). This postion is at approximately the same depth contour as the New England Shelf Experiment 79's (NSFE79) station N2, which is centered within the northern portion of the "Cold Pool".

Figure 3. "Monthly" $\delta^{18} \mathrm{O}(\mathrm{PDB})$ record for each specimen plotted versus its estimated chronology. Linear trends are plotted for each record's Omean (annual mean), Omax (annual maximum), and Omin (annual minimum).

Figure 4. Overlap $\delta^{18} \mathrm{O}$ record comparison. The last parts of the records for Omean, Omin, Omax of the older shells (solid line) are compared with the first parts of the records of the younger shells. These overlap pairs show significant correlation, though the Omin data in the first and third pair are offset, with the older shells' records being more enriched.

Figure 5. Bottom temperature versus bottom salinity (monthly means) at the Nantucket Lightship for the period 1956-1957 and 1960-1971. A quadratic fit to the data is used to model the double salinity maximum occurring when temperatures are coldest and warmest.

Figure 6. Combined shell-derived bottom temperature records, which include annual mean (BTmean), annual (autumn) maximum (BTmax), and annual (spring) minimum (BTmin). Running 10-year means (centered on the year) are plotted for each statistical record.

Figure 7. Seasonal primary production in the stratified region on the southern flank of Georges Bank. The dashed line is the moving average of seven adjacent samples (from $\mathrm{O}^{\prime}$ Reilly, et al., 1987).

Figure 8. Comparison between the shell-derived bottom temperatures (solid lines) and the Nantucket Lightship bottom (dashed lines) and surface (dotted lines) temperatures.

Figure 9. Boothbay Harbor (solid lines) and Brenton Reef Lightship SST (dashed lines) records: annual mean, annual maximum, and April. 10-year running means are plotted for each record. (Boothbay data from Lazzari, 1995 and Brenton Reef Lightship data from Bumpus, 1957)

Figure 10. Regional (coastal northeast U.S. cities) air temperature records: annual mean, summer (maximum), and spring (comparable minimum). 10-year running means are plotted for each record. (data from Boden, et al., 1990)

Figure 11. Detrended sea surface temperature, air temperature, and shell-derived bottom temperature (deviation) Records. Deviation records $=[\mathrm{T}-$ running mean (10y)) $/$ $\mathrm{SD}$ (residuals)]. 


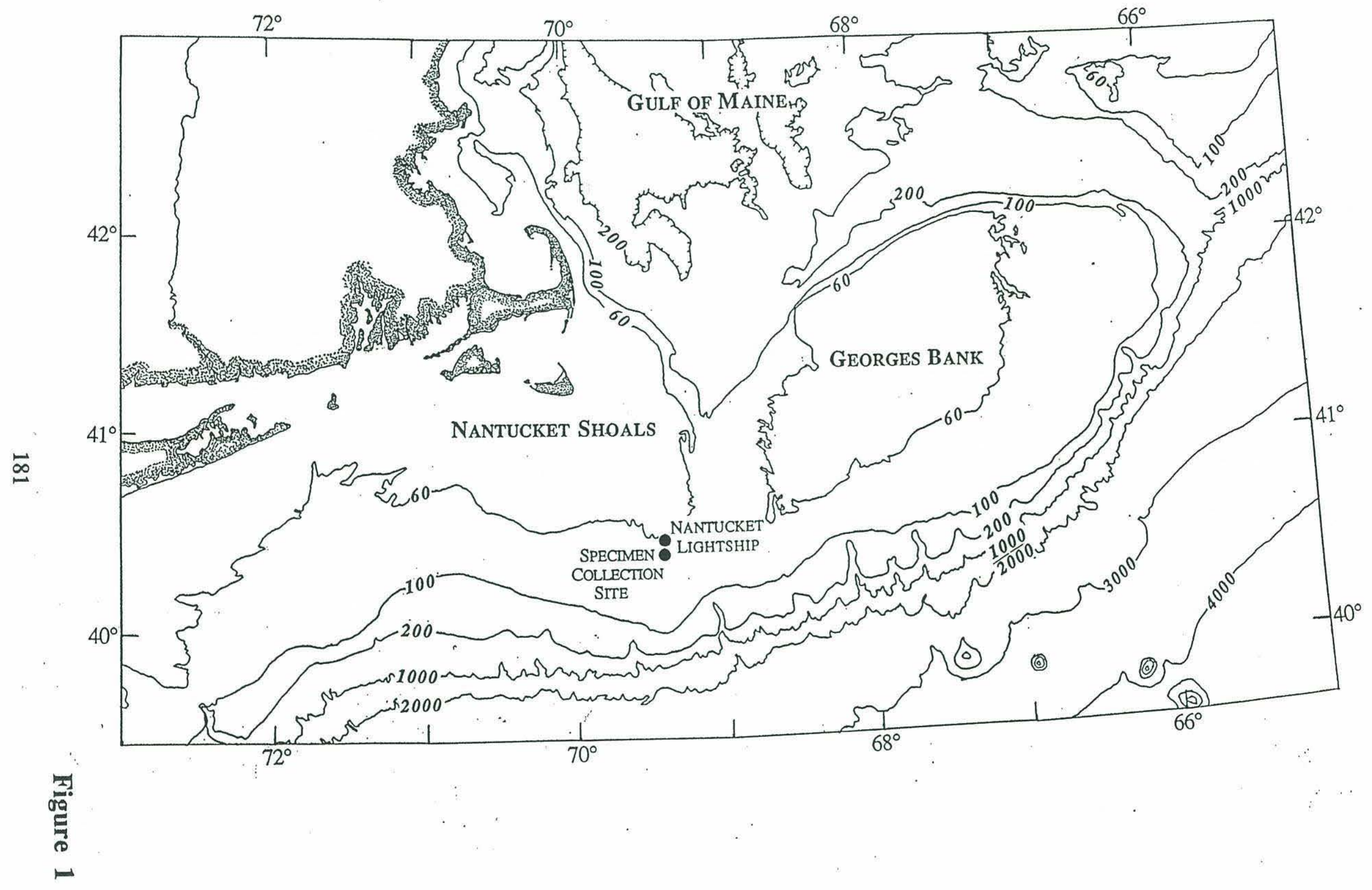




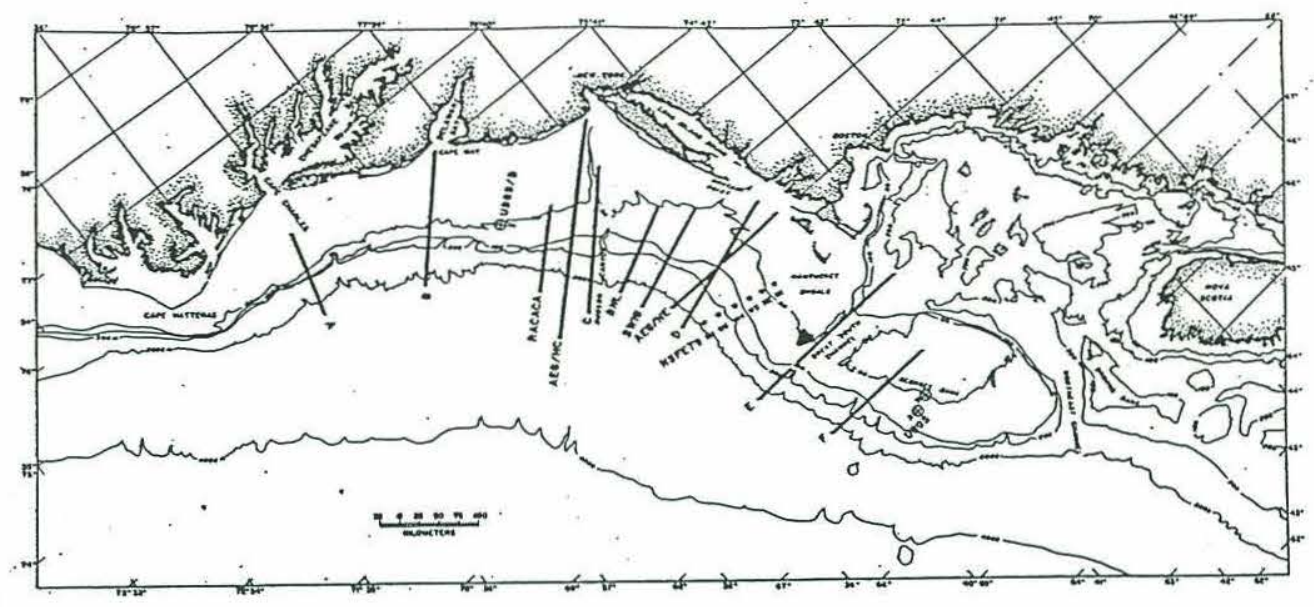

MAB Cold Pool Study (Figures from Houghton, R. W., et al., 1982)

Top: Transect Locations (note NSFE79) Middle: Monthly averaged T along NSFE79 Bottom: Marmap BTs

Specimen collection position (A)
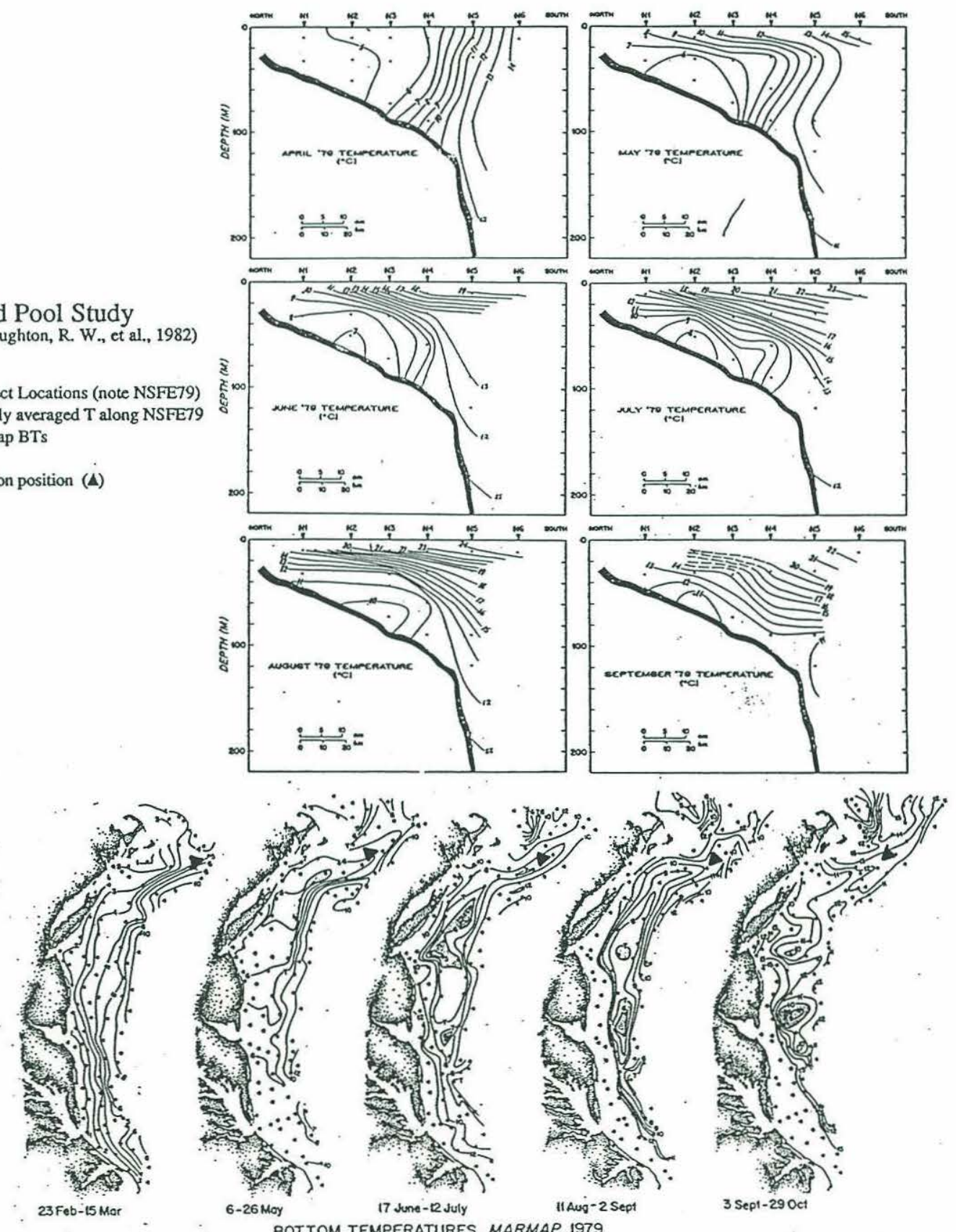

BOTTOM TEMPERATURES MARMAP. 1979

Figure 2 

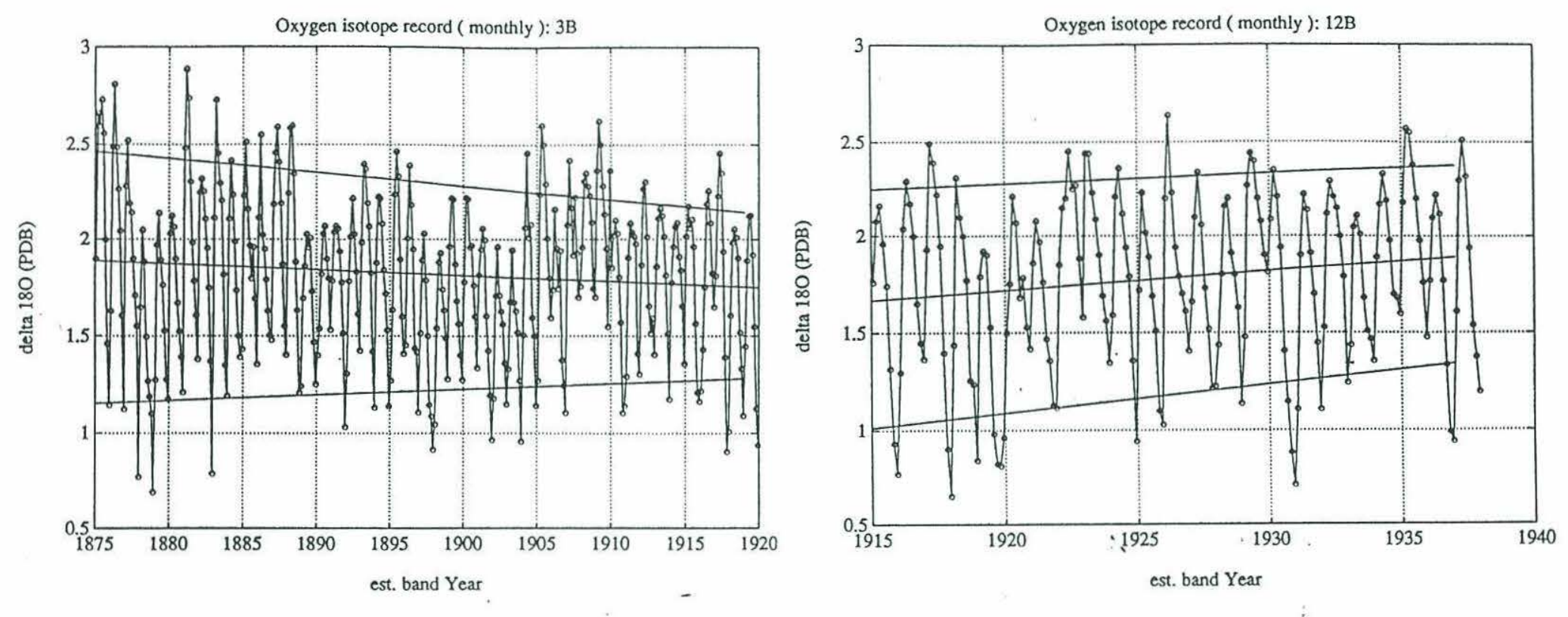

$\underset{\omega}{\infty}$
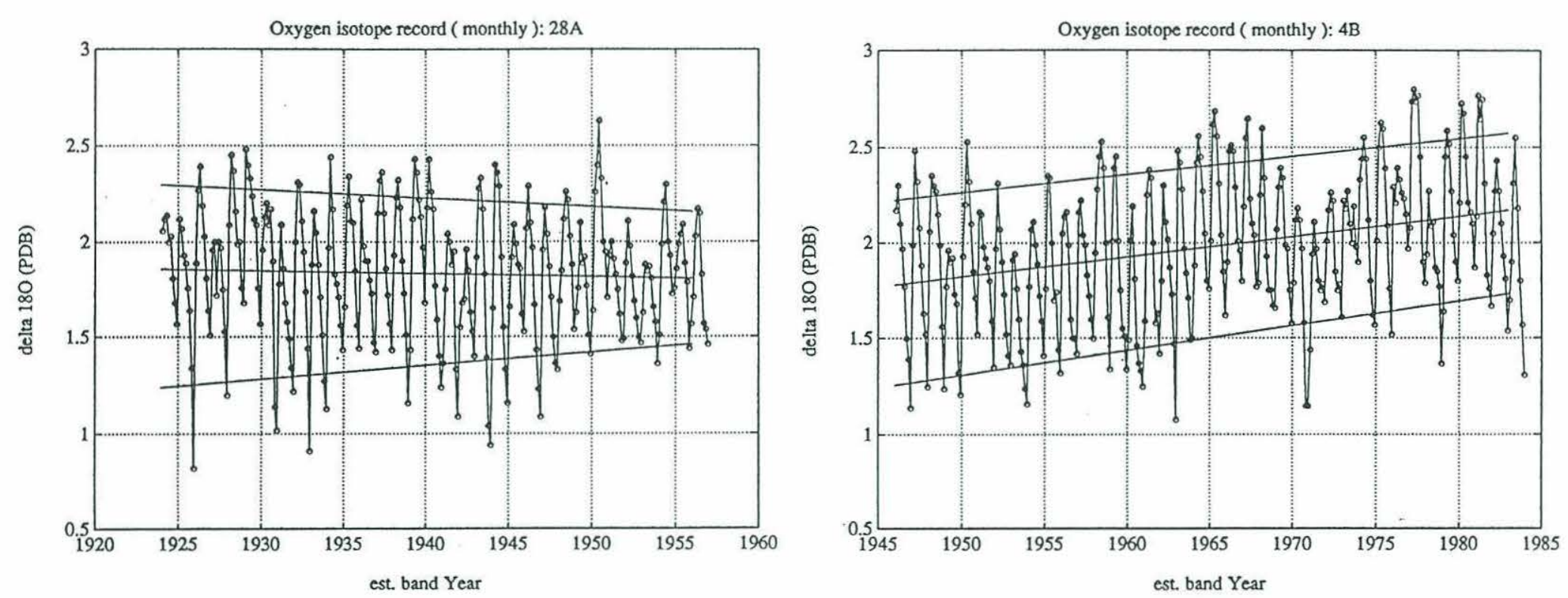

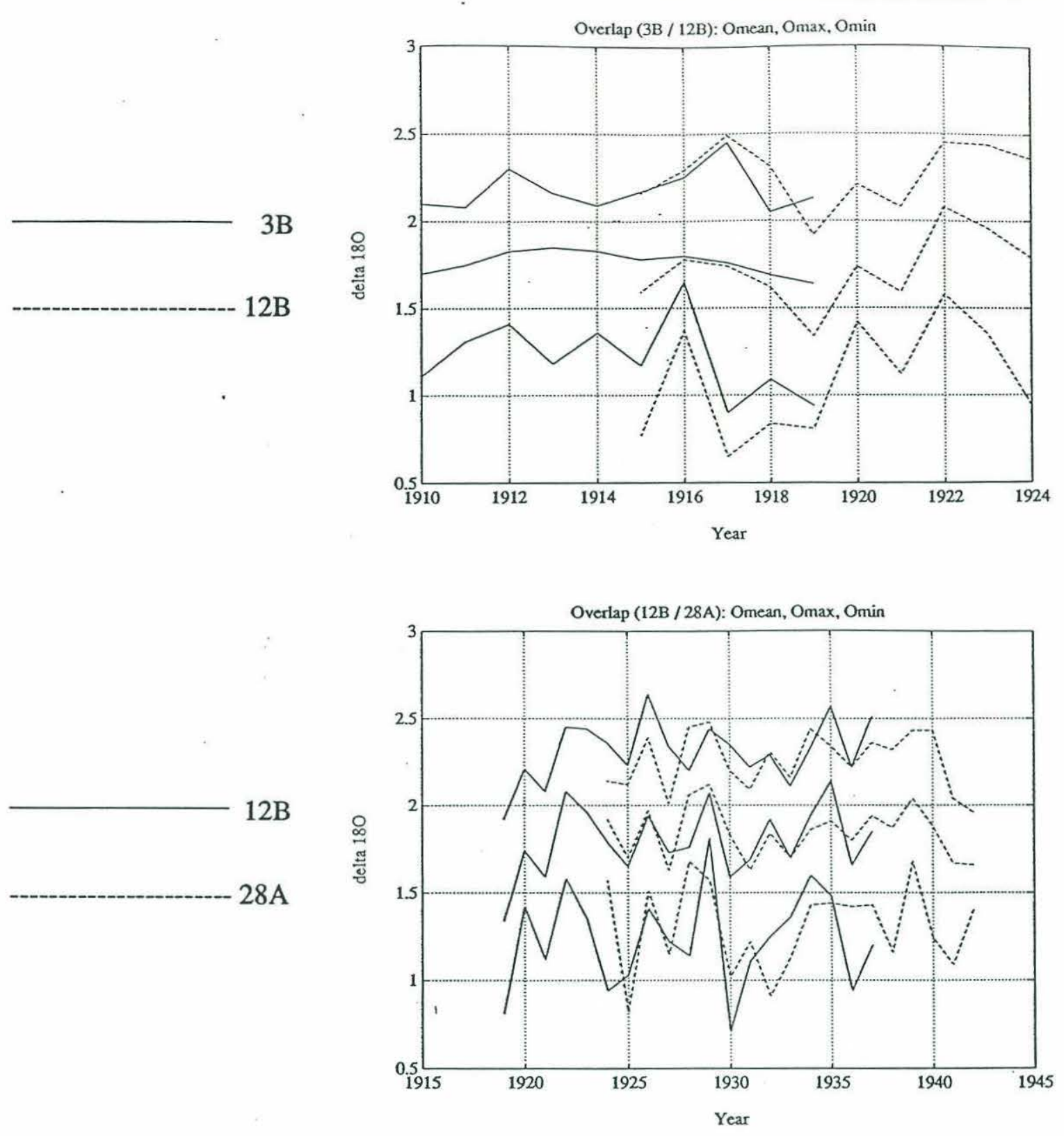

28A

4B

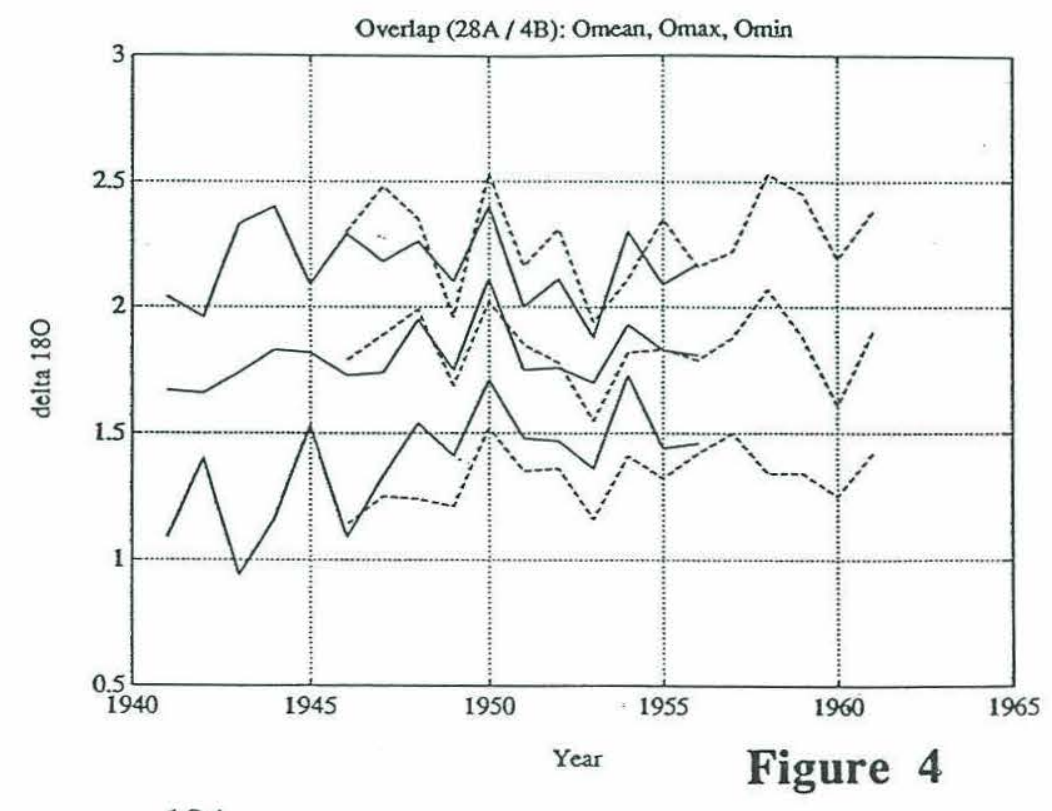




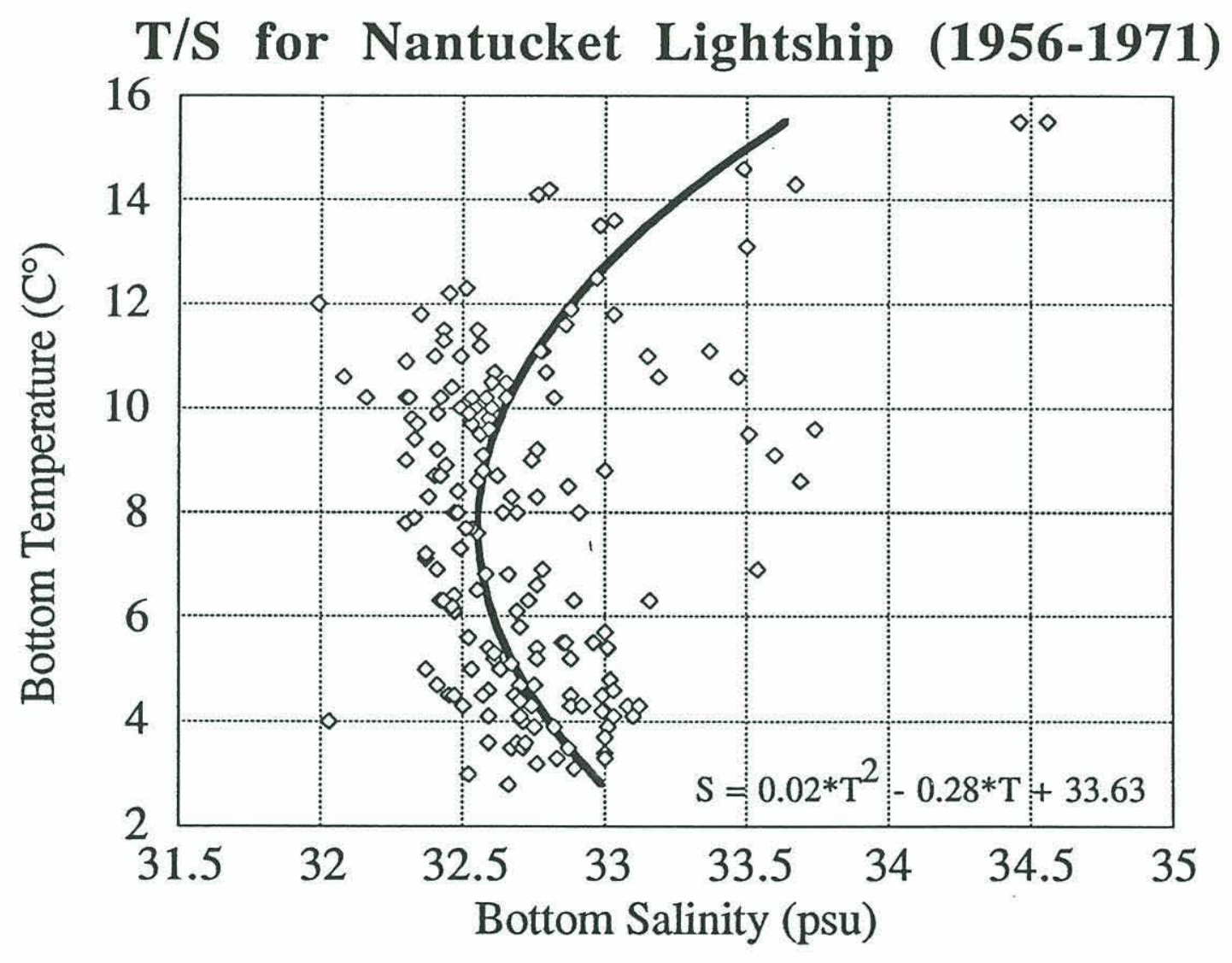

Figure 5 


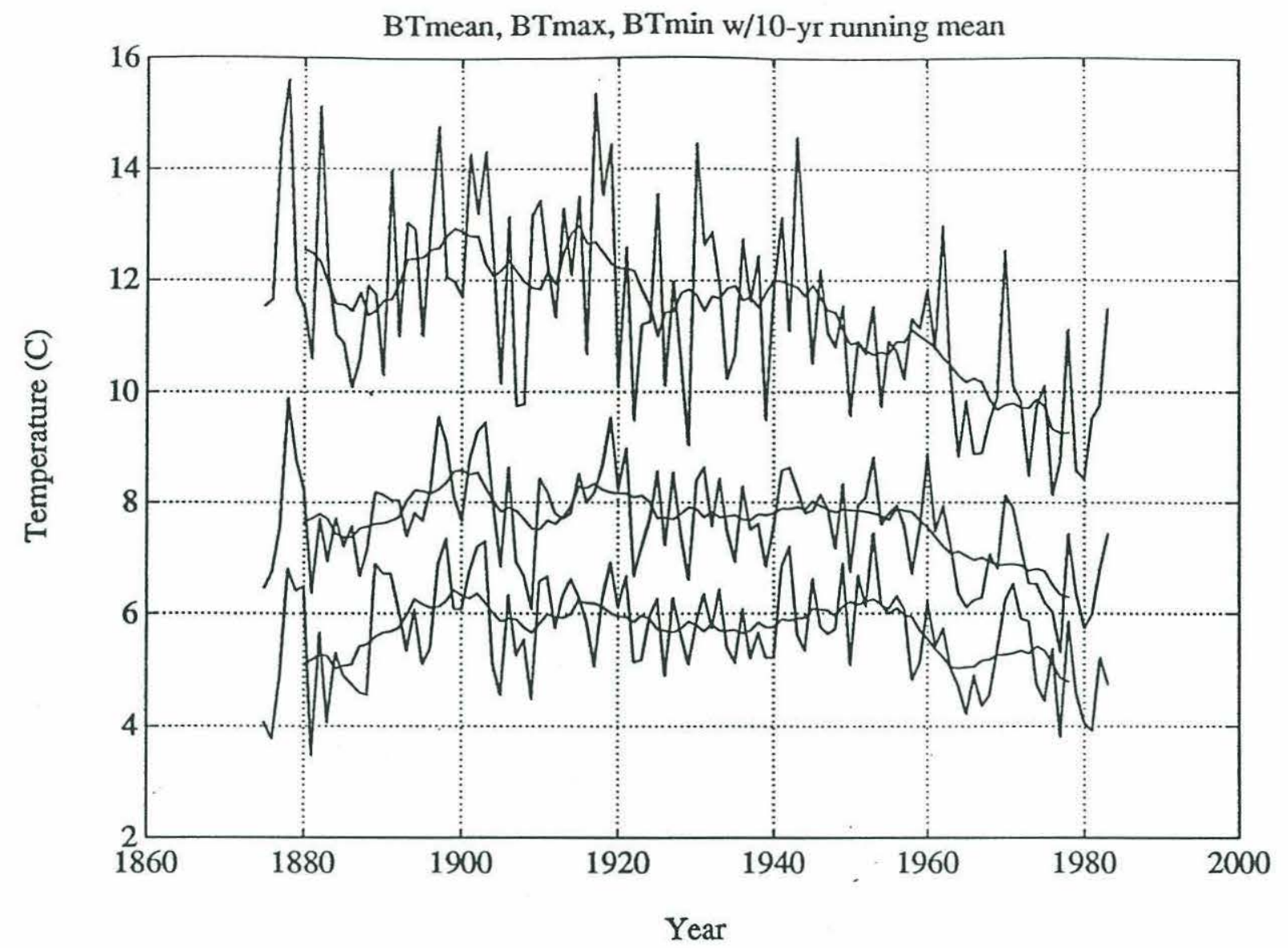

Figure 6 


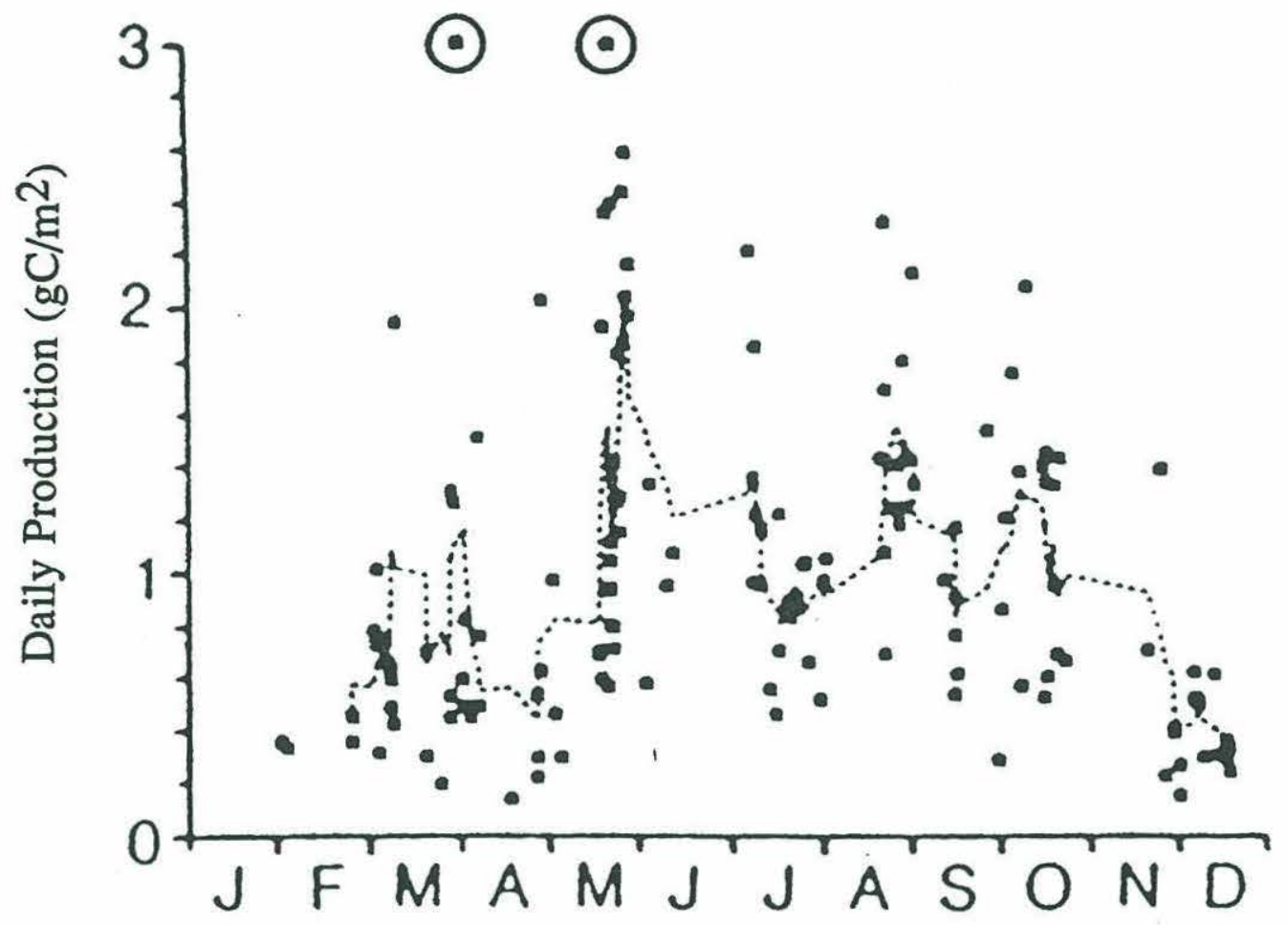

Figure 7 


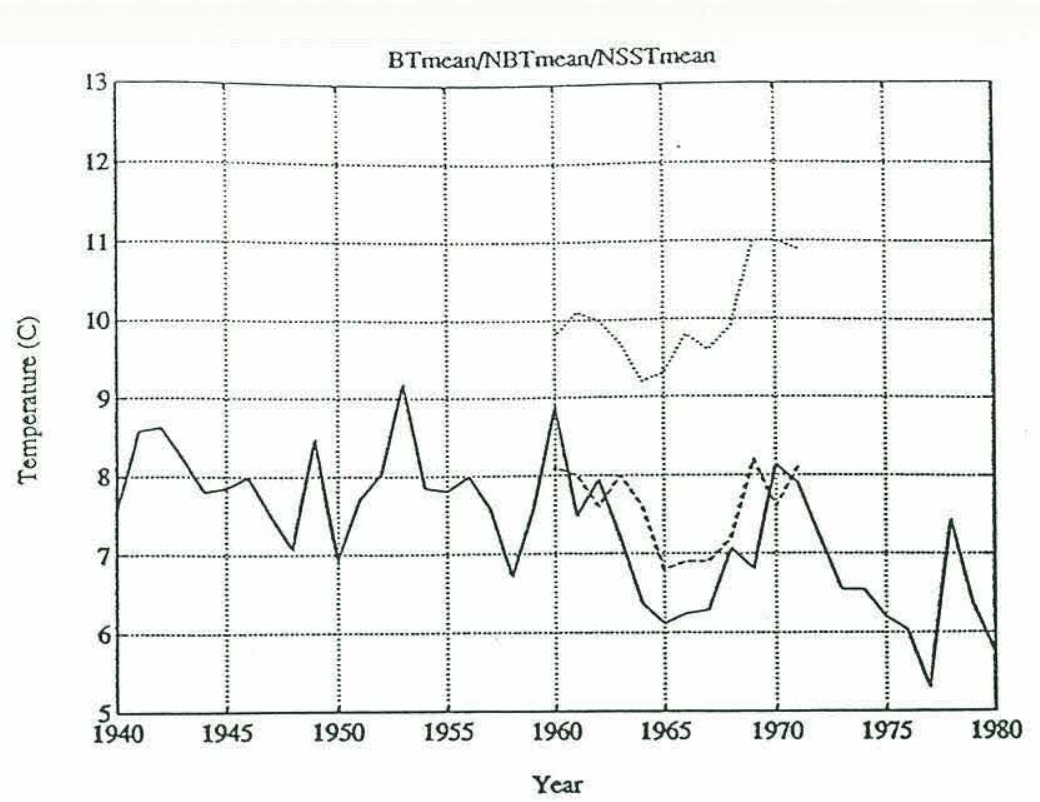

SHELL BT

NTKT BT

NTKT SST
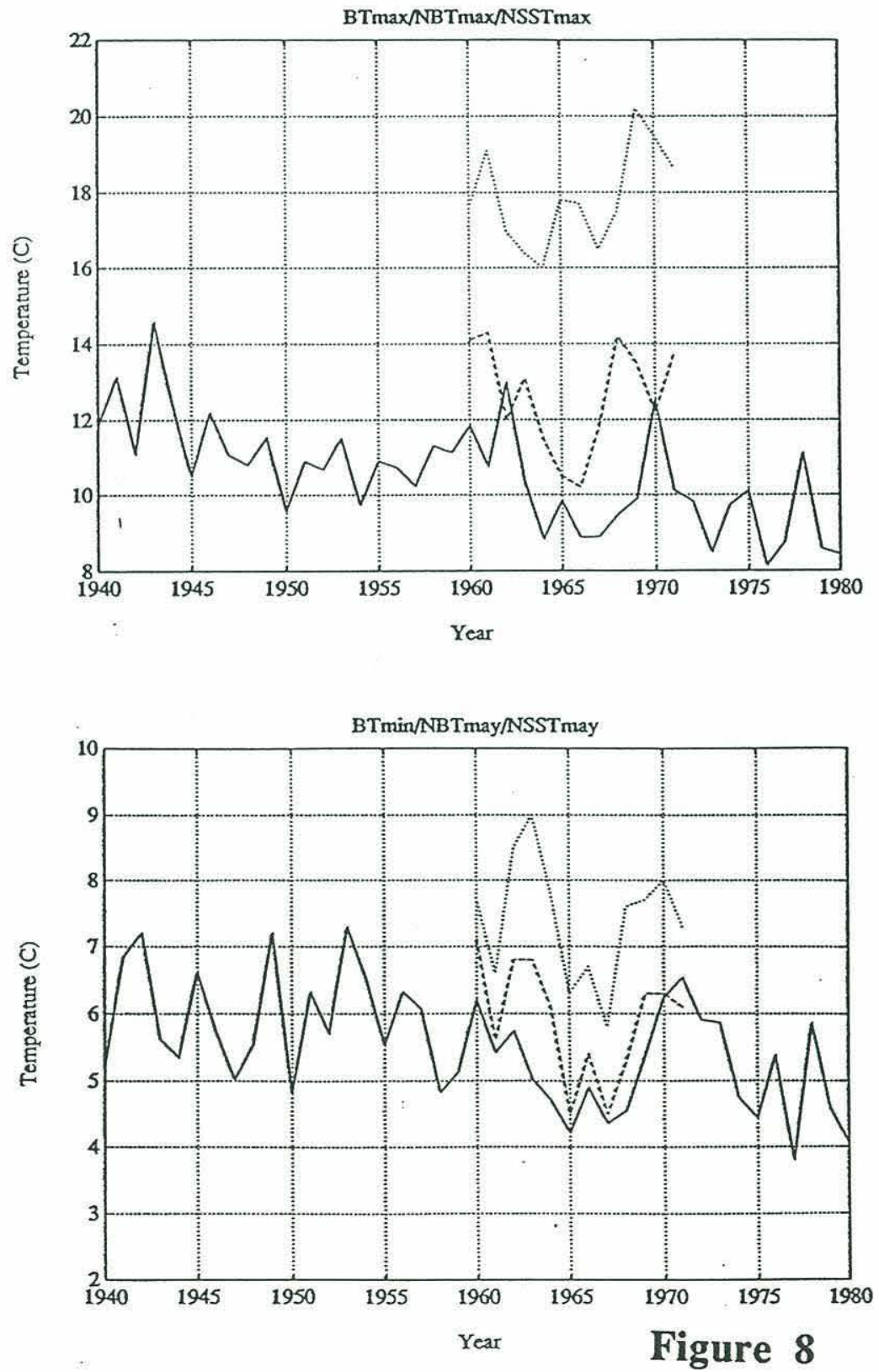
Boothbay \& Brenton Reef SST w/ 10-yr running mean

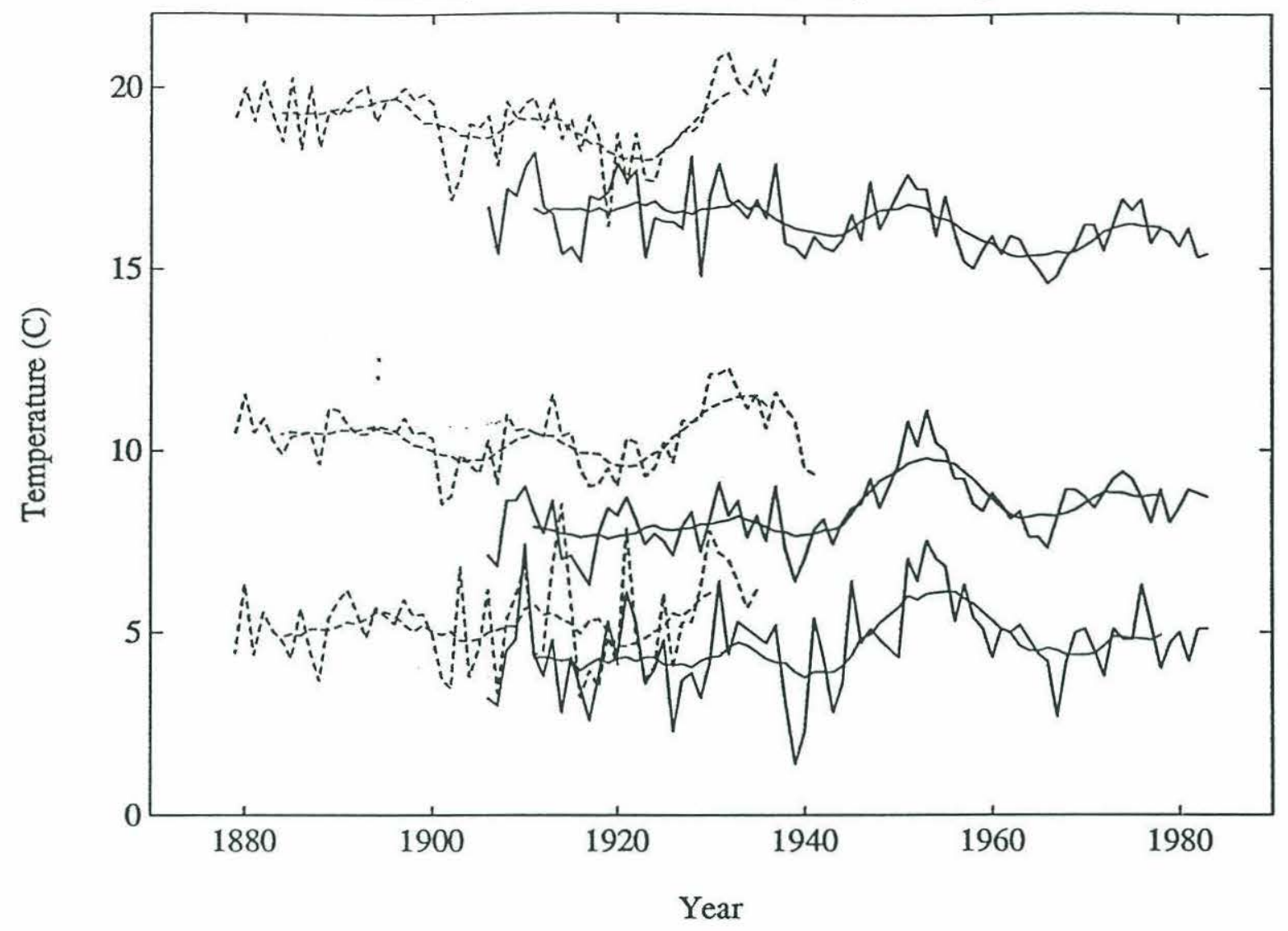




\section{Air Temperatures for Coastal Northeast U.S.}

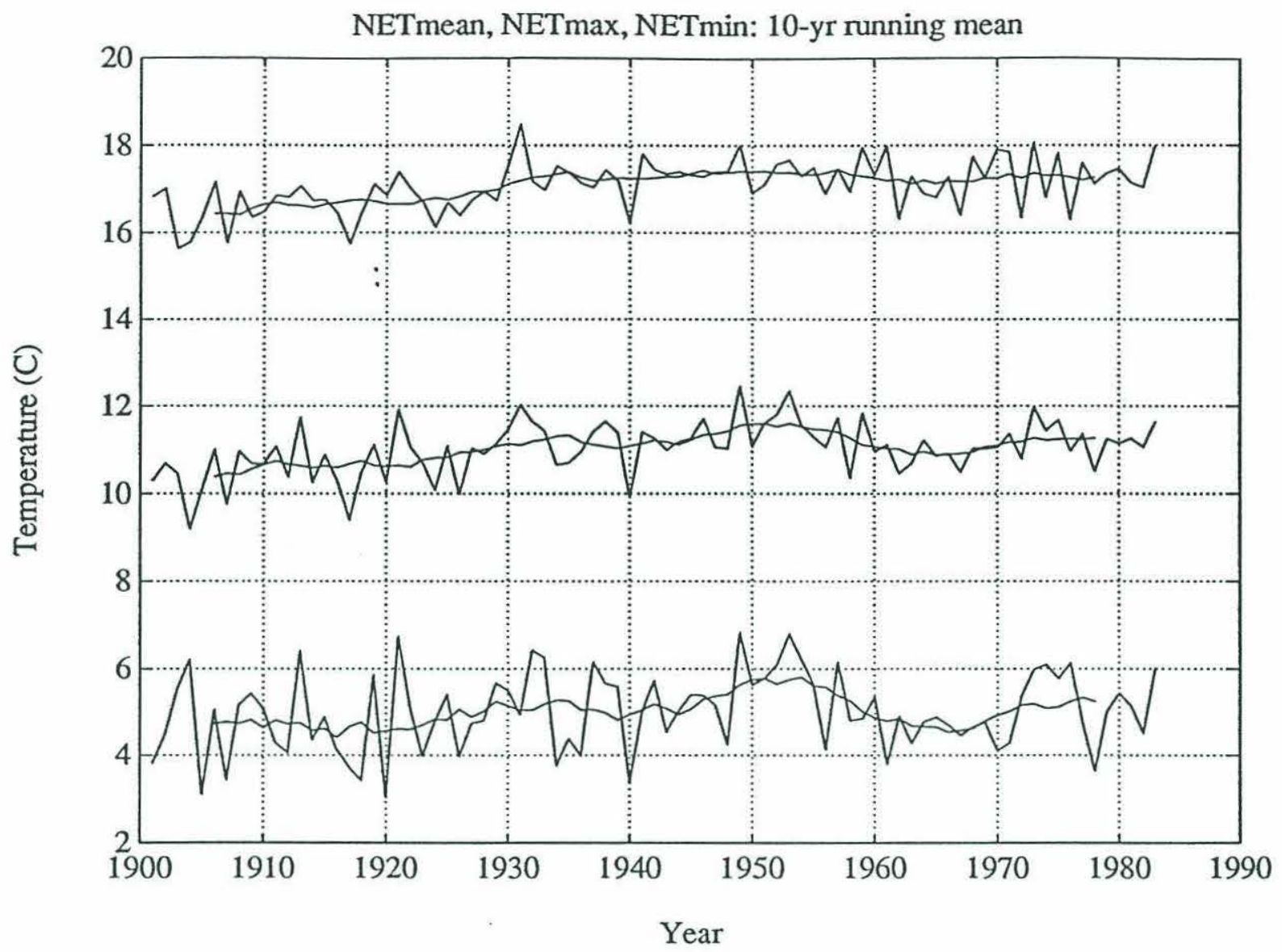


.......... Brenton Reef SST Shell-Derived BT

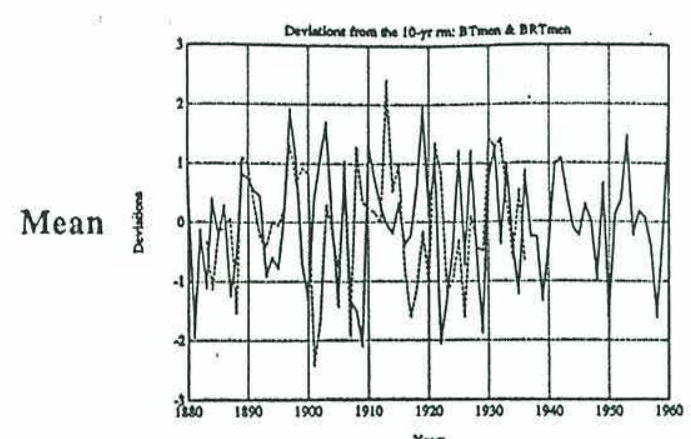

ran

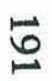
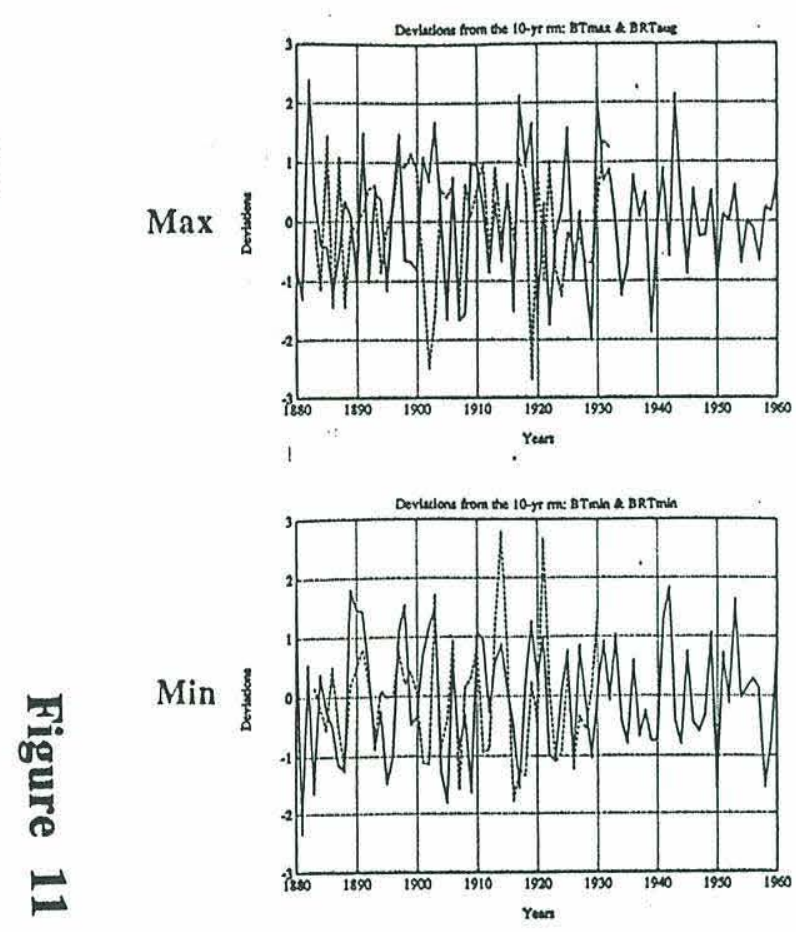

Boothbay Harbor SST

Shell-Derived BT

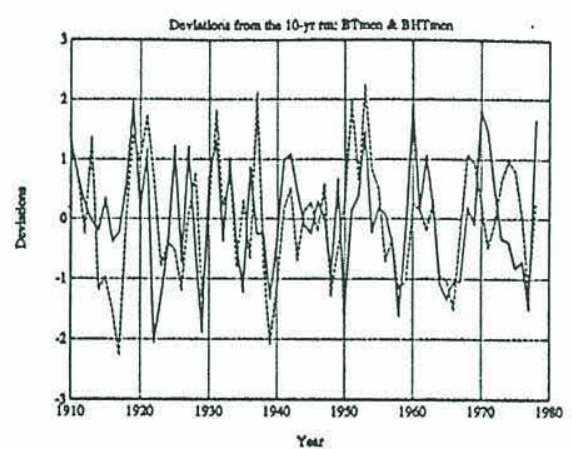

Yout
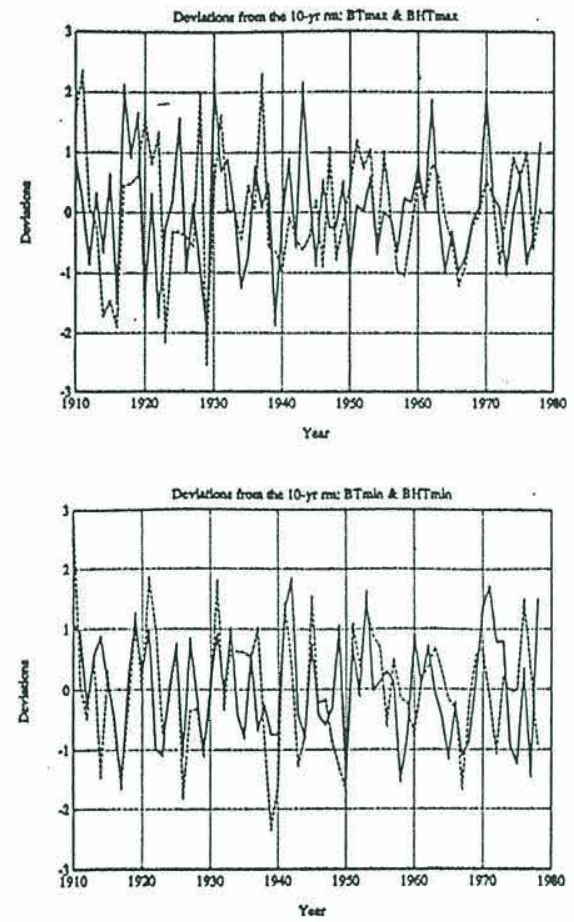

Coastal N.E. Air T

Shell-Derived BT
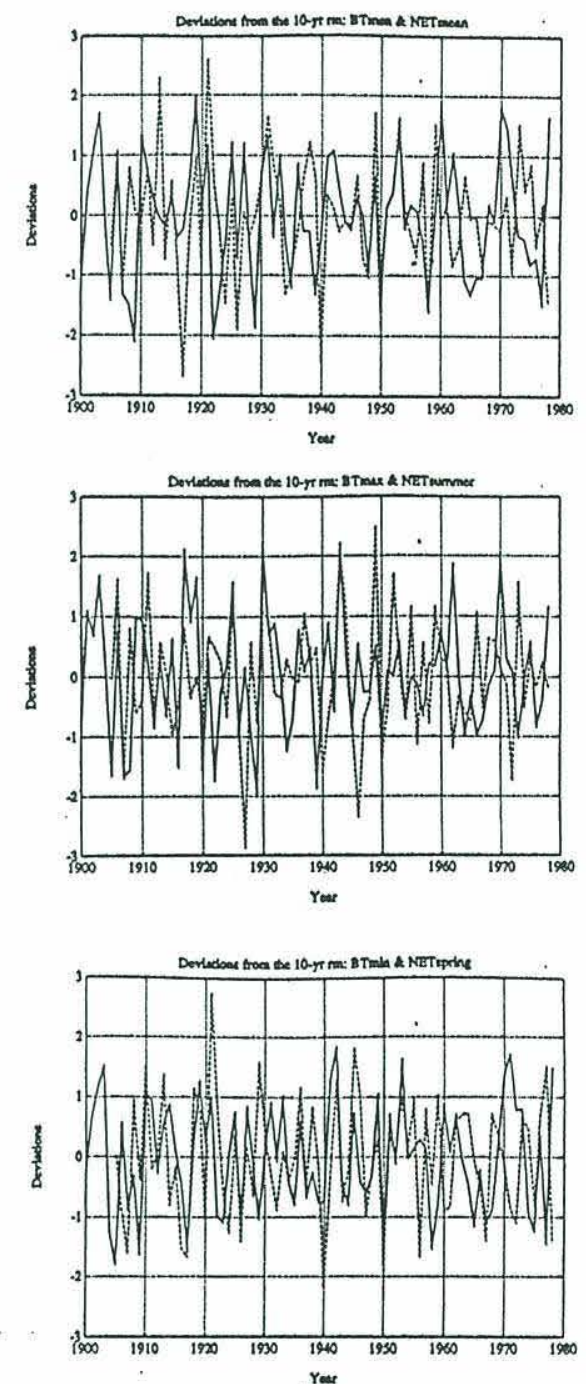


\section{CONCLUSIONS}

The need for methods to reconstruct marine geochemical records of meaningful length with seasonal, annual, and decadal scale resolution for the cold, higher latitude oceans, has long been recognized. The recent availability of computer-aided microsampling equipment and micromass mass spectrometry now provides a way for long-lived, slow growth rate molluscs, such as A. islandica, to be used for this purpose. The primary objectives of this thesis have been: 1) the development and calibration of A. islandica as a new paleoceanographic tool for the mid- and high-latitudes of the North Atlantic Ocean; and 2) the demonstration that $A$. islandica-derived time histories of $\Delta^{14} \mathrm{C}$, and $\delta^{18} \mathrm{O}$ can be reconstructed for periods up to a century, and used to investigate the temporal and spatial variability of the northern North Atlantic's continental shelf bottom temperature, physical circulation, and uptake of atmospheric ${ }^{14} \mathrm{CO}_{2}$. In pursuit of these objectives, the first three chapters have described the developmental aspects and shown that the carbon and oxygen isotopic composition A. islandica shells cạn be used to reconstruct accurate time-series of ambient ocean radiocarbon and temperature. However, the stable carbon isotopic $\left({ }^{13} \mathrm{C}\right)$ composition of the A. islandica shell appears to be offset from "equilibrium" with ambient DIC and its seasonal and interannual variations seem to be largely of physiological origin, and therefore not as useful a recorder of environmental conditions. The last two chapters have focused on applications, describing 1) the evolution of the $\Delta^{14} \mathrm{C}$ signal throughout the surface northern North Atlantic over the last 50 to 100 years, and 2) the first century-long record of continental shelf bottom temperatures for a higher-latitude (cold ocean) location.

In chapter one, a time history of $\Delta^{14} \mathrm{C}$ on Georges Bank from 1939 to 1990 was derived from the annual growth bands of a single shell of the bivalve $A$. islandica. This was the first long-term ${ }^{14} \mathrm{C}$ time-series reconstructed for the North Atlantic outside the subtropical regions and demonstrated that long-lived molluscs can be used for high-latitude 
${ }^{14} \mathrm{C}$ reconstructions. The Georges Bank bomb- ${ }^{14} \mathrm{C}$ signal was shown to be in phase with, but to have a smaller amplitude than, two subtropical North Atlantic bomb- ${ }^{14} \mathrm{C}$ time histories derived from corals. The depleted pre-bomb conditions on Georges Bank imply a deepwater source, which was identified as originating in the Labrador Sea. A model based on continuity between the Labrador Sea and Georges Bank can account for the $\Delta^{14} \mathrm{C}$ budget on Georges Bank and was also used to back calculate a $\Delta^{14} \mathrm{C}$ time history for the Labrador Sea. This calculation prescribes a lower prebomb $\Delta^{14} \mathrm{C}$ value for the surface Labrador Sea than previously estimated, suggesting greater penetration of the bomb signal and uptake of bomb-produced ${ }^{14} \mathrm{C}$. These results strengthen the view that the Labrador Sea is a primary region of deepwater formation as well as a strong sink for atmospheric $\mathrm{CO}_{2}$. Using a mixing model to examine changes in ventilation and/or atmospheric ${ }^{14} \mathrm{CO}_{2}$ uptake in the Labrador Sea, it was suggested that there was greater vertical mixing in the mid1960 s in contrast to reduced vertical mixing in the early 1970s. These results correspond with independent observations of salinity changes in the North Atlantic and Labrador Sea, which are related to the Great Salinity Anomaly, thus indicating a possible linkage between deepwater formation and surface salinity in the northern North Atlantic.

Chapter two describes the first oxygen isotopic evidence confirming that $A$. islandica deposits its growth bands annually, and that the annual mark is deposited at or shortly after bottom temperatures reach their seasonal maximum, which occurs at the Nantucket Lightship location at the autumn overturn. Shell growth appears coincident with the eight warmest months of the year (May-December) and not during the four coldest months (January-April) based on an ambient transition temperature of $\sim 6^{\circ} \mathrm{C}$. The salinity corrected shell $\delta^{18} \mathrm{O}$ data exhibit a relationship to the observed bottom temperatures not significantly different from that predicted using Grossman and Ku's [1986] paleotemperature equations for aragonite (from mollusc data only). This evidence suggests that $A$. islandica deposits its aragonite shell in oxygen isotopic equilibrium with the 
surrounding water and is an accurate $\left( \pm 1.2^{\circ} \mathrm{C}\right)$ monitor of local bottom temperatures during the May through December shell growth season. The consistent cold (shell growth) shutdown temperature observed in this study suggests that $A$. islandica shells have the potential to independently record the paleo- $\delta^{18} \mathrm{O}$ (and paleosalinity) composition of its growth environment.

In chapter three, $\delta^{18} \mathrm{O}$ and $\delta^{13} \mathrm{C}$ records, obtained from the shells of $A$. islandica specimens grown in the laboratory in different substrates for one year, were compared with ambient conditions such as water temperature, salinity, $\delta^{18} \mathrm{O}$-water, water column DIC $\delta^{13} \mathrm{C}$, and pore water DIC $\delta^{13} \mathrm{C}$. Using Grossman and Ku's [1986] aragonite paleotemperature equation (from mollusc data only), the shell $\delta^{18} \mathrm{O}$ records indicate that shell growth occurred when water temperatures were between $5^{\circ} \mathrm{C}$ and $15^{\circ} \mathrm{C}$. Most of shell growth occurred in the last two or three spring months of the experiment, and the springtime shell $\delta^{18} \mathrm{O}$ data closely correspond to the predicted $\delta^{18} \mathrm{O}$ curve for this period. These results suggest that $A$. islandica can be used to accurately reconstruct ambient temperatures within a $10^{\circ} \mathrm{C}$ range from $5^{\circ}$ to $15^{\circ} \mathrm{C}$. The $\sim 5^{\circ} \mathrm{C}$ cold shutdown value is not significantly lower than the $6^{\circ} \mathrm{C}$ value reported in chapter two, but the difference may also be the result of better constraint on the ambient $\delta^{18} \mathrm{O}$-water and the higher-sampling resolution in this laboratory experiment versus chapter two's Nantucket Lightship comparison study.

The $\delta^{13} \mathrm{C}$ composition of $A$. islandica shells does not appear to be in equilibrium with ambient conditions, though exactly what constitutes $\delta^{13} \mathrm{C}$ equilibrium is still unsettled within the stable isotope community. Shell $\delta^{13} \mathrm{C}$ averages about $1 \%$ heavier than ambient DIC, but are from $0.2-1.7 \%$ o lighter than "equilibrium" based on three of the most recently published equilibrium relationships. The shell's seasonal variation of $\sim 2 \%$ cannot be attributed to ambient DIC $\delta^{13} \mathrm{C}$ variations, which were nearly constant throughout the 
period of shell growth. Temperature trends in the fall and spring correlate positively with shell $\delta^{13} \mathrm{C}$ trends as predicted by Mook's [1986] equilibrium relationship, however there are large deviations from this correlation as well. Pore water $\delta^{13} \mathrm{C}$ is shown to have no obvious effect on shell $\delta^{13} \mathrm{C}$. This result does not support the hypothesis that $\delta^{13} \mathrm{C}$ offsets between infaunal and epifaunal bivalves are the result of pore water influence. As external influences cannot fully explain the seasonal $\delta^{13} \mathrm{C}$ signal a physiological effect is suspected which would account for seasonal $\delta^{13} \mathrm{C}$ variation as a positive function of tissue growth. A. islandica shells show a $\sim 1 \%$ o depletion trend during their first 15 years of growth which is related to ontogeny (e.g., reduced tissue growth or the onset of reproductive activity) and not to changes in the external environment.

In chapter four, three shell-derived $\Delta^{14} \mathrm{C}$ time-histories from the eastern North Atlantic are combined with three previously published $\Delta^{14} \mathrm{C}$ records from the western North Atlantic to investigate the evolution of the bomb-signal in the surface North Atlantic Ocean. From these records, pre-bomb ( 1950) surface North Atlantic $\Delta^{14} \mathrm{C}$ values average $-59 \%$, and are most depleted in the Labrador Sea $(\sim-70 \%)$ and most enriched in the Sargasso Sea $(\sim-50 \%$ ). This $\sim 20 \%$ o difference between subpolar and subtropical gyre prebomb surface waters is attributed to a substantial depleted source for the western subpolar regions, such as Antarctic Intermediate Water convectively mixing along the subpolar front and/or southward flowing polar surface waters from the Davis Strait region. In general, the pre-bomb records show depletion trends that are consistent with the Suess effect, but the magnitude of these depletions varies greatly and are largest on the European shelves, and negligible at Iceland. However, in the North Sea and Norway records, these steep trends are driven by very depleted $\Delta^{14} \mathrm{C}$ values in the mid-1950s that cannot be explained easily by the Suess effect depletion of the overlying atmosphere, and may be the result of increased convection or upwelling in the northern North Atlantic in the early 1950s. 
Initial appearance of the bomb- ${ }^{14} \mathrm{C}$ is synchronous in all North Atlantic $\Delta^{14} \mathrm{C}$ records about 1959 ( \pm 1 year). All North Atlantic $\Delta^{14} \mathrm{C}$ records show a steep rise during the the early to mid-1960s and reach maxima in the late 1960s to late 1970s. The North Sea record has the largest amplitude $(\sim 320 \%)$ and the Iceland record has the smallest $(\sim 120 \%)$. Shelf influence is suspected of causing the extremely large amplitude and advanced phase of the North Sea signal relative to other North Atlantic signals. Where shelf influence is considered significant, the adjacent regional ocean $\Delta^{14} \mathrm{C}$ time-histories are corrected by inverting a simple atmospheric uptake model and inputting the shell-derived $\Delta^{14} \mathrm{C}$ records, the shelf water depths, and shelf residence times, and fitting to GEOSECS and TTO surface $\Delta^{14} \mathrm{C}$ data for each ocean region. The Georges Bank, Norway, and North Sea records have been corrected in this way to produce regional records for the Labrador Sea, Norwegian Sea, and the central eastern North Atlantic (Bay of Biscay).

The amplitudes of the "corrected" North Atlantic bomb- ${ }^{14} \mathrm{C}$ signals show a sharp contrast between northern (subpolar gyre) and southern (subtropical gyre) regions with remarkable conformity within each of these regions. Florida, Bermuda, and the central eastern North Atlantic have similar amplitudes of $\sim 220 \%$ and maxima of $\sim+160 \%$. The Labrador Sea, Iceland Sea, and Norwegian Sea have amplitudes of $\sim 120 \%$ and maxima $\sim+60 \%$. These results reflect the contrast between the depths of the winter mixed-layer in the northern and southern regions, but are also consistent with a depleted or deepwater contribution to the subpolar gyre. Also, because the subpolar gyre surface waters are currently more depleted than the atmosphere, these regions should be still increasing their inventory of atmospheric bomb- ${ }^{14} \mathrm{C}$ or maintaining a balance with regional loss through deep water production. A small east-west difference is shown in the relative enrichment of the Norwegian Sea signal versus the Labrador Sea and Iceland Sea signals. This difference is in agreement with deeper mixing in the western section of the subpolar gyre, and the poleward advection of surface Atlantic water into the Norwegian Sea. 
In chapter five, a 109-year annual time-series (1875-1983) of bottom temperatures has been reconstructed from the oxygen isotope records of four A. islandica shells livecaptured near the former position of the Nantucket Lightship at $65 \mathrm{~m}$ depth. This site is centered within the "cold pool", and so this time-series provides a century-long thermal history of this outer continental shelf hydrographic feature. The method of establishing the chronology by annual band counting, and using the overlapped isotope records from several shells of different ages to reconstruct a longer record was validated by significant positive correlations between the overlapped portions of the four shell records. The shellderived bottom temperatures are presented as three annual records: annual mean, annual maximum, and annual minimum. The annual means represent the means of the shell growth seasons, average $7.6^{\circ} \mathrm{C}\left( \pm 0.9^{\circ} \mathrm{C}\right)$, and indicate a century-long cooling of $\sim 1.1^{\circ} \mathrm{C}$. The annual maxima represent bottom temperatures at about the time of the autumn overturn, average $11.5^{\circ} \mathrm{C}\left( \pm 1.7^{\circ} \mathrm{C}\right)$, and indicate a large century-long cooling of $\sim 2.9^{\circ} \mathrm{C}$. The annual minima represent the spring bottom temperatures, average $5.7^{\circ} \mathrm{C}\left( \pm 0.9^{\circ} \mathrm{C}\right)$ and indicate a modest cooling of $\sim 0.4^{\circ} \mathrm{C}$ over the last century. A sharp decline in temperature occurs in all three shell records after 1960, and all records indicate that the mid-1880s, mid-1960s, and mid-1970s were the most prolonged, coldest periods of the past century.

Shell-derived bottom temperature records show a strong similarity to and significant correlation with the Nantucket Lightship bottom temperature records for the period 19601971. The shell-derived bottom temperature records show a poor correlation with the coastal sea surface and air temperature records. However, the positive coherence between these records is greatly improved by comparing their detrended or residual (deviation from 10-year running mean) records. This indicates that the short-term anomaly patterns between the continental shelf bottom temperatures and coastal sea surface and air temperatures are similar, while their long-term temperature trends are dissimilar. The primary contrast 
between the long-term trends is that the shell-derived records indicate a century-long cooling of $\sim 1^{\circ} \mathrm{C}$, while regional air and coastal sea surface records describe a century-long warming of equal magnitude. It was considered whether this temperature contrast is real or an artifact. Biological or "vital effects" have been rejected as a cause of the disparity because the overlapping shell records provide a check on this type of variation. It was estimated that a $10 \%$ increase in the amount of Slope water relative to Scotian shelf water would produce $\sim+0.5 \%$ salinity increase and a $\sim+0.2 \% \circ \delta^{18} \mathrm{O}$-water increase, which would falsely indicate an apparent $\sim 1^{\circ} \mathrm{C}$ cooling. While, this is a possibility, it merely shifts the problem, from one of a significant temperature change to one of a salinity change, either of which would have broad implications for shelf circulation. It seems equally possible that the shell-derived bottom temperature trends are real and of opposite sign to surface temperature trends. To explain this contrast, it was suggested that increased surface warming is related, directly or indirectly, to increased or prolonged stratification of shelf waters and a net reduction in vertical mixing and heat flux into the bottom waters of the "cold pool".

Arctica islandica is an abundant long-lived species on continental shelves of the northern North Atlantic Ocean. In this thesis, evidence has been compiled which demonstrates that important oceanographic problems can be addressed by utilizing the carbon and oxygen composition of $A$. islandica shells. Finally, this thesis fulfills the task laid out nearly two decades ago by Thompson and Jones [1977] that Arctica islandica could someday be used to reconstruct past ocean history as "the tree of the North Atlantic". 


\section{Appendix}

\section{$\mathrm{CO}_{2}-\mathrm{H}_{2} \mathrm{O}$ Equilibration Technique: Modified Anderson Method}

Water samples collected for oxygen isotope analysis were prepared using a slight modification of methods first described in an unpublished report by T. Anderson [1983] at the University of Illinois, Urbana and also later described by D. Allard [1989] in his Master's Thesis at the University of Rhode Island. These methods essentially involve several freeze/thaw routines along with a standard technique consisting of equilibrating an injected aliquot of $\mathrm{CO}_{2}$ of known volume and isotopic composition with a seawater sample. The methods produce high repeatability $( \pm 0.01 \%)$ and accuracy.

\section{Water- $\mathrm{CO}_{2}$ Equilibration:}

1. Using a $5 \mathrm{ml}$ (B-D) plastic syringe fitted to a $0.2 \mathrm{ml}$ (Fisher Brand: length $30 \mathrm{~cm}$, external diameter: $5.7 \mathrm{~mm}$ ) pyrex pipette, several $3-4 \mathrm{ml}$ of seawater from the sample storage bottle is drawn up into the syringe and flushed out as discard at least twice, before drawing up an equal volume to be tranferred to the reaction vessel.

2. Before transferring the sample water to the reaction vessel, any water drops on the outside of the pyrex pipette are dried with a clean tissue.

3. Next the pipette is inserted into the neck of the reaction vessel. Our standard reaction vessel for this procedure is a $20 \mathrm{~cm}$ long pyrex tubing (outside diameter: $9 \mathrm{~mm}$; inside diameter: $7 \mathrm{~mm}$ ) welded to a $10 \mathrm{~cm}$ long, $13 \mathrm{~mm}$ diameter pyrex test tube (with a rounded bottom). This lower $10 \mathrm{~cm}$ portion of the reaction vessel is referred to hereon as the bulb, and the upper $20 \mathrm{~cm}$ portion is referred to as the neck. $1 \mathrm{ml}$ of sample water is then tranferred from the syringe to the base of the bulb and then the pipette is removed from the reaction vessel carefully. Care is taken not to get any sample water drops on the upper insides of the bulb or the neck of the reaction vessel.

4. Next, the reaction vessel, kept upright, is connected to the vacuum line.

5. Before evacuation, the base portion of the reaction vessel is submerged in a $\mathrm{CO}_{2}$ slurry bath for 3 minutes to freeze the water sample.

6. The reaction vessel is then evacuated to a pressure of less than 10 mTorr. This takes about 1 minute on our vacuum line. Anderson has suggested that this step can be repeated meaning the water sample in the reaction vessel can be thawed, refrozen, and re-evacuated. We have found that while this does remove some residual air locked in the ice, the practical effect on the isotopic composition is negligible, while it markedly increases the chances of cracking the reaction vessel. For these reasons we do not repeat this step.

7. The $\mathrm{CO}_{2}$ slurry bath is removed and replaced by a liquid $\mathrm{N}_{2}$ bath.

8. An aliquot $(90 \mu \mathrm{mol})$ of $\mathrm{CO}_{2}$ was then frozen into the reaction vessel. This takes about 3 minutes to complete.

9. Then the neck the reaction vessel is flame sealed, and allowed to thaw.

10. The sealed reaction vessel is then fully emerged in water bath with a temperature maintained at $25^{\circ} \mathrm{C}\left( \pm 0.1^{\circ} \mathrm{C}\right)$. For the water bath we have found that a large insulated picnic cooler filled with $25^{\circ} \mathrm{C}$ water, and then kept in a room whose temperature is maintained close to $25^{\circ} \mathrm{C}$, provides a very satisfactory storage bath. With this low-budget setup, the water should be checked 2-3 times a day to make sure water temperature is maintained at $25^{\circ} \mathrm{C}( \pm 0.1 \%$ ). Our simple bath has no vibrators to hasten equilibration, and we have found that at least two full days are required for complete equilibration, and to be cautious we have allowed samples to equilibrate for three days. 


\section{II. $\mathrm{CO}_{2}$ Extraction.}

1. The equilibrated sample vessel is removed from the water bath, and dried off immediately with a paper towel.

2. The upper neck of the vessel is then scored on one side, and inserted into a tube cracker on the vacuum line.

3. The bulb of the reaction vessel is submerged in a $\mathrm{CO}_{2}$ slurry bath and frozen for 5 minutes.

4. Meanwhile, the cracker chamber is evacuated and checked for leaks.

5. The neck of the reaction vessel is cracked and sample $\mathrm{CO}_{2}$ released.

6. A liquid $\mathrm{N}_{2}$ bath is placed onto the collection vessel (either valve or flame-seal type) and 5 minutes is allowed for the $\mathrm{CO}_{2}$ sample to be transferred.

7. The sample is pumped over for 15 seconds, then collection vessel is isolated (either by closing its valve or by flame sealing).

Extraction is complete. 


\section{Further Procedure Notes}

1. Calibration and Procedure Test

A series of runs with an in-house standard seawater have been carried to test the repeatability of these procedures. Also, this standard has been directly calibrated with VSMOW. Results of these runs follow.

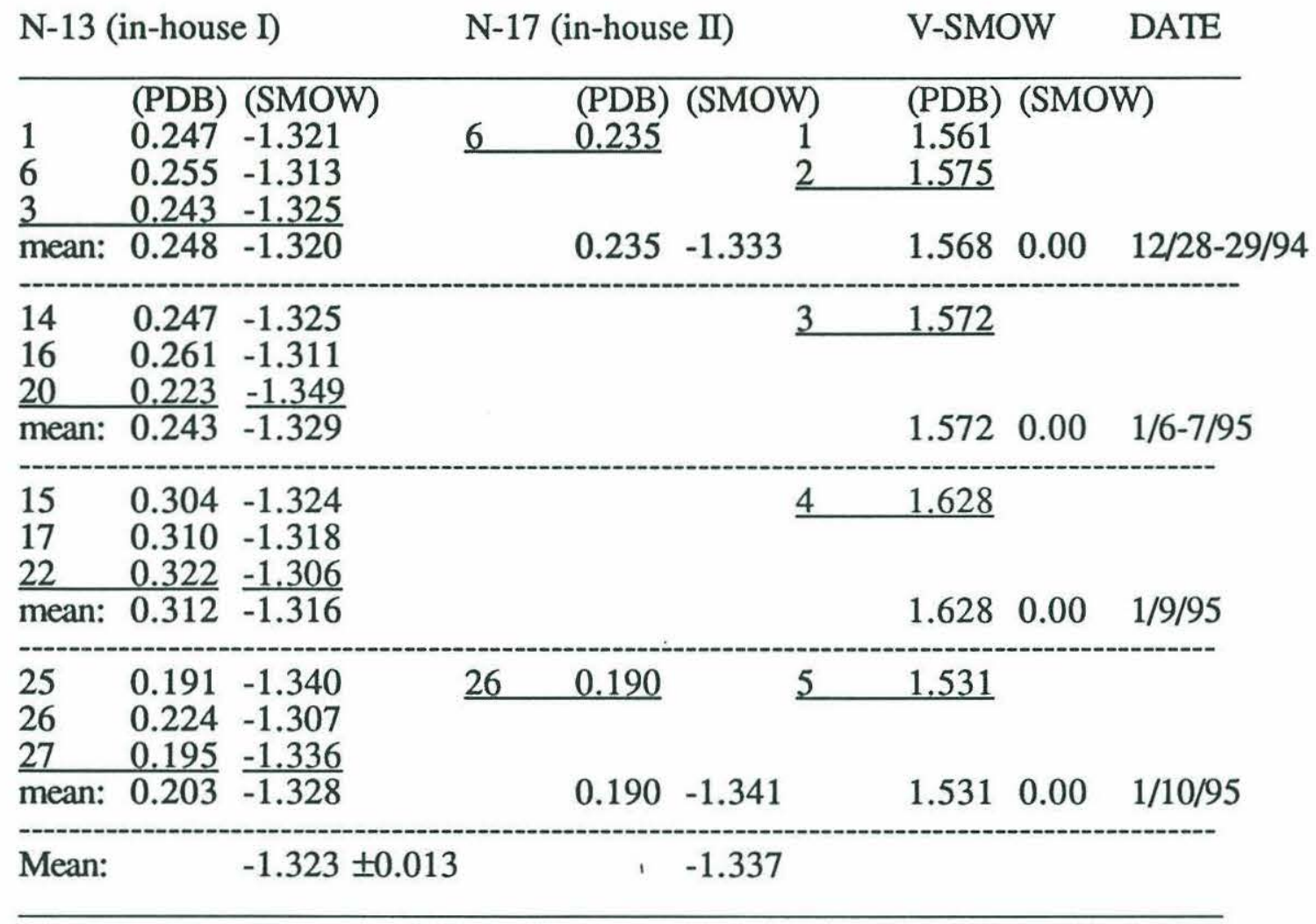

Note: the V-SMOW value of $\sim+1.57 \%$ relative to (PDB) is $\sim 1.85 \%$ larger than the values of $\sim-0.22 \%$ o to $-0.27 \%$ mentioned in the literature for this relative difference. This discrepancy is due to the fact that we have established our reference gas (PDB) value from NIST carbonate standards on a system where the phosphoric acid reaction temperature is $90^{\circ} \mathrm{C}$ rather than the classic $25^{\circ} \mathrm{C}$. Based on Swart et al.'s [Swart, Burns, and Leder, 1991] paper this reaction temperature difference would produce $\sim 2.0 \%$ offset, which is bit larger than the offset in our data. Another small portion of the difference is due to the very depleted $(-17.0 \%$ ) sacrificial gas (our "Matt Gas") used for equilibration. This causes the sample gas (if near V-SMOW values) to be about $0.05 \%$ depleted relative to its actual value. Thus our V-SMOW value is actually $\sim+1.62 \%$ (PDB- $\left.90^{\circ}\right)$ about $1.9 \%$ larger than PDB- $25^{\circ}$ which moves it a bit closer to Swart, et al.'s predicted offset of $\sim 2 \%$.

2. Figure 1 shows the effect of equilibration temperature on 8180 -water. The slope of this line is $-0.165 \% d^{\circ} \mathrm{C}$. This seems to be a potentially important source of analytical error, as a tenth of a degree variation in equilibration temperature can account for most of the analytical error in our data.

3. Figure 2 shows the results of an equilibration completion test. A negative exponetial fit to the data yields a half equilibration time of $\sim 7$ hours or 0.29 days. The exponetial coefficient is - 2.38 with time in days. For an initial water-gas isotopic difference of $16 \%$, it takes approximately 3 days to reach equilibrium (within $\pm 0.01 \%$ of the final value). 


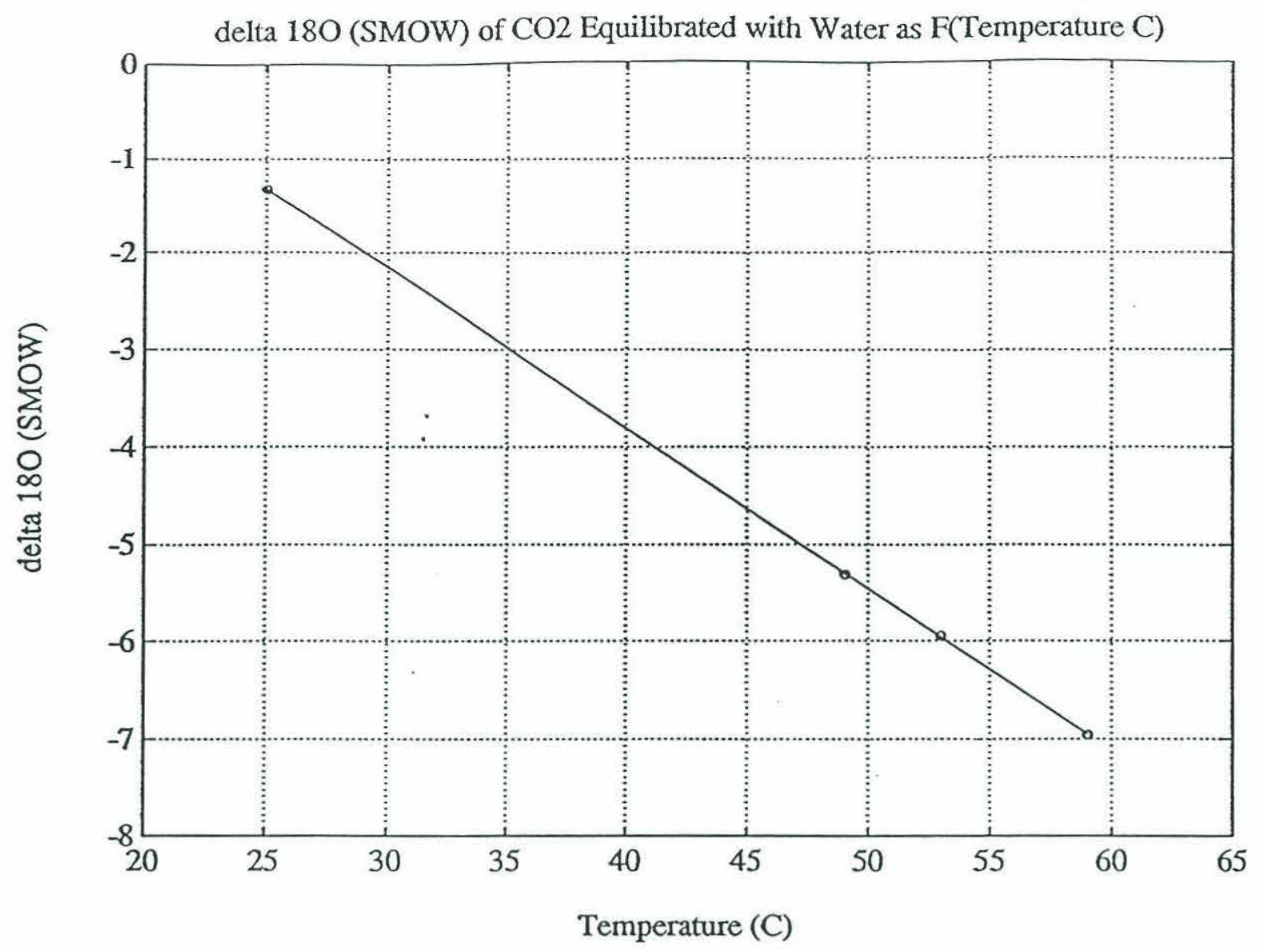

Equilibrium Temperature Data:

\begin{tabular}{cr}
$\begin{array}{c}\text { Temperature } \\
\mathrm{C}^{\circ}\end{array}$ & $\begin{array}{c}\left(\mathrm{N}-13: \mathrm{CO}_{2}\right) \\
\delta^{18} \mathrm{O}(\mathrm{VSMOW})\end{array}$ \\
\hline 25 & -1.32 \\
49 & -5.31 \\
53 & -5.94 \\
59 & -6.95 \\
\hline
\end{tabular}

$\delta^{18} \mathrm{O}_{\text {gas }}=-0.165^{*} \mathrm{~T}+4.135+\delta^{18} \mathrm{O}_{\mathrm{w}_{2}}$ 。 


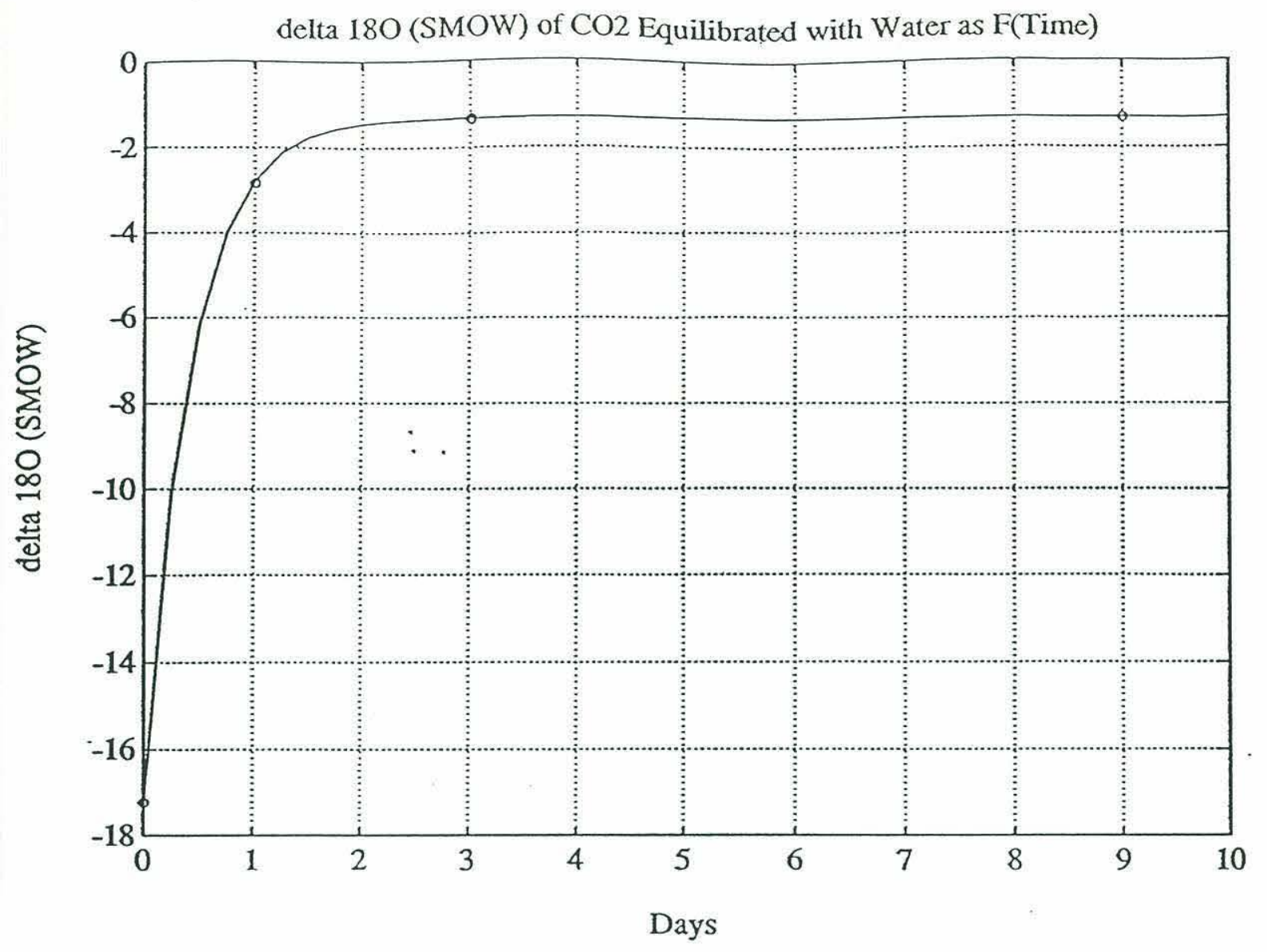

Equilibration Time Data:

\begin{tabular}{lr}
$\begin{array}{l}\text { Time } \\
\text { days }\end{array}$ & \multicolumn{1}{l}{$\mathrm{N}^{18} \mathrm{13}: \mathrm{CO}_{2}$ ) } \\
& \\
\hline 0 & -17.23 \\
1 & -2.81 \\
1 & -2.84 \\
3 & -1.33 \\
3 & -1.32 \\
3 & -1.36 \\
3 & -1.33 \\
9 & -1.32 \\
\hline
\end{tabular}

$\delta^{18} \mathrm{O}_{\text {gast }}=\delta^{18} \mathrm{O}_{\text {water }}-\left(\delta^{18} \mathrm{O}_{\text {water }}-\delta^{18} \mathrm{O}_{\text {gas }}\right) * \exp ^{-2.38 \mathrm{t}}$ 